\title{
The computerization of the labour market
}

Citation for published version (APA):

ter Weel, B. J. (2002). The computerization of the labour market. [Doctoral Thesis, Maastricht University]. Datawyse / Universitaire Pers Maastricht. https://doi.org/10.26481/dis.20020920bw

Document status and date:

Published: 01/01/2002

DOI:

10.26481/dis.20020920bw

Document Version:

Publisher's PDF, also known as Version of record

\section{Please check the document version of this publication:}

- A submitted manuscript is the version of the article upon submission and before peer-review. There can be important differences between the submitted version and the official published version of record.

People interested in the research are advised to contact the author for the final version of the publication, or visit the DOI to the publisher's website.

- The final author version and the galley proof are versions of the publication after peer review.

- The final published version features the final layout of the paper including the volume, issue and page numbers.

Link to publication

\footnotetext{
General rights rights.

- You may freely distribute the URL identifying the publication in the public portal. please follow below link for the End User Agreement:

www.umlib.nl/taverne-license

Take down policy

If you believe that this document breaches copyright please contact us at:

repository@maastrichtuniversity.nl

providing details and we will investigate your claim.
}

Copyright and moral rights for the publications made accessible in the public portal are retained by the authors and/or other copyright owners and it is a condition of accessing publications that users recognise and abide by the legal requirements associated with these

- Users may download and print one copy of any publication from the public portal for the purpose of private study or research.

- You may not further distribute the material or use it for any profit-making activity or commercial gain

If the publication is distributed under the terms of Article $25 \mathrm{fa}$ of the Dutch Copyright Act, indicated by the "Taverne" license above, 
The Computerization of the Labour Market 


\section{B.J. ter Weel, Maastricht}

All rights reserved. No part of this publication may be reproduced, stored in a retrieval system, or transmitted, in any form, or by any means, electronic, mechanical, photocopying, recording or otherwise, without the prior permission in writing, from the author.

Published by Universitaire Pers Maastricht ISBN 9052783527

Printed in the Netherlands by Datawyse Maastricht 


\title{
The Computerization of the Labour Market
}

\author{
PROEFSCHRIFT
}

ter verkrijging van de graad van doctor aan de Universiteit Maastricht, op gezag van de Rector Magnificus, Prof. dr. A.C. Nieuwenhuijzen Kruseman, volgens het besluit van het College van Decanen, in het openbaar te verdedigen op vrijdag 20 september 2002 om 10.00 uur

$$
\text { door }
$$

Bastiaan Johan ter Weel

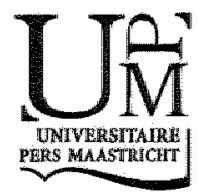




\section{Promotor:}

Prof. dr. L.L.G. Soete

\section{Beoordelingscommissie:}

Prof, dr. R.A. Cowan (voorzitter)

Prof. dr. E.J. Bartelsman (Vrije Universiteit, Amsterdam)

Prof. dr. P.A. David (Stanford University, United States)

Prof. dr. J.A.M. Heijke

Prof. dr. P.J.J. Herings

Dit onderzoek is gefinancierd door de Nederlandse Organisatie voor Wetenschappelijk Onderzoek (NWO), project 425-11-007.

This research has been financed by the Netherlands Organization for Scientific Research (NWO), grant 425-11-007. 


\section{Acknowledgements}

The research included in this study has been carried out in the period August 1999-December 2001 and has been financed by the Netherlands Organization for Scientific Research (NWO). In writing this study I have benefited from my supervisor Luc Soete, whose guidance and comments on how to conduct this research (and how to get the grant) have been of substantial help. Secondly, having Lex Borghans as a co-author on eight papers, which are presented in modified form in Chapters 3-5, and critical commentator on numerous other occasions has been a very fruitful, productive and ongoing experience for which I am most grateful. Furthermore, I would like to thank Allard Bruinshoofd and Hugo Hollanders for joining me in writing several papers on knowledge spillovers, presidential elections, traffic jams and football and in particular for their critical remarks and useful comments on the research carried out for this study.

For their elaborate and constructive comments on my research, I would also like to thank Daron Acemoglu, Jim Allen, Joshua Angrist, David Autor, Eli Berman, Francesco Caselli, Antonio Ciccone, Paul David, Arnaud Dupuy, Luis Garicano, Austan Goolsbee, Eric Gould, Andries de Grip, Jonathan Guryan, James Heckman, Hans Heijke, Caroline Hoxby, Thomas Hubbard, Boyan Jovanovic, Joseph Kaboski, Adriaan Kalwij, Lawrence Katz, Francis Kramarz, Alan Krueger, Victor Lavy, Jasper van Loo, Erzo Luttmer, Stephen Machin, Philip Marey, Omer Moav, Markus Möbius, Richard Murnane, Kevin M. Murphy, Joan Muysken, Derek Neal, Lars Nesheim, Jörn-Steffen Pischke, Erik de Regt, Sherwin Rosen, Mark Sanders, Arthur van Soest, Paul Stoneman, Jonathan Temple, Coen Teulings, Robert Topel, John Van Reenen, Gianluca Violante, Bruce Weinberg, Finis Welch and Thomas Ziesemer. I would also like to thank the members of the reading committee (Eric Bartelsman, Robin Cowan, Paul David, Hans Heijke and Jean-Jacques Herings) for their effort and comments.

In addition, I would like to acknowledge participants at the following conferences and seminars for their comments and suggestions: CentER, the Dutch Central Bank, the Eindhoven Centre for Innovation Studies (ECIS), three European Association of Labour Economists meetings (Jyväskylä, Milan and 
Regensburg), the 2001 European Economic Association meeting (Lausanne), the European Investment Bank (Luxembourg), the 1999 German Association of the Political Economy meeting (Stuttgart), the Graduate School of Business at the University of Chicago, Harvard University, the Institute for the Study of Labor (IZA), the International Conference on Understanding Skills Obsolescence (Maastricht), the International Institute of Infonomics (Heerlen and Maastricht), the London School of Economics, the Maastricht Economic Research Institute on Innovation and Technology (MERIT), MiMaMa (Maastricht), the Ministry of Economic Affairs, the Ministry of Education, the Ministry of Social Affairs, Ohio State University, the Production of Human Capital Workshop (Maastricht), the Research Centre for Education and the Labour Market, the 2000 Society of Labor Economists World Conference (Milan), the Tinbergen Institute, the University of Groningen, the University of Oxford and the $\mathrm{ZEW}$ Conference on the Economics of Information and Communication Technology (Mannheim).

For hospitality during short visits I am indebted to the Department of Economics and the ESRC Centre on Skills, Knowledge and Organisational Performance (SKOPE) of the University of Oxford and the Department of Economics of Ohio State University. Finally, I am grateful to Nic van Hal for able research assistance, to Corien Gijsbers for conscientiously editing the manuscript and to Wilma Coenegrachts and Silvana de Sanctis for secretarial support. support.

Not least, I am most grateful to Gretel and my family for their continuous B.t.W., Maastricht, June 2002 


\section{Contents}

1. Introduction and Overview 1

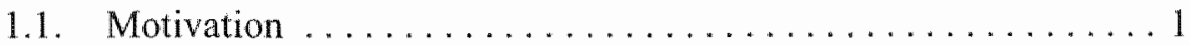

1.2. Aim of the Study . . . . . . . . . . . . . . . 6

1.3. Research Outline ...................... 11

2. Technology, Skills and Wages 15

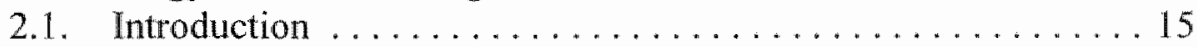

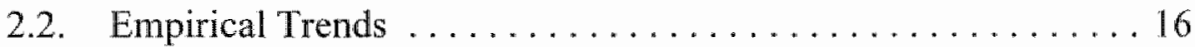

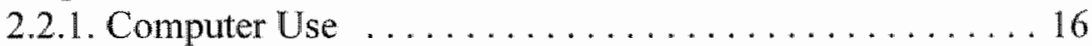

2.2.2. Computer Use and the Price of Computer Equipment . . . 18

2.2.3. Computer Use and Wages ................ 20

2.2.4. Computer Use and Wage Inequality $\ldots \ldots \ldots \ldots \ldots 23$

2.2.4.1. Wage Inequality . . . . . . . . . . . . 23

2.2.4.2. Within-Group Wage Inequality $\ldots \ldots \ldots 26$

2.2.5. Computer Use and Upgrading . . . . . . . . . . . 27

2.2.6. Conclusion . . . . . . . . . . . . . . . . . . . . . . . . 29

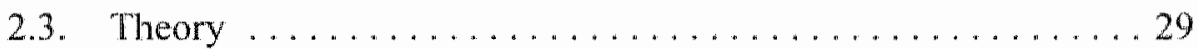

2.3.1. Technological Revolutions ................ . 29

2.3.2. Within-Group Wage Inequality . . . . . . . . . . 33

2.3.3. Technology Adoption and Diffusion ........... 35

2.3.4. An Analysis of the Job ................. 38

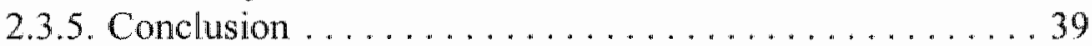

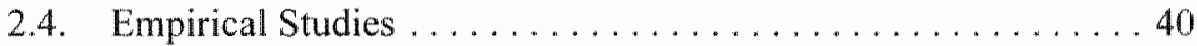

2.4.1. Technology and Wages ................ 41

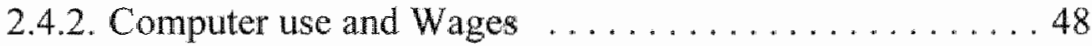

2.4.3. Complementarity ................... 51

2.4.4. Conclusion ...................... . 54

2.5. Conclusion ........................... 55 
3.1. Introduction . . . . . . . . . . . . . . . . . . 57

3.2. A Model of Jobs With Multiple Tasks . . . . . . . . . . . . . . 59

3.3. A Model of Computerization ................. . 67

3.3.1. When Is the Computer Introduced? . . . . . . . . . . 69

3.3.2. The Further Diffusion of Computers . . . . . . . 72

3.4. Implications for Labour and Product Markets . . . . . . . . 78

3.4.1. Product Market .................. . 78

3.4.2. Optimal Skill Requirements . . . . . . . . . . 81

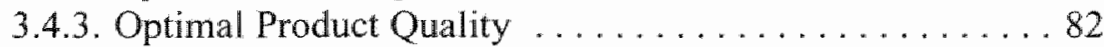

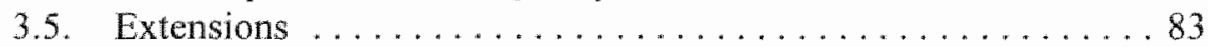

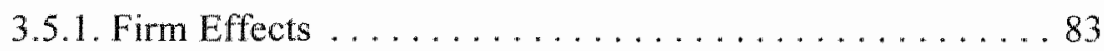

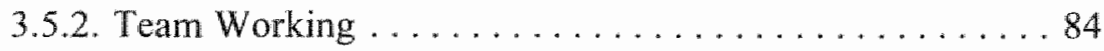

3.5.3. Work Intensity . . . . . . . . . . . . . 86

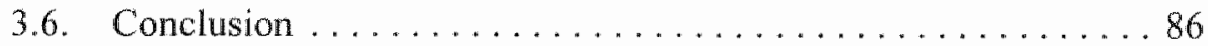

4. Computers, Skills and Wages 89

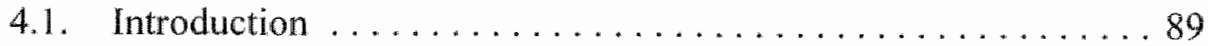

4.2. Data and Skill Measurement ................. 92

4.3. Computer Use and Skills and Wages ............... 100

4.3.1. The Returns to Computer Use and Skills . . . . . . . . . 100

4.3.2. The Value of Computer Skills ... . . . . . . . . 103

4.4. The Validity of the Skill Measure . . . . . . . . . . . 106

4.5. Determinants of Computer Use . . . . . . . . . . . 108

4.5.1. Unionization as an Instrument for Wages ........ 110

4.5.2. The Number and Quality of the Instruments ... . . 112

4.5.3. Estimation Results ... . . . . . . . . . . . . . 114

4.5.3.1. Basic Estimates ................. 114

4.5.3.2. Further Estimates ............. 116

4.5.3.3. Direct and Indirect Impact on Wages . . . . . . . 124

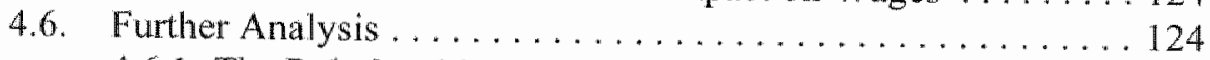

4.6.1. The Relationship Between Wages and Computer Use .. 124

4.6.2. The Relationship Between Tasks and Computer Use ... 125

4.6.3. Alternative Explanations . . . . . . . . . . . . 128

4.7. Computer Skills and Wages $\ldots \ldots \ldots \ldots \ldots \ldots \ldots \ldots \ldots \ldots \ldots$

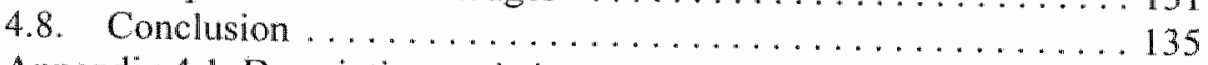

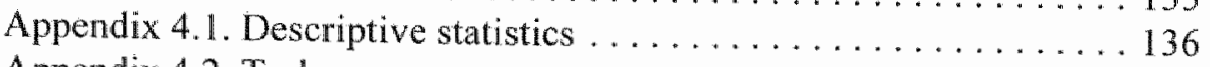

Appendix 4.2. Tasks . . . . . . . . . . . . . . . . . . 137

Appendix 4.3. The Returns to Computer and Writing Skills Revisited 138

A.4.3.1. Computer and Pen Use . . . . . . . . . . . . 138

A.4.3.2. Why Do Pens Still Yield a Wage Premium? ........ . 141 
5. The Diffusion of Computers and the Distribution of Wages

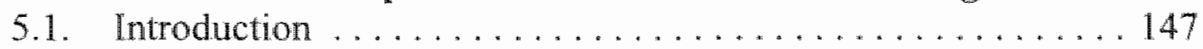

5.2. The Model ............................. 152

5.2.1. Basic Structure of the Model . . . . . . . . . . 152

5.2 .2 . Equilibrium Wages $\ldots \ldots \ldots \ldots \ldots \ldots \ldots \ldots$

5.2.3. Wage Inequality and Diffusion over Time ........ 161

5.3. Is Wage Inequality Temporary or Permanent? . . . . . 162

5.4 . The Timing of Wage Inequality . . . . . . . . . . . . . 164

5.5. Empirical Analysis . . . . . . . . . . . . . . . . 167

5.5.1. Data and Construction of Variables ........... 167

5.5.2. Econometric Specification of the Model . . . . . . . 170

5.5.3. Basic Estimates . . . . . . . . . . . . . . . . 172

5.5.4. Between-Group Wage Inequality ... . . . . . . 174

5.5.5. Within-Group Wage Inequality . . . . . . . . . 175

5.6. Conclusion ............................ 177

6. Job Complexity and Skill Upgrading 179

6.1 Introduction $\ldots \ldots \ldots \ldots \ldots \ldots \ldots \ldots \ldots \ldots \ldots \ldots$

6.2. Data and Preliminary Figures . . . . . . . . . . . 181

6.3. A Simple Framework .................... 185

6.4. Assigning Workers to Jobs . . . . . . . . . . . . . . 190

6.4.1. First-Stage Estimation Results . . . . . . . . . . . 190

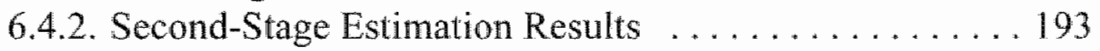

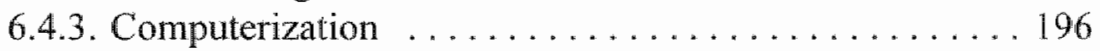

6.5. Conclusion .......................... 203

7. Summary and Conclusions 205

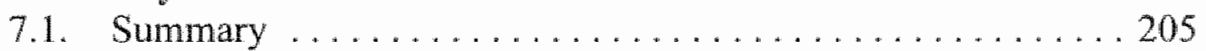

7.2. Future Research ....................... 214

$\begin{array}{ll}\text { References } & 217\end{array}$

Summary in Dutch 229

$\begin{array}{ll}\text { Curriculum Vitae } & 241\end{array}$ 



\section{List of Figures}

Figure 2.1. Computer Investments Per Worker as a Share of Total Equipment

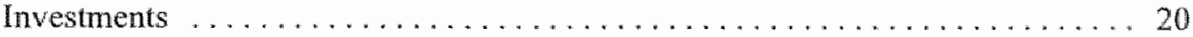

Figure 2.2. Predicting Relative Wages in the United States, 1963-1992 . . . . . . 24

Figure 2.3. Three-Year Moving Average of Within-Group Wage Inequality in the

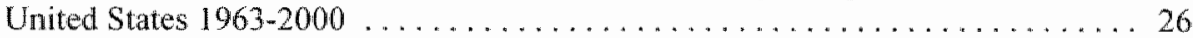

Figure 3.1. The Introduction of Computers Leads to Ever Increasing Wage Differentials . . 75

Figure 3.2. The Diffusion of Computers According to the Model ............. 76

Figure 4.1. Average Wages and Computer Use in Britain by Age ........... 126

Figure 4.2. Percentage of Workers with Wages above Certain Thresholds and Computer Use in Britain . . . . . . . . . . . . . . . . . . . . . . . . . . . . . . . 126

Figure 4.3. Actual Computer Use and Computer Use Predicted by Wage and

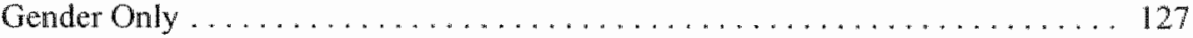

Figure 4.4. Average Wages of Computer Users and Non-Users by Age . . . . . . . . 127

Figure 4.5. Actual computer use and computer use predicted by tasks only . . . . . 128

Figure 4.6. Relationship between Average Computer Use and the Fraction of Olden Worker by Occupation (2-digit)

Figure 4.7. Relationship between Computer Use and Change in Computer Use for All Workers and Older Workers per Occupation .................. 130

Figure A.4.1. Computer and Pen Use for Different Wage Groups in Germany in 1992 . . 139

Figure A.4.2. The Returns to Computer and Writing Skills in Britain 
Figure 5.1a. Within-Group Wage Inequality

Figure 5.1b. Between-Group Wage Inequality

Figure 5.2. Relative Wages over Time

Figure 5.3. Between-Group Wage Inequality ower Time for Differences in Proportional Productivity Gains for Skilled and Unskilled Workers . . . . . . . . . . . . 163

Figure 5.4 . The Timing of Within-Group Wage-Inequality $\ldots \ldots \ldots \ldots \ldots$

Figure 5.5. Imputed Computer Use in the United States 1963-2000 169

Figure 6.1. Indexed Log Gross Hourly Wages by Percentile in the Netherlands, $\rrbracket 986-1998(1986=100)$

Figure 6.2. Indexed Log Gross Hourly Wages by Differences Between Percentiles in the Netherlands, $1986-1998(1986=100)$

Figure 6.3.90 $0^{\text {th }}-10^{\text {th }}$ Percentile of the Log Gross Hourly Wage Differential and Components, 1986-1998 


\section{List of Tables}

Table 2.1. Percentage of Workers in Various Categories Who Directly Use a

Computer at Work ................................ 17

Table 2.2. OLS Regression Estimates of the Effect of Computer Use on Pay ......... 22

Table 2.3. Explaining Wage Inequality in the United States, 1963-1992 . . . . . . 24

Table 2.4. Regressions of Changes in Skilled Labour Share and Earnings from

1997 to 1992 for Computer Investment in the Firm .................. 28

Table 2.5. Percentage of College Graduates and the Rate of Technological Change in Manufacturing Industries in the United States, $1979-1993$. . . . . . . . . . . 42

Table 2.6. Regressions of Changes in High-Skilled, White-Collar High-Skilled and Non-Production Workers' Employment Shares on R\&D Intensity . . . . . . . 47

Table 2.7. Computer Wage Premiums from Some Micro-Level Studies . . . . . . . . . . 49

Table 4. 1. Percentage of Workers in Age, Educational Level and Gender Categories

Using a Computer in Germany, Britain and the United States . . . . . . . . . 94

Table 4.2. Distribution of the Answers to the Questions about Computer Use, the Level of Sophistication of Computer Use, and Computer Skills .......... 96

Table 4.3. Percentage of Computer-Using Workers in Britain Evaluating the Importance of Use, the Level of Sophistication of Use and Computer Skills Categorized by Age . 98

Table 4.4. Correlation Between Computer Use, the Level of Sophistication of Computer Use, and Computer Skills . . . . . . . . . . . . . . . . . . . 99

Table 4.5. OLS Regression Estimates of the Effect of Computers on Pay ......... 104

Table 4.6. The Wage Premium for Computer Skills within Four Different Levels of Sophistication of Computer Use $\ldots \ldots \ldots \ldots \ldots \ldots \ldots \ldots \ldots \ldots \ldots$

Table 4.7. The Robustness of the Skill Measure: OLS Regression Estimates of

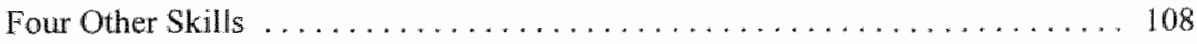


Table 4.9. Logistic Regression of the Determinants of Computer Use without Instruments and with Unionization Variables as Instruments for Wages ............. 115

Table 4.10. Extended Equations of the Logistic Regression of the Determinants of Computer Use with Sector of Industry and Tasks, with Unionization Variables as Instruments for Wages . . . . . . . . . . . . . . . . . . . . . . 1

Table 4.11. Direct and Indirect Effect via Wages of Variables on Computer Use

Table 4.12. Relationship between Computer Use of Older Workers (50-60) and Computer Use of All Workers and the Recent Change in Computer Use per

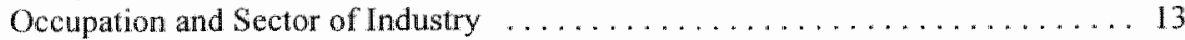

Table 4.13. Estimation of the Level of Computer Skills of Computer Users . . . . . . 133

Table A.4.1. Percentage of Workers in Germany and Britain Using Computers and Pens

Table A.4.2. OLS Regressions for the Effect of Computer and Pen Use on Pay in Germany and Britain

Table A.4.3. OLS Regressions for the Effect of Computer and Different Applications

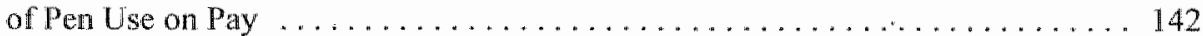

Table A.4.4. OLS Regression for the Effect of Computer Skills and Different Writing Skills on Pay in Britain ................... 144

Table 5.1. Relative Wages in Efficiency Units in Each of the Five Stages . . . . . . . . 158

Table 5.2. Individual Workers' Wages Before and After Adopting Computers in Different Stages of Diffusion ... . . . . . . . . . . . . . . . . . . . . . is9

Table 5.3. Some Basic Estimates of the Time Trend and the Elasticity of Substitution for Different Productivity Gains from Using Computers .

Table 5.4. Estimates for Between-Group Wage Inequality

Table 5.5. Estimates for Within-Group Wage Inequality

Table 6.1. Observable and Unobservable Components in Wages in the Netherlands, 1986-1998

Table 6.2. Regression of the Log Hourly Wage on Personal, Job and Sector

Characteristics in the Netherlands, 1986-1998

Table 6.3. Skill, Job Complexity and Upgrading 


\section{Chapter 1 \\ Introduction and Overview}

\subsection{Motivation}

The relationship between technology and labour has been the subject of public interest and debate for centuries and predates the Industrial Revolution itself. Foremost among the concerns of the discussion, and the subject of a relatively large (and recently growing) body of research, is the relationship between technology, (wage) inequality and the demand for skills.

In the Wealth of Nations, Adam Smith already emphasized the role of the division of labour in improving the productive power of labour:

"The invention of all those machines by which labour is so much facilitated and abridged, seems to have been originally owing to the division of labour ... It is the great multiplication of the production of all different arts, in consequence of the division of labour, which occasions in a well governed society, that universal opulence which extends itself to the lowest ranks of people." (Smith, 1776, Book 1, Chapter 1)

Karl Marx, in contrast, in his treatment of technological change concentrated on process innovations, which would create unemployment and income inequality between the owners of the capital and the workforce. In Das Kapital he developed a theory of fluctuations determined by capital accumulation and technological change. This theory assumed a reserve army of unemployed, which would serve to keep the wages of the workers down, but periodically wages would rise as the stock of capital, which determined the employment of labour, accumulated and caught up with labour supply. The subsequent rise in wages would depress the firms' profits and induce labour-saving innovations, thus creating technological unemployment and rising levels of inequality between the owners of the capital

\footnotetext{
' Card and DiNardo (2002) argue that the debate on the machinery question that emerged in the wake of the Industrial Revolution was instrumental in the birth of the new science of economics during the nineteenth century.
} 
and the workers. ${ }^{2}$

Descriptions of historical events show an equally disperse pattern. In the second half of the nineteenth century, groups of British artisans destroyed new textile machinery in the Midlands and North of England because they believed it would take away their opportunities to earn a living (Wiliams, 1986 and Mokyr, 1990). In addition, Habbakuk (1967) describes the adoption of the Fourdrinier machines after 1800 by English paper manufacturers and the invention of the automatic spinning-mule by Richard Roberts in 1825 as being prompted by the desire to save on the utilization of skilled workers. Goldin and Katz (1998) argue that rather than being the relative complement to skill, technology was, for some time, a relative complement of raw materials and, together with unskilled labour, substituted for skilled individuals: "The prototypical example is gun making. Cheap lumber in America fostered the use of wood lathes and displaced hand fitting in the production of gun stocks by skilled woodworkers. The butcher, baker, glassblower, shoemaker, and smith were also skilled artisans whose occupations were profoundly altered by the factory system, machinery, and mechanization." (pp. 694-695). Furthermore, Braverman (1974) emphasizes that technological change was characterized by a trend towards deskilling of work in the nineteenth century: (i) "the dissociations of the labor process from the skills of the workers. The labor process is to be rendered independent of craft, tradition, and the workers' knowledge. Henceforth, it is to depend not at all upon the abilities of workers, but entirely upon the practices of management" (p. 113); (ii) "therefore, both in order to ensure management control and to cheapen the worker, conception and execution must be rendered separate spheres of work, and for this purpose the study of work processes must be reserved to management and kept from the workers, to whom its results are communicated only in the form of simplified job tasks ... and without comprehension of the underlying technical reasoning or data" (p. 118); and (iii) "[technical change] was to ensure that as craft declined, the worker would sink to the level of general and undifferentiated labor power, adaptable to a large range of simple tasks, while as science grew, it would be concentrated in the hands of management." (p. 121).

\footnotetext{
${ }^{2}$ David Ricardo also emphasized the relationship between technology and labour. In the first two editions of the Principles of Political Economy and Taxation he expressed the opinion that the introduction of labour-saving machinery was generally a good development. However, in the third edition, he wrote that he had become convinced that labour-saving technological change would harm the average worker. See Williams (1986) for an intriguing overview of the changing position of Ricardo in the debate.
}

${ }^{3}$ Habakkuk (1967) argues that this phenomenon was particularly present in England: "... in England elasticity of supply to the individual firm of unskilled labour, in relation to skilled, was greater than in Anerica .... So the scarcity of labour in general relative to capital provided the Americans with a stronger incentive than the English to replace labour by capital, but the English had a stronger incentive than the Americans to replace skilled by unskilled labour." (p. 152). 
By contrast, Goldin and Katz (1998) argue in The Origins of Techmology Skill Complementarity that the spread of batch and continuous process methods of production increased the demand for skills in the early twentieth century, suggesting the presence of technology-skill complementarity: "... the switch to electricity from steam and water-power energy sources was reinforcing because it reduced the demand for unskilled manual workers in many hauling, conveying, and assembly tasks." (p. 695). In addition, Jerome (1934) described the developments in the 1920 s as follows: "there is considerable reason to believe that the effect of further mechanization will be to raise the average skill required." (quoted by Acemoglu, p. 8). Griliches' 1969 paper Capital-Skill Complementarity and subsequent contributions by Welch (1970), Schultz (1975) and Tinbergen (1975) also suggest that technological improvements complement skilled labour; Tinbergen (1975) has characterized the evolution of the wage structure as a "race between technological development and access to education."

Recently, the introduction, adoption and widespread use of computers at the workplace has dramatically changed the labour market. The current concern with the impact of computers on the wage structure and the demand for skills have motivated this study. The computerization of the workplace coinciding with the widening of the wage structure in some countries has led many to conclude that new technologies and human capital are relative complements and that large investments in education and training may be needed to reduce wage inequality resulting from the diffusion of computers at work. This notion of a bias in technologicall change resulting in a complementarity between technology and more-skilled workers has been explained by the three following arguments:

(i) more-skilled workers adapt more easily to technological change than lessskilled workers, because their skills are more general and more widely applicable;

(ii) computer technologies increase the productivity of more-skilled workers to a larger extent than the productivity of less-skilled workers, so that firms assign more-skilled workers to the new technology; and

(iii) a large number of new technologies currently perform repetitive tasks previously carried out by less-skilled workers.

With respect to the first point it has been argued that relatively skilled workers have an advantage over relatively unskilled workers in working with a computer. The often suggested reason for this complementarity between moreskilled labour and computers is that they face lower relative costs to acquire the skills to operate the computer. Greenwood and Yorukoglu (1997) argue that a simple story seems to connect the rate of the adoption and diffusion of computers to the levell of wage inequality:

"The idea is this. Imagine that a leap in the state of technology occurs 
and that this jump is incarnated in new machines, such as information technologies. Suppose that the adoption of new technologies involves a significant cost in terms of learning and that skilled labor has an advantage at learning. Then the advance in technology will be associated with an increase in the demand for skill needed to implement it. Hence the skill premium will rise and income inequality will widen." (Greenwood and Yorukoglu, 1997, pp. 49-50) ${ }^{4}$

The second argument - more-skilled workers gain more in terms of productivity from using a computer than less-skilled workers - has been analysed in Krueger's seminal contribution How Computers Have Changed the Wage Structure (Krueger, 1993). He concludes that

"employees who directly use computers at work earn a 10 to 15 percent higher wage. Furthermore, because more highly educated workers are more likely to use computers on the job, the estimates imply that the proliferation of computers can account for between one-third and one-half of the increase in the rate of return to education observed between 1984 and 1989." (Krueger, 1993, pp. 54$55)^{5}$

Finally, computers generally take over a worker's routine activities, which has led to a substitution of less-skilled workers by computer equipment and to a complementarity between more-skilled workers and computers. ${ }^{6}$ The reason for this trend is that relatively unskilled workers occupy jobs containing a great many routine activities, whereas relatively skilled workers perform many non-routine job activities. Autor, Levy and Murnane (2001) argue in this respect that

"a decline in the price of computer capital lowers the wages of workers carrying out routine tasks and causes employment in these

4 See also Chari and Hopenthayen (1991), Galor and Tsiddon (1997), Jovanovic (1997). Acemogh (1998), Aghion, Howitt and Violante (1998), Heckman, Lochner and Taber (1998), Acemoglu (1999), Caselli (1999), Lloyd-Ellis (1999), Kiley (1999), Galor and Moav (2000), Gould, Moav and Weinberg (2001), Weinberg (2001) and Violante (2002).

'See also Reilly (1995), Bell (1996), Asplund (1997), Entorf and Kramarz (1997), Hamilton (1997), Miller and Mulvey (1997), Oosterbeek (1997), Entorf, Gollac and Kramarz (1999), Haisken-DeNew and Schmidt (1999), Arabsheibani and Marin (2000), Sakellariou and Patrinos (2000) and Hildreth (2001) for similar arguments.

"See e.g., Kremer and Maskin (1997), Bresnahan (1999), Brynjolfsson and Hitt (2000), Katz (2000), Lindbeck and Snower (2000), Caroli and Van Reenen (2001), Garicano (2000) and (2001) and Bresnahan, Brynjolfsson and Hitt (2002). 
tasks to contract. Although the demand for routine task input increases as the price of computer capital falls, this demand is satisfied by substitution of computer capital for human labor. Because greater relative intensity of routine task input raises the marginal productivity of non-routine tasks, the wage per efficiency unit of nonroutine labor input rises." (Autor, Levy and Murnane, 2001, p. 11)

Although the present consensus in the literature seems broad, it is doubtful that computers favour only relatively skilled workers. The data on computer use at work in the early 1980s indeed suggests that more-skilled workers use computers and less-skilled workers do not. However, the picture in the 1990 s looks quite different. Computer use among all workers has increased dramatically and the assumed complementarity between technology and skill at the level of the production process seems to be doubtful in the case of computers. However, the acceleration of wage inequality both between and within groups of skilled and unskilled workers continues to exist and therefore has to be explained from another perspective. In addition, other empirical results concerning the role of computers in explaining the rise in wage inequality raise doubts about the three arguments presented above. For example, workers using the computer for tasks such as emailing and word processing receive much higher wages than workers who do not use computers (Krueger, 1993), although these tasks do not seem to require many skills. Furthermore, rather than electronic or mechanical cash registers, the use of computerized cash registers is associated with a wage premium of 10 to 15 percent, which casts doubts on the interpretation that workers using a computer are rewarded for applying their computer skills (Green, 1999). It has also been shown that it is by no means true that all those who embody (general) computer skills are actually using a computer on the job; a fairly large number of people work in jobs in which computers are used even though they do not report having computer skills. There is also evidence that for most cases of computer use there is no relationship between wages and computer skills (Bell, 1996). Another piece of evidence on the relationship between computer use and wages is that, on average, companies employing computers pay their employees higher wages regardless of whether these employees use these computers (Doms, Dunne and Troske, 1997). Finally, based on job analyses it can be concluded that at all skill levels jobs and tasks are found that seem to be well-suited to computerization (Bresnahan, 1999).

These results illustrate that the way in which computers affect the wage structure and the demand for skills - and the labour market as a whole - is more complicated and that the link between skills and computer use is not so clear. In this study two main questions are analysed to yield an understanding of the computerization of the labour market:

First, from a microeconomic point of view, the study will examine when a worker adopts a computer (the determinants of computer use) and what the subsequent consequences are for the individual worker's job, wages, the demand 
for skills and the changing value of skills.

Secondly, from a macroeconomic point of view, the study will investigate what happens to the wage structure if some workers start using computers and others do not (yet). Of particular interest here are the timing of the adoption of computers by different workers and whether the diffusion of computers leads to long-run skill-biased technological change and wage inequality.

\subsection{Aim of the Study and Summary of the Main Argument}

The aim of the study is to develop a perspective on how computerization has changed the labour market to explain the empirical observations presented above in a consistent manner and to provide a theoretical framework to understand both the impact of computerization on the individual's job at the microeconomic level and the macroeconomic consequences for the wage structure. From a microeconomic point of view, computers change the configuration of the job and the production process of output, which influences labour demand and wages. At the macroeconomic level, these changes have, in some countries, led to an increasing demand for relatively skilled workers and increasing wage inequality both within groups of rather homogeneous workers and between relatively skilled and unskilled workers.

To summarize the main argument of the present study, consider the following line of thought. An essential characteristic of computers is that they support workers in the activities they are involved in during working time. The equipment is somewhere near the individual's workplace: the personal computer with access to the Internet is on one's desktop, the mobile phone is in one's pocket, and the computerized cash register is on the counter. In general, the computer supports a worker by taking over some (routine) tasks, which leads to a more efficient mode of production without taking over all the work and thus rendering the worker superfluous. To determine the influence of computers on the way people work and to find out when a computer will be adopted to support certain activities (the determinants of computer use), it is useful to first take a closer look at the way in which computer equipment is applied at the workplace. To do so, it is important to distinguish three different kinds of activities in a job. First, there are tasks which are taken over by a computer, once introduced. Secondly, other tasks continue to be conducted by the worker after the introduction of a computer. Thirdly, the introduction of a computer may lead to a set of new tasks related to operating the computer. Possibly, or even probably, these tasks are highly interrelated. ${ }^{\top}$

\footnotetext{
Some have stressed that a computer might also change the activities that are not taken over by the computer. Since processing information and communication becomes cheaper, firms might change the organizational structure, the characteristics of the product and the way it is produced
} 
Thinking about a job as a set of tasks that have to be performed enables us to conceptualize how computers change the configuration of the job by changing the importance, skills and time requirements of the performance of the tasks after they are introduced. Of course, each task a worker has to perform requires some part of the working time and the time needed to fulfill a certain task depends on the skills of the worker involved. Some skills (or some measures of skills) might be related to the performance of all tasks, while other, more specific skills are likely to influence the time needed for the performance of a specific task only. For example, workers with more years of education (and hence higher skills) might perform all tasks more rapidly than workers with fewer years of education (both before and after computerization), while a waitress with high-level communication skills might be excellent in dealing with clients, but not perform better in handling the orders before or after using a computerized cash register.

From this conceptualization of the job, the introduction of the computer can be viewed upon as a decision which depends on the costs and benefits involved. This decision is based on a break-even point at which the firm's profits are the same whether or not some part of the job is performed using a computer. ${ }^{8} \mathrm{~A}$ company will only decide to introduce computers if the costs involved match the time that can be gained, which is equivalent to weighing higher costs for the configuration of the job (which now also includes computer capital, computer networks, technical assistance etc.) to increased productivity as a result of the time gain of a more efficient mode of production (which allows the worker to produce more units of output requiring the same amount of time). Apart from considering the costs of buying, designing and maintaining a computer (system), and perhaps initial training to provide the workers with the skills needed to operate the system, the decision is based on three components, which are related to a worker's productivity gain from using a computer: (i) the importance of the tasks that can be computerized within a job, (ii) the skill level of the typical worker involved, and (iii) the wage the employer has to pay the worker or equivalently the wage costs the employer is able to save when production becomes more efficient after the computer is adopted in a particular job.

Let us briefly discuss these three components of the decision to invest in computers. First, it seems to be rather trivial that computer use requires a job which includes tasks that can be computerized. Fortunately, the routine and repetitive

to take advantage of these new possibilities. These changes are likely to affect the noncomputerized part of the work as well. See for example Lindbeck and Snower (2000), Caroli and Van Reenen (2001), Garicano (2001) and Bresnahan, Brynjolfsson and Hitt (2002) for such arguments.

${ }^{2}$ It is irrelevant whether the worker or the firm decides to purchase a computer to carry out the job. The costs and benefits for one individual job will generally be the same, regardless of whether the firm or the worker evaluates the decision to adopt. 
tasks of many jobs can in principle be computerized. ${ }^{9}$ Secondly, the time gained in the production process as a result of computerization is translated into a productivity increase and constitutes savings on labour costs because more output can be produced using the same amount of labour input. This time gain depends on the specific character of the tasks to be performed, but might also depend on the skill level of the worker concerned. The part of the time gain resulting from specific tasks that have to be performed is likely to be reflected in the development of new and more efficient applications, software and hardware. With respect to skills, it is likely that if a particular worker is more efficient in performing the job after computerization, this worker benefits more from computer use than another worker who is less efficient or skilled to do so. To see this, note that when the computer is introduced, the time needed to produce one unit of output is (i) reduced by the time needed to perform the computerized tasks, (ii) increased by the time needed to operate the computer, and (iii) modified due to changes in the other, non-computerized tasks. From a skill perspective, computer use is therefore likely to be most efficient for workers with relatively low skills to perform the tasks that can be computerized and relatively high skills for operating the computer instead and the other, non-computerized tasks. This relationship between the time gain resulting from computerization and a worker's skill level can be defined as the skill bias of the adoption of a new technology because the skills might either be related to the performance of the computerized tasks or to the other tasks, which might be more advantageous to relatively skilled workers compared to unskilled workers.

However, from this skill argument some interesting observations can be drawn, which might question its validity. First, if a relatively skilled worker has a higher work pace for every task, there seems to be no reason to expect computer adoption among these workers from a skill perspective, since it is the relative productivity increase after computerization that matters. If this productivity increase is similar for both relatively skilled and unskilled workers, there seems to be no reason to provide the former with computers and the latter not. Secondly, workers with high abilities to bring to completion the non-computerized (and often the non-routine, cognitive) part of the job, both before and after the introduction of the computer, do not have a higher probability to use the computer because it is likely to leave unaffected the time requirements to carry out the noncomputerized tasks. Finally, even very large differences in computer skills between people might have only a very moderate impact on computerization if the time needed for the computerized (and often routinized) part of the job is marginal compared to the time needed for the other tasks. Hence, the argument that

\footnotetext{
"One could also argue that every job involves tasks which could be computerized if resources are devoted to developing such equipment. However, for some jobs, like cleaning, the current technology is either too expensive relative to the wage costs expected to be saved or too unreliable to be efficient (in the case of the cleaner, the robotic eye in the washing machine appears to be too imprecise to wash the comers of a room).
} 
computer skills are likely to explain the differences in wages between computer users and non-users does not seem to be valid when the computer is used to support a worker's activities. ${ }^{10}$

This brings us to the last point of the job conceptualization, which states that the benefits from the amount of time saved by a computer are also likely to be determined by the wage level of the employee(s) involved (before computerization). A firm paying higher average wages than another firm is therefore more inclined to adopt computers because it can save relatively more on wage costs: if wages are high - given the tasks to be computerized and the relative skills of the workforce - a computer will be worthwhile because it induces a more efficient mode of production in which a relatively high amount of wage costs can be saved compared to a firm paying relatively low wages. The wage level is thus likely to be an important determinant of computer use, which suggests that higher wages increase the probability of using a computer. This observation is consistent with the results of a large number of empirical studies on the computerization of the labour market showing that computer users earn higher wages (e.g., Krueger, 1993). These studies mainly predict higher wages as a result of using a computer, whereas the results of the present analysis suggest that the causality is reversed. Although skills might explain the pattern of computer use, the perspective put forward in this study suggests that (high-)wage arguments are also likely to explain the pattern that higher-skilled (and higher-paid) workers use computers more frequently and that, within each level of education, computer users earn higher wages. This micro-foundation for the effects of computerization at the individual level serves as a starting point for a macroeconomic perspective on how computerization has changed the labour market.

At the macroeconomic level, this perspective on computerization changes the configuration of a job and the skill requirements of the person occupying this job. First, for the relationship between wages and computer use this perspective predicts a particular diffusion pattern, which is important from the worker's point of view. Workers with the highest wages or with tasks relatively well-suited to computerization adopt computers first because it is most cost-effective for them to adopt. Throughout the past three decades, the price of computer equipment, software and networks has dropped significantly (e.g., Greenwood and Yorukoglu, 1997 and Jorgenson, 2001). This development of computer prices and the development of new applications in terms of hardware and software has led to the adoption of computers at lower wage levels, and probably different tasks can now fairly easily be computerized. If productivity differentials between workers from using a computer are comparatively unimportant in the decision to adopt:

\footnotetext{
${ }^{10}$ This finding is consistent with the observation of Levy and Murnane (1996), who find for a large U.S. bank that routine tasks constitute only a relatively smaller part of the job after the introduction of the computer, whille the importance of the non-routine, non-computerized part of the job increases.
} 
computers (as argued above), wage inequality resulting from the adoption of computers will be a temporary phenomenon if computers become sufficiently cheap to operate and maintain. Wage inequality between users and non-users within the same group $G$ of workers is likely to rise in the beginning, because worker $i$ using a computer becomes more efficient and productive than worker $j$ not using a computer. This leads to an increase in the supply of efficiency units of group $G$ workers, which depresses the wage in terms of efficiency units. However, in relative terms worker $i$ gains because he supplies more efficiency units than worker $j$. Once the costs of computers have dropped to a level at which all workers in group $G$ adopt computers, wage inequality will fall again because all workers in this group gain from the increased productivity of using a computer without suffering from differentials in the supply of efficiency units of labour."

Secondly, from the micro-foundation it becomes clear that the computerskill complementarity is not to be found at the level of the production process. The technical complementarity imposed by most macroeconomic studies, between computers and skilled workers, does not seem to hold but is merely a reflection of a statistical complementarity observed at the initial stage of the diffusion. ${ }^{12}$ As technology diffuses and becomes mature and cheaper, ${ }^{13}$ the wage advantage of skilled workers in using a computer disappears and the unskilled also start to use computers. The adoption of computers among unskilled workers increases their supply in efficiency units, which depresses the wages of the non-adopters (just like in the case of the skilled workers not adopting) and increases the wage per worker for the adopters because they supply more efficiency units of labour. This adoption pattern of computers among unskilled workers resulting in an increase in the supply of efficiency units of unskilled labour is likely to have amplified wage inequality between skilled and unskilled workers because in the production function an increase in the supply of efficiency units of unskilled workers raises the relative wages of skilled workers. Hence, not the mere computer use of skilled workers and the non-use of unskilled workers at the beginning of the diffusion process leads to wage inequality between skilled and unskilled workers, as it is often assumed in the literature, but the spread of computers among unskilled workers has induced wage inequality between skilled and unskilled workers to

11 These arguments can be easily constructed in more formal terms by considering a CES

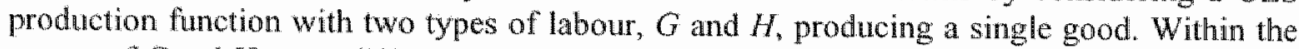
groups of $G$ and $H$, wage differentials will occur if workers $i$ use computers and workers $j$ do not.

${ }^{12}$ More formally, production takes place according to the function $Y=f(S, U)$ (S is defined as skilled and $U$ as unskilled labour inputs) in which $S$ is a function of technological change: $S=S(A)$. A large number of studies formalize this into a CES function of the following type: $Y=\left(A S^{p}+U^{p}\right)^{1 / p}$, in which $A$ is skilled labour-augmenting technological change.

15 The fact that computers become cheaper can also be interpreted as more sophisticated computer equipment being capable of performing more or new tasks at the same costs. 
rise. ${ }^{14}$ At the point where all workers have adopted computers, wage inequality will remain present only if there are differentials in the productivity gains from using computers between different workers. In addition, the widening of the wage structure between skilled and unskilled workers and within groups of skilled and unskilled can be explained by differences in the time of adoption and need not assume skill-biased technological change to be present.

Finally, from the perspective of the job, this conceptual framework reveals that computers de-emphasize routine tasks, which become computerized, and reemphasize the non-routine parts of the job, which become more important. Often, the non-routine tasks involve the skills a worker is typically hired for. For example, a journalist is hired because he is a good reporter who presents creative and indepth views on particular events, and not for his nice handwriting. The writing down of his story can be made more efficient by giving this journalist a PC, which saves time with respect to the routine aspects of the job but emphasizes the creation of a consistent story. This emphasis on the non-routine part of the job is likely to increase skill requirements and job complexity for job $k$ when a computer is introduced relative to job $l$ where no computer equipment is required or available. Hence, from the perspective of the individual job, the observed skill upgrading at the macroeconomic level resulting from the computerization of work is also to be explained by this re-emphasis on the non-routine aspects of the job.

\subsection{Research Outline}

The line of thought explored above is developed in more detail in the other chapters of this study. The following issues are addressed. First, in Chapter 2 the theoretical and empirical literature on skill-biased technological change is reviewed with respect to the impact of computers on the demand for labour and the wage structure. This is done first by putting forward the empirical trends in the data using U.S. information. This is followed by a review of the theoretical literature in which the predicted patterns, the timing of these patterns and sources of wage inequality are of central importance. Finally, this chapter discusses the econometric studies drawing causal relationships between technology and wages with a particular focus on the issues of endogeneity and skill and technology measurement.

Chapter 3 offers a micro-foundation of the impact of computers on the individual worker's job. The model conjectures that wage differentials and the performance of particular job activities between computer users and non-users are

\footnotetext{
14 Again, imagine a CES production function with skilled and unskilled workers being the only factors producing a single good. An increase in the supply of efficiency units of one type of labour is likely to increase the relative wage of the other type of labour, all other things being equal.
} 
consistent with the observation that computers are first introduced in high-wage jobs for reasons of cost efficiency. It also shows that neither computer skills nor complementary skills are needed to explain the observed skill upgrading, changes in product characteristics and the organization and intensity of work. Finally, it is shown that these findings shed a different light on the way computers have changed the labour market and on the changes to be expected following the further diffusion of computers. This micro-foundation of the job is the core of the study from which the further empirical and theoretical work develops. To understand the computerization of the labour market empirically it is acknowledged that technology adoption is an endogenous variable. Hence, the causation of the influence of wages on technology use or the influence of technology use on wages seems to be of central importance to understand the empirical findings. In Chapter 4 , the framework developed in Chapter 3 is applied to the data. The subsequent empirical evidence from Britain shows how computers change the labour market. The empirical results indicate that computer use is to a large extent explained by wages rather than by skills. It is also shown that age and experience are not related to computer use. For example, older workers do not seem to have particular disadvantages of using computerized equipment at work.

In Chapter 5 the diffusion of computers through the labour market is examined at the macroeconomic level. In this approach the diffusion process of computers is considered explicitly, treating skill upgrading as given. The analysis offers a theoretical model of the adoption and diffusion of computers at work to analyse between-group and within-group wage inequality, inspired by the empirical observation that the composition of the group of workers using a computer changes over time and that the timing of the rise in between-group and within-group wage inequality is different. The model conjectures that initially only the most productive workers adopt computers, because they can save more on their wage costs. This leads to within-group wage inequality because computer adopters become more efficient. With falling costs of computerization, only when the number of skilled computer users becomes large or when the unskilled workers start to adopt computers, between-group wage inequality increases because the additional supply of efficiency units of unskilled workers depresses the unskilled wages. The occurrence of wage inequality is caused by the additional supply of efficiency units of labour and productivity gains from using computers and not by assuming that skilled workers gain more in terms of productivity from using a computer than unskilled workers. When all workers have adopted computers, between-group and within-group wage inequality disappear unless there are differences in productivity gains between workers. Based on CPS data, it is shown that the predicted pattern of adoption and diffusion is consistent with the observed pattern and the timing of the rise in between-group and within-group wage inequality in the United States in the period 1963-2000.

Chapter 6 empirically addresses the observed skill upgrading from the perspective of the job, considering the diffusion of computers through the labour 
market as given. This chapter uses bi-annual data from the Netherlands for 1986 1998 to evaluate the effect of the assignment of skills to jobs on the wage structure in the Netherlands. It explains why wages were comparatively stable in the Netherlands in the 1980s and 1990s. Using a simple assignment approach it is found that job complexity has increased, which has led to an increased relative demand for skilled workers. On the supply side of the labour market, returns to education are found to have only slightly increased. It is shown that the increased demand for skilled workers was accompanied by a more efficient assignment of workers to jobs, which prevented relative wages from increasing to the extent they did in the United States.

Chapter 7 concludes, summarizes the main findings, presents the implications of this study, and gives several directions for future research. 



\section{Chapter 2 \\ Technology, Skills and Wages}

\subsection{Introduction}

The aim of this chapter is to provide an overview of the literature concerned with the impact of the use of new technologies on skill requirements and the wage structure. The starting point is the observation that educational wage differentials and within-group wage inequality have expanded in most countries throughout the past three decades, coinciding with the computerization of the workplace. Not surprisingly, attempts have been made to draw causal inferences as to what extent the increases in the demand for skilled workers and rising wage inequality have been driven by the implementation and diffusion of computer equipment (e.g., Bound and Johnson, 1992, Krueger, 1993, Berman, Bound and Griliches, 1994, Autor, Katz and Krueger, 1998 and Berman, Bound and Machin, 1998). 'The four main observations from these studies are that

(i) after controlling for personal and job characteristics, workers using computers earn substantially higher wages than non-users;

(ii) skilled workers (e.g., college graduates) use computers more often than unskilled workers (e.g., high-school graduates);

(iii) computer use has led to an acceleration of both between-group and withingroup wage inequality; and

(iv) the spread of computers has led to significant skill upgrading.

These findings suggest that technological change resulting from the adoption and diffusion of computers has amplified wage inequality, favoured skilled workers more than unskilled workers in terms of usage, and complemented the work of skilled and substituted for the work of unskilled workers. In the literature, such

\footnotetext{
"Recently, Katz (2000), Kramarz (2001) and Card and DiNardo (2002) have also written survey papers on the relationship between computerization of the workplace and the widening of the educational and wage gap over the past thirty years. Acemoglu (2002) and Aghion (2002) offer an overview of the theoretical literature discussing the effect of technological change on wage inequality and Chennells and Van Reenen (1999) review the empirical literature extensively.
} 
findings have been labelled skill-biased technological change, which can be defined as the change resulting from the implementation of new technologies, production processes, or organizational amendments that increases the demand for skilled workers relative to unskilled workers. ${ }^{2}$

This chapter first reviews some of the most important empirical trends, illustrated for the United States. Secondly, an overview of the theoretical and empirical literature is given. Finally, a conclusion sets the research agenda for the remainder of this study.

\subsection{Empirical Trends}

The objective of this section is to illustrate the main trends concerning the distribution of wages and wage inequality in relation to the diffusion of computers. These empirical trends serve as a starting point for the theoretical discussion in Section 2.3 and the review of the empirical literature in Section 2.4. The empirical trends are illustrated using the Supplements of the March Current Population Surveys from 1964 to 2001 and the October Surveys from 1984, 1989, 1993 and 1997, data from the National Income and Product Accounts on computer investments, and data from a study by Krusell, Ohanian, Ríos-Rull and Violante (2000).

\subsubsection{Computer Use}

Table 2.1 shows computer use in the United States in October 1984, 1989, 1993 and $1997,{ }^{3}$ measured by the fraction of workers who use a computer directly. Although this measure does not account for workers who use devices with embedded computer technologies, it is a good illustration of how computers are most often applied at the workplace (e.g., Autor, Katz and Krueger, 1998 for a discussion). In addition, it serves as an illustration of how the adoption and diffusion of computers has evolved over time.

\footnotetext{
2 This literature overview only considers the dynamics of wage inequality that have been attributed to technological change. Other explanations for wage inequality, such as access to education, institutional factors (unions, minimum wages etc.) and political factors are left aside and taken as given.
${ }^{3}$ The figures shown are taken from the only years for which computer use at work is available in the Current Population Surveys. Later Surveys (August 1998 and December 2000) consider computer and Internet use at home, which is not likely to provide useful information for the present analysis.


Table 2.1

Percentage of Workers in Various Categories Who Directly Use a Computer at Work

\begin{tabular}{|c|c|c|c|c|}
\hline & October 1984 & October 1989 & October 1993 & October 1997 \\
\hline \multicolumn{5}{|l|}{ Use a computer } \\
\hline All workers & 24.3 & 37.4 & 45.1 & 52.5 \\
\hline \multicolumn{5}{|l|}{ Gender } \\
\hline Male & 21.0 & 32.1 & 39.6 & 46.7 \\
\hline Female & 28.4 & 43.7 & 51.3 & 59.0 \\
\hline \multicolumn{5}{|l|}{ Education } \\
\hline$<$ High school & 3.8 & 6.0 & 7.2 & 9.8 \\
\hline $\bar{z}$ College $>\mathrm{HS}$ & 21.5 & 33.4 & 37.7 & 43.6 \\
\hline$\geq$ College & 40.1 & 56.7 & 63.9 & 72.6 \\
\hline \multicolumn{5}{|l|}{ Race } \\
\hline White & 25.0 & 38.6 & 46.5 & 53.8 \\
\hline Black & 19.1 & 28.7 & 36.3 & 44.2 \\
\hline \multicolumn{5}{|l|}{ Age } \\
\hline Age 18-24 & 21.1 & 33.0 & 35.8 & 41.5 \\
\hline Age 25-39 & 27.9 & 40.0 & 47.3 & 53.8 \\
\hline Age 40-54 & 22.3 & 37.4 & 46.7 & 55.0 \\
\hline Age 55-64 & 17.0 & 27.1 & 36.9 & 46.8 \\
\hline \multicolumn{5}{|l|}{ Occupation } \\
\hline Blue-collar & 6.7 & 11.2 & 16.5 & 20.3 \\
\hline White-collar & 38.4 & 56.2 & 65.0 & 73.7 \\
\hline \multicolumn{5}{|l|}{ Union member } \\
\hline Yes & 19.2 & 31.6 & 38.6 & 46.8 \\
\hline No & 24.5 & 37.6 & 45.3 & 52.7 \\
\hline \multicolumn{5}{|l|}{ Hours } \\
\hline Part-time & 13.7 & 26.9 & 31.9 & 41.8 \\
\hline Full-time & 26.3 & 37.7 & 45.6 & 54.6 \\
\hline \multicolumn{5}{|l|}{ Region } \\
\hline Northeast & 24.9 & 37.0 & 44.6 & 52.5 \\
\hline Midwest & 23.2 & 36.6 & 45.5 & 53.3 \\
\hline South & 23.0 & 36.6 & 43.4 & 50.9 \\
\hline West & 26.3 & 39.8 & 47.4 & 53.6 \\
\hline
\end{tabular}

Note: Data are from the October 1984, 1989, 1993 and 1997 Current Population Surveys. Sample Sizes are $60,396,58,377,59,473,52,542$ in $1984,1989,1989,1993$ and 1997 respectively. The sample includes all persons that are employed.

The first panel in Table 2.1 demonstrates that computer use more than doubled in the period 1984-1997, from 24.3 percent in 1984 to 52.5 percent in 
1997; an average annual growth rate of almost 6.3 percent. The largest increase in computer use took place between 1984 and 1989 (an average annual growth rate of 9.0 percent) but the general trend of the diffusion of computers at the workplace is rather linear over these four observations. With respect to gender it is shown that female workers use the computer more often than their male colleagues. This observation is consistent with the view that computers (and capital equipment in general) take over tasks which emphasize physical strength and stamina. ${ }^{4}$ The spread of computers among men, however, increased slightly more rapidly than among women throughout the period as a whole: the average annual growth rate for male computer use equals 6.3 percent and for female computer use 5.9 percent.

The growth of computer use has not been uniform across demographic groups. Table 2.1 reports differences in computer use among educational groups, races, age groups, occupations, union members and non-members, full-time and part-time workers and some small differences between regions. Particularly, the differentials in computer use between different educational groups is of interest. ${ }^{5}$ These differentials have been argued to lead to increased wage differentials between for example college graduates and high-school graduates because highlyeducated workers are assumed to be better able to work with computers and gain more from using computers in terms of productivity.

Computer use by industry is also rather different over the years 1984, 1989, 1993 and 1997. Not surprisingly, in 1997 direct computer use by workers became most prevalent in financial intermediation ( 90 percent), public administration ( 76 percent), real estate and business activities (66 percent) and other services (57 percent), which includes a large number of white-collar jobs occupying personal computers. In other sectors such as agriculture, hunting, forestry and fishing (22 percent) and the construction sector ( 21 percent) computer use has been much less prevalent.

\subsubsection{Computer Use and the Price of Computer Equipment}

The decision of an employer to computerize the production process or to

\footnotetext{
See for example Weinberg (2000) for an analysis of this positive impact of computers on the demand for fenale workers.

Note also that the use of computers among different age groups is rather flat. This might indicate that older workers do not have a disadvantage in using computers as is often argued. Friedberg (2001), using the CPS data, and Borghans and Ter Weel (2002), using British data, provide a detailed analysis of computer use in relation to age and arrive at similar conclusions.

"Autor, Katz and Krueger (1997) report computer use for 140 (three-digit) industry groups and also observe fairly large differences in computer use. A similar analysis for different occupations reveals that particularly white-collar professions have relatively high levels of computer use.
} 
provide a typical employee with a computer is likely to depend on the costs of the computer. Jorgenson (2001) provides figures showing a more than 10 percent annual decline in software prices since the 1970 s, while the prices of computer equipment have declined much more rapidly since 1959. Consistent with Jorgenson"s observations, the European Information Technology Observatory (EITO, 2000) supplies figures showing that the price of a $\mathrm{PC}$ running on a Pentium processor of 101 to $149 \mathrm{MHz}$ fell from about U.S.\$2,100 in 1993 to some U.S.\$ 1,400 in 1998. Similarly, the price of a PC running on a Pentium II processor of more than $400 \mathrm{MHz}$ declined from about U.S. $\$ 1,900$ in 1998 to some U.S.\$1,300 in early 2001.

There has also been a dramatic technological improvement in the capacity of semiconductors, which has led to an enormous increase in the capacities and speed of computers to store and process data, given the prices of the computer. These improvements were first described in 1965 by the then chairman of Intel, Gordon E. Moore, as a logarithmic increase in the processing capacity of computer chips. Known as "Moore"s law", these improvements still seem to occur more than 35 years after its first appearance. ${ }^{7}$ It has resulted in a dramatic drop in prices and improvements in quality of computer equipment: about 15 percent annually throughout the past 30 years.

This dramatic fall in the price of computer equipment along with the increases in performance and more advanced software applications are likely to have amplified its diffusion at the workplace. Figure 2.1 shows the investments in computer equipment in the United States in the period 1950-1992 as a share of total equipment investments. ${ }^{8}$ This figure illustrates that since the mid-1970s the

\footnotetext{
'In Moore's own words: "I first observed the doubling of transistor density on a manufactured die every year in 1965, just four years after the first planar integrated circuit was discovered. The press called this "Moore"s Law" and the name has stuck. To be honest, I did not expect this law to still be true some 30 years later, but I am now confident that it will be true for another 20 years. By the year 2012, Intel should have the ability to integrate 1 billion transistors onto a production die that will be operating at $10 \mathrm{GHz}$. This could result in a performance of 100,000 MIPS, the same increase over the currently cutting edge Pentium II processor as the Pentum II processor was to the 386 ! We see no fundamental bariers in our path to Micro 2012, and it is not until the year 2017 that we see the physical limitations of wafer fabrication technology being reached." See the Intel web page for more details http://developer.intel,com.
}

${ }^{8}$ The data are taken from the National Income and Product Accounts (NIPA) on industry capital stocks, investment, and full-time equivalent employees from 1950 to 1992. I would like to thank David Autor for making these data available. The measure of computer investments is defined as investments in office computing and accounting machinery (OCAM) per worker. Berndt and Morrison (1995), Autor, Katz and Krueger (1998) and Allen (2001) use a wider definition of computer equipment, which includes scientific and engineering equipment, communications equipment, and photocopy equipment. However, these types of equipment cannot be attached to an individual"s. job and are therefore not very relevant for the purpose of the analysis here. See also Greenwood and Yorukoglu (1997) for similar figures. 
investments in computer equipment have risen dramatically from about 4 to 6 percent in the period 1950-1975 to more than 10 percent in the 1980s. Particularly, the rise in the mid-1970s is interesting and likely to be the result of IBM's introduction of the first generation of PCs. Hence, the higher use of computers at work seems to be consistent with falling prices, the development of new applications, which have become available because of the growing possibilities resulting from heightened capacity, and the growing investments in computer equipment.

Figure 2.1

Computer Investments Per Worker as a Share of Total Equipment Investments

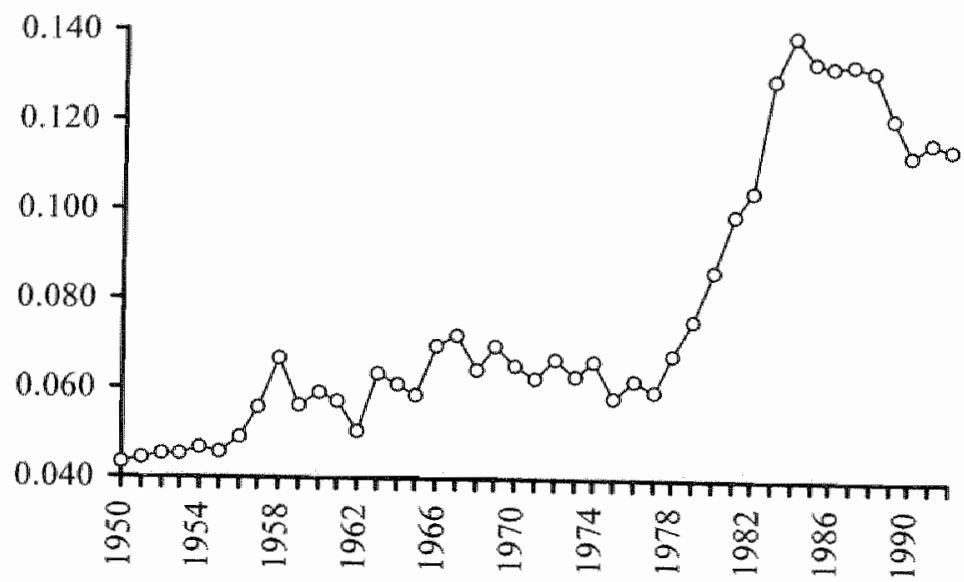

Source: National Income and Product Accounts from 1950 to 1992

\subsubsection{Computer Use and Wages}

It has been argued that workers using computers become more productive and therefore earn higher wages. A seminal paper by Alan Krueger (Krueger, 1993 ) provides estimates of computer users earning substantially higher wages. His initial approach is to augment a standard cross-sectional earnings function to include a dummy variable indicating whether an individual uses a computer at work:

$$
\ln W_{i}=A+\alpha B_{i}+\beta C_{i}+\varepsilon_{i}
$$

where $C_{i}$ represents a dummy variable that equals one if individual $i$ uses a computer at work, and zero otherwise; $\ln W_{i}$ is the $\log$ of the hourly wage of worker $i ; B_{i}$ represents a vector of observed characteristics; and $A$ is the intercept. 
Table 2.2 reports the coefficients of estimating equation (2.1) by OLS for the United States using the 1984, 1989, 1993 and 1997 October CPS. Including only a dummy variable for using a computer at work in columns [1], [4], [7] and [10] leads to wage differentials ranging from 30.2 percent in $1984(\exp (.264)-1)$ to 42.2 percent in $1997(\exp (352)-1)$. In the other columns, several covariates have been added to the wage equation. Although the computer wage premium drops significantly when including more observable characteristics, its effect remains substantial, rather stable over time and highly significant, ranging from 15.5 to 21.3 percent. Although it seems to be clear that computer users earn more than non-users, it is important to understand the effect of computer use on the relationship between earnings and education. A rather simple but straightforward test is to examine equation (2.1) first without computer use and then comparing these coefficients with the ones reported in Table 2.1. In doing so, for the regression equation reported in columns [2], [5], [8] and [11], it turns out that the returns to a year of education without inclusion of the computer use dummy variable are $.076(.001)$ in 1984, $.091(.002)$ in 1989, .092(.001) in 1993 and .092 (.001) in 1997 (standard errors in brackets). In other words, the rate of return to education increased by 1.5 percentage point between 1984 and 1989 if the computer dummy is excluded from the regression equation. If for 1984-1989 the computer dummy is included, the return to education increased by 1.1 percentage point. This implies that almost 30 percent of the increase in the return to education can be attributed to the rise in computer use. The validity of such an exercise is doubtful, because for the other years in the sample the returns to education remain stable while the use of computers increased. In particular, this argument poses two problems. First, if computers increase the demand for skilled workers, they can raise the wages of all skilled workers relative to unskilled workers, regardless of whether they actually use computers at work. Secondly, if something else changes the demand for skilled workers, it may also change the relationship between education and computer use. Therefore, controlling for computer use might lead to attributing wages effects to computer use, if the actual force were something else.

An alternative way to analyse the differentials in computer use by different educational groups is to add the following dummy variable to equation (2.1): computer use $\times$ years of education. If the coefficient of this dummy variable is positive, it indicates that highly-educated workers obtain higher computer wage premiums. Using the specification reported in columns [2], [5], [8] and [11] of Table 2.1 the coefficients for this variable are all insignificant at the 5 percent level. The coefficients are (standard error) $.001(.001)$ for $1984, .006(.003)$ for $1989, .002(.002)$ for 1993 and $-.003(.003)$ for 1997. These results, although drawn from a simple framework, suggest that highly-educated workers do not seem to benefit more - in terms of wages - from computer use than lowly-educated workers. This suggests that the computer wage premium is relatively insensitive to a worker's level of education and that its sources probably lie elsewhere. 


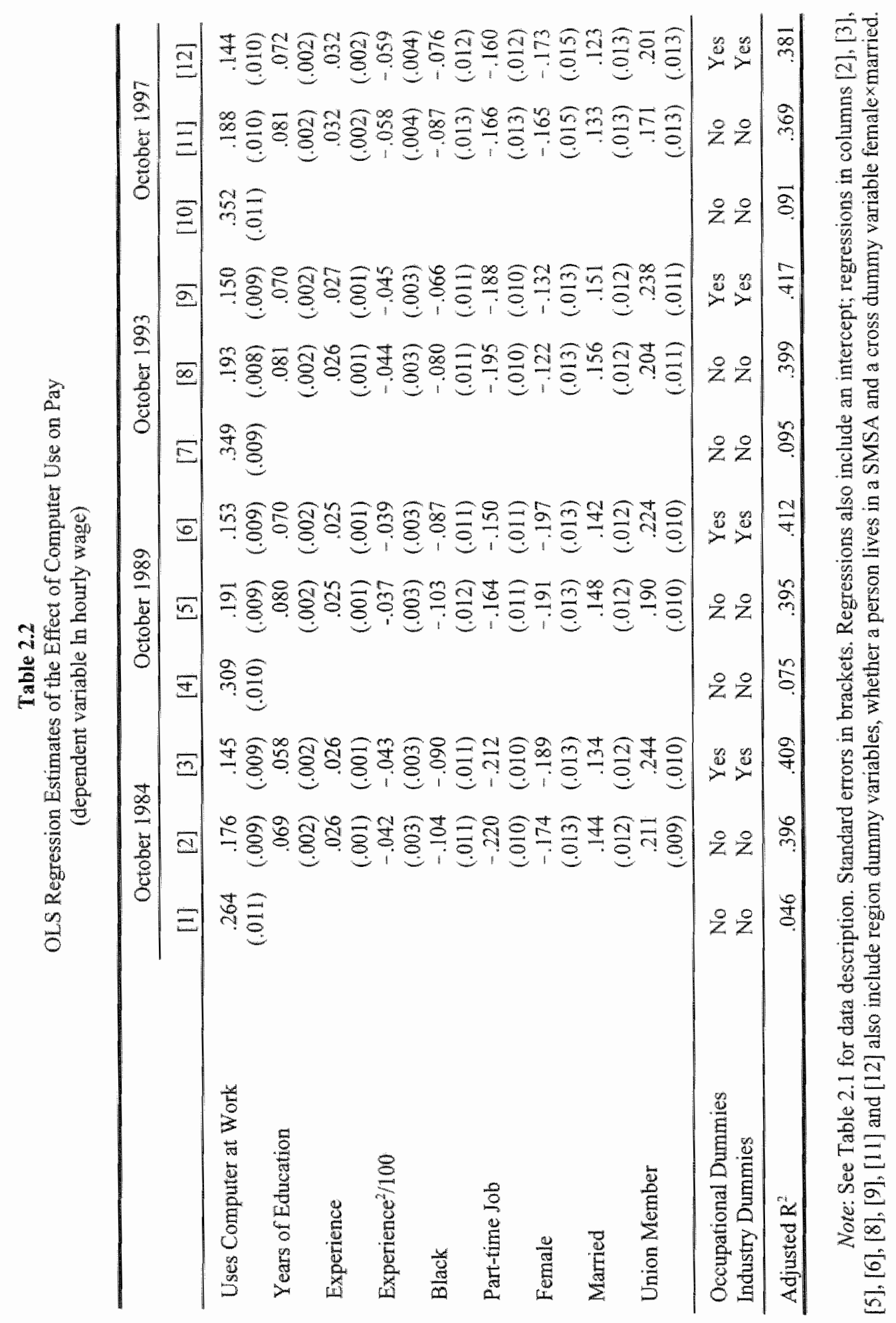




\subsubsection{Computer Use and Wage Inequality}

Section 2.2.2 has demonstrated that the prices of computer equipment have fallen and investments in computers have risen since the mid-1970s. In Section 2.2.3 it has been shown that computer users earn higher wages and that highlyeducated workers use computers more often than lowly-educated workers. Taken together this suggests that there might be a complementary relationship between the capital and pay per worker and the level of education.

\subsubsection{Wage Inequality}

To analyse changes in the wage structure and wage inequality, Katz and Murphy (1992) use a simple supply and demand framework. They specify the log of the relative wages $w_{s t}$ of skilled workers ( $>16$ years of education) at time $t$ relative to the wages $w_{u t}$ of the unskilled workers $(<16$ years of education) as a function of a linear time trend $t$, which represents a relative demand shifter for skilled labour, and the log of the ratio of unskilled $\left(U_{i}\right)$ to skilled $\left(S_{i}\right)$ labour input:

$$
\ln \left(\frac{w_{s i}}{w_{w i t}}\right)=A+\alpha \ln \left(\frac{U_{t}}{S_{i}}\right)+\beta t+\varepsilon,
$$

where $A$ is the intercept and $\varepsilon$ an error term with the usual properties.

Krusell, Ohanian, Ríos-Rull and Violante (2000) argue that the time trend could be interpreted as skill-biased technological change. More precisely, they suggest that the time trend reflects capital-skill complementarity. It is argued that such a complementary relationship exists because equipment capital (such as computers) is more complementary to skilled workers than unskilled workers. Because capital-skill complementarity is hard to measure, Krusell, Ohanian, RiosRull and Violante (2000) use the relative price of capital equipment, collected by Gordon (1990) and Greenwood, Hercowitz and Krusell (1997), as a proxy for such a relationship. Using their data, Table 2.3 reports the estimates of equation (2.2)."

The first column reports estimates using the Katz and Murphy time trend variable. The coefficient $\alpha$ is related to the elasticity of substitution between skilled and unskilled workers: $\alpha=1 /-\sigma$, where $\sigma$ is the elasticity of substitution. From this simple specification $\sigma=1.35$, which is consistent with the value of 1.41 obtained by Katz and Murphy (1992) for the period 1963-1987 and the values between 1 and 2 estimated by Acemoglu (2002). The time trend is about 2.6

\footnotetext{
9. The data appendix in Krusel1, Ohanian, Rfos-Rull and Violante (2000) explains in great detail how the data set is constructed. The data can be obtained from Gianluca Violante"s web site: http:/www ucl ac.uk/ $\sim$ uctpgvi/
} 
percent, which is also in line with earlier estimates. In column [2], the capital equipment per skilled worker is added to the regression instead of a time trend. In this way, one might capture capital-skill complementarity. The coefficient on this variable is significant and indicates that a higher share of capital per skilled worker substantially increases the wage differentials between skilled and unskilled workers. Column [3] reports regression results that replace the time trend with the relative price of equipment capital. This term is significant but the fit of the regression is worse than the Katz-Murphy results reported in column [1]. The reason for the inclusion of these two variables is that they might explain increased computer use among skilled workers and wage inequality since the dramatic increase in investments (Figure 2.1) and fall in prices of computer equipment. Although the fit of these two regressions is worse, the capital intensity and the falling prices of computer equipment explain at least part of the time trend.

\section{Table 2.3}

Explaining Wage Inequality in the United States, 1963-1992

(dependent variable In (wage skilled/wage unskilled)

\begin{tabular}{lcccc}
\hline & {$[1]$} & {$[2]$} & {$[3]$} & {$[4]$} \\
\hline Relative Supply $(\alpha)$ & -.742 & -.498 & -.610 & -.362 \\
& $(.053)$ & $(.051)$ & $(.068)$ & $(.118)$ \\
Time Trend $(\beta)$ & .026 & & & .015 \\
& $(.002)$ & & & $(.004)$
\end{tabular}

Capital Equipment per Skilled Worker

Relative Price of Equipment

\begin{tabular}{lllll} 
Dummy for the period up to 1972 and 1980 & No & No & No & Yes \\
\hline Adjusted $\mathrm{R}^{2}$ & .901 & .845 & .795 & .930 \\
\hline
\end{tabular}

Note: Standard errors in brackets. The regressions also include the unreported intercept A. The data are taken from Krusell, Ohanian, Rios-Rull and Violante (2000) and the original sources are the Demographic Supplements of the March Current Population Surveys from 1964
to 1993.

In column [4], two dummy variables have been added to the equation: one dummy variable equals 1 for the period after 1972 and one dummy variable equals 1 for the period after 1980. The reason for doing so is the following. Using the information on computer use from Table 2.1, it is possible to impute the computer use in the whole sample from 1963 to 1992. Defining skilled and unskilled workers as in Krusell, Ohanian, Ríos-Rull and Violante, two equations for computer use 
(for skilled and unskilled workers) can be estimated. The results show that skilled workers started to use computers around 1972 and unskilled workers around 1980. Including the two dummy variables leads to a rather high elasticity of substitution between skilled and unskilled workers $(\sigma=2.76)$ and a much better fit. ${ }^{10}$ In addition, a large part of the unexplained time trend can now also be explained. Finally, it is remarkably consistent with the prediction of a drop in wage inequality in the 1970s, as shown in Figure 2.2.

Figure 2.2

Predicting Relative Wages in the United States, 1963-1992

(dependent variable $\ln$ (wage skilled/wage unskilled)

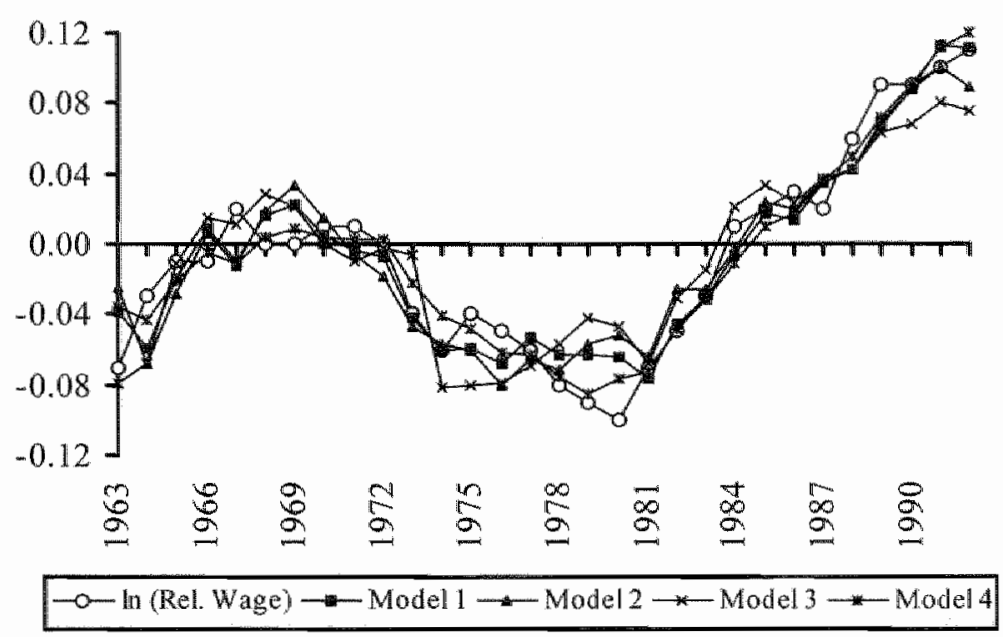

Note: See Table 2.3 for details about the data. The four models are equal to the four columns in Table 2.3 .

Figure 2.2 shows the predicted values of the four regressions and the real evolution of the relative wage. The four models described are the predicted values of the four numbered columns. As can be observed from the adjusted $R^{2} s$ and the figure, the fourth model fits the real evolution of the relative wages best. It is interesting to note that the timing of the fall in relative wages coincides rather well with the imputed introduction of computers among skilled workers. Equally interesting is that the lowest level of the log relative wages is observed in 1980 , which coincides in broad terms with the year in which the unskilled population started to use computers at work. Whether this relationship is accidental or real is

\footnotetext{
${ }^{10}$ Including the log of the relative price of equipment does not substantially change the results nor do other variants of these regressions combining variables change the general message of the table. Also, the results are not highly sensitive to taking the years of initial computer adoption somewhere around 1972 (skilled) and 1980 (unskilled).
} 
not easy to determine but it is striking and the explanatory power of the regression increases by accounting for the introduction of computer use.

\subsubsection{Within-Group Wage Inequality}

To understand the determinants of wage inequality, Bound and Johnson (1992) and Juhn, Murphy and Pierce (1993) investigate whether wage inequality can be attributed to measurable characteristics between different demographic factors such as education and experience. They conclude that the increase in U.S. wage inequality is mainly due to unobserved attributes of workers belonging to the same demographic group. This means that an important component of wage inequality is to be found within the groups of ex ante homogeneous skilled and unskilled workers (Chapter 6 discusses such an approach for the wage structure of the Netherlands).

Figure 2.3

Three-Year Moving Average of Within-Group Wage Inequality in the United States 1963-2000

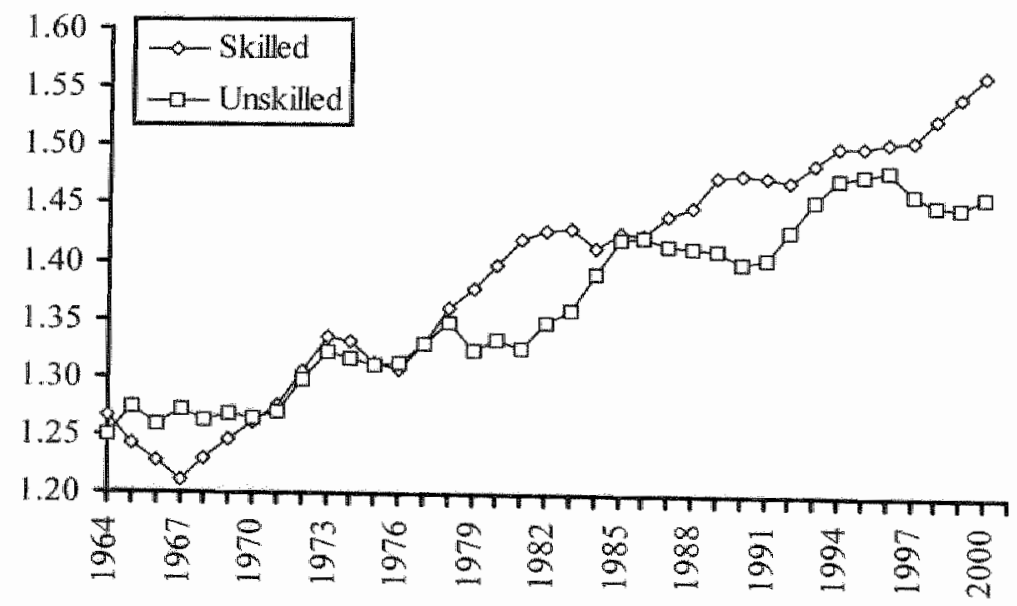

Note: All data are taken from the March CPS 1964-2001. The wage series are computed as a three-year moving average of the $\log$ wage differentials of the $90^{\text {th }}-10^{\text {th }}$ percentiles of the wage distribution of full-time, full-year workers for workers with $>16$ years of education (skilled) and workers with $<16$ years of education (unskilled).

Figure 2.3 plots the time series of wage inequality as measured by the log wage differential between the $90^{\text {th }}$ and $10^{\text {th }}$ percentiles of the wage distribution for skilled and unskilled workers measured by the log wage differential between the $90^{\text {th }}$ and $10^{\text {th }}$ percentiles of their individual wage distributions. Compared to the overall wage inequality reported in Figure 2.2, within-group wage inequality has 
risen more or less steadily since the early 1970s. However, wage inequallity within the group of skilled workers ( $>16$ years of education) has accelerated since the mid-1970s, which seems to be rather consistent with the predicted start of computer use among the first group of skilled workers as shown in Table 2.3. By the same token, wage inequality within the group of unskilled workers $(<16$ years of education) was fairly constant until 1980 and has risen afterwards. This is also consistent with the predicted point in time at which unskilled workers started to use computers. ${ }^{.1}$

Although information on computer use is available only for a limited number of relatively recent years, the timing of an acceleration in wage inequality and surge in the diffusion of computers and the falling prices of computer equipment and increasing investments since the mid-1970s is remarkable. It is also noteworthy that within-group wage inequality has been found to increase at the same time as computer use was initiated within the groups of skilled and unskilled workers.

\subsubsection{Computer Use and Upgrading}

Table 2.1 shows that computers are used mainly by highly-educated workers. To find out whether computer use leads to upgrading, the change in the share of workers in each educational group across industries is related to industry-level measures of computer utilization. Following Autor, Katz and Krueger (1998) and Katz and Autor (1999), I will test the hypothesis that industries that increase computer usage experience an acceleration in the rate of skill upgrading. ${ }^{12}$ Since computer use is available only in 1984, 1989, 1993 and 1997, this hypothesis suggests estimation of the following simple regression model for different time periods:

$$
\Delta W B_{i t}=\psi_{t}+\lambda_{t} \Delta C_{i}+\varepsilon_{i r}
$$

where $\triangle W B_{i}$ represents the change in the wage-bill share of college graduates

\footnotetext{
"Incorporating wage differentials between the $50^{\text {th }}$ and $10^{\text {th }}$ and $90^{\text {th }}$ and $50^{\text {th }}$ percentile of the wage distribution does not yield much additional insight. See for example Juhn, Murphy and Pierce (1993) for such graphs for the United States up to 1988 and Chapter 6 for such an analysis for the Dutch wage structure.

The acceleration of skill upgrading is investigated here, because the level of skill upgrading might reflect past trends in skill upgrading, rather than a discrete break from preexisting trends. In addition, causality could be reversed because hiring more skilled workers may lead an industry to subsequently adopt computers.
} 
in industry $i$ and period $t, \psi_{i}$ is a time effect, $\Delta C_{i}$ is the change in the proportion of workers using a computer in industry $i$ between 1984 and 1993 and $\lambda$, is a time-varying parameter which reflects an acceleration of skill upgrading if the estimates are higher for the most recent period. Autor, Katz and Krueger (1998) present estimates for the $1960 \mathrm{~s}, 1970 \mathrm{~s}, 1980 \mathrm{~s}$ and $1990 \mathrm{~s}$, suggesting that the pace of skill upgrading in industries that adopted computer equipment more rapidly in the period between 1984 and 1993 increased compared to other industries after the $1960 \mathrm{~s}$.

A similar analysis to examine how changes in technology affect the composition and wages of the workforce has been performed by Doms, Dunne and Troske (1997). They estimate the following model for the period 1977-1992:

$$
\Delta L S_{i}=f\left(C_{i}, \Delta K_{j}, X_{j}\right)+\varepsilon_{i}
$$

where $\triangle L S_{i}$ represents the change at firm $i$ between 1977 and 1992 in the skilled worker's labour share or the change in the log skilled worker's earnings, $C$, represents computer investments in that period, $\Delta K$, is the change in the firm"s capital-output ratio, and $X_{i}$ represents a vector of additional firm-level controls.

\section{Table 2.4}

Regressions of Changes in Skilled Labour Share and Earnings from 1997 to 1992 for Computer Investment in the Firm

\begin{tabular}{lccc}
\hline & $\begin{array}{c}\text { Change in Skilled } \\
\text { Labour Share }\end{array}$ & $\begin{array}{c}\text { Change in Skilled } \\
\text { Labour Share }\end{array}$ & $\begin{array}{c}\text { Change in Jog } \\
\text { Skilled Wage } \\
\text { Share }\end{array}$ \\
\cline { 2 - 4 } & {$[1]$} & {$[2]$} & {$[3]$} \\
\hline $\begin{array}{l}\text { Computer Investment } \\
\text { Adjusted } \mathrm{R}^{2}\end{array}$ & .142 & $.056(.022)$ & $-.044(.050)$ \\
\hline
\end{tabular}

Source: Doms, Dume and Troske (1997, Table 7). Standard errors in brackets. The other variables in the regressions are not reported. Computer investment is defined as total computer
investment in 1992 divided by total investment.

The results fron estimating equation (2.4) are shown in Table 2.4. Doms, Dunne and Troske (1997) draw three main conclusions from this table. First, computer investment is positively correlated with firm-level changes in the skilled workers' labour share. Second, the addition of computer investment does not greatly increase the overall explanatory power of the model (cf. column [1] and [2]). Third, while computer investment is positively correlated with changes in the 
labour share of skilled workers, it is relatively uncorrelated with the changes in average wages paid to either skilled and unskilled workers.

The overall conclusion from both studies is that investments in computer equipment have led to skill upgrading, but that the direct effects on the wage-bill share of skilled workers of these investments seem ambiguous.

\subsubsection{Conclusion}

The empirical trends presented above have led many researchers to investigate the impact of technological change on the wage structure. Focussing on the use of computers as a measure of technological change, economic theory explaining the diffusion of computers should be consistent with the following observations:

(i) computer use is higher for skilled workers than for unskilled workers;

(ii) computer users earn higher wages;

(iii) increasing wage inequality between relatively skilled and unskilled workers coincided with the computerization of the workplace but started when unskilled workers adopted computers (early 1980s);

(iv) there is a difference in the timing of within-group wage inequality between the groups of skilled (mid-1970s) and unskilled (early 1980s) workers; and

(v) an upgrading of skill requirements within the job takes place when computers are introduced.

\subsection{Theory}

This section addresses and discusses a simple theoretical framework using several contributions to the literature on skill-biased technological change. First, I will give an overview of the way in which technological change and the use of technology have been incorporated in these models and the consequences of doing so. Secondly, I will discuss to what extent these models have been able to deal with the findings presented above.

\subsubsection{Technological Revolutions}

The introduction and diffusion of computers can be regarded as a technological revolution or as the arrival and diffusion of a general purpose technology. In the literature, such revolutions have been discussed both implicitly and explicitly by Chari and Hopenhayen (1991), Galor and Tsiddon (1997), 
Greenwood and Yorukoglu (1997), Aghion, Howitt and Violante (1998), Heckman, Lochner and Taber (1998), Jovanovic (1998), Acemoglu (1999), Caselli (1999), Lloyd-Ellis (1999), Gould, Moav and Weinberg (2001), Weinberg (2001) and Violante (2002) in a setting of exogenous technological change, and by Acemoglu (1998), Kiley (1999) and Galor and Moav (2000) in a setting where technological change and growth might also be endogenously determined. The objective of most papers is to develop (general equilibrium) models to analyse how the level of wage inequality is affected by such a revolution, and to show that the models can account for a certain fraction of the empirical regularities concerning the recent rise in wage inequality.

Most papers regard technological change to be skill-biased by definition and ex ante distinguish between skilled and unskilled workers, which have different probabilities of adopting the new technology. For example, Greenwood and Yorukoglu (1997) assume that skilled workers adapt more easily to new technologies, which explains the higher rate of computer use and higher wages of skilled workers. Galor and Tsiddon (1997) suggest that high-ability workers are more likely to use new technologies because the costs of their investments in technology-specific skills, when a new technology arrives, are less than the costs for low-ability workers. In the case of computers, the investment in computer skills might be an important burden in understanding why higher skilled workers tend to adopt computers more often than lower skilled workers. Caselli (1999) assumes that a revolution is skill-biased if the new skills are more costly to acquire than the skills required by preexisting types of equipment. In such a setting, workers with low learning costs start using the new, more productive machines and because their capital-labour ratio increases (in terms of efficiency units) their wages rise relative to the workers with high learning costs. Lloyd-Ellis (1999) presents a framework in which there has to be a certain fraction of skilled workers in an economy to make the adoption of a new technology profitable. When the new technology is adopted, wage inequality rises if the rate at which technologies are introduced exceeds the rate at which they are absorbed because of increased competition from technologically mobile (and skilled) workers. Heckman, Lochner and Taber (1998) model different innate abilities for different workers, which leads to different investment decisions in human capital. They can explain rising inequality within low-education groups because workers of different innate ability levels respond differently to the arrival of new technologies. Jovanovic (1998) and Acemoglu (1999) show that the arrival of a new technology raises wage inequality through a higher positive covariance in the assignment of workers who are assumed to possess different abilities to adopt this new technology. Gould, Moav and Weinberg (2001) develop a model which generates two different sources of wage inequality: ability and depreciation of technology-specific skills when a new technology arrives. Finally, Chari and Hopenhayen (1991) and Weinberg (2001) model the relationship between experience and technology adoption in a vintage human capital model and find that experience and skills contribute to the adoption 
of new technologies, such as computers.

To illustrate the main features of these models, let us look at the following framework. Consider two types of labour, skilled (S) and unskilled $(U)$, which both need to be utilized in the production process to produce output $(Y)$. Since the effects of technological change on the labour market are relevant, and not its sources, technological change is represented in terms of an exogenous function over time. Technological change can be either skill-biased $(A)$ or de-skilling $(B)$. An increase in $\gamma(\gamma<1)$ corresponds to some of the tasks previously performed by an unskilled worker being taken over by a skilled worker. Labour inputs in the production process are represented by a CES production function:

$$
Y=F(S, U, t)=\left(\gamma(A S)^{\rho}+(1-\gamma)(B U)^{p}\right)^{1 / \rho}
$$

where $\sigma=1 /(1-\rho)$ is the elasticity of substitution between skilled and unskilled labour. From this production function the relative demand curve for labour can be written as

$$
w=\frac{\partial Y / \partial S}{\partial Y / \partial U}=\left(\frac{\gamma}{1-\gamma}\right)\left(\frac{A}{B}\right)^{\frac{\sigma-1}{\sigma}}\left(\frac{S}{U}\right)^{\frac{-1}{\sigma}},
$$

where $w=w_{s} / w_{u}$ is the relative wage. Equation (2.6) can be rewritten in a more convenient form by taking logs:

$$
\ln w=\ln \frac{\gamma}{1-\gamma}+\frac{\sigma-1}{\sigma} \ln \left(\frac{A}{B}\right)-\frac{1}{\sigma} \ln \left(\frac{S}{U}\right),
$$

which is essentially the same equation as equation (2.2). The only difference is that in equation (2.2) a time trend was included to capture the effect of technological change, whereas in equation (2.7) the time trend is replaced by a term for technological change $(\ln A / B)$ similar to the approach of Krusell, Ohanian, RíosRull and Violante (2000), who use capital as a skilled labour-augmenting factor in the production function.

From this expression it can be observed that if technological change is skillbiased ( $A$ goes up) the demand for skilled labour increases, while the demand for unskilled labour contracts. In a similar fashion, when the supply of one type of worker increases, the relative demand for that type of worker is falling, which is reflected by a falling relative wage: $2 \ln w / \partial \ln (S / U)=-1 / \sigma<0$. This means that the relative demand curve will give relative employment $(S / U)$ as a decreasing function of the relative wage with elasticity $1 / \sigma^{13}$

13 The fact that technology is skill-biased is not explicitly modelled here but assumed for simplicity. The different theories all include different mechanisms by which technology is skill- 
Let us consider the case where the relative demand curve is shifting over time in favour of skilled workers because skilled workers have a higher ability to adopt new technologies or have lower costs in acquiring the appropriate skills, i.e., there is a complementary relationship between technology and skilled labour. By differentiating equation (2.6) with respect to the skill-biased technological change term $A$, the following expression is obtained:

$$
\frac{\partial w}{\partial A}=\frac{\varphi}{A}\left(\frac{A}{B}\right)^{\frac{\sigma-1}{\sigma}}\left(\frac{S}{U}\right)^{\frac{-1}{\sigma}},
$$

where $\varphi=(\gamma /(1-\gamma))((\sigma-1) / \sigma)$. This equation implies that if the elasticity of substitution $\sigma>1$, skill-biased technological progress corresponds to the case where the wages of skilled workers are increasing at a faster rate than the production function is shifting outwards. The converse is obtained when $0<1$, i.e., when an improvement in $A$ shifts the relative demand curve inwards and reduces $w$. However, when skilled workers become more productive - as a result of an increase in $A$ - it is more likely that the skill premium increases, which is consistent with $\sigma>1$. The estimation results presented above confirm that $\sigma>1$. So, a rise in $A$ has the effect that skilled workers become more productive, which ceteris paribus lowers their demand in terms of efficiency units, but increases their demand because of biased technological change. The net effect is a rise in the relative wage $(w)$ of skilled workers.

Another interesting case is that some of the technological developments have been unskilled labour-replacing, corresponding to a rise in $\gamma$ in terms of equation (2.6). For example, some have suggested that computers have replaced many routine tasks, which were mainly performed by unskilled workers. This corresponds to the following effect (if $\gamma<1$ ):

$$
\frac{\partial w}{\partial \gamma}=\left(\frac{\gamma}{1-\gamma^{2}}\right)\left(\frac{A}{B}\right)^{\frac{\sigma-1}{\sigma}}\left(\frac{S}{U}\right)^{\frac{-1}{\sigma}}>0 .
$$

The result shown in equation (2.9) demonstrates that when unskilled workers are replaced by "machines" their wages are likely to fall (given that $\sigma>1$ ). Acemoglu (1999) argues that unskilled workers are replaced as a result of changing organizations, which can be viewed as a rise in $\gamma$. In this regard, Kremer and Maskin (1997) consider a model which shows that a change in technology or an increase in the dispersion of skills may encourage skilled workers to match with other skilled workers, rather than work with unskilled workers; Dunne, Foster, Haltiwanger and Troske (2000) present evidence consistent with the KremerMaskin model. Finally, Autor, Levy and Murnane (2002) find evidence that some

biased. However, they all essentially boil down to the specification chosen in equation (2.5). So without lack of generality this assumption reflects the most important conclusions of these types
of models. 
of the tasks previously performed by unskilled workers have been replaced by computers.

The main feature of the models discussed in this section along the lines of the simple framework presented above is that the adoption of new technologies is skill-biased because skilled workers have a higher ability or lower costs in acquiring the skills necessary to adopt new technologies. This skill bias in the adoption of new technologies leads to wage inequality between skilled and unskilled workers because the new technology causes an outward shift of the production function, which leads to higher wages for the adopters. The features of these models seem to be broadly consistent with the evidence presented above: Computer use is higher among skilled workers and computer users earn higher wages than non-users. However, the timing of between-group wage inequality is inconsistent with the findings above. In these models, wage inequality between adopters and non-adopters increases once the computer is adopted (if $\sigma>1$ ), whereas wage inequality between skilled and unskilled workers started to increase only when unskilled workers started to adopt computers. Secondly, these models do not tell us much about within-group wage inequality for workers from the same demographic or skill groups. The models presented here assume that all workers within the group of skilled and unskilled workers adopted the new technology at the same time, generating wage differentials only if the moment of adoption between skilled and unskilled workers is different, whereas the empirical trends suggest that within-group wage inequality is an important source of wage inequality.

\subsubsection{Within-Group Inequality}

Several recent papers have developed models in which workers are not ex ante different and divided into groups of homogeneous skilled and unskilled workers. This equality of workers is a potential important feature to understand, because Bound and Johnson (1992), Juhn, Murphy and Pierce (1993) and the evidence presented in the previous section suggest that within-group wage inequality is an important source of wage inequality. This line of research includes papers by Aghion, Howitt and Violante (1998), Acemoglu and Shimer (2000), Violante (2002) and to some extent Galor and Moav (2000) and Gould, Moav and Weinberg (2001). The main feature of these models is that they assume some sort of inequality due to labour-market frictions, random assignment, technology shocks, or just luck. For example, Aghion, Howitt and Violante (1998) assume that wage inequality arises because some workers are fortunate enough to be adaptable to work with the most recent vintage of machines. Acemoglu and Shimer (2000) argue that when search is costly, there will be wage dispersion among identical workers because firms invest in technologies with different productivities (and hence wages). Gould, Moav and Weinberg (2001) develop a model in which 
technological change hits sectors randomly, which leads to a disproportionate depreciation of technology-specific skills among equal workers in different sectors. Galor and Moav (2000) present a model in which there is ex ante inequality in the ability levels between workers. However, they also use an ability distribution within groups to examine within-group inequality. They use a continuous ability distribution, which leads to different investment decisions both within and between groups of workers. Finally, Violante (2002) presents a model based on labourmarket frictions. Such frictions lead ex ante identical workers to be matched randomly with jobs which include machines embodying different vintages of technology. In such a setting, he shows that an acceleration of technological change (or an increase in the arrival rate of new technologies or applications) raises wage dispersion between ex ante equal workers.

To grasp the main features of these models, some kind of distribution within the groups of skilled and unskilled workers has to be assumed, e.g. $s_{j}=s\left(a_{i}\right)$ and $u_{i}=u\left(a_{i}\right)$. In doing so, the skill level of worker $i$ depends on some parameter $a_{b}$ which is increasing but concave in $s$ and $u$. The parameter $a_{i}$ might be thought of as ability, the assignment to more modern and productive machines, luck or whatever one likes to assume to generate within-group inequality. Now assume that the composite labour input $L$ is a weighted sum of the number of (efficiency units of) skilled $S=\sum s_{i}\left(a_{i}\right)$ and unskilled $U=\sum u_{i}\left(a_{i}\right)$ workers employed in production: $L=\theta_{s} S+\theta_{u} U$. To design this formalization in such a way that the effect of an increase in the rate of technological progress on the composite labour input $L$ to capture the observation that technological change is skill-biased, assume that $\theta_{s}$ captures the costs of schooling and assume the weight in the composite labour input such that $\theta_{s}=1$. For $\theta_{u}$ assume the following: $\theta_{t}=1-\left(A_{t}-A_{t-1} / A_{t-1}\right)$, which reduces the weight given to unskilled labour due to the rate of (skill-biased) technological change. In such a setting the relative wage $w=w_{w} / w_{t}$ is again a function of technological change, but now also within the groups of workers because every worker $i$ has a different $a_{i}$. This generates within-group wage inequality resulting from differences in $a_{i}$.

Another source of within-group wage inequality is generated by opportunities for unskilled workers to become skilled workers. If unskilled workers become skilled workers, the supply of skilled labour increases, and it depends on the rate of technological change whether this translates into higher wages for the skilled workers. To become a skilled worker depends on $u\left(a_{i}\right)$ relative to $s\left(a_{i}\right)$. It can be easily shown that the threshold level $a^{*}$ depends on the rate of skill-biased technological change $a^{*}\left(\theta_{2}\right)$, which decreases monotonically in the rate of technological change. ${ }^{10}$ In this framework,

\footnotetext{
${ }^{14}$ Caroli and Garcia-Penalosa (2001) present a model of both between-group and within-group wage inequality based on the assumption that wages have become more volatile. If individuals exhibit decreasing relative risk-aversion, their attitude towards risk will change as the economy grows (as $A$ increases over time). A higher level of income makes a worker less risk averse and
} 
the decision to become a skilled worker might depend on a worker's innate ability, which is further pursued by Galor and Moav (2000).

What is striking about these models is that they present outcomes that are broadly consistent with the empirical evidence on within-group wage inequality. However, considering computer use it might not depend on a random process, luck or labour-market frictions which workers use computers and which workers don't. For example, the fact that some sectors use computers more often than others is not likely to be the result of random technology shocks hitting these sectors (e.g., Gould, Moav and Weinberg, 2001). In addition, why would some workers be more fortunate than others in adopting new technologies? Looking at the large wage differentials of computer users and non-users within ex ante homogeneous groups of workers does not seem to fully justify an element of luck (Aghion, Howitt and Violante, 1998 and Acemoglu and Shimer, 2000). Furthermore, labour-market frictions and technological differences between machines do not answer the question why particular workers adopt new technologies and others do not (Violante, 2002), i.e., the determinants of computer use are not clear. Also, these approaches do not answer the question why within-group wage inequality started to increase initially within the group of skilled workers and only later within the group of unskilled workers. Finally, between-group wage inequality is often not discussed or a possibility in these models because all workers are ex ante homogeneous.

\subsubsection{Technology Adoption and Diffusion}

A potential important and interesting mechanism which has been neglected in the theoretical literature but might influence computer use is the relatively high costs of adopting a computer system and technology in general. Although such arguments have been used in the technology diffusion literature, they have not been linked to the literature on skill-biased technological change and wage inequality. ${ }^{15}$ The literature on technology diffusion focuses mainly on the question why a new technology diffuses rather slowly. If a new technology is really a significant improvement over existing technologies, it is important to understand why some firms adopt more slowly than other firms. In addition, the literature has

therefore eligible for a random wage contract, which on average yields a higher wage for skilled workers than for unskilled workers. The crucial assumption of their model is that changes in wage-setting practices driving individuals attitudes towards risk shape between-group and within-group wage inequality. However, no empirical support for this assumption is presented.

"David's illustration of the adoption of mechanical reapers being an exception (David, 1975 ). He argues that the adoption of these machines would make sense only if the savings in wage costs exceed the costs of the machine. However, the treatment of wage inequality is only implicit. 
been heavily focussed on the time path of adoption, which follows an S-shaped pattern: at first diffusion rates rise and then fall over time, leading to a period of relatively rapid adoption accompanied by an early period of slow take up and a late period of slow approach when proceeding towards satiation.

The numbers presented in Figure 2.1 , which are initially rather stable but then show an increase in the investments in computer equipment, and the figures from the CPS in 1984, 1989, 1993 and 1997 on computer use at work, indicates that it is worthwhile discussing the pattern of computer diffusion from this perspective. The diffusion literature has addressed a number of models of technology. The most popular explanations of technology diffusion have been the epidemic model of information diffusion and the probit model, which argue that differences in the timing of adoption reflect heterogeneity among firms. For the purpose of the study of computer adoption and diffusion, the probit model seems the most relevant one to consider because it starts from the observation that differences between individuals may have a potentially important role to play in explaining the pattern of adoption. ${ }^{16}$ Chari and Hopenhayen (1991) distinguish in this respect between experienced and unskilled workers. They consider an infinitehorizon, overlapping-generations model of agents who live for two periods. A new technology appears in every period and is utilized according to the production function $\kappa f(U, Z)$ where t denotes the period in which the technology appeared, $U$ is the input of unskilled workers, $Z$ the input of experienced workers, and $\kappa>1$ defining a growing output over time. A given set of technologies is available in period $t=0$, which implies that old technologies not only continue to be used when superior technologies are available but both unskilled and experienced people also continue to invest in old technologies. This feature of the model is attractive and distinguishes the Chari-Hopenhayen approach to some extent from the models on between-group inequality above in that the initial phase of adoption involves not only skilled workers, but also unskilled workers. Depending on the arrival rate of new technologies, rather than on their skill level per se workers invest in new technology-specific skills and adopt the new technology. "The feature Chari and Hopenhayen fail to take into account, however, is that firms and workers have to pay for the technology they use; in their

\footnotetext{
16. There are also theoretical approaches stressing the role of uncertainty about the quality of the new technology (Jensen, 1983), the strategic use of technology (Kamien and Schwartz, 1972) and the role of spillover effects and learning by doing (David, 1969). Other diffusion models are the legitimation and competition models (e.g., Hannan and Freeman, 1989). Competition arises when only a limited number of firms are able to survive when a new technology arrives. Legitimation refers to the changing organization of work and the ability among firms to do so. Geroski (2000) offers a reasonable overview of these latter two models of technology diffusion.

17 Weinberg (2001) shows that younger workers are more able to adapt to new technologies, such as computers. He attributes this finding to the observation that younger workers have skills of a more recent vintage, which are more adaptable to the new technologies.
} 
perspective, it just arrives and can be utilized after the appropriate skills become available.

A simple exposition of their model including the costs of new technology to the firm has been presented in Davies (1979) and implies that individuals will adopt a new technology if the length of the period during which the firm can gain back the money invested in the new technology is less than some threshold time. Assume that a firm will choose to adopt at time $t$ if its expected return $\pi_{i}$ exceeds a threshold return of $\pi^{*}$. If not, the firm will not adopt at time $t$. Davies assumes that firm size is the main distinguishing factor in the adoption of new technologies. This is consistent with the theoretical work on threshold models by Salter (1966), Mansfield (1968) and David (1969) and more recent work by David and Olsen (1986) and Helpman and Trajtenberg (1998), and empirical studies by Mansfield (1963), Metcalfe (1970), David (1975) and Stoneman (1976). These studies look for and discuss the determinants of the thresholds. Likely candidates put forward have been firm size, technological expectations, learning and search costs, switching costs and opportunity costs.

Assume that threshold $T$ is the factor determining adoption and that the expected returns are a simple function of $T$ :

$$
\frac{\pi_{i}}{\pi^{*}}=\delta T^{v}
$$

which implies that the threshold value of $T$, at which $\pi_{i}=\pi^{*}$, equals $(1 / \delta)^{1 / v}$. If $T \sim[\underline{T}, \bar{T}]$, firms adopt the new technology in the order $\underline{T}, \ldots, \bar{T}$ if $v<0$ and in the order $\bar{T}, \ldots, I$ if $v>0$. The speed and pattern of diffusion depends on the distribution of $T f(T)$. If the distribution of $T$ is normal and the diffusion over time is constant, the diffusion pattern yields a S-shaped diffusion curve. If the distribution of $T$ is uniform and the diffusion over time is first rising and then falling, a S-shaped pattern also emerges. David (1969) shows that for any distribution of $T$, a S-shaped pattern of diffusion can be obtained, consistent with the pattern of diffusion observed for many new technologies.

Focussing again on the diffusion of computers through the labour market, a definition of $T$ should be found to be consistent with the observed pattern of diffusion and, more importantly, wage inequality. The literature has offered two main determinants of computer use: differences in computer skills among skilled and unskilled workers (Krueger, 1993) and tasks that seem suitable for computerization (Autor, Levy and Murnane, 2001). With respect to computer skills, an employer might face a trade-off between the costs of buying a computer for a particular worker and his ability to use a computer. This might explain the patterm of diffusion among skilled workers in the 1970s. However, in the 1980s many unskilled workers started to use computers while not yet all skilled workers had adopted one. This pattern of diffusion is consistent with the argument that the falling prices of computer equipment lower the threshold value $T$ at which a 
computer becomes effective, but is inconsistent with skill level being an explanation for the pattern of diffusion.

The second argument put forward in the literature is that particular tasks are more suitable for computerization than others and that these tasks are particularly found in skilled jobs. In addition, many unskilled jobs have disappeared as a result of computerization (the $y$-factor in the model discussed above). The computers software developed throughout the last decades has made an increasing number of tasks suitable for computerization. In other words, the tasks of not only skilled workers are more efficiently conducted using computers, but also that some tasks of the unskilled part of the population can efficiently be computerized.

The diffusion literature is therefore able to explain a particular pattern of diffusion among skilled and unskilled workers. The major problem with these models is, however, that the determinants of diffusion are exogenous to the model of technology diffusion and can be chosen in an ad hoc manner. To understand the determinants of diffusion, they should be solved by the model.

\subsubsection{An Analys is of the Job}

So far, the production process within a firm and the individual worker's job have been a black box to the analysis, only defined in terms of a (CES) production function. Since computers influence the job of the individual worker directly, an analysis of the job might provide insight into how computers change work. Bresnahan (1999), Autor, Levy and Murnane (2001) and Garicano (2001) offer such theories. They argue that computerization involves the routinization of whitecollar tasks. Simpler, repetitive tasks are argued to be more amendable to computerization than complex and more idiosyncratic tasks. Bresnahan (1999) posits such a complementarity between computers and workers who possess both greater cognitive and people skills. Accordingly, computers increasingly substitute for the routine information-processing, communications, and coordinating functions performed by clerks, cashiers, telephone operators, bank tellers, bookkeepers, and other handlers of repetitive information processing tasks.

Autor, Levy and Murnane (2001) conceptualize the job in a series of activities and then ask what tasks can be computerized. They argue that the capabilities and limitations of present computer technology make it more substitutable for routine than non-routine tasks. By implication, computers are relative complements to workers engaged in non-routine tasks. The complementarity in this model is derived from two different channels. First, at a mechanical level, computers increase the share of human labour input devoted to non-routine tasks. Secondly, workplace computerization appears to increase the demand for problem-solving tasks - a non-routine task. They assume that the comparative advantage of labour in a computerized environment is specifically in handling non-routine problems such as resolving production deficiencies, handling 
discrepancies and exceptions, and detecting and resolving unanticipated bottlenecks. Solving a simple model, their framework boils down to the observation that a decline in the price of computer capital lowers the wages of workers carrying out routine tasks and causes employment in these tasks to contract. Although the demand for routine tasks increases as the price of computer capital falls, this demand is satisfied by substitution of computer capital for human labour. Because greater relative intensity of routine tasks raises the marginal productivity of non-routine tasks, the wage per efficiency unit of non-routine labour input rises. ${ }^{18}$ However, Autor, Levy and Murnane do not explicitly discuss the determinants of computer use and when an employer decides to buy a computer for a typical worker.

Kremer and Maskin (1997) and Garicano (2001) present approaches in which computer technology lead to more decentralization as workers can deal with more tasks on their own. Garicano's approach aims to understand the joint impact of technology on the internal organization of firms and on the distribution of wages. He distinguishes between information and communication technology. Information technology increases information available at a given cost, which reduces the cost for workers of learning to perform new tasks. Communication technology leads to specialists communicating more efficiently with other specialists. He shows that the internal organization of the firm is amended when computers are introduced. This leads to wage inequality because a fall in the price of information and communication technology equipment or an increase in the availability of the equipment leads firms to increase their demand for skilled workers. In addition, more inequality will exist in equilibrium whenever a technology change leads workers to learn more tasks. Kremer and Maskin (1997) show that the arrival of computers leads skilled workers to work with other skilled workers and unskilled workers to work with other unskilled workers. This divides the production into high- and low-quality goods and amplifies wage inequality.

Such micro-economic analyses at the firm and job level are able to explain the observed skill upgrading because routine job activities are substituted by computers and non-routine job activities become more important, which leads to an increasing demand for skilled workers. Secondly, these models explain why skilled workers use computers more often than unskilled workers because upon the computerization of a job particular skills, like problem-solving skills, are increasingly demanded. Also, the wage differentials between computer users and non-users are explained by the fact that the focus on non-routine job activities requires more non-routine skills, which raises the marginal productivity of these tasks and hence the wage.

\footnotetext{
18 Other studies dealing with this are Zuboff (1998), Osterman (1994), Leigh and Gifford (1999), Caroli (2001), Greenan, Mairesse and Topiol-Bensaid (2001) O'Shaughnessy, Levine and Cappelli (2001), and Bresnahan, Brynjolfsson and Hitt (2002).
} 


\subsubsection{Conclusion}

Economic theory developing models to describe the labour market changes following the introduction and spread of computers has been able to clarify much of the recent trends. From these theories the following picture emerges.

First, there seems to be a complementary relationship between skill and technology, which leads to wage inequality between skilled and unskilled workers. The question is how to interpret this complementary relationship and to understand the peculiarities of this complementarity between technology and skill. Most models assume a complementarity between technology and skill and explain increasing between-group wage inequality resulting from technological revolutions. However, the complementarity between computers and skill is not so obvious because it is likely to have changed over time. At first, only skilled workers used computers, which has been translated into a complementarity at the level of the production function. After a while, unskilled workers also started to use computers, which cannot be captured by a complementary relationship at the level of the production function. Given the timing of between-group wage inequality - which did not start until unskilled workers adopted computers - it is likely that skilled workers benefit from the computer use of unskilled workers. This complementarity between computers and skill is therefore far more important in explaining computer-skill complementarity than a complementarity at the level of the production function, as the models discussed in Section 2.3.1 assume.

Secondly, the timing of within-group wage inequality seems to be consistent with the facts on computer use. However, as discussed above, the determinants of within-group wage inequality are not so obvious. Another issue is that skilled workers use computers more often than unskilled workers. A random assignment process is therefore not the right avenue to pursue. The focus should be on defining the determinants of computer use from solving the model. In most cases the complementarity between computers and skill is shown to be the most likely determinant, but this complementarity is not to be found at the level of the production function.

Thirdly, skill upgrading in most models is explained by a complementary relationship between computers and skill at the level of the production function. While the results with respect to the pattern of upgrading are consistent with the empirical observations, the way in which these patterns are generated is inconsistent with a complementary relationship at the level of the production
function.

Finally, a theory at the level of the job seems to be able to explain the evidence reasonably well. Perhaps the development of such a theory provides insight into how to develop a consistent theory at the macro-economic level. 


\subsection{Empirical studies}

A large number of empirical studies are concerned with the correlation between technological change and wage inequality. Studies investigating the impact of computers on wages have also been frequently performed. From an empirical perspective, the endogeneity of the relationship between technology and skill and the measurement of technological change and skills is of important concern.

\subsubsection{Technology and Wages}

Much of the econometric and case-study evidence indicates that the relative utilization of skilled workers is positively related to capital intensity and the adoption and diffusion of new technologies both across industries and across plants within industries. Since the majority of databases and studies do not include information about a directly observable measure of technological change faced by the individual worker in his place of work, the information on individual workers has to be linked with several proxies for technological change. These proxies have been divided into two categories: (i) output-based measures, like total factor productivity (e.g., Kahn and Lim, 1998), and (ii) input-based measures, like the investment in computer equipment (e.g., Berman, Bound and Griliches, 1994 and Doms, Dunne and Troske, 1997), R\&D-intensities (e.g., Chennells and Van Reenen, 1997 and Adams, 1999), the number of patents used in the industry (e.g., Bruinshoofd, Hollanders and Ter Weel, 2001), and the ratio of scientific and engineering employment to total employment (e.g., Allen, 2001). Each proxy is likely to capture a different aspect of technological change and is also likely to have a different impact on the firms' decision to employ particular workers or to reward particular skills more than others. In addition, one might be talking about totally different firms, which operate in separate markets, facing different market conditions, having different size, and so on.

Bartel and Sicherman (1999) analyse all of these proxies for technological change. Within each group of industries, they calculate the percentage of workers who are college graduates, for all workers and for production and non-production workers separately using the NLSY79 and NLSY93. They divide the sample into two groups on the basis of whether a worker is employed in a low-tech or hightech manufacturing industry, using the median as a cutoff point. Table 2.5 reports that for all five measures of technological change, the percentage of college graduates is higher in the high-tech industries than in the low-tech manufacturing industries. These figures are consistent with the view that industries employing a large number of highly-educated workers have a higher rate of technological change than industries employing a smaller number of highly-educated workers. In addition, detailed findings reported by Berman, Bound and Griliches 
(1994) on U.S. manufacturing firms suggest that the employment of highlyeducated workers has increased in recent periods because there has been a shift from unskilled towards skilled workers due to unskilled labour-saving technological change. This seems to be consistent with the figures reported in Table 2.5. Finally, Bartel and Sicherman (1999) find that workers employed in high-tech manufacturing industries earn higher wages relative to workers employed in low-tech industries.

Table 2.5

Percentage of College Graduates and the Rate of Technological Change in Manufacturing Industries in the United States, 1979-1993.

\begin{tabular}{lccc}
\hline $\begin{array}{c}\text { Measure and Rate of } \\
\text { Technological Change }\end{array}$ & All Workers & $\begin{array}{c}\text { Production } \\
\text { Workers }\end{array}$ & $\begin{array}{c}\text { Non-Production } \\
\text { Workers }\end{array}$ \\
\hline $\begin{array}{l}\text { Investmen in computers in 1987 } \\
\text { Low }\end{array}$ & 6.04 & 1.20 & 20.29 \\
High & 14.30 & 2.41 & 29.02 \\
Use of patents & & & \\
Low & 6.46 & 1.11 & 20.96 \\
High & 12.64 & 2.28 & 28.10 \\
Investment in R\&D & & & \\
Low & 7.12 & 1.32 & 22.09 \\
High & 13.72 & 2.31 & 28.71 \\
Percentage of S\&E & & & \\
Low & 7.24 & 1.46 & 21.86 \\
High & 11.85 & 1.82 & 27.71 \\
Total factor productivity & & & 23.96 \\
Low & 8.28 & 1.52 & 25.92 \\
High & 10.44 & 1.70 & \\
\hline
\end{tabular}

Soupe: Bartel and Sicherman (1999, Table 1). Industries are considered low-tech if their rate of technological change is below the median. They are high-tech if their rate of technological change is above the median of the sample. S\&E in the founth row of the table stands for scientists and engineers.

Studies aiming at international comparisons of skill-biased technological change use proxies such as the ratio of production to non-production workers, that of blue- and white-collar workers, or the share of the workforce with a higher education qualification, which does not reveal crucial information about the type of tasks these workers have to perform. For example, Berman, Bound and Machin (1998) use data from the United Nations' General Industrial Statistics Database, which covers 28 manufacturing industries from Australia, Austria, Belgium, Denmark, Finland, Germany, Japan, Luxembourg, Norway, Sweden, the United 
Kingdom, and the United States. The sample period is 1970-1990. The analysis includes data about the employment and wage bill of all employees and operatives. Employees are defined as the average number of employees during the year (nonproduction workers) and operatives refers to employees directly engaged in production (production workers). The information about wages and salaries includes all payments in cash or in kind made to employees or operatives during a particular year. The evidence Berman, Bound and Machin provide can be summarized as follows. First, they observe that manufacturing employment declined substantially and that production workers were typically hit by this reduction in employment. Secondly, the relative wages of non-production workers rose by an average of 4 percent in the $1980 \mathrm{~s}$, thereby increasing the wage gap between production and non-production workers.

A second example of an international comparison of wages and employment is the paper by Machin and Van Reenen (1998), who use the same United Nations data source and some additional OECD figures on R\&D and computer investment to obtain information about the wage costs and number of production and nonproduction workers for Denmark, France, Germany, Japan, Sweden, the United Kingdom, and the United States. For the period 1973-1989 they find that the nonproduction worker share of the wage bill rose in all countries and that, in absolute terms, the largest increase took place in the United Kingdom and the United States and the smallest in Japan and Sweden. There is a similar pattern for employment shares, but far less pronounced. In addition, they find a positive correlation between R\&D intensity and the wage bill share for non-production workers. Based on the proportion of workers using a computer at work in the mid-1980s as a more direct measure of the diffusion of technology, they obtain similar results. ${ }^{19}$

There are a number of problems with such estimates. First, while these correlations seem to be rather consistent and strong, a problem most of these studies do not deal with is the (potential), endogeneity of technological change. In other words, do firms adopt new technologies because their workforce is able to adapt to new technologies or do firms hire more highly skilled workers to cope

\footnotetext{
"See also the various papers in the conference volume edited by Freeman and Katz (1995); Blau and Kahn (1996) for an analysis of several OECD countries; Nickell and Bell (1996), who make a distinction at the country level between skilled and unskilled employment and wages for several OECD countries; Gottschalk and Joyce (1998) for a study on several OECD countries in the period 1970-1992; Leuven, Oosterbeek and Van Ophem (1998) for a study on male wage inequality using the International Adult Literacy Survey; Card, Kramarz and Lemieux (1999) for a comparison of the United States, Canada and France; Desjonquers, Machin and Van Reenen (1999), who test for the manufacturing of several OECD countries whether increased exposure to trade with less developed countries is causal to the fall in unskilled labour demand using United Nations and OECD data sources in the period 1970-1990; and Hollanders and Ter Weel (2002) for a study of six OECD countries using new OECD data, which do not only distinguish production workers from non-production workers but also blue- and white-collar workers and high-skilled and low-skilled occupations.
} 
with the new technologies. Both lines of reasoning lead to the empirical observation that firms employing a relatively large number of skilled workers use more advanced technologies, but the causation of events is not determined. Bartel and Sicherman (1999) also struggle with this problem when they conclude with respect to their latter finding that

"this [education] premium was found to be correlated with the industry rate of technological change, with race and sex held constant. We conclude that the observed effects of technological change on the wage structure are due to the sorting of individuals based on their unobserved characteristics, and not due to sorting solely on race or sex" (Bartel and Sicherman, 1999, p. 310)

but continue to indicate that firms with high rates of technological change have a higher capacity to innovate (without providing consistent evidence whatsoever). In addition, the employment of relatively highly-educated workers might also suffer from an endogeneity problem: do high-tech industries recruit highlyeducated workers because they need such workers to produce output, or does the supply of highly-educated workers induce some firms to innovate more than others?

The second problem of studies examining the correlation between technological change and skill upgrading might be that few of them are able to directly link technological change to a worker's job. ${ }^{20}$ The importance of this problem has been discussed from a theoretical point of view in the previous section. In estimating the relationship between technology and skill, the implicit assumption is often that there exists a complementary relationship between technology and skill at the level of the production function. This makes the results sometimes hard to interpret. For example, an implication that can be directly drawn from the findings of Bartel and Sicherman (1999) is that a secretary (nonproduction worker) working in a firm which devotes a relatively large amount of resources to the process of $R \& D$ earns a higher wage than the same secretary employed in a firm which spends less on R\&D. This is hard to understand and it seems likely therefore that a direct measure of technology is more appropriate to use in these kinds of analyses, when one wants to examine and understand the correlation between skill and technology, skill upgrading and the determinants underlying skill-biased technological change down at the job level. Katz and Autor (1999) argue in this respect that

\footnotetext{
${ }^{23}$ Of course, technological change might influence the workplace without having a direct impact on the worker's job. Organizational change is in this respect a likely candidate to explain upgrading and wage inequality (e.g., Bresnahan, 1999, Caroli and Van Reenen, 2001, Garicano, 2001 and Bresnahan, Brynjolffson and Hitt, 2002).
} 


\begin{abstract}
"The causal interpretation of contemporaneous correlations of technology indicators such as R\&D intensity and computer use with skill upgrading is unclear since R\&D activities directly used highlyeducated workers and since other sources of changes in the use of skilled workers could drive variation across industries in purchases of computers." (Katz and Autor, 1999, p. 1532)
\end{abstract}

The third problem is the measurement of skills. This problem has been investigated in a paper by Hollanders and Ter Weel (2002) using data on changes in employment structure in the manufacturing sector in six OECD countries in the period 1975-1995. Positive correlations have been reported in the literature between R\&D intensity and the employment of highly-skilled workers and between increasing levels of R\&D effort and skill upgrading. Table 2.6 shows the results of a regression only including $R \& D$ intensity ( $R \& D / v a l u e$ added) as an explanatory variable for the changing employment structure. The estimated model is one including five-year changes for six countries (Finland, France, Germany, Japan, the United Kingdom and the United States). Each equation also includes a set of country dummies to control for country-specific shocks and is weighted by industry size. The table reports estimates for three different dependent variables. The first column reports regressions taking high-skilled workers (high-skilled white-collar and blue-collar workers) as the dependent variable, the second column only white-collar high-skilled workers, and the third column non-production workers (white-collar workers). The total effect of R\&D intensity on employment shares has been estimated for each country. ${ }^{21}$

Consistent with the estimates reported in the literature, in all cases the estimated coefficients on the R\&D variable are positive and in most cases significant at the 5 percent level. Only the coefficients for France, Japan, United Kingdom and the United States (high-skilled workers) and the non-production workers in Japan are not significantly positive at the 5 percent level. The coefficients for the employment shares of high-skilled workers are worse than the coefficients found for non-production workers. This might indicate that particularly white-collar workers benefit in terms of employment shares from R\&D efforts, whereas high-skilled blue-collar workers do not seem to benefit much from innovation efforts. Investigating the employment shares of white-collar highskilled workers only, it turns out that their employment shares reveal a higher and

\footnotetext{
${ }^{21}$ In the cases where data is available in ISCO-88 format, occupations were aggregated by the OECD secretariat at different levels as follows. White-collar high-skilled: legislators, senior officials and managers, professionals, technicians and associate professionals (including scientists and engineers). White-collar low-skilled: clerks, service workers, shop and market sales workers. Blue-collar high-skilled: skilled agricultural and fishery workers, craft and related trade workers. Blue-collar low-skilled: plant and machine operators and assemblers, elementary occupations.
} 
more significant correlation with $R \& D$ intensity. These results may not come as a surprise since scientists and engineers are included in the group of high-skilled white-collar workers. It seems rather obvious that their employment shares increase when a firm decides to put more effort into the process of research and development. ${ }^{22}$

Decomposing the effects of R\&D intensity on employment shares of moreskilled workers by technology advancement of a sector shows that in the high-tech industries there is a stronger and significant relationship between R\&D intensity and the employment shares of more-skilled workers. For most countries the coefficients are positive and significant at the 5 percent level for the high-tech industries (with the exception of highly-skilled workers in Finland). For the lowtech industries, the correlations are not so obvious and the results show a mixed pattern. ${ }^{23}$ For some definitions of more-skilled workers, like white-collar highskilled workers, positive and significant results are obtained in all cases, except for France; for the high-skilled workers, none of the coefficients are significant at the 5 percent levell. The coefficients for non-production workers suggest positive and significant results, except for France and the United Kingdom.

The overall reading of these results is that there seems to be a positive relationship between skill upgrading and R\&D efforts. ${ }^{24}$ From decomposing the industries into high-tech and low-tech industries, the results suggest that in all six countries industries with higher R\&D intensities have upgraded their work force more rapidly. However, the coefficients are sensitive to the definition of "skilled" workers. ${ }^{25}$

\footnotetext{
22 The correlation between the employment shares of scientists and engineers and R\&D intensity is incleed higher than the correlation between the employment shares of white-collar high-skilled workers and R\&D intensity.
}

27 "The high-tech industries are: Acrospace (3845), Office and computing equipment (3825), Electrical machinery (383-3832), Pharmaceuticals (3522) and Instruments (385). The mediumtech industries are: Other chemicals $(351+352-3522)$, Rubber and plastic products $(355+356)$, Non-ferrous metals (372), Non-electrical machinery (382-3825), Radio, TV and communication equipment (3832), Automobiles (3843), Other transport (384-3841-3843-3845) and Other manufacturing (39).

The lowtech industries are: Food, beverages and tobacco (31), Textiles, apparel and leather (32), Wood products and furniture (33), Paper, paper products and printing (34), Refined oil and related products $(353+354)$, Glass, stone and clay (36), Ferrous metals (371), Metal products (381) and Shipbuilding (3841).

${ }^{24}$ These estimates are in line with the results presented by Berman, Bound and Machin (1998), Machin and $V$ an Reenen (1998) and Berman and Machin (2000) for both OECD and developing countries. Estimates for the Netherlands over the period 1986-1998 by Bruinshoofd, Hollanders and Ter Weel (2001) are also in line with the estimates here.

${ }^{25}$ It is not possible to statistically discriminate between the coefficients at the 5 percent level, but this is possible in most cases at the 10 percent level. 


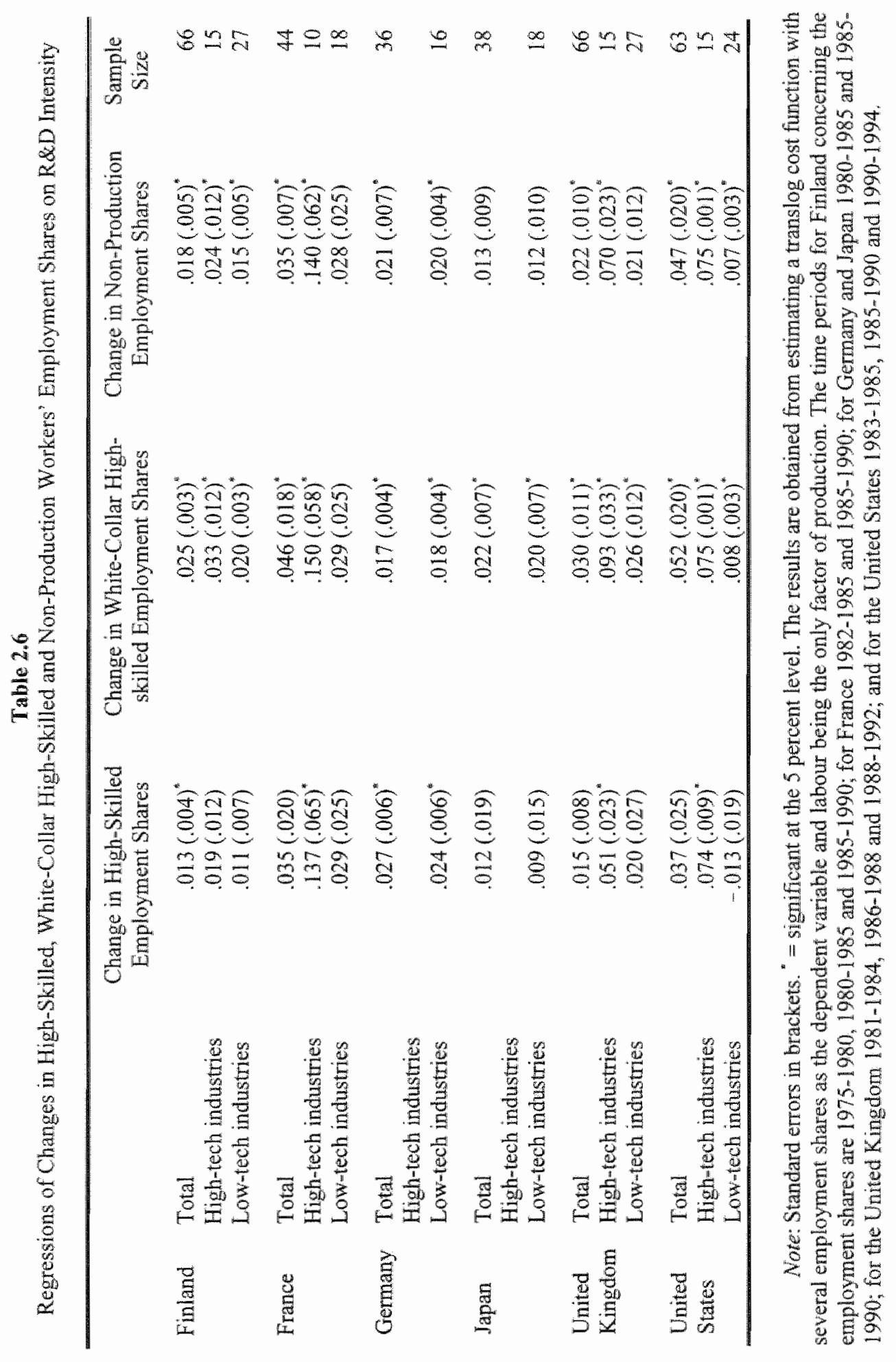


Taking the change in the employment share of high-skilled workers as the dependent variable leads to less convincing results than using the change in the employment share of white-collar high-skilled workers; using the change in the employment share of non-production workers provides results that lie in between. The fact that a significant correlation is obtained for the employment shares of more-skilled workers can be viewed as a reassuring observation for interpreting the observed changes in "skilled" workers" employment shares. Investigating the changes in employment shares of skilled workers based on their occupational level (defined as high-skilled workers) leads to less significant results and makes the correlation between "skill" and "technology" less clear.

\subsubsection{Computer Use and Wages}

Computer-skill complementarities have been analysed using cross-sectional and longitudinal and panel data. Similar to the technology-skill studies, these studies also potentially suffer from endogeneity and skill measurement problems. A major advantage of using information on computer use is that the technology variable is rather clear and has a one-to-one relation with the job.

Krueger (1993) is the seminal paper to address the impact of computer use on wages. By estimating a cross-sectional wage equation and controlling for observed characteristics, he finds that workers using computers at work earn wage premiums of a large magnitude relative to non-users (see also the regression results for 1984-1997 in Table 2.2). In addition, he argues that the diffusion of computers can account for between one-third and one-half of the increase in the rate of return to education observed between the sample years 1984 and 1989 he uses. Following Krueger (1.993), several authors have investigated computer wage premiums for other countries. Table 2.7 gives an overview of some of these studies and the coefficients for computer use. Most studies find a similar computer wage premium as that revealed by Krueger's study. The differences might be due to the differences in diffusion of computers. Card, Kramarz and Lemieux (1999) compare Canada, France and the United States and find that at the end of the 1980s computer use was very similar in these countries. They also show that in all three countries, women and educated workers use computers more than other types of workers.

The figures in Table 2.7 reveal that most coefficients are comparable, with the exception of the ones found in Finland. Asplund (1997) finds rather low computer wage premiums, which become even insignificant in 1993. A comparison of computer usage in Finland to that in the United States in 1993 shows that computer use in Finland increased from 33 percent in 1987 to 56 percent in 1993. For the United States, computer use increased from 24 percent in 1984 to 53 percent in 1997. Looking at the differences in computer use among education groups reveals similar figures for both countries. Hence, these results do not seem 
to be in accordance. Another puzzling observation is that DiNardo and Pischke (1997) find large wage differentials associated with the use of calculators, pens or pencils, or for those who work while sitting down. They conclude that wage differentials associated with on-the-job computer use are the result of unobserved heterogeneity. By the same token, Krashinsky (2000) finds that computers do not have a significant effect on wages, after controlling for selection biases.

Table 2.7

Computer Wage Premiums from Some Micro-Level Studies

\begin{tabular}{|c|c|c|c|}
\hline Author(s) & Country & Data & $\begin{array}{l}\text { Wage } \\
\text { premiunt }(\%)\end{array}$ \\
\hline Krueger (1.993) & USA & Current Population Survey & $\begin{array}{ll}1984: & 15.0 \\
1989: & 17.6\end{array}$ \\
\hline Reilly (1995) & CAN & General Segmentation Sirvey & $1979: \quad 14.4$ \\
\hline Bell (1996) & UK & $\begin{array}{l}\text { National Child Development } \\
\text { Study }\end{array}$ & $1991: 17.0$ \\
\hline Asplund (1997) & FIN & Finnish Labou" Force Survey & $\begin{array}{l}1987: 8.5 \\
1991: 6.5\end{array}$ \\
\hline $\begin{array}{l}\text { DiNardo and Pischke } \\
\text { (1997) }\end{array}$ & GER & Qualification and Career Survey & $\begin{array}{ll}1979: & 11.9 \\
1984: & 17.0 \\
1991: & 18.6\end{array}$ \\
\hline Entorf and Kramarz (1997) & FRA & French Labour Force Survey & $1987: \quad 17.1$ \\
\hline Hamilton (1997) & USA & High School and Beyond Survey & $1986: 17.9$ \\
\hline Miller and Mulvey (1997) & AUS & $\begin{array}{l}\text { Survey of Training and Education } \\
\text { in Australia }\end{array}$ & 1993: 13.2 \\
\hline Oosterbeek (1997) & NLD & Durch Brabant Survey & $1993: 11.8$ \\
\hline $\begin{array}{l}\text { Sakellariou and Patrinos } \\
(2000)\end{array}$ & $V \rrbracket \mathbb{E}$ & $\begin{array}{l}\text { Higher Education Tracer Study in } \\
\text { Vietnam }\end{array}$ & $1993: 12.8$ \\
\hline
\end{tabular}

Note: This table provides only limited information on these studies and is aimed at documenting and presenting the computer wage prenium. A lot of studies do not conclude that the relationship between wages and computer use is causal. However, the table reports the estimates of including a dummy for computer use in a wage regression for different countries. Finally, the table only includes some examples; there are many other studies on the relationship between computers and wages. $\mathrm{AUS}=\mathrm{Australia}, \mathrm{CAN}=\mathrm{Canada}, \mathrm{FIN}=$ Finland, FRA $=$ France, GER $=$ Germany, $N L D=$ the Netherlands, UK = United Kingdom, USA = United States and VIE $=$ Vietram. 
To find evidence on how computers have changed the labour market in terms of wages, three directions of research have been proposed. First, elaborate information on the particular use of computer equipment gives an indication of the skills involved. Hence, the level of sophistication of computer use provides insight into the particular skills involved. Second, the importance of computer skills has been investigated and in particular the labour-market value of these skills for certain occupations. Finally, to confirm the hypothesis of increased demand for higher-skilled workers, it must be shown that the introduction of computers has been associated with an increase in productivity, and therefore an increase in wages, i.e. technology should be treated as an endogenous variable. In fact, Krueger's approach using wage equations does not provide a definitive answer to the exact question if workers who use computers are better paid than non-users: is it because they were more able before the introduction of the computers or because computers increased their productivity?

Krueger (1993) analyses the returns to various uses of computers included in the CPS for the United States in 1989. He runs a wage regression including the usual suspects and the following specific tasks (coefficients and standard errors in brackets): word processing $(.017(.012))$, bookkeeping $(-.058(.013))$, computerassisted design $(.026(.020))$, electronic mail $(.149(.016))$, inventory control $(-.056(.013))$, programming (.052 (.031)), desktop publishing or newsletters $(-.047(.021))$, spread sheets $(.079(.015))$, sales $(-.002(.016))$. What is striking about these results is that the use of electronic mail yields the highest computer wage premium (16.0 percent) and that the computer wage premium for programming is relatively small (5.3 percent) and insignificant. Given the fact that programming most likely involves computer skills and the use of e-mail probably does not (in relative terms), these results suggest that the computer wage premium might not reflect returns to computer skills. ${ }^{26}$

A major drawback of the data used by Krueger and many others reported in Table 2.7, is that only information about computer use is available and no information about the actual computer skills. Computer skills have been measured only indirectly in the literature as some kind of "computer ability" (Bell, 1996) or "computer knowledge" (DiNardo and Pischke, 1996 and Hamilton, 1997). Bell uses data from the U.K. National Child Development Study. DiNardo and Pischke utilize data from the West German Qualification and Career Survey conducted by

\footnotetext{
2. Entorf and Kramarz (1997) and Entorf, Gollac and Kramarz (1999) report simillar findings but attribute such results to unobserved heterogeneity. Doms, Dunne and Troske (1997) examine the use of advanced technologies by firms. They distinguish between plants using less than 4 technologies, plants using 4 to 6,7 to 8,9 to 10,11 to 13 and plants using more than 13 technologies. Their results suggest a monotonically increasing relationship between technology use and the educational level of the workforce. Finally, Haisken-DeNew and Schmide (1999) show that in Germany no computer wage premium can be obtained when they control for unobserved heterogeneity. See also a recent study by Lang (2001) for an interpretation of the premium.
} 
the Federal Institute for Vocational Training. In this data information on both "computer use" and "computer knowledge" is available. Hamilton uses variables from the $1986 \mathrm{High}$ School and Beyond survey indicating whether an individual has ever used software packages or has used a computer language to program. These three studies find support for the thesis that a number of particular computer skills are rewarded in the labour market while others are not.

Finally, the issue of the endogeneity of technology adoption and use needs to be addressed. Following the design of most studies, many have claimed that the adoption of computers should lead to higher wages. However, these studies are often based on cross-sectional databases and do not include information about the moment in time when a particular worker started to use a computer. Chennells and Van Reenen (1997) investigate such information. They use data drawn from the 1984 and 1990 British Workplace Industrial Relations Surveys. These data consist of stratified random samples of over 2,000 plants in Great Britain and Northern Ireland employing at least 25 workers. The key techmology question asked of managers was, whether during the last three years there had been any introduction of new plant machinery or equipment including the new microelectronics technology (including computer controlled plant, machinery or equipment) that had affected the workforce. The data uncover a positive correlation between technology use and wages. However, using various models, Chennells and Van Reenen arrive at the conclusion that

"higher earnings exert a positive influence on the probability of introducing technical change, but that technical change per se has little direct influence on earnings" (Chennells and Van Reenen, 1997, p. 599)

These findings are consistent with the evidence brought together by Entorf and Kramarz (1997) and Entorf, Gollac and Kramarz (1999) for France. They also obtain a strong correlation between individual wages and the use of computers and argue that this was most likely due to the fact that higher-quality/wage workers were more likely to be matched with these new technologies. Doms, Dunne and Troske (1997) find that computer investment is positively correlated with plantlevel changes in the non-production labour share, but that it is not correlated with changes in average wages paid to either unskilled or skilled workers, as shown above.

\subsubsection{Complementarity}

The empirical literature discussed so far does not directly address the issue of whether the spread of computers has significantly changed the composition of the workforce, organizational practices and skill demand. Computers often involve 
the routinization of many tasks, such as repetitive tasks, whereas more complex and idiosyncratic tasks have been less amendable to computerization. Computers may also increase the returns to creative use of more widely available information to tailor products and services more closely to customers' specific needs and to develop new products.

One of the most widely used databases is the U.S. Current Population Survey (CPS). The three main reasons to use this data are that (i) in the United States wage inequality has grown substantially compared to other countries; (ii) the United States is a large country, which yields many observations to construct a relatively large database; and (iii) the CPS includes detailed information about a great number of worker and job characteristics (on an annual basis) since the $1960 \mathrm{~s} .{ }^{27}$ The measure most often used to determine the workforce's skill level is the educational composition of employment. For example, Autor, Katz and Krueger (1998) and many others use high-school dropouts, high-school graduates, people with some college education, college graduates and college equivalents to distinguish the different types of workers they consider. They then proceed to compute the changes in relative employment and wages between college graduates and the other workers and observe that the rate of growth of the relative supply of college graduates (both graduates and equivalerts) has increased since the $1970 \mathrm{~s}$, which is also the period in which wage inequality between college graduates and other workers increased substantially. They conclude from a simple supply and demand framework that an increased pace of demand shifts (in the face of increasing supply), most likely due to technological change, favouring highlyeducated workers seems to explain the rise in the wage premium for college graduates over the past thirty years. ${ }^{2.8}$

The use of the educational composition of the workforce and observing that both the supply and demand for highly-educated workers has increased is appealing for the purpose of most studies on the changing educational structure of

\footnotetext{
27 These studies include e.g., Davis and Halliwanger (1991), Bound and Johnson (1992), Katz and Murphy (1992), Murphy and Welch (1992) and (2000), Juhn, Murphy and Pierce (1993), Krueger (1993), Autor, Katz and Krueger (1998), Kahn and Lim (1998), Murphy, Riddell and Romer (1998), Card, Kramarz and Lemieux (1999), Harrigan and Balaban (1999), Heckman, Lochner and Taber (1999), Katz and Autor (1999), Dunne, Foster, Haltiwanger and Troske (2000), Weinberg (2000), and Allen (2001).

28. Analyses on other countries with respect to upgrading have been performed by for example Betts (1997), Baldwin, Dume and Haltiwanger (1998), Beaudry and Green (1998) and MacPhail (2000) for Canada, Vainiomaki and Laaksonen (1995) for Finland, Entorf and Kramarz (1997) and Entorf, Gollac and Kramarz (1999) for Erance, DiNardo and Pischke (1997), Boeri and Bellman (1998) and Blechinger and Pfeifer (2000) for Germany, Draper and Manders (1997) and Bruinshoofd, Hollanders and Ter Weel (2001) for the Netherlands, Martinez-Ross (2001) for Spain, and, Machin (1996), Chennells and Van Reenen (1997) and (1998), Haskel and Heden (1999) and Hildreth (2001) for the United Kingdom.
} 
employment. Yet, it does not reveal information about the skills these workers have in particular jobs. Murnane, Willett and Levy (1995) argue that quantitative research has provided few clues about what skills might be in growing demand. They report results for the United States on the following question: how do the mathematics skills of graduating senior high school graduates affect their wages at age 24? From this question they try to determine whether these basic cognitive skills are becoming more important in determining wages over time. The definition of basic mathematics is based on a test score including the abillity to follow directions, manipulate fractions and decimals, and interpret line groups. The test does not contain items involving knowledge of geometry or advanced algebra. They first examine data for the group of 1972 high school from the National Longitudinal Study of the High School Class of 1972 (NLS72), and for 1980 high school from the High School and Beyond (HSB) survey. Murnane, Willett and Levy report findings suggesting that the mastery of basic mathematics is more important in predicting subsequent wages among 1980 high-school graduates with the same educational attainment than among 1972 graduates with similar attainments. ${ }^{29}$ Similarly, Gould (2000) uses an IQ proxy from the NLS79 to see whether this type of cognitive skill is becoming more important within occupations. ${ }^{30}$ Dividing the data into three sectors (professional, service and bluecollar sector), he finds an increasing role for IQ to explain wage inequality within all three occupational sectors.

To conceptualize jobs in terms of their component tasks rather than the educational attainment of the job holders, Autor, Levy and Murnane (2001) build an approach using the fourth and revised fourth edition of the U.S. Department of Labor's Dictionary of Occupational Titles (DOT), which allows them to measure the changes in task content within occupations over time. Using the DOT occupational characteristics they distinguish seven groups of variables: (i) worker functions, (ii) training times, (iii) aptitudes, (iv) temperaments, (v) interests, (vi) physical demands, and (vii) working conditions. From these seven groups of

\footnotetext{
20 While the measures used to define the skill level of a worker are a more direct approach relative to using educational levels and experience, IQ scores and other test scores also refer to ability because they are not necessarily related to the job and probably not specific enough to make a judgement on the performance and requirements of a worker embodying particular sikills. In addition, by measuring whether the returns to schooling have increased over the past few decades, these studies use cognitive test scores to examine whether the returns to some ability measures have increased. Heckman and Vytlacil (2000), using the NLS data as well, show that the separate effects of ability or schooling on earnings cannot be identified and show that the increased retums to schooling are only obserwed mildly for the most-able men with low levels of work experience, leaving other results inconclusive.
}

${ }^{30}$ Ferguson (1993) finds that adding basic abilities to the wage regression wipes out the estimated growth in the return to schooling in the 1980 s in the United States. Using scores for arithmetic reasoning, word knowledge, and paragraph comprehension he finds that the returns were rising. 
characteristics they define five task measures: (i) non-routine cognitive and analytic tasks, (ii) non-routine cognitive interactive tasks, (iii) routine cognitive tasks, (iv) routine motor tasks, and (v) non-routine motor tasks. They find that in executive, administrative and managerial, professional speciality, technicians and related support, and sales occupations, non-routine cognitive and analytic tasks are more important compared to the other occupations. For the first two occupation groups, non-routine cognitive and interactive tasks also seem to be important, while there seems to be an important role for routine cognitive tasks in technicians and related support occupations and for routine motor tasks in the sales occupations. Non-routine motor tasks do not seem to be important in these four occupations. For administrative support occupations, machine operators, assemblers, and inspectors, and transportation and material moving equipment occupations, particular emphasis is on routine cognitive tasks. What is also interesting to note is that occupations requiring more than 13 years of education on average emphasize the performance of non-routine tasks, while routine tasks become relatively more important in the other occupations.

Case studies of individual firms or plants might also provide an understanding of what tasks workers perform and what requirements seem to be beneficial to perform these tasks or job aspects most effectively. One of the first case studies in this regard is performed by Groot and De Grip (1991), who analyse the occupational and educational structure of a large Dutch bank using a detailed database on the employees' occupational and educational status. Unfortunately, their data do not include information on the tasks different workers have to bring to completion. Another case study by Levy and Murnane (1996) examines a large U.S. bank and considers an employee's work as containing two kinds of tasks. ${ }^{31}$ The first are routine tasks and the second are skilled tasks. Consistent with the observations of Autor, Katz and Krueger (1998), Bresnahan (1999) and Autor, Levy and Murnane (2001), they find that the demand for skilled tasks has increased while the demand for routine tasks has fallen. This has led to a trend in recruiting highly-educated workers and to a redesign of jobs. However, no additional insight beyond the educational composition of the bank's workforce can be gained from these two case studies.

Fernandez (2001) studies the impact of technological change on changes in the overall job complexity and skill requirements within the context of a longitudinal case study of the retooling of a food-processing plant. He finds that job complexity has increased with respect to analysing, supervising and setting up one's own activities. ${ }^{32}$ With respect to particular skills he finds that language, math

\footnotetext{
${ }^{31}$ Autor, Levy and Murnane (2002) perform a similar case studly in which they describe how new technology led to the substitution of computers for high-school graduates.
}

${ }^{32}$ Similar arguments apply to the case study of Levy, Beamish, Murnane and Autor (1999). They describe some uses of computers as they affect a Boston area car dealership and obtain findings 
and reasoning skills have gained importance, while no change is observed with regard to specific vocational preparation.

\subsubsection{Conchusion}

The evidence presented in this section suggests that computer users earn higher wages than non-users, that the results from cross-sectional studies in interpreting the computer-wage premium as a premium for computer skills is doubtful, that longitudinal and panel data studies obtain much more modest estimates of the relationship between computers and wages and cast doubt on the causal interpretation of computers and wages, and that computers are complementary to certain activities while substituting for others. Three important issues still have to be addressed to study the computerization of the labour market.

First, the causal relationship between computers and wages has to be determined. Comparing the results of the cross-sectional studies with those using longitudinal and panel data leads to ambiguous results. Secondly, the measurement of skill is important. It has been shown that different measures of skill lead to different coefficients. Moreover, computer skills seem to be important in explaining the use of computers. Finally, the direct substitution and complementarity channel both predict an increase in the relative demand for skilled workers that should be associated with computerization. However, with the exception of some case studies, these channels have not been investigated theoretically nor empirically.

\subsection{Conclusion}

This chapter has presented the empirical trends and the theoretical and empirical approaches addressed in the literature on skill-biased technological change. Focussing on the adoption and diffusion of computers it seems clear that (i) computer users earn higher wages than non-users; (ii) computers are more often used by skilled workers; (iii) the introduction of computers has led to an acceleration in wage inequality both between and within groups of workers; and (iv) computer use leads to skill upgrading.

However, other than suggesting particular tasks and skills, the literature does not present clear evidence about the determinants of computer use. From a theoretical point of view it is not clear how tasks and skills relate to the adoption and spread of computers. In Chapter 3 I develop therefore a model in which the determinants of computers are analysed. 
In addition, from an empirical perspective there is no information available about the skills workers possess and about the tasks they have to carry out at work. In that sense, the determinants of computer use are highly unclear. Chapter 4 presents estimates of the determinants of computer use using unique data which contains information about the skills and tasks of British workers.

Thirdly, the diffusion of computers in relation to wage inequality is likely to be an important route to explore. The most important line in that route is a model capable of explaining both between-group and within-group wage inequality in relation to the spread of computers and dealing with a technology-skill complementarity not only at the level of a production function. Such a model is developed in Chapter 5 , which also presents evidence consistent with the model explaining a large part of between-group and within-group wage inequality.

Finally, skill upgrading is a matter of labour demand and supply. Therefore, the complexity of the job (demand) and the skill level of the worker (supply) should be linked. In Chapter 6 these two are linked in an empirical analysis of the Dutch wage structure in the most recent period. 


\section{Chapter 3}

\section{What Happens When Agent $T$ Gets a Computer?}

\subsection{Introduction}

This chapter considers the determinants of computer use and the subsequent changes at the workplace when the computer has been implemented.' The most common explanation for computer use has been that it requires specific skills. The basic findings seem to fit in well with the argument that workers possessing such skills earn higher wages and are allocated to jobs in which computers are used. Apparently these skills are particularly present among skilled workers, which explains the differences in computer use between relatively skilled and unskilled workers. Unobserved differences in skill requirements for computer use are reflected in a computer wage premium and the increased demand for skilled workers following the introduction of the computer seems to confirm that higher-skilled workers are needed to operate a computer. Apart from computer skills (e.g., Krueger, 1993, Hamilton, 1997, Miller and Mulvey, 1997 and Green, 1999), various studies discuss complementary skills, by which some workers benefit more from the possibilities computers offer than workers who do not possess these skills (e.g. Levy and Murnane, 1996, Bresnahan, 1999 and Autor, Levy and Murnane, 2001). The figures presented in the previous chapter, however, suggest that it is not so clear what happens when a worker gets a computer.

More insight into the impact of computers on the labour market could therefore be gained in an experimental setting in which a computer is made available to a randomly drawn group $T$ of treated workers, while a control group $U$ (untreated people) does not get one. An advantage of such an approach is that random assignment excludes selection effects and only addresses the effects of the computer at work. Because of the small scale of this experiment, market

\footnotetext{
'As argued by Katz (2000), there is no a prioni reason why the introduction of computers only affects the position of workers who actually work with a computer. This chapter investigates primarily what happens to computer users, to improve the understanding of these changes.
} 
effects due to changes in product prices and market wages are negligible. ${ }^{2} \mathrm{~A}$ problem of such an experiment is that it is not clear what kind of computer facilities group $T$ should be provided with, because the usefulness of the facilities depends heavily on the tasks to be performed, the configuration of the computer, the particular software available and installed, and the information databases available for use. Furthermore, settings between different jobs will vary to a large extent and it seems to be impossible to guarantee an acceptable experiment. In addition, the possibility to use a computer requires users to recognize its options. The practice that the introduction of a computer is preceded by a detailed investigation of the wishes of both firms and workers can seldom be simulated in such an experiment.

As an alternative route to investigate the impact of computers on an individual worker's job, this chapter proposes a simple model analysing what would have happened when such an experiment had been carried out. As a main feature, the model considers two identical workers who have simillar jobs consisting of two tasks, one of which can be computerized, while the other cannot. The analysis examines what will happen if a computer is assigned to agent $T$ and not to agent $U$. Because artificial agents are dealt with here rather than real workers, differences between workers can be abstracted from. This enables an investigation of the different effects of the introduction of the computer separately and it is possible to rule out the effects of unobserved heterogeneity. Most importantly, this approach opens the possibility to compare the impact on two identical people in a situation where one is provided with a computer and the other is not. Similarly, it also allows for a comparison of the effects of computer use between two workers who differ only in one specified aspect of their job. Although the primary focus is on the impact of computers in the workplace, market effects resulting from the introduction of computers are also derived by aggregating the results (Chapter 5 deals in detail with the macroeconomic issues). Based on the insights into how work changes following the introduction of a computer, the model provides predictions when a firm decides to introduce a computer in a particular job and it is possible to derive the effects on wages, skill requirements, product characteristics, and the organization and intensity of work. It is shown that the rather puzzling empirical findings presented in Chapter 2 fit into this model in a rather straightforward manner. In particular, it is shown that, given the tasks of a worker, wages are an important factor in explaining the introduction of

\footnotetext{
${ }^{2}$ DiNardo and Pischke (1997) also put forward a case in favour of such an experiment without
discussing it in further detail.

For example, what is the point of assigning a computer to a lumberjack or taxi cab driver and measuring the labour market impact? Such an exercise would be about as meaningful as
randomly assigning a chainsaw to an economist to do his job.
} 
computers because the relative costs for high-wage workers to carry out a task are much higher than for low-wage workers accomplishing the same task. Hence, a firm gains more by letting a high-wage worker bring this task to completion using a computer. This is consistent with the arguments and findings of Chennells and Van Reenen (1997), Entorf and Kramarz (1997) and Entorf, Gollac and Kramarz (1999) who argue that due to the endogeneity of technology, the effects of computers on wages are not so clear. Here it is shown that the causation is likely to be one which explains computer use because of higher wages rather than computer use leading to higher wages.

In addition, and in line with this argument, it could be concluded from the model that neither computer skills nor complementary skills are necessarily needed to explain the observed wage differentials between computer users and others. It is shown that even random wage differentials between identical workers lead to differences in computer use. These findings shed a different light on the way computers have changed the labour market and on the changes to be expected following the further diffusion of computers at the workplace. Although the introduction of computers might induce skill upgrading and affect wages, the model predicts that wage differentials first increase and then fall within a group of identical workers as computer use increases. On the other hand, if computers will have become sufficiently cheap, unskilled workers will also face increased computer use and experience similar patterns of inequality. ${ }^{4}$

This chapter proceeds as follows. In Section 3.2 the basic set-up of the model is developed, in which jobs with multiple tasks are discussed. Section 3.3 introduces agent $U$ and $T$ and discusses what happens when agent $T$ is provided with a computer to carry out his job. Section 3.4 examines the effects of the introduction of the computer on the product market and labour demand, and interprets the value of skills and the way in which a computer changes the optimal skill level and product characteristics. Section 3.5 presents some extensions to the model. Section 3.6 concludes.

\subsection{A Model of Jobs With Multiple Tasks}

To investigate when an employer decides to introduce a computer in a particular worker"s job a simple threshold model of technology diffusion is developed. To do so, the focus is on the role of the employer's costs to implement the computer. The model shows that firms will adopt computers if the benefits exceed the costs. It is argued that computer costs, productivity gains, and wage costs determine the adoption and diffusion of computers. The

\footnotetext{
${ }^{4}$ In Chapter 4 these predictions of the model are empirically tested. Chapter 5 develops a model in which the diffusion of computers is shown to be consistent with falling pricess of computers and initially increasing and then falling wage differentials.
} 
productivity gains might depend on the specific tasks and skills of the worker. The basic setting of the economy is the following: a market equilibrium is considered in which the decision making of one firm concerning one single job will be investigated. In this market equilibrium any individual firm will treat the wage structure, i.e. the wage for any particular worker with any set of characteristics, as given. By the same token, the price for the firm's output is also given. A job consists of several tasks and the production function of the firm describes the possibilities to combine these tasks to produce each good and the time needed by each worker to do so. It is assumed that the skill level of the worker in the job under investigation determines the time requirements to carry out the tasks within this job. Given these ingredients, the firm chooses a product, a division of tasks within the job, and a worker with certain skills to maximize profits.

Consider an agent with skills $s$, where $s=\left(s_{1}, s_{2}, \ldots, s_{n}\right)$ might be either a uni- or multi-dimensional parameter describing the skills of this agent. The $n$ components of the vector $s$ are the agent's characteristics determining the ability to perform a certain task. Years of education will typically be one component of the vector $s$, but also more specific characteristics such as mathematical skills or social abilities and experience are included in this vector. In addition, the agent produces a good or service with characteristics $p$, which is sold on a competitive goods market at price $\rho$.

To perform his job, agent $i$ has to fulfil two tasks: task 1 and task 2. For simplicity, it is assumed that task 1 generally represents aspects of a job that could in theory be computerized. Furthermore, it is assumed that task 2 is one that cannot be computerized. ${ }^{5}$ These tasks represent two independent aspects of a job that are nevertheless undeniably interrelated and very hard to separate. ${ }^{6}$

Based on arguments of comparative advantage, it is usually assumed that every worker performs only those tasks in which his relative productivity is

\footnotetext{
"Naturally, the boundary between what can be computerized at a given moment in time and what cannot, is vague. Huge investments and the use of a large number of programmers might ensure computerization of tasks that cannot usually be performed by a computer. However, it is assumed that the boundary between what can be computerized and what cannot, is a clear: one. By generalizing the findings, it can be shown that if a more gradual transition is assumed, highly expensive automation investments will be made under certain circumstances, while under other circumstances only cheaper applications will be used.
}

"An optician's job, for example, involves making and selling (sun)glasses. It is important for the optician to repair, cut and assemble the glasses with the utmost care (task 1). Additionally, she must be able to address the customers' wishes with accuracy and patience in order to be able to fulfil their demands and advise them on a good pair of glasses (task 2). Another example is a chief editor, who has to keep track of and process data that dictate the contents of a newspaper, magazine, or radio or tellevision program (task 1). At the same time, it is important that he has the capacities to manage and imspire people to do their jobs well and cooperate as an editing team (task 2 ). 
highest. Occupational descriptions like the Dictionary of Occupational Titles, however, show that in practice occupations tend to include several tasks, which clearly require entirely different types and levels of skills. The reason why it would be costly to separate the two job aspects in question is related to transaction costs: if two tasks are part of one job but carried out by two different people, this will lead to additional costs. ${ }^{7}$ In particular, the costs of fine-tuning execution of the two tasks between two (or more) people will result in transaction costs in this case. The time needed to brief a colleague about the work that has to be done might therefore not compensate for the gains achieved by separating the two tasks.

To produce one unit of output, agent $i$ needs $\tau_{i}(s, p)$ units of time to complete task $j$, where $j=1,2$. The time needed for both tasks depends on skills $s$ and product characteristics $p$. Hence, the total time needed to produce one unit of output equals

$$
\tau(s, p)=\tau_{1}(s, p)+\tau_{2}(s, p) .
$$

Now, define $\theta_{k}^{\prime}(s, p)=-\left(\partial \tau_{j}(s, p) / \partial s_{k}\right) /(\tau(s, p))^{8}$ as the time for task $j$ saved by a marginal increase in the $k^{\text {th }}$ component of skill $s\left(s_{k}\right)$. Here, it is assumed that $\theta_{k}^{\prime} \geq 0$ because an increase in $s_{k}$ leads to a higher productivity. Since $s_{k}$ might reflect both general and specific skills, time savings might vary between tasks." Similarly, $\theta_{p}^{\prime}(s, p)=\left(\partial \tau_{j}(s, p) / \partial p\right) /\left(\tau_{j}(s, p)\right)$ is defined as the extra time requirement for task $j$ due to a marginal change in product characteristic $p .{ }^{10}$ In this setting, the production of a more advanced product does not necessarily mean that the time spent on both tasks will increase, i.e. $\theta_{p}^{j} \geq 0$ does not apply in all cases. As will be argued later in this section, more advanced products might also require a substitution from one task to the other." It is assumed,

\footnotetext{
${ }^{7}$ For the time being, it is assumed that these transaction costs are high enough to exclude separation of task 1 and 2. Section 3.5 .2 extends the model and shows that changes in income and the introduction of new technology might change the decisions regarding the division of tasks within a company.
}

${ }^{8}$ For convenience the indices $s$ and $p$ are skipped, except in cases where new functions are introduced and where derivatives are explicitly taken into account.

${ }^{4}$ For example, a mathematician with high math skills might be able to perform a large number of tasks more rapidly than an unskilled worker, but the time gain will be particularly large when she has to solve a mathematical problem.

${ }^{10}$ Because the model is mainly concerned with the skill content of technological change, product characteristics are simply uni-dimensional.

"In the case of the optician in footnote 6 this means that advising a client requires more time in case of a more advanced product, because the performance of a pair of glasses requires 
however, that the production of a more advanced product always requires more time for task 2 (the task that cannot be computerized) to be carried out, i.e. $\theta_{p}^{2} \geq 0$.

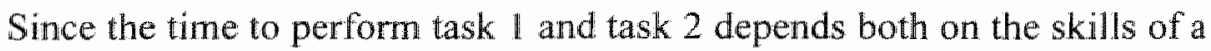
worker and the product specifications, four cases can be distinguished, two with respect to skill requirements and two with respect to product characteristics: (i) task 1 is a routine task, (ii) task 1 is a skilled task, (iii) task 1 and task 2 are substituter, and (iv) task 1 and task 2 are complements.

Definition 1: Task 1 is a routine task for skill $k$, if the time saved by $s_{k}$ to perform this task is less than the time saved to perform task 2 , i.e.

$$
\frac{-\partial \tau_{1}(s, p) / \partial s_{k}}{\tau_{1}(s, p)}<\frac{-\partial \tau_{2}(s, p) / \partial s_{k}}{\tau_{2}(s, p)} \text { i.e. } \theta_{k}^{\prime}(s, p)<\theta_{k}^{2}(s, p) \text {. }
$$

Definition 2: Task 1 is a skilled task for skills $k$ if the time saved by $s_{k}$ to perform this task is more than the time saved to perform task 2 , i.e.

$$
\frac{-\partial \tau_{1}(s, p) / \partial s_{k}}{\tau_{1}(s, p)}>\frac{-\partial \tau_{2}(s, p) / \partial s_{k}}{\tau_{2}(s, p)} \text { i.e. } \theta_{k}^{\prime}(s, p)>\theta_{k}^{2}(s, p) .
$$

It is reasonable to assume that in most cases the job aspects that can be computerized are routine tasks. ${ }^{12}$ Autor, Levy and Murnane (2001) point out that whether or not a task can be computerized does not depend on the skill level, but mainly on the character of the cognitive process needed to perform a task. Hence, tasks which can be computerized are found in jobs at all skill levels. As a counter example in which task 1 is a skilled task one might refer to a chess player. IBM has shown that thinking about algorithms for the next move can be computerized successfully, but at the same time it requires a huge number of skills from the chess player. Yet moving the chess pieces and intimidating the competitor (task 2) takes the real Garry Kasparov and cannot (easily) be computerized. However, these cases are rare to the extent that it may be assumed that for the labour market as a whole the effects of cases in which task 1 is a routine job will prevail.

more time in terms of explaining the advantages and drawbacks and the eventual advice given
to the customer.

${ }^{12}$ For example, in the case of the optician, cutting glasses is a routine activity, while distilling the customer's wishes is different in each case and requires a great deal of attention. The same line of reasoning applies to the chief editor: sorting incoming information is a routine-based cooperation and team spirit are aspects requiring a cditors keep a sharp eye and encouraging 
In a similar vein, the production time needed for both tasks depends on product characteristics that will be chosen by the firm in order to maximize profits. If the configuration of the product changes, the time required to perform task 1 and task 2 also changes. ${ }^{1.3}$ Variations in these product characteristics therefore involve substitution between task 1 and task 2 and hence lead to the following definition:

Definition 3: Task 1 and task 2 are substitutable tasks with respect to product characteristic $p$ if a change in the product characteristic shifts time requirements from one task to the other, i.e.

$$
\frac{\partial \tau_{1}(s, p) / \partial p}{\tau_{1}(s, p)}<0 \text { and } \frac{\partial \tau_{2}(s, p) / \partial p}{\tau_{2}(s, p)}>0
$$

i.e. $\theta_{p}^{\prime}(s, p)<0$ and $\theta_{p}^{2}(s, p)>0$. Task 1 and task 2 could, however, also complement one another with respect to a certain product characteristic. ${ }^{1 / 4}$ This leads to the final definition.

Definition 4: $\quad$ Task 1 and task 2 are complementary tasks with respect to product characteristic $p$ if a change in the product characteristic changes time requirements for both tasks simultaneously in the same direction, i.e.

${ }^{13}$ Let us compare, for example, a fashion store where customers can come in and show their trousers to the shop assistant, who can hellp them to find a matching shirt, with a shop where customers have to go through a catalogue, fill in a form and collect their order at the desk. In this example, the distinguishing product characteristic is the personal advice given by the shop assistant in the former and the catalogue in the latter case. Another example might be the repair of a broken-down television set. In one workplace, a technician opens the set to look what caused the defect. When she finds the cause of the problem, she repairs it by replacing one component or, if that is not possible, by finding a creative solution to get the television set going again. In another workplace, the television set is treated as a combination of modules. The technician checks the modules and replaces any malfunctioning ones. If this does not solve the problem, he advises the customer to buy a new television set. In these two examples p represents personal advice and the level of diagnostic checking, respectively. Typically, the more these characteristics are included, both product characteristics require fewer routine tasks and more custom-made service.

1. A good example is the optician mentioned in footnote 6. Measuring more aspects of the eye will generate more precise information, but also requires more interaction between the optician and the customer. Similarly, a journalist who uses a larger database to gather information for an article also needs more time to write the article integrating all this information. 
64. What Happens When Agent T Gets a Computer?

$$
\frac{\partial \tau_{1}(s, p) / \partial p}{\tau_{1}(s, p)}>0 \text { and } \frac{\partial \tau_{2}(s, p) / \partial p}{\tau_{2}(s, p)}>0
$$

i.e. $\theta_{p}^{l}(s, p)>0$ and $\theta_{p}^{2}(s, p)>0$. These four definitions concerning the skill and procluct content of the job provide tools to analyse changing skill requirements and the production of goods and services.

If a firm pays a wage $w$ to agent $i$, the costs $k$ per unit of final output the firm incurs equal

$$
k=w\left(\tau_{1}+\tau_{2}\right)
$$

Since the wage depends on productivity, it is related to the time needed to perform each task. To compare different agents with different characteristics, wage differentials are decomposed into (i) the pace at which a certain product is produced (or the time required to produce one unit of output, i.e. $\tau_{1}+\tau_{2}$ ), and (ii) the price per efficiency unit of output, $q(p)$, which depends solely on the product characteristics. Now, for agent $i$ 's wage to reflect productivity the following identity must hold:

$$
\bar{w}\left(\tau_{1}+\tau_{2}\right) \equiv q .
$$

Agent $i$ 's actual wage $w$ might however deviate from this productivity wage $\bar{w}$, because apart from productivity, wages are often also dependent on or correlated with, for example, gender, tenure and union membership. A situation in which $w$ deviates from $\bar{w}$, by say $\omega$, is represented by $w=\bar{w}+\omega$ and leads to the following costs $k$ to be incurred by the firm producing one unit of output by agent $i$ :

$$
k=\bar{w}\left(\tau_{1}+\tau_{2}\right)+\omega\left(\tau_{1}+\tau_{2}\right)=q+\omega\left(\tau_{1}+\tau_{2}\right) .
$$

The products produced by agent $i$ are sold at price $\rho(p)$. Then, the profit per product unit produced by agent $i$ is defined in a similar way as income minus expenditure and can be written as

$$
\Pi=\rho-w\left(\tau_{1}+\tau_{2}\right) .
$$

The total production of agent $i$ equals $P$. Hence, total demand for agent $i$ 's services equals

$$
D=P\left(\tau_{1}+\tau_{2}\right)
$$

The skills required for this prodluction process and the product specifications made can be viewed as the result of profit maximization at the 
hands of the firm. Since changing the skill requirements affects both productivity in task 1 and task 2 , changes in the required skills are not profitable for a certain skill $s_{k}$ from the vector $s$ when

$$
\frac{\partial \Pi}{\partial s_{k}}=\frac{\partial\left(\rho(p)-w(s)\left(\tau_{1}(s, p)+\tau_{2}(s, p)\right)\right)}{\partial s_{k}}=0 .
$$

The intuition behind this result is that if a firm hires a higher skilled worker $i$, its productivity and income $(\rho)$ increase but the wage costs $(w)$ it has to incur also increase. This tradeoff between higher skills and higher wages, the partial derivative $\partial w / \partial s$, gives the firm"s optimal skill choice, i.e.

$$
w\left(\frac{\partial \tau_{1}(s, p)}{\partial s_{k}}+\frac{\partial \tau_{2}(s, p)}{\partial s_{k}}\right)=-\frac{\partial w(s)}{\partial s_{k}}\left(\tau_{1}+\tau_{2}\right)
$$

After some rewriting the following expression from this derivative is obtained:

$$
-\frac{\tau_{1}}{\tau_{1}+\tau_{2}}\left(\frac{\partial \tau_{1}(s, p) / \partial s_{k}}{\tau_{1}}\right)-\frac{\tau_{2}}{\tau_{1}+\tau_{2}}\left(\frac{\partial \tau_{2}(s, p) / \partial s_{k}}{\tau_{2}}\right)=\frac{\partial w(s) / \partial s_{k}}{w}
$$

which equals

$$
\frac{\tau_{1}}{\tau_{1}+\tau_{2}} \theta_{k}^{1}+\frac{\tau_{2}}{\tau_{1}+\tau_{2}} \theta_{k}^{2}=\frac{\partial w(s) / \partial s_{k}}{w}
$$

Equation (3.10) is an important result for the analysis because it reveals three factors determining the optimal skill level of the job of agent $i$ : (i) an increase in the marginal wage costs of skills $((\partial w / \partial s) / w)$ leads to a decrease in demanded skill requirements, ${ }^{15}$ (ii) an increase in the advantage skill $k$ in performing task $j$ (i.e. an increase in $\theta_{k}^{j}$ ) leads to an increase in demanded skill requirements, and (iii) a change in the relative weights of the two tasks in the production process $\left(\tau_{1} /\left(\tau_{1}+\tau_{2}\right)\right.$ and $\left.\tau_{2} /\left(\tau_{1}+\tau_{2}\right)\right)$ leads to an increase in demanded skill requirements in the case of a shift towards a skilled task and leads to a decrease in demanded skill requirements in the case of a shift towards a routine task. ${ }^{16}$

15 This can be seen from the second-order condition. Since equation (3.10) reflects a maximum, the second-order condition equals

$$
\frac{\partial\left(\tau_{1} /\left(\tau_{1}+\tau_{2}\right) a_{s}+\tau_{2} /\left(\tau_{1}+\tau_{2}\right) \theta_{3}^{2}\right)}{\partial s_{k}}<\frac{\partial\left(\partial w(s) / \partial s_{k} / w\right)}{\partial s_{k}} .
$$

This means that if $s_{k}$ becomes more expensive, employers will diminish their demand for $s_{k}$.

16 Because the relationship between skill and productivity generally differs between both tasks, each task would have a different skill requirement if carried out by separate workers. Skill requirements for the routine task would be lower than skill requirements for the skilled 
Similar to equation (3.7), profit maximization implies that product specifications are optimal and that a change in product specifications does not increase profits if

$$
\frac{\partial \Pi}{\partial p}=\frac{\partial\left(\rho(p)-w(s)\left(\tau_{1}(s, p)+\tau_{2}(s, p)\right)\right)}{\partial p}=0,
$$

in which the tradeoff between a more advanced product and a higher price, the partial derivative $\partial \rho(p) / \partial p$, gives the firm's optimal product specifications, i.e.

$$
w\left(\frac{\partial \tau_{1}(s, p)}{\partial p}+\frac{\partial \tau_{2}(s, p)}{\partial p}\right)=\frac{\partial \rho(p)}{\partial p} .
$$

Similar to equation (3.8), this can be rewritten as

$$
\tau_{1}\left(\frac{\partial \tau_{1}(s, p) / \partial p}{\tau_{1}}\right)+\tau_{2}\left(\frac{\partial \tau_{2}(s, p) / \partial p}{\tau_{2}}\right)=\frac{\partial p(p) / \partial p}{w}
$$

which equals

$$
\tau_{1} \theta_{p}^{1}+\tau_{2} \theta_{p}^{2}=\frac{\partial \rho(p) / \partial p}{w}
$$

As in the case of optimal skill demand, the weighted average of the extra time needed for production in order to increase product quality $p$ determines the optimal product specification. The major difference with the optimal skill equation is that rather than the relative time spent on each task, the absolute amount of time needed determines this equilibrium. If wages increase or if the price increase of a more advanced product diminishes, the optimal amount of time available to produce falls. This means that product quality measured in terms of $p$ will go down both if task 1 is a routine task and if task 1 and 2 complement one another. In the first case, this means that agent $i$ 's production time shifts from task 2 to task 1 , while in the second case agent $i$ 's time spent on both tasks diminishes. ${ }^{17}$

task. Since it is assumed that both tasks can not be separated, this implies that the actual skill level is a compromise between the skill levels that are optimal for these tasks separately. The skill level resulting from this compromise depends on the time needed for each task. A change in the relative time required for each task affects the weighting of these effects and therefore influences the recruitment decision.

17 Equation (3.14) provides an interesting link between the marginal product price and the marginal price per efficiency unit of production because wages are endogenous in the model. This yields the following equation:

$$
\frac{\partial q(p)}{\partial p}+\omega\left(\frac{\partial \tau_{1}(s, p)}{\partial p}+\frac{\partial \pi_{2}(s, p)}{\partial p}\right)=\frac{\partial p(p)}{\partial p} .
$$

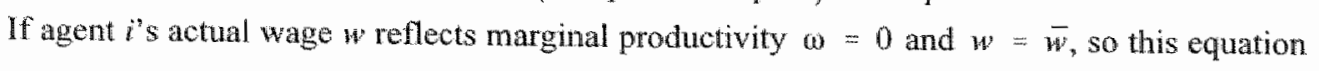




\subsection{A Model of Computerization}

The basic approach of the previous section describes the production costs of a job that consists of two tasks and puts forward its skill requirements and product characteristics as a profit optimizing decision of the firm. This model opens possibilities to perform a hypothetical experiment. Consider two agents, $T$ and $U$, who are identical in their skill level and vector $s$ and produce the same product with characteristics $p$. Now suppose agent $T$ gets a computer to perform task 1 and agent $U$ continues to perform task 1 without a computer. ${ }^{18}$

This experiment implies that agent $T$ no longer has to perform task 1 directly or manually. Instead, he has to operate a computer which assists him to perform this aspect of the job. To operate the computer takes time $\tau_{c}(s, p)$, which depends on $s$ because using a computer might require skills and the time involved to operate the computer might therefore vary with the skills of the worker; $\tau_{c}$ also depends on $p$ because due to the different characteristics of different products and production processes, the production of one good can more easily be automated than that of another product. Computerization of task 1 might also have (a more indirect) impact on the time required to perform task 2. If the good produced and the way it is produced - either by man or by computer - remains unchanged, there is in fact no reason why the time required for task 2 should change. However, the complementarity between computers and particular human tasks is generally regarded as an important route for changing configurations of jobs and skill-biased technological change. In this setting, such a complementary relationship arises once a firm uses the possibilities of a computer to change the characteristics $p$ of the product or

equals equation (3.14). However, if agent $i$ 's actual wage lies above marginal productivity, i.e. $W=-\omega$, profit per product unit remains the same, but the product price exceeds the marginal price per efficiency unit by $\omega\left(\left(\partial \tau_{\|}(s, p) / \partial p\right)+\left(\partial \tau_{2}(s, p) / \partial p\right)\right)$.

${ }^{18}$ Let us take as an example a writer who has to think about the story she wants to tell (task 2) but also has to put down her thoughts one way or another to codify the ideas, either by using a pen or a dicta-phone (task 1). Another example might be a truck driver who has to read a map to get from the loading-berth to the place where he has to unload (task 1), but also has to drive his truck safely (task 2). In the first example, writer $T$ might be giwen a word-processing software package to write down the ideas, while writer $U$ continues to put the story on paper using a pen. In the second case, truck driver $T$ is now using a geographic positioning system (GPS) to decide which road is optimal given the distribution of traffic at that moment and truck driver $U$ still uses a road map (e.g., Hubbard, 2001 for an analysis of truck drivers). In these examples, the writer still has to come up with original thoughts and the truck driver still has to drive the truck (task 2). By the same token, the optician and chief editor discussed in the previous section also perform tasks that can be computerized. In the case of optician $T$ the preparation of glasses is automated by using a computer. Similarly, the Internet assists chief editor $T$ in gathering information more efficiently, and a word-processing and typesetting package helps editor $T$ to put the information in the right format to smooth publication. 
production process. For the time being, the time needed to perform task 2 is allowed to change as a result of computerization: ${ }^{19} \hat{\tau}_{2}=\tau_{2}+\Delta$. If $\Delta<0$, $\hat{\tau}_{2}<\tau_{2}$ and if $\Delta>0, \hat{\tau}_{2}>\tau_{2}$. In the case where $\hat{\tau}_{2}<\tau_{2}$ computerization of task 1 results in less time required to perform task 2 ; more time to perform task 2 is required when computerization of task 1 leads to $\hat{\tau}_{2}>\tau_{2}$. In general, the time agent $T$ needs to produce one unit of output equals

$$
\tau_{T}=\tau_{c}+\hat{\boldsymbol{\tau}}_{2}
$$

whereas agent $U$ needs production time equal to equation (3.1), i.e. $\tau_{U}=\tau_{\mathrm{i}}+\tau_{2^{*}}$. Note that $\tau_{r}<\tau_{U}$ if $\tau_{c}+\hat{\tau}_{2}<\tau_{1}+\tau_{2}$.

Now, if it is assumed that the same person with the same qualifications contimues to be employed on this job and that the wages for these qualifications remain the same (reflecting a true small-size experiment), the introduction of the computer changes the costs incurred by the employer as defined in equation (3.2) by $(w+c)\left(\tau_{c}+\hat{\tau}_{2}\right)-w\left(\tau_{1}+\tau_{2}\right)$ to

$$
k_{T}=(w+c)\left(\tau_{c}+\hat{\tau}_{2}\right)
$$

where $c$ reflects the costs of computer use by agent $T$. These costs can be thought of as maintenance, depreciation and operating costs, but also as costs for buying new software applications and hardware. The total costs the employer has to incur when he gives agent $T$ a computer are higher than the costs of not giving him one if $c\left(\tau_{c}+\hat{\tau}_{2}\right)>w\left(\tau_{1}+\tau_{2}\right)-w\left(\tau_{c}+\hat{\tau}_{2}\right)$. An important assumption of the model is that the costs of the equipment are related to the time agent $T$ needs to finish the manufacturing of one product. This assumption reflects an essential characteristic of the way in which computers, and PCs in particular, are currently used in the workplace. After all, the part of the working time the computer is actually used depends mainly on the time the employee needs to fulfil the computerized task. ${ }^{20}$ Implicitly it is also assumed that $c$ has to be paid for the entire duration of the whole working time, which essentially equals one machine per employee. This means that the computer stands idle, when agent $T$ is performing task 2 . The interrelatedness between the two tasks and the assumption that one person has to carry out the job makes this

\footnotetext{
19. Section 3.4.3 will go into more detail on this issue.

20 Previously, the calculation speed of the computer was the main limiting factor in the efficiency of the performance of the computerized task, but these types of situations are now rare. The reason for this is that there are few computer applications requiring the employee to give instructions so that she can attend to other tasks until the computer has completed the
task.
} 
assumption realistic. ${ }^{21}$

\subsubsection{When Is the Computer Introduced?}

If computers are not randomly assigned to agent $T$ but firms are free to invest in computers, the decision to introduce a computer depends on the costs involved to computerize some part of the job. This decision is based on the break-even point at which the firm's profits are the same for agent $T$, who uses a computer to perform task 1 , and agent $U$, who does not use a computer to complete task 1. After combining and rewriting equations (3.2) and (3.16), the break-even point $b$, at which $c\left(\tau_{c}+\hat{\tau}_{2}\right)=w\left(\tau_{1}+\tau_{2}\right)-w\left(\tau_{c}+\hat{\tau}_{2}\right)$, equals

$$
b=w\left(\frac{\tau_{1}+\tau_{2}}{\tau_{c}+\hat{\tau}_{2}}-1\right) \text {. }
$$

The interpretation of equation (3.17) is the following. If $b>c, a$ computer is profitable because the actual costs of the computerization of task 1 are below the break-even point. Allowing for some randomness in the actual costs of computer use ( $c=\hat{c}+\varepsilon$, where $\varepsilon$ is an error term with the usual assumptions), a higher $b$ can be interpreted as a higher probability that task $\mathbb{1}$ is carried out by making use of a computer, i.e. $P($ computer $)=P(b>c)$.

The essence of equation (3.17) is that higher wages increase the probability of using a computer. For a good interpretation of equation (3.17), it is important to know why wages differ between employees. To examine the impact of these differences on the introduction of the computer, the relationship between the pace of production and wages, as articulated in equation (3.4), can be incorporated into equation (3.17). This leads to the following break-even decision to introduce a computer:

$$
b=\frac{\left(\omega\left(\tau_{1}+\tau_{2}\right)+q\right)}{\left(\tau_{c}+\hat{\tau}_{2}\right)}\left(1-\frac{\tau_{c}+\hat{\tau}_{2}}{\tau_{1}+\tau_{2}}\right) .
$$

This equation consists of three parts. ${ }^{22}$ First, $\omega\left(\tau_{1}+\tau_{2}\right)+q$ brings about the

2II In footnote 22 it is shown that the results of the model are the same if this assumption is relaxed.

2? Note that if the computer is only needed to perform task 1 or just a part of the time to carry out task 2 (with $\dot{\lambda}$ reflecting this fraction), the expression for the break-even cost becomes

$$
b=\left(\frac{\omega\left(\tau_{1}+\tau_{2}\right)+q}{\tau_{c}+\lambda \hat{\tau}_{2}}\right)\left(1-\frac{\tau_{c}+\tau_{2}}{\tau_{1}+\tau_{2}}\right) .
$$


influence of wages on computer use. Secondly, $\tau_{c}+\hat{\tau}_{2}$ represents the amount of time the computer is needed for each product to be produced. Finally, $1-\left(\tau_{c}+\tau_{2}\right) /\left(\tau_{1}+\tau_{2}\right)$ represents the time gain of using a computer to perform task 1

By changing the assumptions underlying the model it is possible to derive these three parts of equation (3.18) separately. This enables us to make explicit several discussions in the literature about computer use and to illustrate the meaning of these three components in detail. First, let us assume that the costs of computer use depend only on the advancement of the product produced, such that a doubling of the advancement would also double the costs of computer use in terms of efficiency units of output, i.e. $w\left(\tau_{c}+\hat{t}_{2}\right)+c q$. Given that wages perfectly reflect productivity, the break-even point would be proportional to the first term of equation (3.18), i.e.

$$
b=\left(1-\frac{\tau_{c}+\hat{\tau}_{2}}{\tau_{1}+\tau_{2}}\right) .
$$

Assuming that the job consists of only one task $\left(\tau_{2}=\hat{\tau}_{2}=0\right)$, equation (3.19) results into $b=\left(1-\tau / \tau_{1}\right)$. This simplification of equation (3.19) has three interesting implications because it demonstrates that the introduction of the computer to perform task 1 depends on the skill level of the worker in a specific job. First, if task 1 becomes more routinized due to computerization (as an extreme case one could imagine that $\tau_{c}(s, p)$ is constant in $\left.s\right)$, the ratio $\tau_{c} / \tau_{1}$ is increasing in the worker's skill level, so the introduction of the computer is most profitable for jobs in which routine tasks are prevailing, i.e. in unskilled jobs. This is by and large in accordance with the argument underlying the fear of de-skilling the workforce as a result of computerization as perceived in the 1970s (see Braverman, 1974 and Freeman and Soete, 1994 for an overview). Secondly, if the computerization of task 1 is skill-neutral (i.e. $\tau_{c} / \tau_{1}$ is constant in s), the time gain for skilled workers equals the time gain for unskilled workers and nothing changes. Finally, the observation that computers are used mainly among skilled workers might lead to the conclusion that skilled workers gain proportionally more from computer use than unskilled workers. This indicates that the productivity of agent $T$ depends more on his skill level than the productivity of agent $U$, which is consistent with the observation that computer skills are highly valued and that the computer can be regarded as a direct source of skill-biased technological change and the dispersion of wages.

The gain from only using the computer for some time further increases the benefits of introducing a computer. The use of the computer in this case often leads to a situation in which more than one employee makes use of one single computer. This is common, for example, in clothing stores, where a computerized cash register is used the moment a salesperson sells an item. The same cash register is used by a colleague selling an item to
another customer. 
However, most workers do not seem to spend their working time on operating a computer only (programmers being the notable exception). They merelly use the computer equipment for some job aspects, which in most cases is some fraction of the total working time. As a consequence, even if operating a computer requires a high level of computer skills and even if computers are mainly used in high-skilled jobs, its effect on the use of computer equipment is largely offset by the time needed for other tasks that are part of the job. This can be easily seen from the configuration of two tasks because $\left(\tau_{c}+\hat{\tau}_{2}\right) /\left(\tau_{1}+\tau_{2}\right)$ goes to unity when the time needed for task 2 becomes relatively more important. For that reason, several authors have focussed on the job aspects included in task 2 and have stressed the importance of the skills needed to complement the use of the computer (e.g., Levy and Murnane, 1996). The main thesis put forward in these studies is that skilled workers profit in particular from the computer equipment in task 1 , because of the complementarity between the computerized task 1 and task 2 (in terms of equation (3.15) task 2 becomes more skilled) and not necessarily because it reduces the time needed to perform task 1 more for skilled workers than for unskilled workers.

Before returning to the assumptions about the costs of using a computer, one might ask what the effects on the break-even decision of the firm would be if wages do not fully reflect productivity. If, as elaborated in equation (3.4), $w=\bar{w}+\omega$, the break-even point for computer use becomes

$$
b=\left(\omega\left(\tau_{1}+\tau_{2}\right)+1\right)\left(1-\frac{\tau_{c}+\hat{\tau}_{2}}{\tau_{1}+\tau_{2}}\right) .
$$

This implies that workers with relatively high wages, compared to their productivity, have a higher probability to get a computer. This is simply the case because the employer paying such a wage has a larger incentive to save on expensive working time.

Because it seems to be implausible to argue that the cost of computers are directly dependent on the value of the product produced, the model leads to the second building block of equation (3.18). For example, an excellent novel writer does not require a more advanced PC than the journalist of some local newspaper. Hence, although the written texts delivered by both persons differ to a large extent with respect to quality and the pace of production, it is most likely that the costs of the $\mathbb{P C}$ they both use are quite similar. Assuming that computer costs are constant for each unit of product $\left(w\left(\tau_{c}+\hat{\tau}_{2}\right)+c\right)$ therefore leads to inclusion of the second part of equation (3.18), i.e.

$$
b=\left(\omega\left(\tau_{\|}+\tau_{2}\right)+q\right)\left(1-\frac{\tau_{c}+\hat{\tau}_{2}}{\tau_{1}+\tau_{2}}\right) .
$$

This equation implies that computer use is not only predicted by wages that deviate from the productivity wage (as in equation (3.20)), but also by products that are more valuable on the market. Workers eaming higher wages, simply 
because they work faster before computerization, do not have a higher probability to get a computer. Because of higher wages the time saved will be more valuable, but at the same time, less time is saved due to the higher pace before computerization of task $1 .^{23}$

Finally, when it is assumed that the costs of a computer are proportional to the production time, equation (3.13) is obtained once again. Now, the probability that a computer is introduced can be written as

$$
P(\text { computer })=P(b>c)=P\left(\left(\frac{\omega\left(\tau_{1}+\tau_{2}\right)+q}{\tau_{c}+\hat{\tau}_{2}}\right)\left(1-\frac{\tau_{c}+\hat{\tau}_{2}}{\tau_{1}+\tau_{2}}\right)-c>0\right)
$$

\section{3,2. The Further Diffusion of Computers}

Computers are not only used by the high-wage workers anymore. Using the October supplements of the Current Population Surveys, it is interesting to note that workers with lower levels of education experienced a slightly more rapid increase in computer use than the higher educated workers. For example, computer use for workers with at least a college degree increased from 42.1 percent in 1984 to 76.8 percent in 1997, whereas computer use among workers with only a high school diploma increased from 19.2 percent to 38.7 percent. In fact, from 1984 to 1997 the workers with an educational level of less than high school using a computer at work more than doubled from 5.1 percent to 12.6 percent. This suggests that while computers were mainly used by the highest skilled workers initially, the diffusion of this technology to lower skilled workers becomes common. Following equation (3.18), the diffusion of the computer at the workplace can be attributed to three developments: (i) the development of new applications, software and hardware, which influences the productivity of computerized production ( $\tau_{c}$ versus $\tau_{1}$ and indirectly also $\hat{\tau}_{2}$ versus $\tau_{2}$ ), (ii) the decline in the cost of computers, and (iii) the changing wage distribution itself.

With respect to the first point, it seems obvious that certain tasks are more suitable to computerization than others. Of course, particularly in the case of tasks requiring information to be managed in a straightforward way (such as reading, writing, checking, or registration), time can be gained by using a computer and/or appropriate computer applications. However, an increasing number of applications have been developed for tasks that were thought to be less easy to computerize in the past (e.g., mathematical analyses in Mathematica and translation work but also new developments in communication technology

\footnotetext{
23 Weinberg's (Weinberg, 2000) observation that women are more likely to work with a computer than men, fits into this result. Lower wages for women, which might reflect this initial disadvantage, will not hamper computer introduction, because due to this productivity disctvantage, women's work is more likely be computerized.
} 
like voice recognition software). An efficient computer application is a conditio sine qua non for profitable computerization: as long as $\tau_{c}+\hat{\tau}_{2}>\tau_{1}+\tau_{2}$, production without a computer is preferred, no matter how high the wages of these workers are. Considering the division of the ratio $\left(\tau_{c}+\hat{\tau}_{2}\right) /\left(\tau_{1}+\tau_{2}\right)$ for all tasks in the labour market, it seems plausible that the introduction of new applications will lead to a less disperse wage distribution. The reason for this is that as more tasks become suitable to computerization, the wage (in relation to computer costs) increasingly becomes the decisive factor in implementing a computer at work or not. This partially explains the tendency for the so-called computer wage premium to increase, as reported, among others, by Krueger (1993) and DiNardo and Pischke (1997). Krueger's (1993) finding that tasks like email and word-processing have a high wage premium can also be understood from this perspective. Since these are tasks which are relevant for a large fraction of jobs, the wage rather than job characteristics seems to be the decisive factor determining computer introduction for these kinds of use.

With regard to the second point, Greenwood and Yorukoglu (1997) provide interesting figures in which they show that the price of new equipment has fallen dramatically since the early 1970s and that the share of IT investment has risen from about 10 percent in 1970 to some 40 percent in 1990 . Of course, this fall in the price of new equipment has led to lower costs for employers to introduce computers and hence to widespread diffusion. The exact decline in the costs of computers is hard to monitor and only few figures are available on the micro level. Lower computer costs will certainly foster computer use, among both relatively skilled and unskilled workers. The main question is, however, whether mainly skilled workers -- being more familiar with computers - will benefit more from these developments than unskilled workers, or that unskilled workers will gain from increased productivity in a similar vein as mainlly skilled workers have done until now.

From the model it follows that a firm adopts computers to support agent $T$ in performing task 1 when $b$ exceeds the actual cost of the equipment $(b>c)$. Ceteris paribus, the decrease in the real costs $c$ of computers experienced in recent decades increases the probability of computer use. The fall in the costs has directly affected both workers that already used a computer (more efficient applications become available) and those who started to use one because the profits of computer use increase as computer costs continue to fall. Once the computer is introduced, every decrease in computer costs will also decrease the firm's costs, while other costs and the worker's productivity remain unaffected (hereby abstracting from indirect market effects). In a small experiment, wages will of course remain unchanged, because the worker involved has to compete with a pool of workers with similar characteristics for which productivity remains the same; all productivity gains therefore directly increase the firm's profits. In the case where all firms for which it is profitable to introduce computers would make a computer available to all workers, a new equilibrium 
wage will settle.

Assuming that the increased demand for computers will not increase costs, competition on the product market causes profit differentials between firms in this equillibrium to be absorbed by higher wages and/or lower product prices, depending on the elasticities of supply and demand. Assuming no systematic differences in these elasticities between different skill levels, profits per dollar wage costs - after deduction of the costs of computer use - provide therefore an indication of the wage differentials between different categories of workers once a new market equilibrium has been established. ${ }^{24}$ Note that as personal characteristics rather than computer use itself will be rewarded in equilibrium, the same wage effects will be found for similar workers who are not using a computer. After all, if a firm requiring a skilled worker for a job without a computer is not willing to pay the same wage as another firm that does use computers, the worker will be lured into the computer-using firm.

Now how will the further diffusion of computers affect skilled and unskilled workers? The answer to this question depends on how to interpret the typical empirical finding that computer use is relatively high among relatively skilled workers and that computer users earn higher wages than non-users even after controlling for many job, personal and sector characteristics. Crucial to the explanation of these wage differentials is whether computer use is the result of a bias in the embodiment skills (either computer skills or complementary skills), as in equation (3.19), or whether wage costs are able to explain the lead taken by skilled computer-using workers, as in equation (3.18).

Let us start by analysing the first interpretation. According to equation (3.19), differences in the probability of computer use are explained by differences in the factor $\left(\tau_{c}+\hat{\tau}_{2}\right) /\left(\tau_{1}+\tau_{2}\right)$. This factor therefore has to be decreasing in skills as shown in the first panel of Figure 3.1. If $c \rightarrow 0$, the introduction of a computer is worthwhile starting from a skill level of $x$, i.e. the level at which the agent needs an equal amount of time to perform the job with a computer as he does without one $\left(\left(\tau_{c}+\hat{\tau}_{2}\right) /\left(\tau_{1}+\tau_{2}\right)=1\right)$.

Since the unit of measurement in Figure 3.1 is one expressed in time units, $c$ has to be divided by the wage to be comparable in different situations. In addition, it is assumed that computer costs are proportional to the productivity of a worker. Therefore, a constant factor is added in the graph to the productivity line to represent total costs. Now it can be seen that in a situation in which computer costs are high, the break-even decision is at skill level $z$. With a relatively low (but still positive) $c$, this break-even point is reached at point $y$.

\footnotetext{
${ }^{24}$ In Section 3.4 .1 it will be shown that computer use itself might lower wages due to increased productivity. However, within the group of computer users these productivity
effects will not alter the wage differentials.
} 
Figure 3.11

The Introduction of Computers Leads to Ever Increasing Wage Differentials

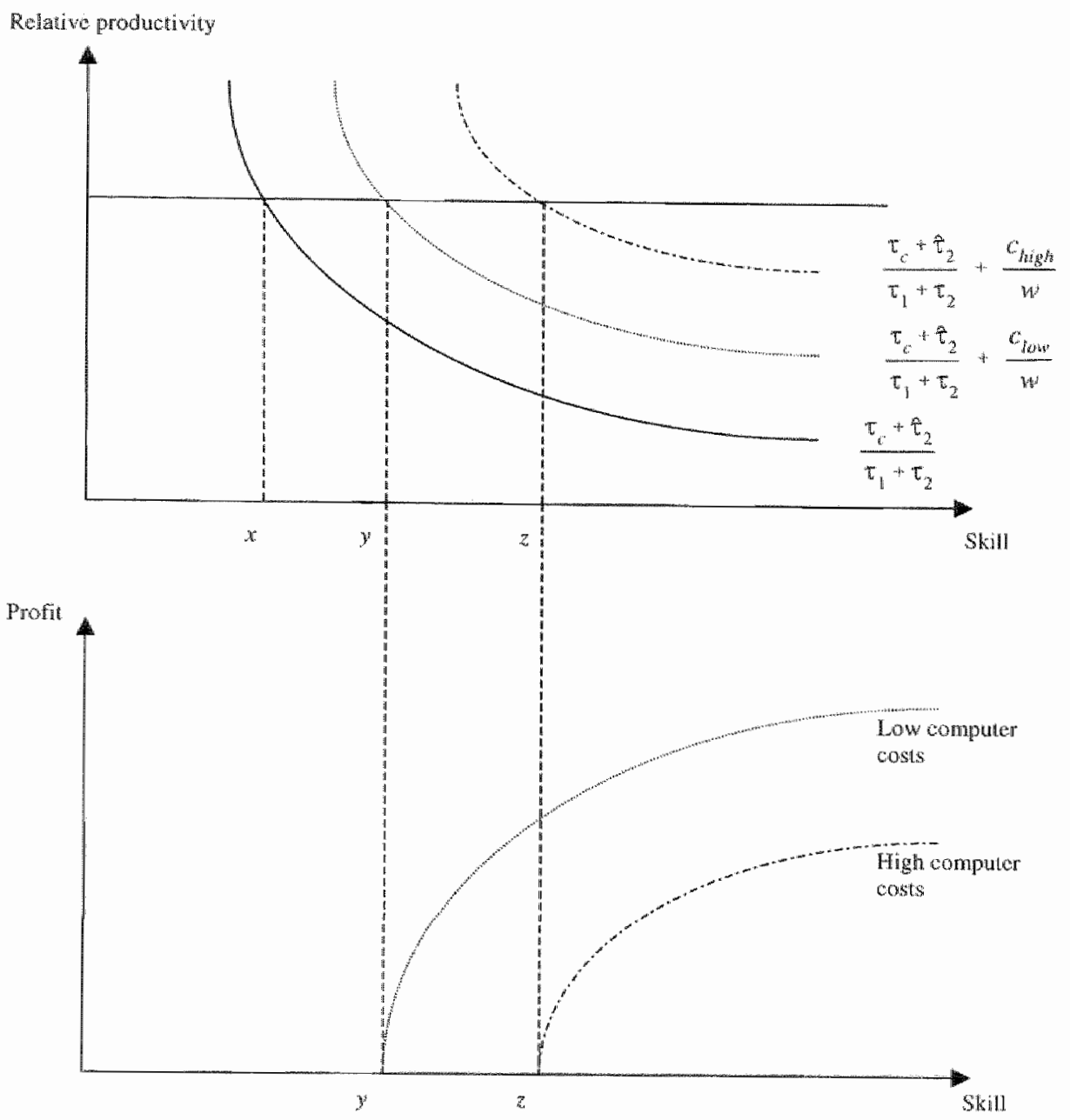

The second panel of Figure 3.1 shows the changes in profits for the firm per unit of time worked in the situation where $c$ is relatively high and in one where $c$ is relatively low. This panel shows that the firm's profits are increasing in the skill level of its workforce. It is also observed that if $c$ drops, the further diffusion of computers leads to a profit increase, which is similar for all workers. In other words, the introduction of computers among lower skilled. workers seems to further increase the wages of higher skilled workers because their (computer or complementary) skills become an increasingly scarce factor. 
76. What Happens When Agent T Gets a Computer?

Figure 3.2

The Diffusion of Computers According to the Model

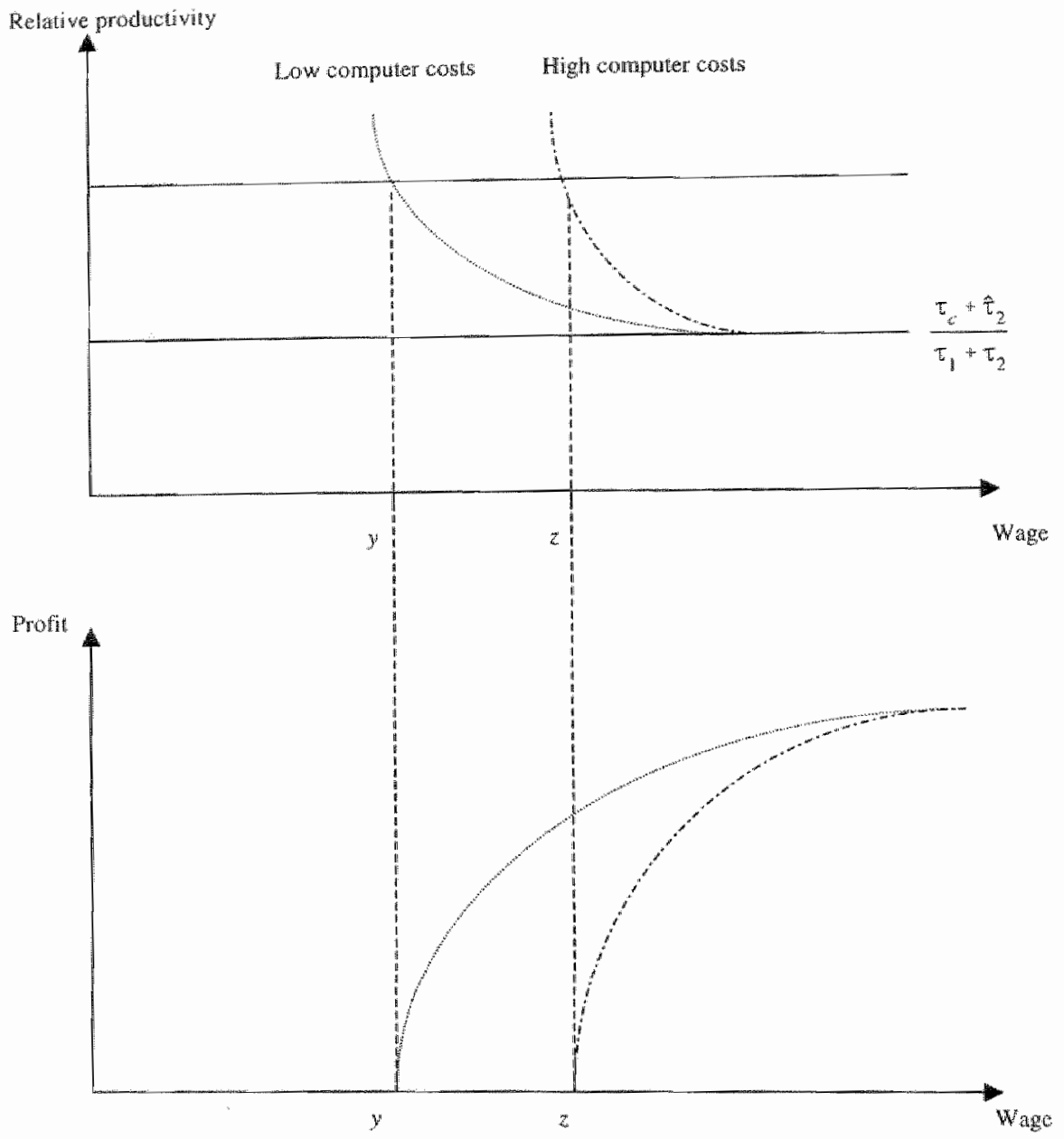

These patterns become rather different if the concentration of computer use among skilled workers is explained by wage considerations, i.e. if it is assumed that $c$ is mainly determined by the fraction of production time a computer is used. The graphical analysis of this argument is shown in Figure 3.2. In this case the productivity gain for computer use is constant in terms of time units. Since $c$ is equal per unit of time, its relatedness to the wage decreases in wages, explaining computer use restricted to wages of at least $z$ if computer costs are relatively high and at least $y$ if they are relatively low. There are two important differences compared to the situation sketched in Figure 3.1. First, there appears to be no longer a saturation point $x$ beyond which workers will never use a computer, even when $c \rightarrow 0$ : ultimately everyone will use a 
computer to carry out task 1. Secondly, the lower panel of Figure 3.2 shows - in contrast to the pattern shown in Figure 3.1 - that the profits of using a computer converge to a constant rate. Contrary to Figure 3.1, the major increases in profits are for the new computer users. For workers that already used a computer, the profit reaches a maximum at the point where computer costs are negligible compared to their wage. Within the group of computer users, changes in relative wage differentials are comparatively small and fully disappear if $c \rightarrow 0$.

Whether one assumes skills or wages to be the explanation for computer use to be allocated mainly in the upper segment of the labour market, in an equilibrium framework, the wages of these workers will always tend to rise initially. However, the skill argument seems to imply that with the further diffusion of computers, skilled workers will continue to gain from their skills, and although computers might also be made available to unskilled workers, the financial gains will mainly go to the skilled workers. In the long run, this will create a divide between higher skilled workers on the one hand and lower skilled workers on the other. The latter group is able to use this technology only with large difficulties or may never get a computer at work.

If it is assumed that the wage itself is the main reason for the current unequal distribution of computers over the labour market, computer diffusion might move through the labour market and consequently through the wage distribution, if computers become sufficiently cheap. In such a scenario, highwage workers will initially face a wage increase, but with the further diffusion of computers this group will not benefit further. Furthermore, lower wage groups will experience similar wage increases, until in the theoretical end of the wage distribution every worker will use a computer, and every worker will have received a similar wage increase (in percentages) (see also Chapter 5).

It is interesting to note that according to equation (3.18), computer use is affected not only by changes in the costs of computers but also by changes in wages themselves. This implies that an increase in average wages will stimulate computer use at work. Since computers are at this moment mainly used by higher earners, a change in the wage distribution might also affect total computer use. As long as a minority of workers use a computer, increased wage dispersion - at a constant average wage - will increase computer use, whereas if a majority of the workers use a computer, a decrease in the dispersion will positively affect computer use. Chapter 5 elaborates further on this issue. ${ }^{25}$

\footnotetext{
${ }^{25}$ Caselli and Coleman $I 1$ (2001) also investigate computer adoption. They do so by relating: data on imports of computer equipment for a large number of countries between 1970 and 1990. Their findings suggest that computer adoption is strongly related to human capital. levels and international trade. Since they do not have data on the wage distribution, they are not able to investigate how computers have diffused through the wage distribution in the countries they investigate.
} 


\subsection{Implications for Labour and Product Markets}

In the previous section it has been discussed what happened when agent $T$ got a computer. The model reflected the true nature of a small experiment because the experiment did not influence market prices and wages. Furthermore, agent $T$ 's job was not threatened and his tasks remained essentially the same. This experimental design enabled us to focus on the way a computer directly changed the tasks of a worker. However, once the computer is introduced, this is likely to have an impact on the decision making of the firm and if many firms change their production decisions this influences both the labour and goods market equilibrium. First, if the quantity of the goods or services produced is kept unchanged, the productivity gain of the computer influences the demand for labour directly. Secondly, the price of the product or service on the market is also influenced by the computerization of agent $T$ 's job and hence the demand for the product or service changes. This changing demand for goods might lead to a different production volume, which again affects the demand for labour (indirectly). Finally, the behaviour of the firm is likely to have changed fundamentally resulting from the introduction of the computer.

In this section it will be shown that even if the computer does not demand specific skill requirements, the firm does have incentives to upgrade its skill demand for workers who use a computer. Furthermore, product specifications are also expected to change. These effects are investigated for the labour market and product market, skill requirements and product specifications.

\subsubsection{Product Market}

If it is profitable for a firm to introduce a computer in agent $T \mathrm{~S}$ job, the time needed to produce decreases, i.e. $\left(\tau_{1}+\tau_{2}\right)>\left(\tau_{c}+\tau_{2}\right)$. In the experiment - if one could prevent other firms from introducing computers - this particular firm could lower its product price and expand its market share infinitely. On the other hand, by keeping the product price and total product demand equal, the production time needed to produce total output $P$ falls. As a consequence, demand for labour in the firm goes down with the factor

$$
\frac{\tau_{1}+\tau_{2}-\left(\tau_{c}+\hat{\tau}_{2}\right)}{\tau_{1}+\tau_{2}}<1 .
$$

Equation (3.23) shows (if product and labour demand remain constant) the factor by which the firm's demand for agent $T$ goes down because the time to manufacture $P$ is reduced. If, in a competitive labour market only this gain in productivity is incorporated, without any change in product demand, agent $T \mathrm{~s}$ 
Wage falls. ${ }^{26}$

In general, an increase in productivity implies that production costs go down and when the computer is adopted in all jobs similar to agent $T$ s job, the market price for the good falls. More specifically, production costs are reduced by

$$
\left(\frac{\omega\left(\tau_{1}+\tau_{2}\right)+q}{\tau_{c}+\hat{\tau}_{2}}\right)\left(1-\frac{\tau_{c}+\hat{\tau}_{2}}{\tau_{1}+\tau_{2}}\right)-c
$$

This term is positive if the introduction of a computer is profitable for the firm. If a firm lowers the product price according to these production costs, product demand increases. As a consequence, there will be an indirect positive effect on labour demand depending on the elasticity of demand for this good 7 , i.e.

$$
\eta\left[\left(\frac{\omega\left(\tau_{1}+\tau_{2}\right)+q}{\tau_{c}+\hat{\tau}_{2}}\right)\left(1-\frac{\tau_{c}+\hat{\tau}_{2}}{\tau_{1}+\tau_{2}}\right)-c\right]
$$

The total effect on labour demand depends on the overall effect of the two counteracting effects. Note from equation (3.25), that the costs of computer use $c$ influence the positive indirect labour-demand effect of equation (3.24) but do not have an impact on the negative direct effect of equation (3.23). This can be understood as follows: when the costs of introducing a computer exactly match the costs of working without a computer, the productivity gain decreases the demand for labour. Since there is nothing to be gained in the costs, no additional demand will be created and the firm's profits remain equal. As discussed in Section 3.3.2, every further fall in computer costs keeps the productivity change unaltered, but lowers production costs, increases profits and enables the firm to increase goods demand by lowering prices. Now, if goods demand is very inelastic, in a new competitive equilibrium, prices are lower to bring profits back to zero. In contrast, if goods demand is very elastic, profits go down because the workers on the computerized jobs have to be paid higher wages. This is the effect described in Section 3.3.2 that, given the fact that a job is computerized, workers in jobs close to the break-even point are

26. This result is in line with Acemoglu's (1998 and 2002) observation for the analysis of increasing demand for skilled workers relative to unskilled workers. Although it is often argued that increased productivity of skilled workers leads to increased demand and higher wages for skilled workers, he obtains that the actual labour-market effects depend crucially on the elasticity of substitution between the goods these skilled workers produce and the goods unskilled workers produce. In the case of a Leontief production function - in which demand for one good will not react on a change in the price - demand for skilled labour falls, and thus their wages indeed fall. Acemoglu (2002) indicates that substitution on the goods market and substitution of labour within an industry together constitute the elasticity of substitution between two types of workers (in his setting skilled and unskilled workers). Since in this experiment the qualifications of the worker within a job has been kept fixed until now, only substitution at the goods market matters here. 
likely to profit less (in percentages).

Since it is likely that computers are initially introduced in high-wage jobs, computerization might lead to skill-biased technological change if the indirect effect exceeds the direct effect on the goods market. The reported absence of intra-industry shifts in employment as a result of computerization suggests however that on average no such demand shifts occur. ${ }^{27}$ This effect can be compared to the elasticity of substitution between skilled (college graduates) and unskilled (high school graduates) workers. Katz and Murphy (1992) estimate the elasticity of substitution between college graduates and high school graduates 10 be about 1.4, which implies an increased demand for skilled workers when their productivity increases. Acemoglu (2002) points out that this elasticity reflects both within job changes in the demand for skilled workers and demand shifts related to shifts on the product market. The part of the elasticity of substitution that matters here is related to product market shifts only. Thus, the introduction of computers might both lead to an increase and a decrease in the demand for labour in the sectors introducing computers. No empirical evidence is available that points towards increased goods demand or increasing sector volume as such due to computerization, which is consistent with the model in that computers have not increased productivity differentials between more and less-skilled computer users (e.g., the comparison between Figures 3.1 and 3.2 in the previous section). Furthermore, when computers become less expensive, job aspects at lower wage levels are also likely to become computerized and similar effects on demand might occur at such lower levels. Hence, although the introduction of the computer influences labour demand, there seems to be no reason to expect that it leads to skill-biased technological change via inter-industry shifts in employment.

\subsubsection{Optimal Skill Requirements}

Section 3.3 .2 showed that the skills demanded by a firm for a certain job are determined by the trade-off between increased productivity due to higher skills and the higher wages people possessing more skills have to be paid. The introduction of the computer is likely to alter the value of skills and to change the optimal skill demand of the firm.

The main issue regarding the effect of computerization on skill requirements seems to be whether a firm changes its demand for particular skills. Equation (3.10) showed that skill requirements can be seen as a profit maximizing decision of the firm. The following expression shows the optimal

\footnotetext{
${ }^{27}$ See e.g., Autor, Katz and Krueger (1998) for U.S. evidence in this respect. See also Machin and Van Reenen (1998) for international evidence obtaining similar results.
} 
skills recruitment after computerization:

$$
\frac{\tau_{c}}{\tau_{c}+\hat{\tau}_{2}} \theta_{k}^{c}+\frac{\hat{\tau}_{2}}{\tau_{c}+\hat{\tau}_{2}} \hat{\theta}_{k}^{2}=\frac{\partial w(s) / \partial s_{k}}{w} .
$$

Keeping the wage structure constant, this means that the optimal skill requirements might change in three different ways as a result of the introduction of the computer.

First, if task 1 becomes a more-skilled task for which the relative time to produce depends more on skills than before the introduction of a computer, the firm demands higher-skilled workers because of the importance of computer skills. Secondly, due the computerization of task 1, the performance of task 2 might demand a higher-skilled worker. This means that for complementarity reasons skilled workers relatively gain more time (or loose less time) than unskilled workers, after the introduction of the computer, to perform tasks 2 . This argument is used by Levy and Murnane (1996) who examine the impact of computers on skill demands in the custodian unit of a large U.S. bank. They particularly address the question with what skills computers form a complementary relationship. Thirdly, even if the influence of skills on both tasks is kept constant, the weight of both influences changes after the introduction of the computer in task 1 . This means that if task 1 is a routine task (Definition 1) skill requirements increase because the introduction of the computer puts more weight (in term of time units) on task 2. An important implication of this result is that for all jobs in which the computerized task is a routine task, the introduction of a computer seems to increase skill requirements, even if the effect of skills on both tasks separatelly is kept constant. This suggests that neither computer skills, nor arguments for the increasing importance of complementarity skills are necessarily needed to explain a skill bias in the recruitment decisions of firms for jobs in which the computer is introduced and/or used as found in many studies.

This third finding is remarkable because it shows that even if working with a computer does not increase the comparative advantage of skilled workers in each task, skill requirements might nevertheless be raised. This effect might explain the difficulties in the search for a direct link between increased skill demand and technological change to explain skill-biased technological change, which arise from the fact that the focus was on the first two arguments underlying equation (3.10). ${ }^{28}$ Secondly, the framework is able to interpret the findings of Autor, Levy and Murnane (2001) who find that computers substitute for some routine job aspects and complement other job aspects which are nonroutine tasks. Finally, the finding of Doms, Dunne and Troske (1997), that

\footnotetext{
28 For example, Autor, Katz and Krueger (1998) attribute the strong correlation between the rate of skill upgrading and computerization at the industry level to the fact that new technologies and skilled labour seem to complement each other in a direct way.
} 
computer investment is uncorrelated with changes in average wages paid to either unskilled and skilled workers but highly correlated with the relative number of skilled workers, seems to be understood in terms of the arguments of the impact of computerization on the firm's recruitment behaviour: the implication of the model is that skill upgrading will take place at those jobs currently being computerized. Until the mid-1990s, computers have been mainly introduced in high-school level and college level jobs, which explains the shift in labour demand from high-school graduates to college graduates. With the further diffusion of computers this implies that skill upgrading might take place in unskilled jobs, leading to a shift in demand for unqualified workers as well.

\subsubsection{Optimal Product Quality}

After the introduction of a computer, an employer also reconsiders the configuration of the goods the firm produces. In equation (3.14) the optimality condition for the product specification is derived when agent $i$ does not use a computer. After the introduction of the computer, this equilibrium condition becomes

$$
\tau_{c} \theta_{p}^{c}+\hat{\tau}_{2} \hat{\theta}_{p}^{2}=\frac{\partial \rho(p) / \partial p}{w} .
$$

Since the introduction of the computer reduces production time, either the time needed for task 1 or the time needed for task 2 diminishes, by assumption. The time required for task 2 depends positively on product quality and a reduction in production time due to complementarity between the two tasks lowers the marginal costs of a better product (see Definition 3 and 4). This induces a firm to improve product quality. A reduction in the time needed for task 1 could also lead to the opposite outcome. Since time needed for task 1 depends negatively on product quality if task 1 and 2 are substitutes (Definition 3 ), $\tau_{c}<\tau_{1}$ increases the marginal costs of extra product quality and provides incentives to the firm to lower product quality. In this case the product is based on a more routinized production process, which makes use of the advantages of the computer.

Computerization of task 1 leads to a change in the specifications of the product. By defining the new product specifications $p^{*}$, the time needed for tasks 1 and 2 now equals $\tau_{0}\left(s, p^{*}\right)$ and $\hat{\tau}_{2}\left(s, p^{*}\right)$, respectively. Given these new product specifications, employers might also have different incentives for the skill level they demand when $\tau_{c}\left(s, p^{*}\right) \neq \tau_{c}(s, p)$ and $\hat{\tau}_{2}\left(s, p^{*}\right) \neq \hat{\tau}_{2}(s, p)$. Furthermore, the derivatives $\theta_{s}^{c}$ and $\hat{\theta}_{s}^{2}$ might have different values at $p^{\frac{c}{3}}$. This notion provides another interpretation of the complementarity between computers and skills: $\Delta$ can now be interpreted as the difference between the time needed for task 2 for product $p^{*}$ and product $p$. With $\Delta$ being positive, this 
would lead to a skill bias in labour demand if task 2 is a skilled task (which is a plausible assumption as shown above). In addition, an increase in $\hat{\theta}_{s}^{2}$ might further increase this skill bias. ${ }^{29}$

\subsection{Extensions}

\subsubsection{Firm Effects}

The introduction of computers at work is not restricted to one individual worker, but probably related to a firm's behaviour towards implementing new technologies thereby affecting the firm's workforce as a whole. Until now it is assumed that firms decide upon computer investments for each worker separately, however. In practice it seems to be impossible to introduce a computer system at the workplace of the firm's high-wage workers, leaving the way the low-wage workers operate unaffected. Doms, Dunne and Troske (1997) and Dunne, Forster, Haltiwanger and Troske (2000) show indeed that all workers in firms that have implemented computers to assist the work receive higher wages than workers in firms that have not implemented such new technologies. Such findings suggest that, at the firm level, the correlation between computer use and wages is primarily due to the fact that firms with relatively high-wage workforces are more likely to adopt new technologies than firms with relatively low-wage workforces.

The model can be extended to deal with the firm's decision upon implementing computers for its workforce. To do so, the additional profit from computerization changes into

$$
\left(\sum_{i} w_{i}+c N f(N)\right)\left(\sum_{i} \tau_{i}+\sum_{i} \hat{\tau}_{2}\right)-\sum_{i} w_{i}\left(\sum_{i} \tau_{1}+\sum_{i} \tau_{2}\right) .
$$

In this equation total wage costs rather than individual wage costs matter; total time spent on both tasks matters and computer costs per worker become lower if the number of employees increases. The function $f$ describes the ratio between the actual costs per worker and the costs per worker in a one-worker firm. Hence, $f(1)=1$ and since the costs per worker decrease in $N, f^{\prime \prime}(N)<0$. In a similar fashion, the break-even costs $b$ for computer use per worker now equal

$$
b=\frac{1}{f(N)} \frac{\frac{1}{N} \sum_{i} \cos \left(\sum \tau_{1}+\sum \tau_{2}\right)+q}{\sum \tau_{r_{c}}+\sum \tau_{2}}\left(1-\frac{\sum r_{c}+\sum i_{2}}{\sum r_{1}+\sum r_{2}}\right) .
$$

20. Such an increase in $\hat{\theta}_{s}^{2}$ can also be interpreted from an extension of the model with more than two tasks un which the change in product quality asks for more additional time in one non-computerized task than in another non-computerized task, with the first of these two tasks being more skilled than the second. 
In this situation, three properties of the break-even decision change compared to the individual equation. First, the break-even point now depends on the level of average wages in the firm rather than on the level of some individual's wage. This means that a single low-wage worker within a firm, which pays on average high wages, might also get a computer because the machine is profitable to implement for his fellow workers. Secondly, the break-even point depends on the average time spend on each task rather than individual time. So workers who spend only a relatively small amount of their working time on task 1 might also get a computer. Thirdly, the break-even point is increasing in firm size $N$. Hence, larger firms more easily introduce computers than smaller firms.

\subsubsection{Team Working}

Firm characteristics rather than individual characteristics might not only affect the decision to invest in computer equipment, but, once the computer is introduced, it might also affect the way in which workers cooperate or work together. An important assumption of the model is that one worker might perform different tasks, possibly with different skill requirements. This assumption has been justified by the observation that it might cost time to involve other workers in a certain activity. By making this argument more explicit, it is shown that the introduction of the computer seems to affect the way in which different workers within a firm operate together.

Consider task 1 to be a routine task (Definition 1). Furthermore, imagine a situation in which task 1 is carried out by an unskilled worker, while task 2 is carried out by a skilled worker. This is efficient if the time needed to instruct the unskilled worker to perform task 1 is recovered by the lower wage costs needed to bring to completion task 1, i.e.

$$
\left(\tau_{2}+\tau_{\text {insisucic }}\right) w+\tau_{i}^{\text {unsikillecid }} w_{\text {unstilled }}<\left(\tau_{1}+\tau_{2}\right) w
$$

or

From these expressions it can be observed that splitting the two tasks into two different jobs becomes more likely if (i) the wage differential between both workers is larger, (ii) instruction time is shorter, (iii) unskilled workers are relatively good at performing task 1 (i.e. task 1 is indeed an routine task) and (iv) task 1 is a time consuming task relative to task 2 .

The introduction of a computer changes the time needed for task 1 into the time needed for the computerized task, from $\tau_{1}$ to $\tau_{c}$. Now, the question is whether after the introduction of the computer 


$$
\frac{\tau_{c}-\tau_{\text {instruct }}}{\tau_{\tilde{c}}^{\text {sunkilled }}}>\frac{w_{\text {tenskilled }}}{w}
$$

still holds. The answer to this question depends on (i) the reduction in time needed for the routine task, i.e. $\tau_{i c}$ versus $\tau_{1}$ and (ii) on the time required for computer use by the unskilled worker relative to the skilled worker, i.e. $\pi_{c}$ versus $\tau_{c}^{\text {minskifled }}$. In a situation in which $\tau_{c}^{\text {urstilled }}>\tau_{c}^{\text {skilled }}$ it might be beneficial to undo the separation of tasks into two distinct jobs. However, if there is no skill bias in performing task 1 the fact that the time needed to operate a computer falls (rather than to carry out task 1), might lead to an integration of both tasks again. Computerization might therefore reduce cooperation between workers of different skill levels. Note that this reintegration process is more likely to occur if the wage differential between skilled and unskilled workers is smaller. Another interesting observation is that if this integration of routine tasks into a skilled job takes place, this reduces the tendency to increase the skill requirements within the job.

Kremer and Maskin (1997) and Acemoglu (1999) argue that there is not only a tendency towards a reduction in cooperation between skilled and unskilled workers, but at the same time an increase in cooperation between workers of equal skill level. From the above, it is not so straightforward to explain this tendency to work together in teams of similar skill levels. The changes described by Kremer and Maskin (1997) are driven by the notion that if the distribution of skills is sufficiently disperse, a further increase in the variance of skills induces skilled workers to work with other skilled workers and increase inequality. Acemoglu (1999) considers a model in which the supply of skilled workers reaches a critical number, so that it becomes profitable to change the composition of jobs and to create jobs designed only for skilled workers. In terms of the approach developed here, such changes depend on the way in which team work influences the time requirements for certain activities and of the job in general. For example, a weekly meeting $\left(\tau_{\text {meet }}\right)$ in which workers discuss their experiences on their performance of task 2 might save an amount $\tau_{\text {feami }}$. This is only profitable when

$$
\tau_{1}+\tau_{2}-\tau_{\text {reant }}+\frac{\tau_{\text {meet }}}{h}\left(\tau_{1}+\tau_{2}-\tau_{\text {team }}\right)<\tau_{1}+\tau_{2}
$$

i.e.

$$
1+\frac{\tau_{\text {meet }}}{h}<\frac{\tau_{1}+\tau_{2}}{\tau_{1}+\tau_{2}-\tau_{\text {ream }}} .
$$

The right-hand side of equation (3.33), indicating the relative amount of time needed without team working, increases when task 1 takes less time because of the implementation of computers. Team working only becomes profitable when 
the work becomes more concentrated on task 2 . Hence, although a different route is taken, the findings here seem to be consistent with Kremer and Maskin's (1997) approach of diverging production processes among skilled and unskilled workers and Acemoglu's (1999) findings of changing composition of jobs within a firm.

\subsubsection{Work Intensity}

The concentration of work on the skilled task 2 might not only affect the way in which workers cooperate, but also the intensity of their work. Computer use is often associated with work intensification. Effects of using a computer screen, but also the increased amount of information that has to be processed by workers are put forward as explanations for this. However, Lantz (1998) shows that workers who spend time on a computer to email do not suffer from a higher work intensity.

The model offers an explanation for these two contrasting findings. It is often assumed that a job requiring higher skill levels is experienced as more intensive and it is also true that diversity in tasks reduces work intensity due to variety. According to the model, the introduction of the computer increases work intensity, because it generally increases the time spent on skilled tasks and. reduces the time spent on routine tasks. The relatively more time spent on task 2 offers an explanation for the fact that work intensity increases and that computerization of the routine part of the job leads to some offsetting phenomenon captured by sending an email or browsing the Internet.

\subsection{Conclusion}

Computers have brought about a dramatic change in the labour market in the past decades. A large number of economists and commentators regard the introduction and implementation of the computer as a major determinant underlying the contemporary trend towards skill-biased technological change. They do so because the computerization of the labour market seems to go with increased skill upgrading and wage inequality. So far, computers have been used mainly by higher-skilled workers and there has been a substantial wage differential between computer users and non-users. Therefore, it seems to be plausible that certain skills enable workers to make more effective use of the possibilities offered by a computer. Other results contradict such findings, however. This raises doubts about the specific way in which computers change the labour market. In this chapter a simple model has been developed that explores the following experiment: what happens when agent $T$ gets a computer? This set up has been able to show what happens to agent $T$ "s job, 
skill demand, the production process, product demand, and the organization and intensity of work upon the introduction of computers. The results from this exercise contribute to the understanding of how computers change the labour market.

First, it is shown that Krueger's (1993) computer wage premium is not the result of the allocation of workers possessing the highest level skills to the jobs in which computers are utilized most, justifying doubts concerning the extent and existence of this premium. In addition, it is argued that the computer wage premium does also not result from some spurious correlations or unobserved skills as argued by DiNardo and Pischke (1997). On the contrary, the computer wage premium seems to be a reflection of the opposite: it is more likely to be profitable for a firm to give a comparatively high-wage worker a computer because the efficiency gain is relatively larger than for a relatively low-wage worker. Hence, workers earning relatively high wages have a higher probability to work with a computer than low-wage workers. Neither computer skills nor complementary skills are necessarily needed in the analysis to understand why computers are used by high-paid (and therefore higher-skilled) workers; the argument merely runs through the benefits from implementation of the computer. Furthermore, from the same perspective these results offer an answer to the question why workers in firms operating advanced and new technologies earn higher wages (e.g. Doms, Dunne and Troske, 1997). Studies based on panel data which typically find that computers are introduced among high-wage workers first, but only lead to very modest wage increases afterwards, also fit to this framework: rather than viewing high wages as a proxy for skills, these analyses seem to show that high wages lead to computer use. $^{30}$

Secondly, the observation that it is unlikely that skills related to effective computer use explain the patterns of diffusion and wage differentials does not imply that computers are not a source of skill-biased technological change. In theory there are three reasons explaining the recent increase in the demand for skilled (college) workers. First, the demand for skilled workers might have increased because of the importance of the skills needed to operate a computer or because of skills complementary to the computer. The model shows that this explanation is not the most likely one. Secondly, the productivity gain resulting from computerization reduces the price per efficiency unit of output and increases the demand for those products and hence skills. Since skill-biased technological change is not associated with inter-industry shifts in labour demand, this explanation of skill upgrading and wage inequality is also unlikely to hold. Finally, the approach developed here demonstrates that employers seem

${ }^{30}$ E.g., Chennells and Van Reenen (1997), Entorf an Kramarz (1997) and Entorf, Gollac and Kramarz (1999). 
to upgrade their workforce because computerization enables firms to use higher-skilled workers more effectively as a result of the diminishing importance of routine tasks. Thus, rather than decreasing the demand for relatively unskilled workers and increasing the demand for relatively skilled workers in general, the introduction of computers at work seems to induce a gradual shift in skill requirements for jobs that are computerized. This latter channel is likely to be the most important source of skill-biased technological change in understanding how computers change the demand for labour. The changing way in which workers can be deployed is also shown to lead to a better understanding of changes in work organization, product characteristics and work intensity and seems to be consistent with the empirical results from the literature.

Thirdly, based on the model, as computers become cheaper and more applications become available, the majority of low-wage workers is also likely to be provided with a computer at work. Consequently, the current shift in demand from high-school graduates to college graduates might well change into a shift from workers without any degree to high-school graduates; so this particular kind of skill-biased technological change resulting from computerization will be continued at lower ends of the labour market. It is likely that this continued skill bias will not be explicitly observed as a further increase in wage dispersion in the economy as a whole because it concerns wage shifts in the centre of the wage distribution.

Finally, this simple framework has put forward three interesting and testable implications to enhance the understanding of how computers have changed the labour market. First, computer skills and complementary skills do not seem to be very important in explaining why some workers use computers and others do not. Wages are likely to be a main determinant. In the next chapter (Chapter 4) this predictions will be tested more formally using data from Britain. Secondly, the diffusion of computers seems to be related to the wage distribution. To see whether this prediction holds, the relationship between the diffusion of computers and the distribution of wages could provide more insight into the computerization of the labour market. This will be discussed and investigated in Chapter 5. Finally, the introduction of computers at work seems to lead to a more complex work environment because the emphasis is now on the more skilled tasks (the computer takes over routine tasks). To show whether job complexity and skill requirements have increased, Chapter 6 provides an empirical test of whether this is the case in the Netherlands. 


\section{Chapter 4 \\ Computers, Skills and Wages}

\subsection{Introduction}

The computerization of (some parts of) jobs has led to a changing work environment. In this chapter the focus will be on the changing importance of particular skills when the computer is implemented in a certain job. The previous chapter has shown that there are at least three possible explanations for the introduction of a computer at work. First, it might be the case that particular skills, like computer skills or complementary skills, determine the effective use of computers. Secondly, the performance of particular tasks might become more efficient when a computer is used and hence workers who have to carry out such tasks might be more likely to use computers than other. Thirdly, the wage levell of the individual worker is found to be an important determinant of computer use. When a firm has to decide to buy expensive capital to support the work of its employees, the model predicts that it will give the computer to the person whose working time is most expensive, i.e. the employee who earns the highest wage or whose wage costs for the firm are highest.

In this chapter these three possible determinants of computers use are examined. Using British data from the Skills Survey of the Employed British Workforce, new empirical findings are presented, which are in accordance with the model presented in Chapter 3. The first finding is that the value of computer skills does not offer an adequate explanation for the wage differentials between computer users and non-users. It is shown that computer skills do not possess market value if the computer is mainly used for routine procedures (which is what the computer is typically used for). Secondly, it is shown that wages, together with some specific tasks, are the main determinants of computer use. Thirdly, neither educational levels, nor age or experience are found to determine computer use, suggesting that the specific pattern of computer use is not likely to be explained by arguments pointing at the importance of educational levels and complementary skills.

The implications of these findings are important in three ways. First, if computer skills are not important to work with a computer, everyone could get a computer at work and the skills needed to work with a computer will not be a limiting factor in the further diffusion of computers at work. This implies, 
consistent with the analysis in Chapter 3 , that the main question is no longer "what skills are needed to use a computer", but "when is it worthwhile to get a computer". It is shown that the answer to this question depends on the tasks of a worker and, more importantly, on the wage cost for the employer. Some tasks can be easily computerized, but the benefit of doing so depends on the wage costs that can be saved. This reverses the causation of the computer wage premium.' Because wages are endogenous to the model, the wage has to be instrumented to determine the causation and the size of its impact on the determinants of computer use. Using instrumental variables it is indeed shown that higher wages increase computer use. The empirical finding that computer users earn much higher wages is therefore not likely to be explained by their level of (computer) skills, but seems to be an illustration of the opposite: highwage workers use a computer because it is more profitable to computerize (some part of) their jobs. It can therefore be expected that as the computer becomes cheaper, more and more workers will start using one. This increase in the adoption of computers as a result of its falling price will be discussed in the next chapter.

Secondly, computer use has been labelled a possible source of skillbiased technological change. Assuming that computers require specific skills, increasing computer use indeed makes computer skills a scarce resource. High levels of computer use among higher-skilled workers and the obtained computer wage premium suggest that this hypothesis holds. Of course, this is likely to be the case for computer programmers, for example, and other jobs in which computer skills are the main skills to be used, but it does not seem to apply to the vast majority of computer users. Therefore, one should probably focus on a perspective of computer utilization in which workers get a computer when their wage level or the tasks they perform make it worthwhile to the employer to buy one. Increasing computer use is thus likely to reflect an increase in the number of high-wage workers, the availability of new applications, and/or a lower price of computer equipment. In other words, increased computer use does not provide direct evidence for skill-biased technological change. ${ }^{2}$

Special attention has been given to older workers because it is inferred that they have great difficulty in understanding and adapting to the changing

\footnotetext{
Acemoglu (1998) also argues that developments in technology might reflect a change in the composition of the labour force, rather than technology shifts causing a change in labour
demand.

This does not exclude that computer use leads to skill-biased technological change. It is argued that the channel through which skill-biased technological change occurs is not computer skills. The model in the previous chapter implies that the introduction of computers leads to a focus on the core tasks of a job. This induces a demand for higher qualified workers. Hence, the computer is indeed a source of skill-biased technological change. This
will also be empirically shown later.
} 
configuration of work when a computer is introduced. ${ }^{3}$ This might be due to the fact that computers seem to have altered skill requirements. Since older workers have skills of an older vintage, they will probably suffer more from technology shocks relative to younger workers, whose skills are of a more recent vintage. In addition, older workers are thought to have lower learning capabilities than younger workers. Therefore, they will have more difficulty in learning how to use computer equipment and might try to avoid work involving computers. Furthermore, the introduction of new technologies might require additional training. ${ }^{4}$ The incentive to participate in such training programmes will be lower for both the older workers themselves and the employer because there is less time during which the returns to the training investment can be recovered, while the costs of this investment are generally higher due to the higher salary of older workers. The introduction of new technologies might therefore lower the older workers" wages, increase unemployment and induce early retirement because employment and earnings seem to become less secure. From this perspective, one might expect computer use to be highly concentrated among younger workers. Yet, as noticed by Friedberg (2001) and Weinberg (2001) this does not turn out to be the case. The analysis here adds a new perspective both to the existing literature on the computerization of the labour market and to the position of older workers in a labour market subject to rapid technological change. First, after controlling for the tasks to be performed and the wage costs

\footnotetext{
See for example the Committee for Economic Development (1999), who wrote a voluminous report titled "New opportunities for older workers". With respect to computerrelated training for older workers, they conclude that "the value of age-segregated classrooms may be greatest in computer-related training. Younger trainees generally possess more background knowledge that can aid in learning new applications, while older trainees are more likely to be starting from scratch. Mixing the two is likely to firustrate the younger trainees, who must move at a slower pace, and intimidate the older ones, who may feel overwhelmed." (p. 42). Furthermore, Microsoft has launched the Microsoft Senior Initiative to increase access and provide computer and Internet literacy to seniors; SeniorNet provides older adults with access to computer technology to enhance their lives and enable them to share their knowledge; and Computer $U$ sets up franchised computer training centres for older adults.
}

* In this regard, Bartel and Sicherman (1993) consider the retirement decision of older workers. They observe two opposing effects. First, they find a direct positive effect of technological change on the amount of on-the-job training, which dellays the retirement decision of older workers. Secondly, they obtain a more indirect effect of technological change that suggests that human capital depreciates faster as a result of the introduction of new technologies. The former effect is more likely in the case of gradual technological change, whereas the latter is particularly observed following an unexpected increase in the rate of technological change. This is confirmed by Allen (2001), who observes that the wage growth of older workers is much higher in R\&D-intensive industries than in industries with little R\&D activity. In contrast, Peracchi and Welch (1994) and Ahituv and Zeira (2001) observe a decline a labour participation rates of older men and argue that these workers have been pushed out of the labour market as a result of technological change. 
that can be saved, no separate age effects of computer use are found. Secondly, research into computer skills for the different age groups has indicated that older workers possess lower computer skills than younger workers. This observation turns out to be mainly a gap between the youngest workers (20-29) and the other age groups and does not seem to affect the oldest workers (50-60) specifically. Experience with using a computer and the frequency of computer use at work seem to be the main determinants of computer skills; however, even after controlling for these variables, younger workers still possess more computer skills. Finally, the effects of computer skills on wages are investigated. The results show that older workers are not affected by their relatively lower levels of computer skills in terms of wages.

The remainder of this chapter is organized as follows. Section 4.2 presents a description of the data and preliminary statistics. In Section 4.3 the relationship between computer use, skills and wages is examined. Section 4.4 discusses the validity of the skill measure. Section 4.5 investigates the determinants of computer use. Section 4.6 presents a further analysis of the findings in graphical terms. Section 4.7 addresses the determinants of computer skills, particular attention paying to the computer skills of older workers. Section 4.8 concludes.

\subsection{Data and Skill Measurement}

The data used in this chapter has been collected in a survey, conducted in the first half of 1997, entitled the Skills Survey of the Employed British Workforce. ${ }^{5}$ The survey includes a relatively small, but representative, number of workers $(2,467)$ from Britain. ${ }^{6}$ Participants were asked several dozens of questions on their labour-market situation during face-to-face interviews to obtain information on various aspects of their jobs, including qualifications, responsibilities, skills, tasks, and training.

Table 4.1 summarizes the incidence of computer use at work for different categories of workers in Britain in 1997 and a similar tabulation for computer use in Britain in 1985 and 1990 and comparable years for Germany and the United States. Computer use in the mid-1980s is lower in Germany and Britain than in the United States. In the early 1990 s, the gap between the USA and Britain and Germany has further increased, but in 1997 the fraction of workers using computers at work in Germany and Britain passed the U.S. level of utilization. Differences in these figures might of course be related to different wordings of the questions in the surveys, but comparisons with other sources of

\footnotetext{
Ashton, Davies, Felstead and Green (1999) provide a description of the survey and the full
questionnaire.
}

Appendix 4.1 reports some descriptive statistics of the variables used in the analysis. 
information about computer use suggest that these effects are small. The most important message from Table 4.1 is that although computer use at work is increasing over time, the patterns of use among various labour-market groups are highly similar in relative terms. In all three countries, computers are used predominantly by the higher-educated workers. In contrast to what is often expected, in all years and countries included in the table, the highest rate of computer use is not found in the youngest age group (20-29): workers in the age group 30-39 or 40-49 are in all cases except one the most frequent users.

To investigate how computers have changed the labour market, the questions in the British data concerning the importance of computer use, the level of sophistication at which computers are employed, and computer skills offer a detailed picture of the computerization of the workplace. Particularly the information on the latter two is unique. With respect to the level of sophistication of computer use, Entorf and Kramarz (1997) use the Enquête sur la Technique et l'Organisation du Travail auprès des Travailleurs Occupés, in which they distinguish three levels of computer use related to the autonomy of each worker. This is an indirect measure of the level of sophistication of computer use because it relates to the job in general, whereas our data relates it to the sophistication of the computerized task. Computer skills have been measured only indirectly in the literature as some kind of "computer ability" (Bell, 1996) or "computer knowledge" (DiNardo and Pischke, 1996 and Hamilton, 1997). Bell uses data from the U.K. National Child Development Study. DiNNardo and Pischke utilize data from the West German Qualification and Career Survey conducted by the Federal Institute for Vocational Training. This data offers information on both "computer use" and "computer knowledge". Hamilton uses variables from the 1986 High School and Beyond Survey, indicating whether an individual has ever used software packages or has used a computer language to program. The advantage of the measure used here is that it is a direct measure of computer skills related to the tasks a worker is expected to carry out.

In line with the model presented in the previous chapter, these questions are related to the tasks a worker has to carry out at the workplace. With regard to computer use the following question was asked: "In your job, how important is using a computer, PC, or other types of computerized equipment?". The response scale offered was fivefold: "essential", "very important", "fairly important", "not very important", and "not at all important or does not apply". 


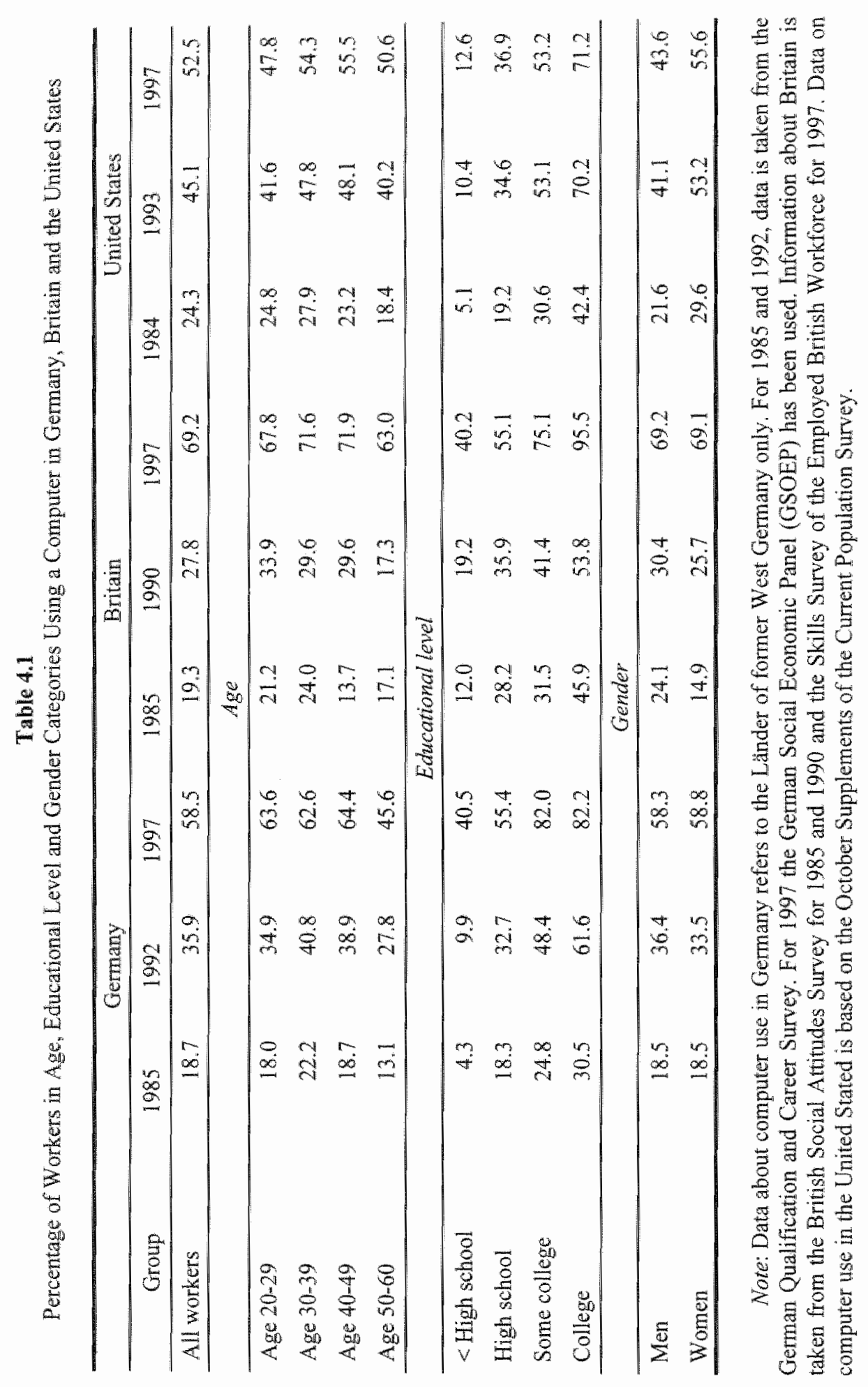


With respect to the level of sophistication of computer use the following question was asked: "Which of the following best describes your use of computers or computerized equipment in your job?". The answers are divided into four different levels of sophistication. "Simple" use indicates "straightforward use, e.g., using a computer for straightforward routine procedures such as printing out an invoice in a shop". "Moderate" use means "e.g., using a computer for word processing and/or spreadsheets or communicating with others by email". "Complex" use is defined as "e.g., using a computer for analysing information of design, including use of computer aided design or statistical analysis packages". Finally, "advanced" use is described as "e.g., using a computer syntax and/or formulae for programming".

Finally, computer skills are measured using the following question: "When your job involves using a computer, PC or other type of computerized equipment, are you able to do this effectively?". Six possible answers were offered: "always", "nearly always", "often", "sometimes", "hardly ever" and a remaining category "does not apply". Note that the design of the questions in the survey is such that questions on the level of sophistication of utilization and on computer skills have not been asked to people who had indicated that they do not use a computer at work. People not using a computer at work are defined as those workers reporting their importance of computer use to be "not at all important or does not apply".

The question used to measure skills has been the subject of substantial debate among economists, psychologists and sociologists, especially in the literature regarding the importance of language skills (see for example Chiswick and Miller, 1995, Dustmann and Van Soest, 2001, and Berman, Lang and Siniver, 2002). Surveys relying on the respondent's self-assessed skills often use questions like "How would you rate your current writing skills in English?"? to measure these skills. The response alternatives vary from "very good", "good", "fair", "poor", to "cannot write in English". Such answers, in the absence of independent verification (e.g., objective tests), question the reliability of the responses because of issues of social desirability and selfreferencing, which might bias the data in unidentifiable ways. See for example Spenner (1990) for a discussion of these kinds of data problems, and Bertrand and Mullainathan (2001) for a summary of the literature using such measures and the integration into a measurement-error framework as to understand what they imply for empirical research relying on subjective data.

For academic skills like reading and math it is possible to measure by test items, which has the obvious advantage that the skills are measured in an identical way for all respondents. While the OECD will use this approach for numeracy and literacy skills in the forthcoming Life Skills Survey, computer

See for example the questionnaire of the $\mathrm{OECD}^{2}$ s Intemational Adult Literacy Survey (IALS). 
skills seem to be too much context- or task-related to allow for a general set of test questions (see OECD, 2000). Although the approach taken in the data used here also relies upon self-assessed skills, the main strategy has been to assess skills through questions on several tasks a respondent has to carry out at work, rather than directly asking the respondent to evaluate his own skill level.

Table 4.2

Distribution of the Answers to the Questions about Computer Use, the Level of Sophistication of Computer Use, and Computer Skills

\begin{tabular}{|c|c|c|c|}
\hline \multicolumn{4}{|c|}{$\begin{array}{l}\text { Panel A: } \\
\text { Computer Use }\end{array}$} \\
\hline & & $n$ & percentage \\
\hline \multicolumn{2}{|l|}{ 1. Essential } & 748 & 30.3 \\
\hline \multicolumn{2}{|l|}{ 2. Very important } & 363 & 14.7 \\
\hline \multicolumn{2}{|c|}{ 3. Fairly important } & 313 & 12.7 \\
\hline \multicolumn{2}{|c|}{ 4. Not very important } & 283 & 11.5 \\
\hline \multicolumn{2}{|c|}{ 5. Not at all important, or does not apply } & 760 & 30.8 \\
\hline \multicolumn{4}{|c|}{$\begin{array}{l}\text { Panel B: } \\
\text { Level of Sophistication of Computer Use }\end{array}$} \\
\hline & & $n$ & percentage \\
\hline \multicolumn{2}{|l|}{ 1. Advanced } & 84 & 3.4 \\
\hline \multicolumn{2}{|l|}{ 2. Complex } & 299 & 12.1 \\
\hline \multicolumn{2}{|l|}{ 3. Moderate } & 645 & 26.1 \\
\hline \multicolumn{2}{|l|}{ 4. Simple } & 637 & 25.8 \\
\hline \multicolumn{2}{|c|}{ 5. Non-response } & 42 & 1.7 \\
\hline \multicolumn{2}{|c|}{ 6. Does not apply ( 5 in panel $A$ ) } & 760 & 30.8 \\
\hline \multicolumn{4}{|c|}{$\begin{array}{c}\text { Panel C: } \\
\text { Level of Computer Skills }\end{array}$} \\
\hline & & $n$ & percentage \\
\hline 1. Always & Very high & 667 & 27.0 \\
\hline 2. Nearly always & High & 612 & 24.8 \\
\hline 3. Often & Intermediate & 177 & 7.2 \\
\hline 4. Sometimes & Low & 140 & 5.7 \\
\hline 5. Hardly ever & Very low & 107 & 4.3 \\
\hline 6. Non-response & & 4 & 2 \\
\hline 7. Does not apply & 5 in panel $\mathrm{A}$ & 760 & 30.8 \\
\hline
\end{tabular}

Note: The data is from the Skills Survey of the Employed British Workforce. 
The main reason for using this approach is that being asked to describe whether one carries out the tasks at work effectively seems to be much less subject to self-esteem than being asked to assess one's own abilities. Furthermore, the skill question is directly linked to the tasks to be fulfilled and seems to be well-suited to an empirical analysis of a model based on the performance in different tasks. Rather than collecting information about an abstract skill, the question directly addresses the success in using a computer, in other words, the question is competence-based. ${ }^{8}$ In Section 4.4 , the validity of the skill measure is addressed in more detail.

The answers to the computer skill question have been translated as follows. Respondents answering "always" to the question whether they are able to effectively use a computer, $\mathrm{PC}$ or other type of computerized equipment embody "very high" computer skills. Answering "nearly always" makes that a worker has "high" computer skills; "often" involves "intermediate" computer skills; "sometimes" makes that a worker has "low" computer skills and "hardly ever" involves "very low" computer skills.

Table 4.2 reports the distribution of the answers to the three computer questions. Panel A indicates that computer use is "essential" in almost one-third of all cases, and in 14.7 percent it is regarded as "very important". Slightly over 40 percent of the respondents answered that computer use is "not very important" or "not important at all, or does not apply". The level of sophistication of use in Panel B is skewed towards "simple" and "moderate" tasks like routine procedures such as printing out an invoice in a shop and using a computer for word processing and/or spreadsheets or communicating with others by email. Only 3.4 percent of the respondents uses computerized equipment at the "advanced" level. Panel C shows that more than half of the workers in the sample possesses "very high" or "high" computer skills. Among those using a computer there seems to be a relatively small group of people with "low" or "very low" computer skills (10.0 percent).

Table 4.3 summarizes the importance of computer use, the level of sophistication of computer use and computer skills for the different age groups. The top panel shows that the importance of computer use is highest in the age groups of workers aged 30-39 and 40-49. It also becomes clear that computers are least important for the oldest age group (50-60).

The second panel reveals a negative correlation between age and the sophistication of computer use, since younger workers tend to utilize computers at a more advanced level than their older colleagues: 18.3 percent of the workers aged 20-29 uses a computer at a level higher than "moderate" compared to $17.1,14.6$ and 11.2 percent for workers aged $30-39,40-49$ and $50-$

\footnotetext{
"Spenner (1990) reports evidence from a number of studies finding high correlations between self-assessed skill measures obtained by this way of questioning and measures obtained from objective judgements by experts and external experi systems, used to develop the Dictionary of Occupational Titles.
} 
59 , respectively. Finally, the answers to the computer skills question are reported in the third panel of Table 4.2 .

\section{Table 4.3}

Percentage of Computer-Using Workers in Britain Evaluating the Importance of Use, the Level of Sophistication of Use and Computer Skills Categorized by Age

Panel A:

Computer Use

1. Essential

2. Very important

3. Fairly important

4. Not very important

5. Does not apply

\begin{tabular}{cccc}
\multicolumn{4}{c}{ Age } \\
\hline $20-29$ & $30-39$ & $40-49$ & $50-60$ \\
\hline 32.2 & 33.5 & 29.2 & 24.3 \\
11.8 & 14.3 & 18.4 & 13.7 \\
12.8 & 12.2 & 14.0 & 11.6 \\
11.0 & 11.6 & 10.3 & 13.3 \\
32.2 & 28.4 & 28.1 & 37.0 \\
\hline
\end{tabular}

Panel $\mathbb{B}$ :

Level of Sophistication of Computer Use

1. Advanced

2. Complex

3. Moderate

4. Simple

5. Does not apply

\begin{tabular}{rrrr}
\multicolumn{4}{c}{ Age } \\
\hline $20-29$ & $30-39$ & $40-49$ & $50-60$ \\
\hline 4.3 & 4.4 & 2.5 & 2.1 \\
14.0 & 12.7 & 12.1 & 9.1 \\
25.4 & 25.9 & 29.2 & 23.3 \\
23.3 & 27.1 & 25.8 & 26.4 \\
33.1 & 30.0 & 30.3 & 39.1 \\
\hline
\end{tabular}

Panel C:

Level of Computer Skills

1. Very high

2. High

3. Intermediate

4. Low

5. Very low

6. Does not apply

\begin{tabular}{rrrr}
\multicolumn{4}{c}{ Age } \\
\hline $20-29$ & $30-39$ & $40-49$ & $50-60$ \\
\hline 34.7 & 27.9 & 23.5 & 22.0 \\
21.7 & 26.0 & 29.7 & 19.5 \\
4.7 & 8.0 & 7.2 & 8.5 \\
3.7 & 5.7 & 7.0 & 6.0 \\
3.1 & 3.7 & 4.4 & 6.7 \\
32.2 & 28.7 & 28.3 & 37.2 \\
\hline
\end{tabular}

Note: The data is taken from the Skills Survey of the Employed British Workforce. All columns add up to 100 percent. See Table 4.1 for more details. 
Table 4.4

Correlation Between Computer Use, the Level of Sophistication of Computer Use, and Computer Skills

Panel A:

Frequencies of Skill Levels within

Different Levels of Importance of Computer Use (percentages)

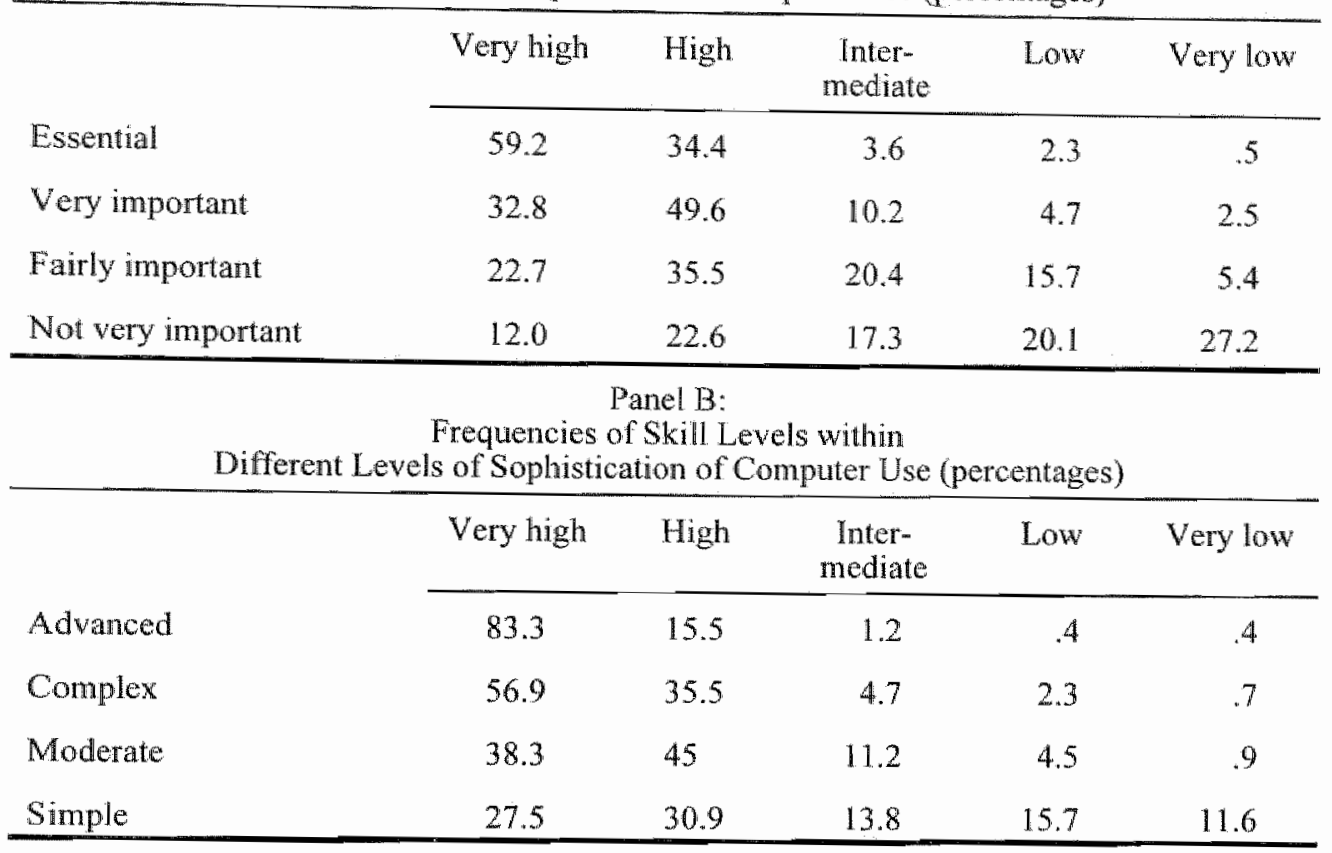

Note: The data is taken from the Skills Survey of the Employed British Workforce. In bot thanels the columns define the skill level ranging from "very high" to "very low". The rows in Panel $A$ define the importance of computer use (ranging from "essential" to "not very important"). The rows in Panel B define the level of sophistication of computer use (ranging from "adwanced" to "simple"). The rows in the table add up to 100 pereent. The definitions of computer use, the level of sophistication of computer use and computer skills are reported in Table 4.2.

The main insight from this panel is that younger workers generally possess a higher level of computer skills than older workers, which is consistent with the general perception that younger workers seem to be more able to use a computer than older workers. Also interesting to note is that particularly the youngest workers possess the highest computer skills. A comparison of the two highest levels of computer skills reveals that 56.4 percent of the youngest workers (20-29) possesses at least a "high" level of computer skills compared to $53.9,53.2$ and 41.5 percent of workers aged $30-39,40-49$ and 50-60, respectively. Looking at the group of workers having only "very low" computer skills one can observe that more than twice as many workers aged $50-60$ report having "very low" computer skills compared to the youngest workers (20-29): 6.7 percent versus 3.1 percent. The overall pattern revealed by the distribution 
of the answers to the questions related to the computerization of the job reported in Table 4.3 suggests that workers in the age group 50-60 are less able to work with a computer than younger workers and use the computer at a less sophisticated level.

Table 4.4 reports the correlation between computer skills within different levels of computer use and between computer skills within each level of sophistication of computer use, respectively. Panel A gives information on the skill distribution for different levels of computer use. From this panel is becomes clear that workers in jobs in which a computer is more important generally seem to possess more advanced computer skills. Similarly, Panel B provides information about the skill level of workers who use the computer at different levels of sophistication. Again, higher levels of sophistication seem to go hand in hand with higher levels of computer skills.

Although there is little doubt that computer users possess more computer skills than non-users, one might wonder whether there are returns to computer skills and whether computer skills determine computer use. To find an answer, it is important to disentangle the different roles of the level of sophistication of computer use, and computer skills in wage formation. Even if computer skills have no market value for whatever reason, one would expect users to acquire these skills by experience in using the equipment. The main problem therefore is that if computer use is more common among high-wage workers, a spurious correlation between computer skills and wages might show up. Conversely, the use of a computer might be a necessary condition to be paid for computer skills. Differences in earnings between computer users and non-users do therefore not necessarily show the value of computer skills. For this reason, the research strategy is based on the fact that, given the level of sophistication at which a computer is used, computer users are not equally able to use a computer."

\subsection{Computer Use and Skills and Wages}

\subsubsection{The Returns to Computer Use and Skills}

To examine the wage differential associated with computer use and computer skills, a number of (OLS) wage regressions are run, which are augmented from the standard cross-sectional wage equation by including a

\footnotetext{
"Alan Krueger argued in an email: "Shaquille O'Neal has great basketball skills, but if he doesn't use those skills on the basketball court I doubt they'd be well paid". Hence, the research strategy is based on the fact that not all players have the same talent. A difference in earnings between O'Neal and me does not show the value of basketball skills. However, the wage differential between O'Neal and Michael Smith (Washington Wizards) shows that these skills have market value. It is shown that differences in computer skills, within the same kind of level of sophistication of use do not seem to be rewarded.
} 
dummy for computer use. The wage equation for worker $i$ then looks like

$$
\ln W_{i}=X_{i} a+C_{i} \beta+\varepsilon_{i}
$$

where $\ln W_{i}$ is the $\log$ gross hourly wage rate, $X_{i}$ is a vector of observed individual characteristics and $C_{i}$ represents a dummy variable that equals $l$ if worker $i$ uses a computer, and 0 if not; $\alpha$ and $\beta$ are the estimated parameters and $\varepsilon_{i}$ is an error term with the usual assumptions and properties.

The results of estimating different forms of equation (4.1) are reported in Table 4.5. The first column of this table includes the usual covariates like education, age and experience and age and experience squared, and the dummy variables female, married, married $\times$ female, union member and supervisor. Including also a dummy variable for computer use leads to a computer wage premium of 21.4 percent $(\exp (.194)-1)$ and the usual findings for the other covariates: the wage is increasing in educational level; age and experience are also positively correlated to the wage as well as the gender (being male), marital status, supervision and union variables. ${ }^{10}$ These results are consistent with the estimates for the United States and the findings from many other studies reported in Chapter 2 and suggest that the definition of computer use in the data used here is robust.

In the analysis reported in columns [2]-[4], the dummy for computer use has been split according to the importance of on-the-job computer use (column [2]), the level of sophistication of computer use (column [3]) and computer skills (column [4]). Workers not using a computer are taken as the reference group. The results in column [2] suggest that workers whose importance of computer use is "essential" to perform the job receive the highest wage premium (34.0 percent); workers whose importance of computer use at work is "not very important" receive a wage premium of 12.2 percent, compared to workers that do not use a computer. The results reported on the level of sophistication of computer use in column [3] are similar: workers using the computer at the most advanced level receive the highest wage premium and workers using the computer at the least advanced level receive the lowest computer wage premium. Finally, column [4] reports the returns to computer

${ }^{10}$ Other specifications of the wage equation all lead to a computer wage premium of around 20 percent. These different specifications are not included in Table 4.5 , because they do not lead to additional insight into the results presented in the first column. Some specifications including sector dummies (1-digit SIC) and dummies for the size of the company have also been tested. Furthermore, tenure, whether or not a worker has a permanent job, and hours worked and hours worked squared were included into different specifications. However, the magnitude of the results did not change when these additional covariates were included in the regression. Regmessions ran separately for men and women did not significantly change the magnitude of the results. Additionally, the results of taking into account the importance of computer use, its level of sophistication and computer skills later on in the analysis do not seem to be sensitive to different specifications. 
skills. The coefficients at the four highest levels indicate a return to computer skills but do not significantly differ from each other. All workers earn between 22.1 and 25.1 percent higher wages than workers not using a computer, irrespective of their skill level; workers with "very low" computer skills have much lower wages which are not significantly higher than the wages of nonusers.

The values of computer skills in column [4] are interesting. Due to the strong correlation between the level of sophistication of computer use and computer skills reported in Table 4.4, one might also expect a positive correlation between computer skills and wages, even if computer skills are not positively correlated with wages within each level of sophistication. So even without controlling for the level of sophistication of computer use, computer skills do not seem to be correlated with wages in the sense that higher levels of computer skills lead to higher wages.

A possible reason for the lower returns to computer skills for workers who only possess a "very low" level of computer skills is that a lot of these people started to use the computer only recently. Since the model presented in Chapter 3 suggests that wages are one of the determinants of computer use, recent users will (on average) have lower wages, which points towards a very selective group of users. Since they probably just started to use a computer, this group might lack the knowledge of using the computer equipment because they are inexperienced users, which might lead to a spurious correlation between wages and computer skills. The data offer a possibility to test this because information on computer use at work five years prior to the survey has also been collected. Using the information about computer use at work in 1992 and excluding those workers who did not use a computer at that time leads indeed to different regression coefficients. The results reported in column [5] of Table 4.5 show that particularly the coefficient for the least computer-skilled workers has gone up. "This suggests that workers who have used the computer for a longer period of time receive the same return to computer skills, irrespective of whether they have "very high" or "very low" levels of computer skills." This

\footnotetext{
"Excluding the most recent usets from the other regressions reported in Table 4.5 obviously leads to an increase in the coefficients. For example, the dummy for conputer use reported in column [1] increases by .122 to .315 when excluding workers that have used the computer during less than five years. The coefficients for the importance of computer use and the level of sophistication of computer use indicate similar increases. However, in contrast with the coefficients for computer skills the significant differences remain the same.
}

${ }^{\prime 2}$ It is also important whether the coefficients on the importance of computer use, the level of sophistication of computer use and computer skills statistically differ from each other. A comparison of the highest premium with the other estimates using a one-tailed t-test shows that the coefficients for workers whose computer use is "essential" are statistically different at the 5 percent level from the coefficients of workers whose computer use is "very important", and at the 1 percent level from the coefficients of the workers whose computer use is onlly 
result is also consistent with the possibility put forward by the model that it is the use of the computer that matters in terms of differences in wages, not necessarily the skills involved.

\subsubsection{The Value of Computer Skills}

The data distinguish four different levels of sophistication of computer use:" "advanced", "complex", "moderate" and "simple". To disentangle the effects of computer use on wages from computer skills on wages, the returns to computer skills within each level of sophistication are estimated. Table 4.6 presents the results from this analysis.

The first column in Panel A indicates that at the "advanced" level of sophistication of computer use, workers with "very high" computer skills receive the highest wage premium. Although significant at the 10 percent level only, this might suggest that at this "advanced" level computer skills are related to wages, which is plausible given the character of the work. This group of workers consists mainly of programmers for whom the computerized task can be defined as a skilled task in terms of the model in Chapter 3 and particularly in terms of Definitions 1 and 2, whereas for most other workers the computerized task is a routine task.

The next three columns show a different pattern. At the "complex" level of sophistication of computer use, workers receive the highest wage when their computer skills are only "intermediate". At the remaining two levels of sophistication of computer use, workers whose level of computer skills is "low" receive the highest wage. In the analysis reported in Panel B the recent users are excluded from the analysis. The results are similar to the results reported in Panel A. ${ }^{13}$

"fairly important" or less. For the level of sophistication of computer use it is found that the coefficients of using the computer at the "advanced" level are statistically different from the coefficients of using the computer at the "moderate" level and of using the computer at the "simple" level of sophistication, both at the 1 percent level. With regard to computer skills, a difference is observed only in column [4] of Table 4.5 between workers having "intermediate" computer skills compared to workers possessing "very llow" computer skills (1 percent level). If recent users are left out (column [5]) there are no significant differences between the skill levels distinguished.

${ }^{13}$ The same regressions have been run to investigate the effect of computer skills within each level of importance of computer use and are similar to those presented in Table 4.6 . 


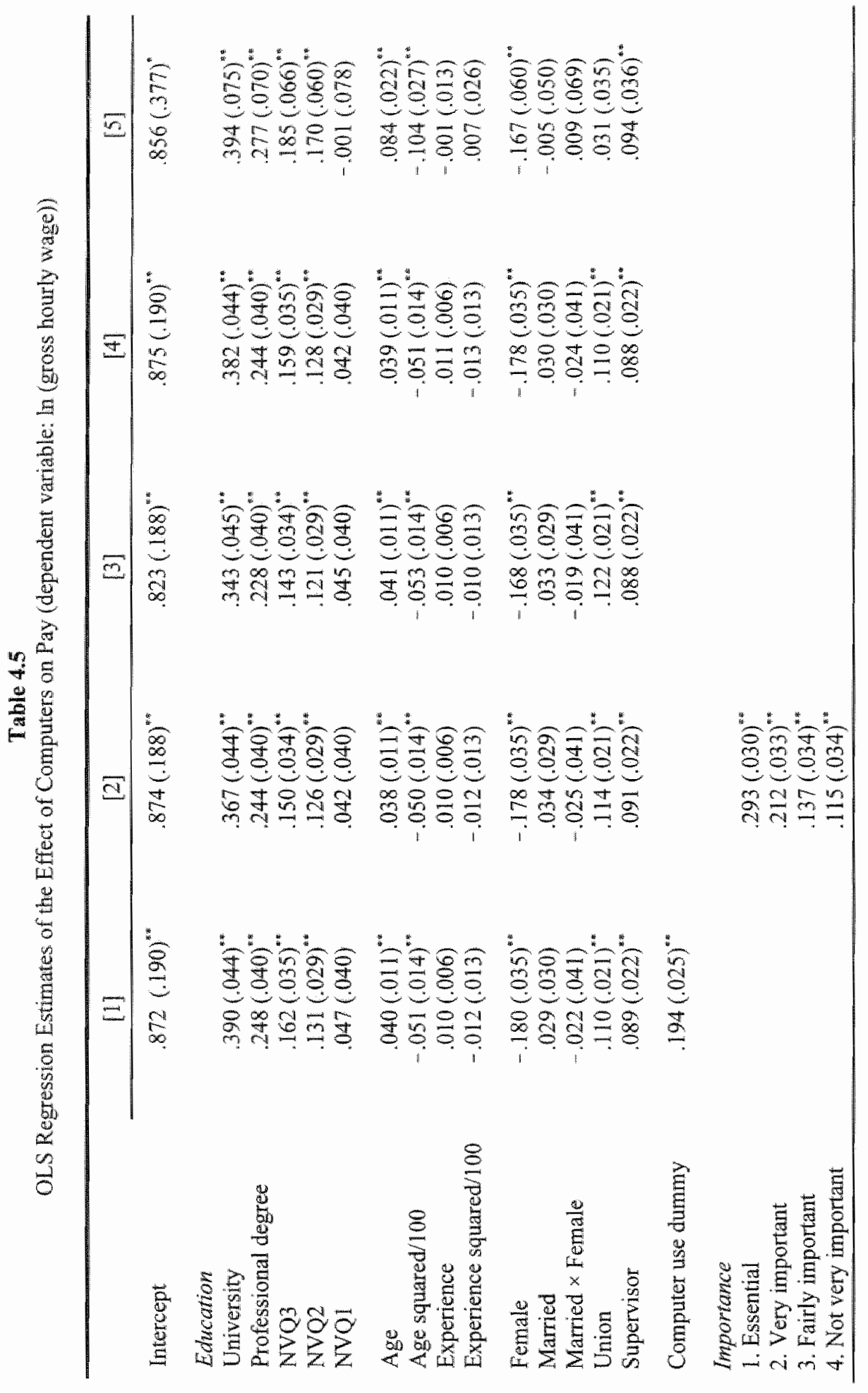




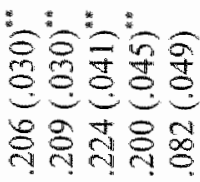

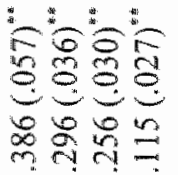

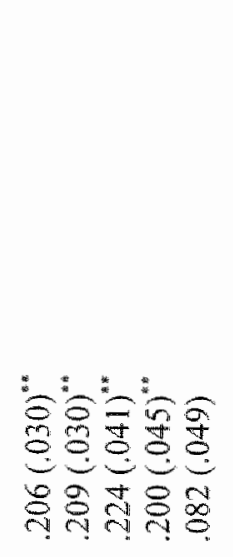

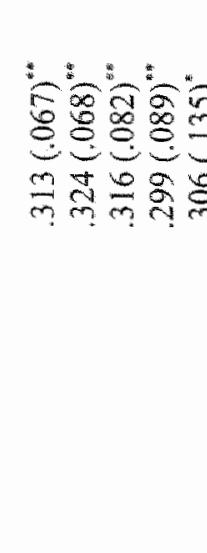

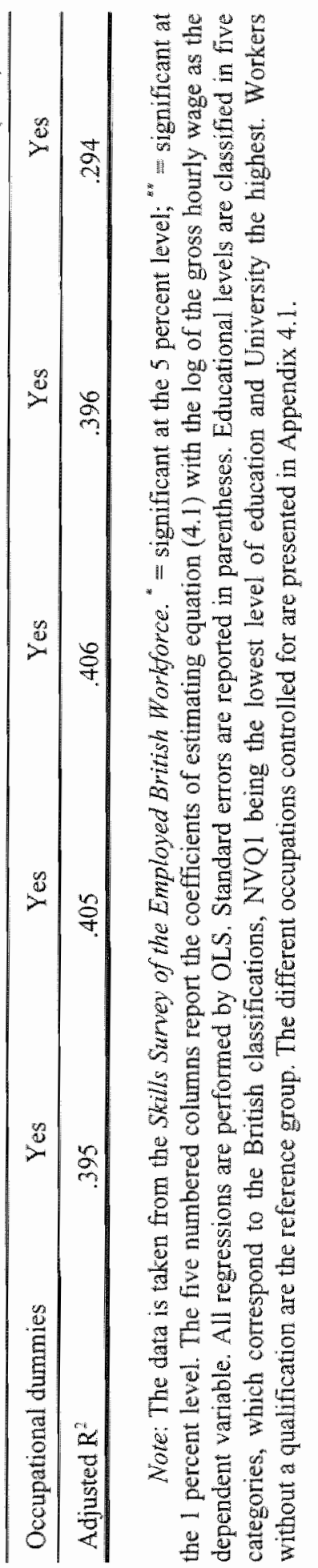


These results are consistent with the model and with the preliminary findings in Table 4.5 that computer skills utilized to perform the tasks required to carry out the job seem to be a relatively unimportant determinant for most jobs in explaining the higher wages associated with computer use. It is also consistent with the results of the model in Chapter 3 that the computerized task is likely to be of minor importance and does not emphasize the skills a worker is hired for.

Table 4.6

The Wage Premium for Computer Skills within Four Different Levels of Sophistication of Computer Use (dependent variable: In (gross hourly wage))

Panel A:

Workers Using a Computer in 1997

Computer skills

Level of Sophistication of Computer Use

\begin{tabular}{lllll} 
& Advanced & Complex & Moderate & Simple \\
\cline { 2 - 5 } 1. Very high & $.418(.061)^{* *}$ & $.278(.043)^{* *}$ & $.222(.039)^{* *}$ & $.081(.041)^{*}$ \\
2. High & $.235(.124)$ & $.290(.051)^{* *}$ & $.272(.036)^{* *}$ & $.124(.039)^{\circ *}$ \\
3. Intermediate & - & $.536(.120)^{* *}$ & $.296(.060)^{* *}$ & $.141(.053)^{* *}$ \\
4. Low & - & $.350(.167)^{*}$ & $.316(.092)^{* *}$ & $.165(.050)^{\circ *}$ \\
5. Very low & - & - & $-.003(.197)$ & $.054(.058)$ \\
\hline
\end{tabular}

Panel B:

Workers Using a Computer both in 1992 and 1997

Computer skills

Level of Sophistication of Computer Use

\begin{tabular}{lllll} 
& Advanced & Complex & Moderate & Simple \\
\cline { 2 - 5 } 1. Very high & $.516(.096)^{* *}$ & $.341(.075)^{* * *}$ & $.312(.073)^{* *}$ & $.170(.078)^{*}$ \\
2. High & - & $.355(.084)^{* *}$ & $.385(.071)^{* *}$ & $.204(.077)^{* *}$ \\
3. Intermediate & - & $.613(.158)^{* *}$ & $.345(.100)^{*}$ & $.195(.100)^{*}$ \\
4. Low & - & - & $.395(.135)^{* *}$ & $.228(.098)^{*}$ \\
5. Very low & - & - & $.245(.507)$ & $.262(.161)$ \\
\hline
\end{tabular}

Note: The data is taken from the Skills Survey of the Employed British Workforce. "significant at the 5 percent level" " = significant at the 1 percent level. The coefficients are OLS regression estimates with a dummy for each combination of level of sophistication of computer use and computer skills, also including all other variables of column [4] in Table 4.5 (standard errors in parentheses). - indicates less than 5 observations.

\subsection{The Validity of the Skill Measure}

An important concern that might question the results in Tables 4.5 and 4.6 is whether the skill measure is robust. Although subjective measurement will always suffer to some extent from limited self-knowledge and possible mistakes in valuing one's own skills, the findings suggest that this subjective skill measure is valid on the basis of four arguments. 
First, comparison of the results for computer skills with other skill measures from the same survey shows that relative scores are consistent: people give themselves lower grades for skills that are generally viewed as difficult, such as analytical thinking and mathematical calculations.

Secondly, the positive correlation between the importance of computer use, its level of sophistication and computer skills reported in Table 4.4 shows the consistency of the measure in this respect.

Thirdly, in Appendix 4.3 it is shown why writing skills do seem to have market value and computer skills do generally not. This third result is remarkable, since it implies that DiNardo and Pischke's "joke paper" that pens have changed the wage structure in a similar way as computers have is likely to be invalid (DiNardo and Pischke, 1996 and 1997). In the appendix it is shown that writing skills are underlying the pen wage premium, while computer skills do not seem to be underlying the computer wage premium.

Finally, large measurement errors and biases in the skill measure would imply that other skills are not related to wages either. Table 4.7 presents regression results for other skills measured in the same subjective way, which reveal positive correlations between the levels of skills and wages.

Table 4.7 reports the results from the same regression as in column [4] of Table 4.5 for four different skills, other than computer skills: (i) analysing complex problems in depth; (ii) spotting problems or faults; (iii) making effective speeches or presentations; and (iv) writing short documents with correct spelling and grammar. These skills have been selected because they seem to reflect four different aspects of the job that (some) workers come across when performing their job. The regression results reported in Table 4.7 show that for these job aspects higher skills are generally associated with higher wages.

It is interesting to obtain whether the coefficients shown in Table 4.7 are statistically different from the highest premium found. For tasks involving the in-depth analysis of complex problems, the coefficients for workers with "low" and "very low" skills levels are significantly lower than the coefficients for workers with "very high" skills levels at the 5 percent level. The same applies to making effective speeches or presentations and writing short documents with correct grammar and spelling. For spotting problems or faults it is impossible to distinguish the coefficients. A regression with a variable ranging from 1 to 5 for the different skill levels and a dummy to identify whether this task is a part of the job shows that all skill measures are positively correlated with the wage at the 5 percent level, with the exception of spotting problems or faults, which is only significant at the 10 percent level. The most important insight is, however, that performing the same analysis for computer skills does not yield a significant and positive correlation between computer skills and wages. 
Table 4.7

The Robustness of the Skill Measure: OLS Regression Estimates of Eour Other Skills (dependent variable: $\ln$ (grosis hourly wage))

\begin{tabular}{|c|c|c|}
\hline \multicolumn{2}{|l|}{ Skill measure } & \multirow{2}{*}{$\begin{array}{c}\text { Wage premium } \\
.164(.033)^{\circ .} \\
.140(.029)^{\circ} \\
.113(.036)^{\circ} \\
.051(.044) \\
.038(.052)\end{array}$} \\
\hline Analysing complex problems in depth & $\begin{array}{l}\text { 1. Very high } \\
\text { 2. High } \\
\text { 3. Intermediate } \\
\text { 4. Low } \\
\text { 5. Very low }\end{array}$ & \\
\hline Spotting problems or faults & $\begin{array}{l}\text { 1. Very high } \\
\text { 2. High } \\
\text { 3. Intermediate } \\
\text { 4. Low } \\
\text { 5. Very low }\end{array}$ & $\begin{array}{l}.204(.050)^{\circ} \\
.191(.049)^{\circ} \\
.162(.057)^{\circ} \\
.104(.080) \\
.106(.137)\end{array}$ \\
\hline Making effective speeches or presentations & $\begin{array}{l}\text { 1. Very high } \\
\text { 2. High } \\
\text { 3. Intermediate } \\
\text { 4. Low } \\
\text { 5. Very low }\end{array}$ & $\begin{array}{l}.189(.037)^{*} \\
.159(.030)^{\circ} \\
.162(.036)^{* *} \\
.084(.037)^{*} \\
.061(.036)\end{array}$ \\
\hline $\begin{array}{l}\text { Writing short documents with correct } \\
\text { spelling and grammar }\end{array}$ & $\begin{array}{l}\text { 1. Very high } \\
\text { 2. High } \\
\text { 3. Intermediate } \\
\text { 4. Low } \\
\text { 5. Very low }\end{array}$ & $\begin{array}{l}.162(.030)^{\circ} \\
.154(.030)^{\circ} \\
.092(.042)^{\circ} \\
.051(.054) \\
.060(.056)\end{array}$ \\
\hline
\end{tabular}

Note: The data is taken from the Skills Sumey of the Employed British Workforce." = significant at the 5 percent level; ${ }^{\text {** }}=$ significant at the 1 percent level. The second column only reports the coefficients for the five specific skills of estimating equation (4.1) with the log of the gross hourly wage as the dependent wariable. All regressions are performed by OLS and are similar to the regression in Table 4.5, column [4] and include the same variables. Standard errors are reported in parentheses. The adjusted $R^{2}$ 's of the regressions are 386 , $.384, .383 .389$, and .387 , respectively.

\subsection{Determinants of Computer Use}

The model developed in the previous chapter suggests that computer use might be related to (i) wages, (ii) the tasks involved in a job, and (iii) the skills workers possess. In this section the determinants of computer use are empirically addressed. The model provides the possibility to compare empirically the effect of skills and wages on computer use. If one assumes the error term $(\varepsilon)$ to be logistically distributed and to include linear effects for skills $(S)$ and tasks $(T)$ and other controls $(X)$, the model can be rewritten as: 


$$
P(\text { computer })=P\left(\alpha+\beta \ln (w)+S \gamma_{S}+T \gamma_{T}+X \gamma_{X}>0\right)
$$

$$
=\frac{1}{1+e^{-\left(\alpha+\beta \ln (w)+S \gamma_{S}+T \gamma_{\left.T^{+}+X \gamma_{X}\right)}\right.}} \text {. }
$$

Here, $X$ includes personal characteristics such as age, age square, gender and marital status. The main problem of estimating equation (4.2) is that wages and skills will be highly correlated, while it is likely that there is a measurement error in the wages and part of a worker's skills might not be observed directly, but reflected in the wages. Furthermore, there might be endogeneity of computer use influencing wages. If a substantial part of the skills is unobserved, part of the effect of skills on computer use will be absorbed by wages in the regression. This causes an upward bias in the parameter for the wage effect and a downward bias in the skill parameters. If the main problem is the measurement error in wages, the wage parameter will be downward biased while the skill parameters absorb this effect. To estimate equation (4.2), instrumental variables for the wages are therefore used.

Since it is plausible to assume that variables related to unionization influence wages but do not directly interfere with skills and computer use, several variables related to the unionization of the job involved are used as instruments for wages to investigate the determinants of the probability of using computer equipment at work. In Britain, about 50 percent of the workers are covered by a union, the coverage being fairly equally spread over occupations and sectors, and union coverage having a substantial effect on wages. ${ }^{14}$ For these three reasons, the instruments provide an opportunity to investigate the direct link between wages and computer use from a statistical point of view. In the next section the choice of the instrument is discussed in depth from an economic and econometric point of view.

To instrument the wage, a linear equation explaining $\ln w$ with the same $X, S$ and $T$ vectors plus these union variables is added to this model and $\ln w$ is replaced by its predicted value in equation (4.2):

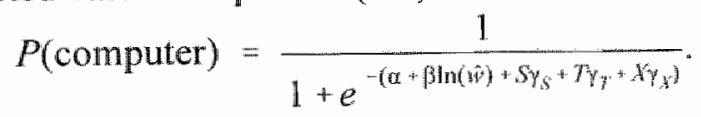

where

$$
\ln (\hat{w})=\alpha_{w}+S \delta_{S}+T \delta_{T}
$$

with $\ln (w)-\ln (\hat{w}) \sim N\left(0, \sigma^{2}\right)$. These equations are estimated simultaneously by maximum likelihood.

Due to the non-linearity of equation (4.3), inclusion of the predicted wage

14 See also Appendix 4.1 for more details on unionization of the variables included in the regression analysis. 
to proxy for the wage leads to some bias in the estimation. Angrist (1991) therefore prefers a simple linear regression. Especially if most cases in the logistic regression do not have very high or low probabilities, such a linear function might be a good approximation of the logistic curve avoiding these inconsistencies connected to IV-estimation. However, since in the estimations for computer use a relatively large number of people with low and high wages do have extreme probabilities of computer use, this linear model leads to a bias in the results. To estimate equation (4.3) it therefore seems more appropriate to use the logistic model. ${ }^{15}$

\subsubsection{Unionization as an Instrument for Wages}

The data include a number of questions on unionization, from which the following possible instruments are selected: (i) "at your place of work, are there unions, staff associations or groups of unions?"; (ii) "are you a member of a (if the answer on question (i) is no, any other) trade union or staff association?"; (iii) the cross-dummy for workers answering yes to both question (i) and question (ii); (iv) "are any of them recognized by management for negotiating pay and/or conditions of employment?"; and (v) "is it possible for someone in your job to join one of these unions or staff associations?". Appendix 4.1 provides details about these unionization variables and the distribution among several variables used in the analysis.

For the instrument to be adequate, unionization variables should not influence computer use directly, while additionally the unionization variables should not proxy for unobserved skills. Some studies have investigated whether unions directly influence the investment decisions of firms. Some of these studies argue that unions oppose to the introduction and adoption of new technologies and therefore reduce the firm's investments. ${ }^{16}$ For example, Fallick and Hassett (1999) estimate the impact of unionization on firms' investment behaviour. For the period 1962-1984 they use firm-level data taken from

\footnotetext{
is Inclusion of the residual of the wage equation as a variable in the logistic equation, as a check for possible problems related to this non-linearity, does not change the results substantially.
}

16 A large number of studies on the relationship between unionization and the firm"s investment behaviour and decisions focus on the fact that, on average, unionized firms seem to invest less in research and development than non-unionized firms (e.g., Connoly, Hirsch and Hirschey, 1986 and Hirsch and Link, 1987). Such findings are not necessarily inconsistent with the use of unionization variables as instruments for the wage, because research and development does most likely not directly influence the adoption of computerized equipment at the workplace of the typical worker. Moreover, research and development is an input into the process of innovation of the firm, which seems unlikely to affect the decision to adopt a computer by the ordinary manager, secretary or clerk. 
Compustat's Full Coverage file for a sample of firms restricted to those employing between 200 and 750 workers and another sample of firms with at least 750 workers. The firms are involved in union elections during the sample period. They report estimates both for the effects of firms experiencing a winning union election in a given year and for the fraction of a firm's workforce involved in a winning election on the ratio of investment to the existing capital stock. An estimate of several models indicates that a successful certification election decreases the investment to capital ratio by .04 in the following year. However, estimates for the subsequent years $(t+2 \ldots t+n)$ do not yield significant results of unionization on investment decisions, so the question of whether investment is permanently depressed or whether the firms' investment decisions are permanently lower by the advent of a union cannot be answered and does not seem to be likely given the evidence presented. A paper by Denny and Nickell (1992) investigates the impact of unions on investment in the British manufacturing sector to study whether unions influence investments because of the upward pressure they exert on wages. Providing a framework and estimating this framework using data from the 1980 and 1984 Workplace Industrial Relations Survey (WIRS) and controlling for wages, they report evidence that unions might reduce investment. However, the overall effects of unionization on investments do not appear to yield strong correlations about this effect within reasonable margins. A study by Machin and Wadhwani (1991), using the same data from the WIRS, shows no significant effect of unionization on investment or on the adoption of new technologies. Consistent with the estimation model, however, they do find a positive correlation between unionization and investment, which is attributed to the fact that unionized firms pay significantly higher wages. Taymaz (1991) demonstrates that the extent of unionism has no impact on the diffusion of numerically controlled machine tools in the U.S. engineering industries in the period 1979-183, but he does not take into account the wages these firms pay. Finally, Lintner, Pokorny, Woods and Blinkhorn (1987) present evidence related to the influence of unions on the adoption of Computer Aided Design and Manufacturing equipment (CADCAM) in the U.K. mechanical engineering industry in the early $1980 \mathrm{~s}$. They report findings that unions did not exert any significant influence on the adoption of all forms of technology included in CADCAM, but they too did not explicitly consider the wages unionized firms pay in their regression analyses. My reading of these results from the literature is that although unionization exerts an upward pressure on wages, there does not seem to be a direct link between a firm's investment decisions and unionization. For the purpose of our study, the findings of Machin and Wadhwani (1991) and Denny and Nickell (1992) provide the strongest case in favour of unionization variables as instruments for wages because they explicitly consider wages as an explanatory variable in the decision of firms to adopt new technologies and report no direct impact of unionization on investment. In addition, they use U.K. data, as in this study. 
Secondly, for an adequate analysis, the instruments need to be uncorrelated with unobserved skill components. Unionized firms might be inclined to hire more-skilled workers, because they are forced to pay higher wages. This would suggest that unionization affects computer use not only through wages but potentially through any computer-skill linkage. However, considering different skill classes, Card (1996) and Lemieux (1998) report true union effects for the United States and Canada, suggesting that unionization is at least for some significant part independent of the skill level of workers. Using data from the Current Population Survey for 1973-1974 and 1993, Card (2001) reports estimates that there might be some selection effects, besides the true union effects, because union workers with lower observed skills are positively selected while those with higher observed skills are negatively selected. However, these estimates yield only some moderate effects. Investigating the British data used here, no significant evidence is found arguing that union membership or union coverage is typically higher for workers with a higher level of education, more years of experience or a higher age, which could all be defined as a proxy for skill.

A third argument would be that unionization may also proxy for other aspects of firms that are more likely to adopt computers. Industry would be a likely candidate. However, the regressions control for this by including industry dummies in the regression equations. In the regression analysis below, it will be shown that the results are similar when including industry dummies (comparison of the estimates in Table 4.9 with the ones in Table 4.10 , column 1, shows this to be the case).

\subsubsection{The Number and Quality of the Instruments}

An important issue in IV-estimation is choosing the number and quality of the instruments to use in the regression analysis. Recently, Donald and Newey (2001) presented a selection criterion to choose the number of instruments from different sets and combinations of instruments, by minimizing approximate mean-squared errors (MSE). It is shown that this method can substantially improve the finite sample properties of IV-estimators. As the preliminary IV-estimator, a basic model with union coverage as the only single instrument (instrument (i)) is estimated and Mallows's goodness-of-fit criterion is used to evaluate its performance.

Since five possible instruments for the wage are available, all of which are related to unionization, the most obvious sets are chosen first. Obvious sets of instruments will contain either variable (i) union coverage and/or (ii) union membership, possibly combined with (iii) the cross dummy of coverage and membership. The set can be further extended with additional information from question (iv) "Are any of them recognized by management for negotiating pay 
and/or conditions of employment?" and (v) "Is it possible for someone in your job to join one of these unions or staff associations?". The results reported in Table 4.8 suggest that union coverage and the cross effect of coverage and membership lead to the lowest MSE and therefore to the most efficient instruments to use in the regression analysis. Hence, in the remainder of the analysis these variables are used to instrument the wage. ${ }^{17}$

\section{Table 4.8}

Donald-Newey-test to Determine the Optimal Number of Instruments

\begin{tabular}{|c|c|}
\hline Instruments Used & Approximate MSE \\
\hline (ii) & 3073.27 \\
\hline (ii) & 3087.88 \\
\hline (i), (ii) & 3067.77 \\
\hline (i), (iii) & 3065.84 \\
\hline (ii), (iii) & 3074.56 \\
\hline (i), (ii), (iii) & 3068.59 \\
\hline (i), (ii), (iii), (iv) & 3071.26 \\
\hline (i), (ii), (iii), (iv), (v) & 3074.02 \\
\hline
\end{tabular}

Note: The data are taken from the Skills Survey of the Employed British Workforce. (i) "at your place of work, are there unions, staff associations or groups of unions?"; (ii) "are you a member of a (if the answer on question (i) is no, any other) trade union or staff association?"; (iii) the cross-dummy of answering yes to both (i) and (ii); (iv) "are any of them recognized by management for negotiating pay and/or conditions of employment?"; and (v) "is it possible for someone in your job to join one of these unions or staff associations?"

A F-test for the joint contribution to the wage equation of the set of instruments equals $29.41\left(F_{2203,05}^{2}=3.00\right)$ in the basic equation and 18.90 $\left(F_{2160005}^{2}=3,00\right)$ in the most extended version. Following the criterion of Staiger and Stock (1997) that this F-value should be larger than 10, this suggests that the instruments are strong enough to avoid serious problems in our IVregressions. ${ }^{I B}$

The use of the second- and third-best set of instruments - i.e. the combination of (i) union coverage and (ii) union membership and (i) union coverage, (ii) union membership and (iii) its cross effect - gives qualitatively similar regression results.

Also the other sets of instruments satisfy the requirements. 


\subsubsection{Estimation Results}

\subsubsection{Basic Estimates}

Table 4.9 reports the basic estimation results. The first column shows the results from a maximum likelihood estimation of equation (4.2) in which the wage is not instrumented. This equation includes a number of standard labour market variables and the log of the gross hourly wages. The results suggest that particularly the wage and the highest levels of education exert a positive impact on the probability of using a computer at work but that age does not affect computer use. ${ }^{19}$ In addition, female workers have a higher probability to work with a computer. Because the wage variable potentially suffers from measurement error, the inclusion of unobserved skills in the wage variable and endogeneity, one has to be careful in interpreting the coefficients of this estimation. The two union variables selected above are therefore used to instrument the wage. In column [2] of Table 4.9, the results of the IV-estimation are reported. The top panel shows the estimates from the first stage and the bottom panel shows the estimates from the second. The top panel shows the usual effects of the labour market variables on wages: the higher the level of education the higher the wage; age has a positive but diminishing effect on wages; women earn less and married workers more. The results of the logit equation are reported in the bottom panel of Table 4.9. The IV-estimates suggest that wages still exert a substantial, significant and positive influence on the likelihood of using a computer at work but that the education variables and age do not seem to significantly impact the probability to use a computer at work. The likelihood ratio test reported at the bottom of the table shows that neither the education nor the age variables have a joint significant impact on computer use. The size of the wage coefficient implies that if a worker's wage is increased by 1 percent, the probability of him using a computer at work increases by about .613 percent. Although not significant, the influence of education on the probability of using a computer is still present in the point estimates. Comparison of a worker without an educational degree (the reference group) to a worker with a university degree, demonstrates that the probability to use a computer increases by 28.2 percent. $^{20}$

${ }^{19}$ Age is used here as a proxy for experience.

${ }^{20}$ For workers with a professional degree, the probability to use a computer at work relative to a worker without a degree is 15.0 percent higher, for a worker with a NVQ3 degree this probability is 11.3 percent higher, for a worker with a NVQ2 degree it is 9.8 percent higher, and for a worker with a NVQ1 degree the likelihood of using a computer at work relative to a worker without a degree is 6.6 percent higher. Note, however, that these are marginal effects from the point estimates which turned out to be insignificant. 
Table 4.9

Logistic Regression of the Determinants of Computer Use without Instruments and with Unionization Variables as Instruments for Wages

(dependent variable: likelihood of computer use)

\begin{tabular}{|c|c|c|c|c|}
\hline & \multicolumn{2}{|c|}{ Without Instruments } & \multicolumn{2}{|c|}{ With instruments } \\
\hline & $\begin{array}{c}\text { Beta } \\
\text { (Standard Error) }\end{array}$ & $\begin{array}{l}\text { Marginal } \\
\text { Effect }\end{array}$ & $\begin{array}{c}\text { Beta } \\
\text { (Standard Error) }\end{array}$ & $\begin{array}{c}\text { Marginal } \\
\text { Effect }\end{array}$ \\
\hline \multicolumn{5}{|l|}{ Instrumental Equation } \\
\hline Union Coverage & & & $.174(.027)^{6.4}$ & \\
\hline Union Coverage \& Membership & & & $-.059(.028)^{*}$ & \\
\hline University Degree & & & $.722(.044)^{*}$ & \\
\hline Professional Degree & & & $.564(.041)^{*}$ & \\
\hline NVQ3 Degree & & & $.330(.043)^{\circ}$ & \\
\hline MVQ2 Degree & & & $.275(.038)^{. * 4}$ & \\
\hline NVQ1 Degree & & & $.119(.055)^{*}$ & \\
\hline Age & & & $.067(.008)^{* * *}$ & \\
\hline Age Squared & & & $-.078(.010)^{* 0}$ & \\
\hline Female & & & $-.203(.042)^{. *}$ & \\
\hline Married & & & $.069(.033)^{*}$ & \\
\hline Female $\times$ Married & & & $-.094(.050)$ & \\
\hline Constant & & & $.171(.164)$ & \\
\hline \multicolumn{5}{|l|}{ Logit Equation } \\
\hline Ln Gross Hourly Wage & $1.634(.091)^{* 4}$ & .349 & $2.871(.887)^{4 *}$ & .613 \\
\hline University & $2.562(.354)^{\circ *}$ & .547 & $1.322(.774)$ & .282 \\
\hline Professional Degree & $1.682(.221)^{* *}$ & .359 & $.704(.589)$ & .150 \\
\hline $\mathrm{NVQ}^{3}$ & $1.107(.175)^{* *}$ & .236 & $.529(.402)$ & .113 \\
\hline NVQ2 & $.935(.142)^{0 *}$ & .200 & $.457(.326)$ & .098 \\
\hline NYQI & $.512(.196)^{6.4}$ & .109 & $.309(.306)$ & .066 \\
\hline Age & $.025(.037)$ & .005 & $-.088(.080)$ & -.019 \\
\hline Age Squared & $-.038(.046)$ & -.008 & $.093(.095)$ & .020 \\
\hline Female & $.816(.193)^{\circ .6}$ & .174 & $1.047(.310)^{6.4}$ & .224 \\
\hline Married & $.127(.162)$ & .027 & $.017(.213)$ & .004 \\
\hline Female $\times$ Married & $-.468(.229)^{\circ}$ & -.100 & $-.327(.316)$ & -.070 \\
\hline Constant & $-3.579(.715)^{18}$ & & $-3.215(.948)^{*}$ & \\
\hline s.e. & & & $.475(.003)^{*}$ & \\
\hline Log Likelihood & -1107.57 & & -648.87 & \\
\hline $\begin{array}{l}\text { LL Model without Education } \\
2 \text { LLR }\end{array}$ & $\begin{array}{l}-1168.53 \\
121.92^{* 4}\end{array}$ & & $\begin{array}{c}-650.66 \\
3.58\end{array}$ & \\
\hline $\begin{array}{l}\text { LL model Without Age } \\
2 \mathrm{LLR}\end{array}$ & $\begin{array}{l}-1108.34 \\
1.54 \\
\end{array}$ & & $\begin{array}{c}-650.99 \\
4.24 \\
\end{array}$ & \\
\hline
\end{tabular}

Note: The data are taken from the Skills Survey of the Employed British Workforce: = significant at 5 percent level;" = significant at 1 percent level. Standard errors in parentheses. 
In addition, older and more-experienced workers do not seem to have a significantly lower probability of using a computer at work, although the point estimate is negative. This result is consistent with the findings of Friedberg (2001) and Weinberg (2001) for the United States, who find that computer use is surprisingly flat over a worker's life cycle. ${ }^{21}$ Finally, female workers have a notably higher probability of using a computer at work than their male colleagues (22.4 percent). This finding is consistent with the observation of Weinberg (2000) for the United States, who argues that computers take away some of the (physical) disadvantages women have in a non-computerized labour market.

Finally, note that the coefficient of the wage has increased in the IVestimates compared to the non-instrumented regression. This suggests that wages have been measured less accurately than educational levels. The upward effect of measurement error seems to be larger than the possible downward effect of unobserved skills.

\subsubsection{Further Estimates}

The basic estimation resullts reported in Table 4.9 can be extended by including industry dummies, which might be important because computer use could differ between industries. ${ }^{22}$ The reason for different computer use between industries might be attributed to applications which can be used effectively in one industry but not in the other or the fact that, in some sectors, the composition of the workforce is different in terms of educational levels or other characteristics influencing the estimates. In terms of the model, one might argue that, in some industries, tasks are subject to computerization because of the availability of a certain application, while in other industries this application is useless. Appendix 4.1 indeed shows that computerization is quite different between industries, ranging from 37.8 percent computer use in agriculture, forestry and fishing to 82.4 percent in transport and communications. Second, some industries could pay higher wages than others, which could be related to union coverage. Hence, including industry dummies into the regression equation leads to additional insights into the determinants of computer use.

The first column of Table 4.10 reports the results from the logit equation of the IV-estimation including 8 industry dummies. It can be observed that the coefficient on the wage variable has slightly increased, whereas the influence of

21 This result is also in line with the findings of Allen (2001), for the use of technology in general, who argues that more-experienced workers do not particularly suffer from technology adoption.

${ }^{22}$ For technical reasons, the inclusion of industry dummies might also be important because the unionization instruments might be sensitive to industry effects. 
educational levels on computer use has decreased. ${ }^{23}$ My interpretation of these coefficients is that wages seem to be a strong determinant of computer use, while skills (measured by educational levels) do not seem to contribute directly and significantly to the probability of using a computer at work. ${ }^{24}$

One might also argue that different occupations include different tasks, which are likely to effect the probability of using a computer. When occupational dummies are included into the regression, the results look similar to the ones presented in column [1] of Table 4.10, thereby once again reinforcing the significant impact of the wage level on the likelihood of computer use.

The data enable us to explicitly analyse the importance of 35 tasks at work. ${ }^{25}$ As a first step, only the tasks reported as being "essential" or "wery important" by the respondents are included into the regression anallysis; these tasks are regarded as important to carry out the job. The results of this regression are reported in column [2] of Table 4.10. This column shows that most tasks do not exert a positive impact on the probability of computer use. A number of tasks increase the probability to use a computer, i.e., counselling, advising, or caring for customers or clients, knowledge of the organization of the workplace, writing long documents, and especially adding, subtracting, multiplying, or dividing numbers, and calculating using more advanced mathematical or statistical procedures. The first two tasks are related to jobs of senior staff members and not so much to computerized tasks, while the latter three are probably directly linked to routine tasks in which the computer can be used to improve efficiency. These results suggest that a worker is more likely to use a computer if certain tasks are important to carry out the job, such as writing, calculating and math, and if a computer application leads to a more efficient performance of these tasks.

An assumption of the model in the previous chapter is that computers are typically used to perform routine tasks, which are probably not essential to carry out the job. To test the consistency of this assumption, one might argue that if a certain task is a routine job activity, it is not very important for carrying out the job. Column [3] of Table 4.10 reports estimates including tasks that are labelled "not very important" or higher, but excludes the tasks that are "not at all important". Consistent with the model, the estimates show again that the wage is an important determinant of computer use. In addition, a number of tasks also

${ }^{2} 3$ Appendix 4.1 lists the industries. Agriculture, forestry, fishing, energy and water supply are used as the reference group.

${ }_{24}^{24}$ The first-stage results are not reported in Table 4.10 because they do not yield additional insight. The F-test criterion of Staiger and Stock (1997) is easily passed for all three regressions reported in Table 4.10 .

25 Appendix 4.2 provides an overwiew of these 35 tasks. 
seem to increase the probability of obtaining a computer, in particular listening carefully to colleagues, knowledge of the organization of the workplace, reading written information such as forms, notices, or signs, adding, subtracting, multiplying, or dividing numbers, and calculating using more advanced mathematical or statistical procedures. In addition, if physical stamina is part of the job, the likelihood of computer use is significantly lower. It is also interesting to note that the estimation based on all tasks, both relatively important and unimportant (column [3]), explains computer use much better than the estimation based on important tasks (column [2]). This suggests that, in general, computers are not used for the core tasks of the job, but rather that secondary tasks make the adoption of the equipment worthwhile. ${ }^{26}$ This observation is consistent with the assumption that computer use generally depends on routine tasks - rather than on skilled tasks - which are likely to be of secondary importance to skilled workers. Hence, the upgrading of skill requirements is not likely to be due to the increasing importance of skills used to perform the computerized job activities but more likely to be due to a reemphasis on the non-computerized and skilled tasks. ${ }^{27}$

Again, in both specifications including the tasks, the variables related to education and age are not significant. In the specification including all tasks that are at least "not very important", the likelihood ratio tests show that not only the educational dummies together, but also the age variables together do not significantly improve the fit of the model. Particularly, level of education and age are often used as the main determinants of the skill measure. These results suggest that productivity advantages in using a computer because of a worker"s skills do not seem to be major explanations of the pattern of computer use. The latter result is also of interest to determine the channel of skill upgrading; it suggests that the employer does not increase its demand for more-skilled labour because skilled workers gain more time than unskilled workers upon the adoption of the computer, but that it is more likely that the weight attached to both tasks changes towards the performance of the more-skilled job activities. ${ }^{28}$

\footnotetext{
26 For a number of tasks almost every respondent answered that these aspects were at least "not very important". This led to numerical problems in the maximum likelihood estimation. For this reason, tasks which were reported by at least 95 percent of the workers to be part of their job have been excluded from the estimation reported in column [3].
}

${ }^{27}$ This result is consistent with the findings of Levy and Murnane (1996) and Autor, Levy and Murnane (2001).

28 Similar to the results reported in Table 4.9 , the point estimates and marginal effects of education are substantial but not significant. Relative to a worker without a degree, a worker with some sort of degree has a larger probability to use a computer at work. 


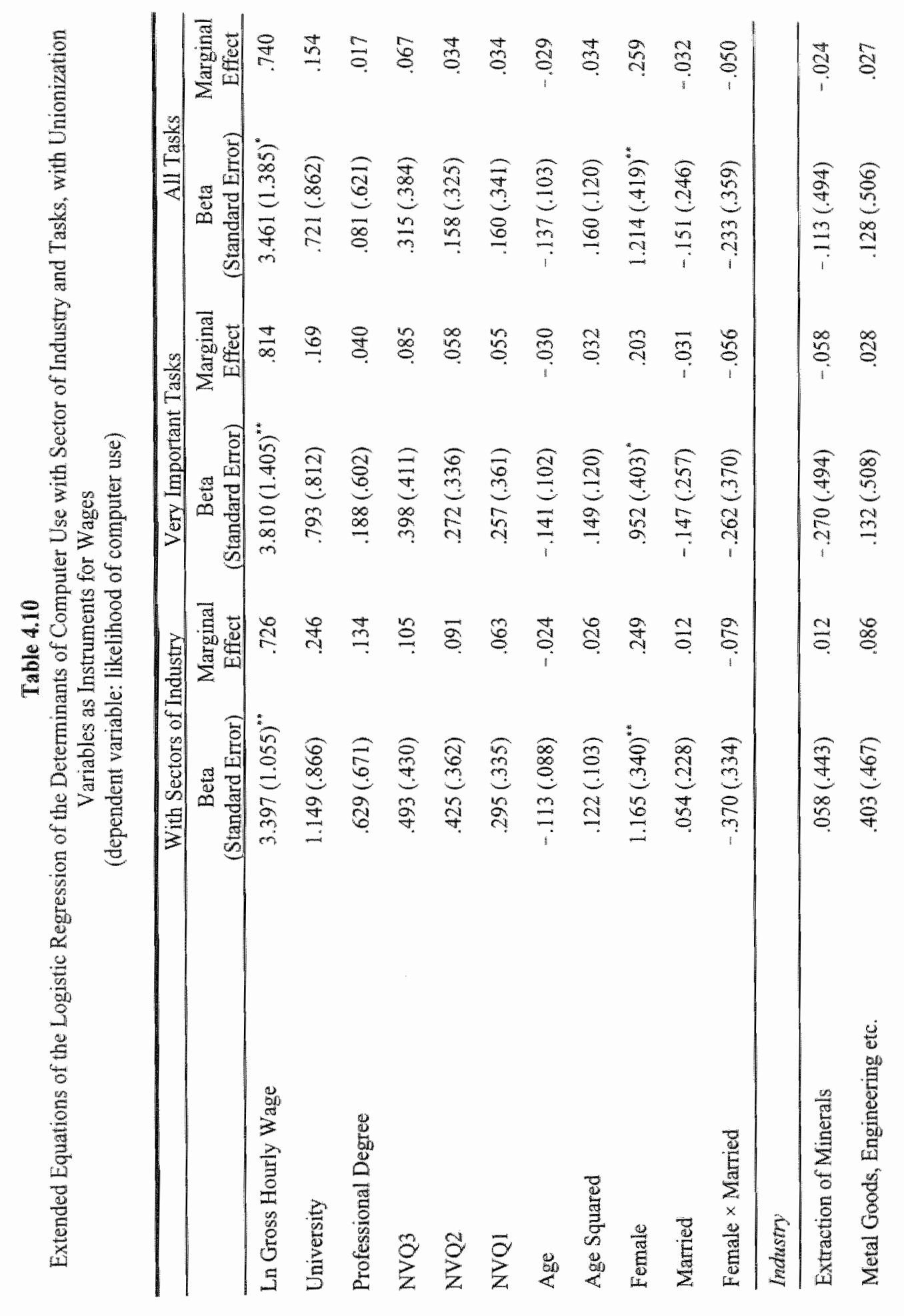




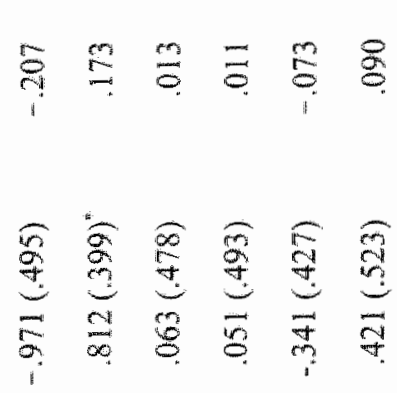

ะ

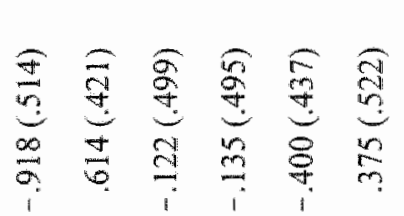

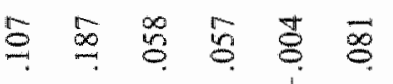

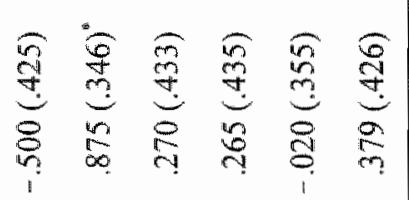

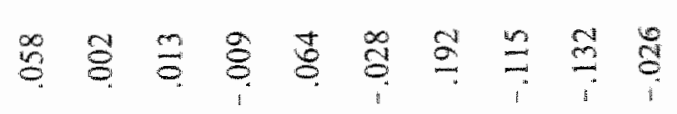

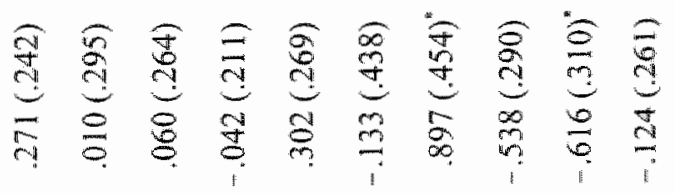

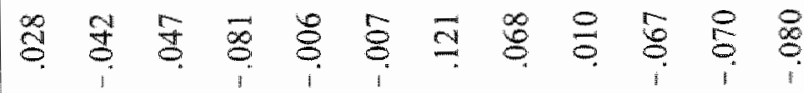

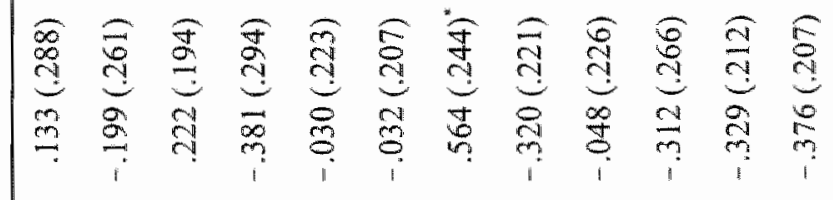

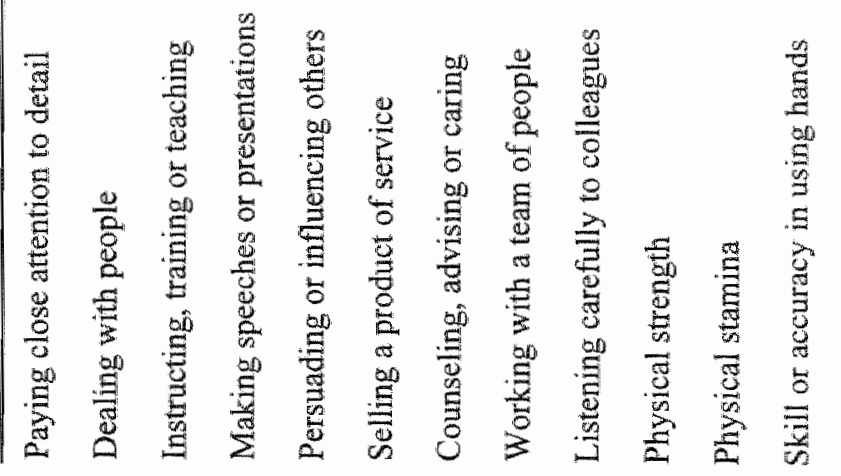




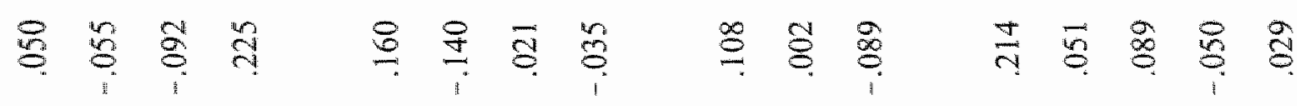

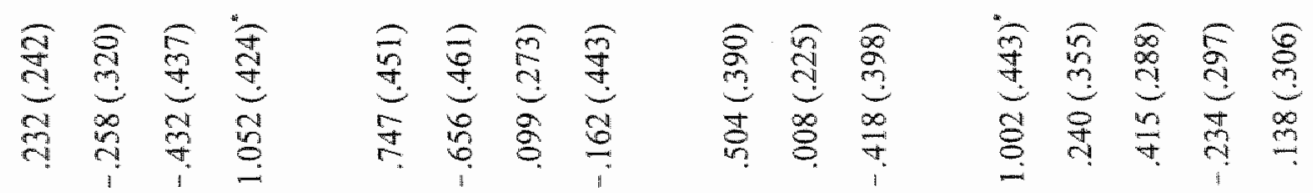

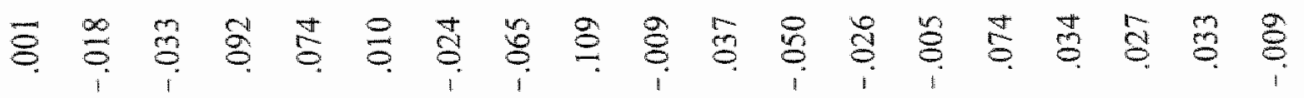

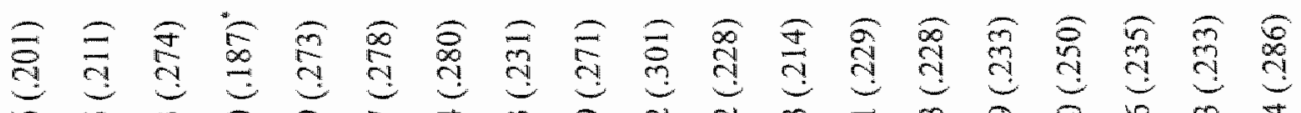

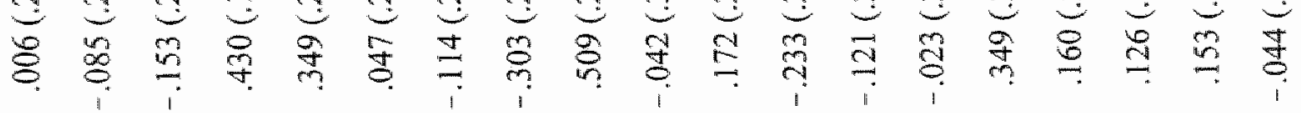

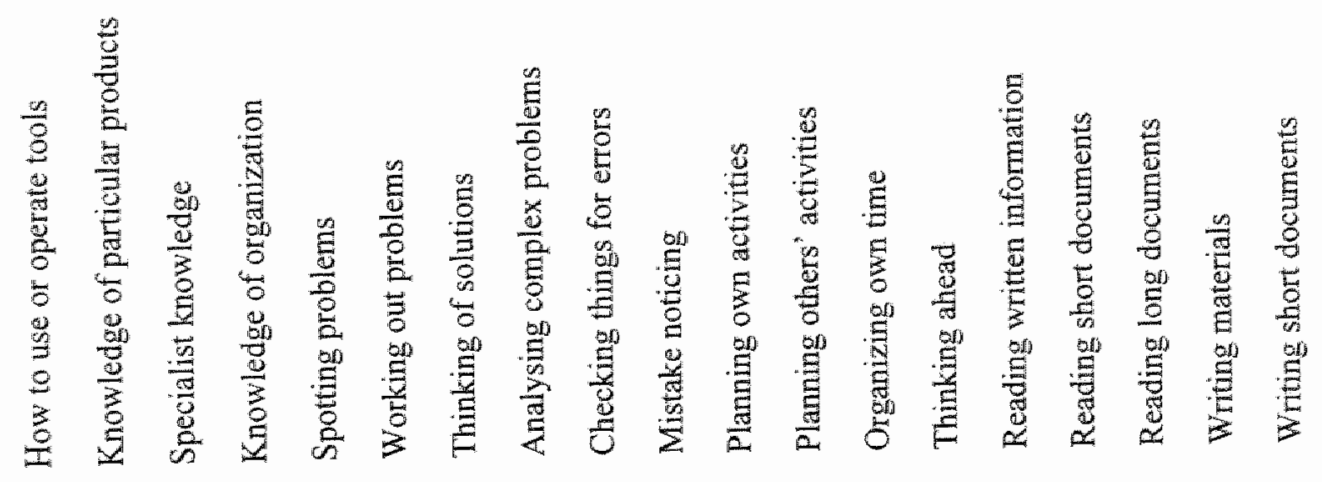




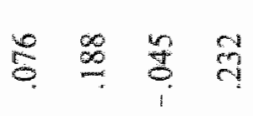

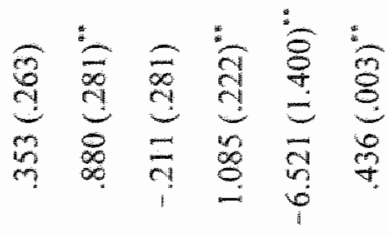

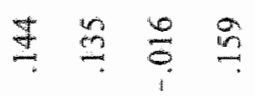

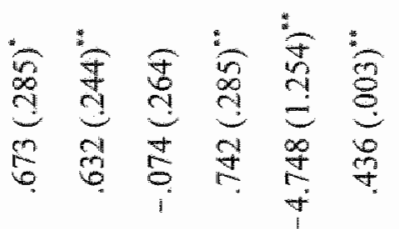

$$
\begin{aligned}
& \stackrel{4}{8}
\end{aligned}
$$

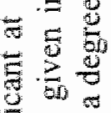

$$
\begin{aligned}
& \text { E. }
\end{aligned}
$$

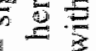

$$
\begin{aligned}
& \text { * } 7
\end{aligned}
$$

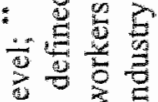

$$
\begin{aligned}
& \text { 苛要 } 8 \\
& \text { 部密 }
\end{aligned}
$$

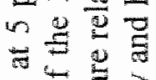

$$
\begin{aligned}
& \text { 岸 } \\
& \text { 的 } \frac{5}{8} \\
& \text { 诃 } \\
& \text { की } \\
& \text { II } \\
& \text { 额总 }
\end{aligned}
$$

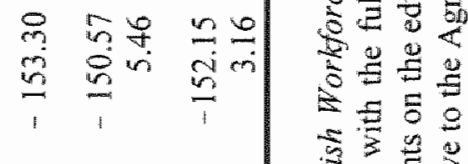

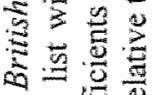

$$
\begin{aligned}
& \text { 电 } \\
& \text { 要 } \\
& \text { 害 } \\
& \text { 密的形 } \\
& \text { S. }
\end{aligned}
$$

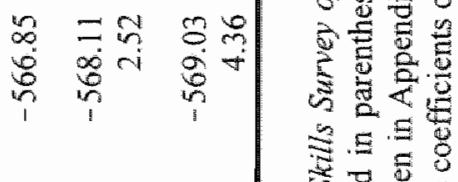

$$
\begin{aligned}
& \text { 蛋离品 } \\
& \text { 은. }
\end{aligned}
$$

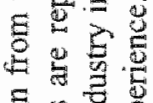

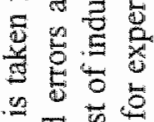

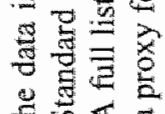

$$
\begin{aligned}
& \text { 焉到品 }
\end{aligned}
$$

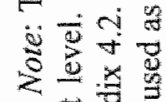

$$
\begin{aligned}
& \text { 惹离 } \\
& \text { 龸兽 } \\
& \text { 尊是要 }
\end{aligned}
$$




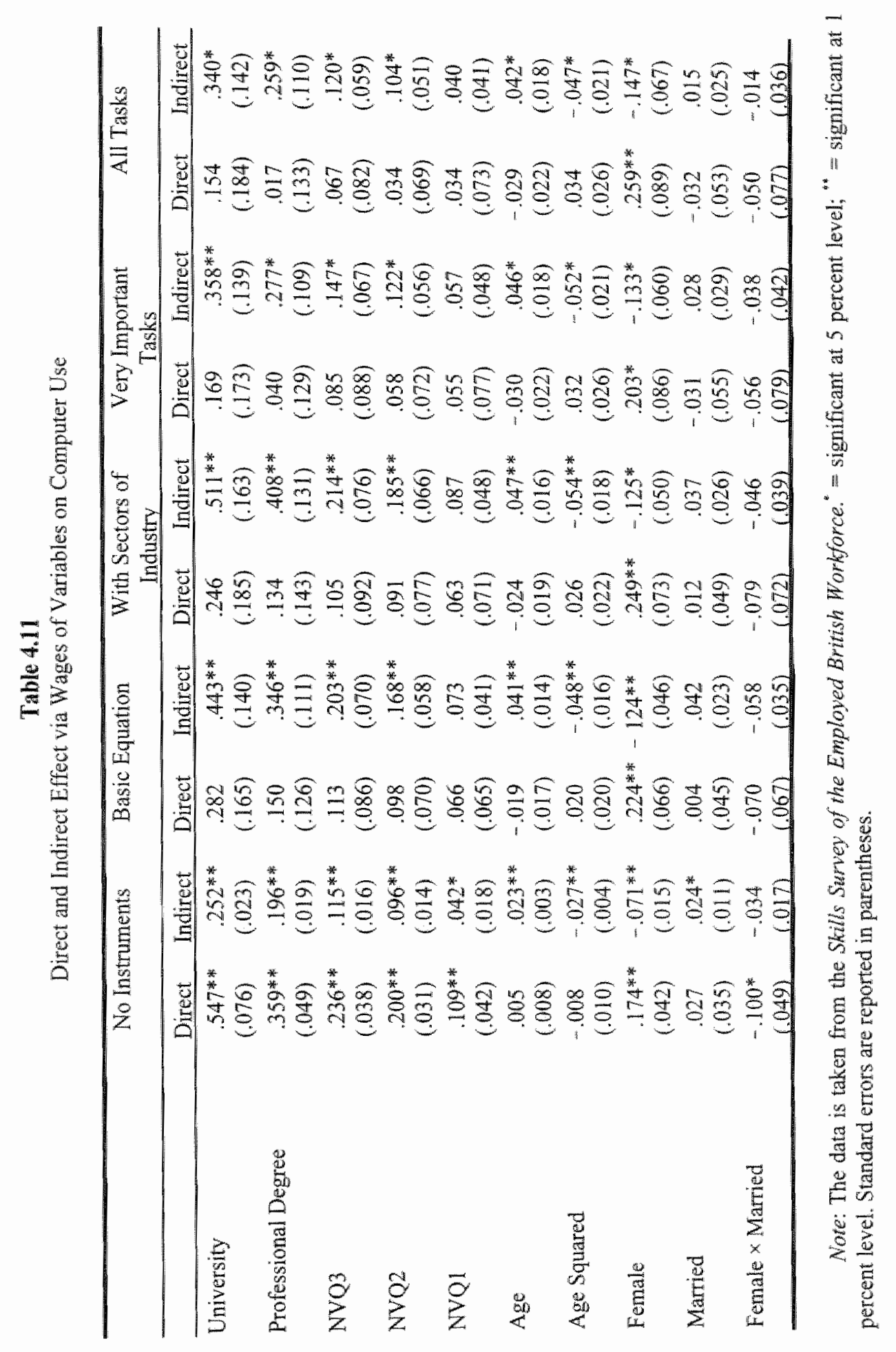




\subsubsection{Direct and Indirect Impact on Wages}

The estimation results suggest that the effect of wages on computer use, are of greater importance than the effect of skills, measured by the qualifications of the respondents and most tasks, measured by the importance of certain job activities. To compare the effects of wages and skills, Table 4.11 provides the direct and indirect marginal effects of different educational levels. The direct effect equals the marginal effect of each educational dummy in the logistic regressions reported in Tables 4.9 and 4.10. The indirect effect of education on the likelihood of computer use is estimated in the wage regression multiplied with the marginal effect of wages on computer use.

According to the estimates without instruments, all educational levels have a significant direct and indirect effect on computer use. The direct effect is approximately twice as high as the indirect effect via the wages. Once the wage is instrumented, only the indirect effects of education on computer use turn out to be significant. This indirect wage effect is approximately twice as large as the direct effect for most educational levels. This suggests that differences in computer use among skilled workers have to be explained by the fact that these workers earn higher wages rather than by an direct impact of their skills on computer use. Also, age and age squared have no significant direct impact on computer use. The age profile of computer use can be explained by the relationship between age and wages. Only for women is there a significant direct effect on the likelihood of computer use, which is partly set off by a negative indirect effect since women's wages are generally lower than men"s wages.

\subsection{Further Analysis}

The analysis has put forward two explanations for computer use at work, which are not related to skills, but which is likely to contribute to an explanation of the age structure of computer use. These explanations for the use of computers are the wage (wages are typically first increasing with age and then decreasing) and particular tasks (older workers are often located in other parts of the firm than younger workers). By means of a more detailed graphical analysis the impact of these variables is examined for age and computer use profile.

\subsubsection{The Relationship Between Wages and Computer Use}

Figure 4.1 provides both the age profile of the (mean log gross hourly) wage and computer use. The figure illustrates that wages follow a similar 
inverted u-shaped pattern as computer use does. The dip in both curves at the age of 30-35 is likely to be due to the relative high participation of women in this age group. This additional group of women earns a relatively low wage and although women generally have a higher probability of computer use, this relatively low wage is likely to cause te more limited use of computers. The figure also suggests that, compared to the wage curve, computer use among young workers is relatively high and computer use among older workers is relatively low.

The framework of computer use developed in Chapter 3 suggests that the fraction of workers above a certain "threshold" wage - rather than the mean wages - explains actual computer use. To gain insight into this prediction, Figure 4.2 depicts fractions of workers above a certain threshold as a function of age. The graph shows lines with $\log$ threshold wages at $4.0,4.5,5.0,5.5$ and 6.0. The results from this exercise reveal that from this point of view the relationship between wages and computer use becomes more pronounced, supporting the arguments in favour of wage costs determining computer use.

Due to heterogeneity in other job characteristics and due to the effect of gender on computer use, the threshold wage is likely to vary for different workers. Figure 4.3 therefore provides a reconstruction of the predicted computer use per age group, assuming that computer use in each wage category is constant for both sexes. This means that the probability of computer use for each worker in the sample has been set equal to the fraction of computer use in the wage and gender category of each individual worker. Although some underestimation of computer use among younger workers and overestimation among older workers remains apparent, the lines in Figure 4.3 show that wages and gender explain the bulk of the pattern of computer use.

In addition, if indeed computer use increases wages, the low average wages of older workers could also be a result of their low adoption rate. Figure 4.4 presents the average wages of both computer users and non-users. The graph reveals that the argument that computer use leads to higher wages is not very likely to hold, since both the wages of users and non-users have an inverted ushaped form. The decreasing wage of older workers is therefore not likely to be the result of a shift between both groups.

\subsubsection{The Relationship between Tasks and Computer Use}

A second explanation for computer use that has become apparent from the framework and the estimation results reported in Table 4.8 is the performance of particular tasks at work. To show the impact of different tasks on the age profile of computer use, Figure 4.5 presents the prediction of the regression reported in column [3] of Table 4.10, in which all aspects except the tasks are kept constant. The figure shows that the different tasks workers have 
to fulfill contribute to the explanation of the relationship between age and computer use. Based on tasks only both the computer use of younger and older workers would be over-predicted to some extent, however.

\section{Figure 4.1}

Average Wages and Computer Use in Britain by Age

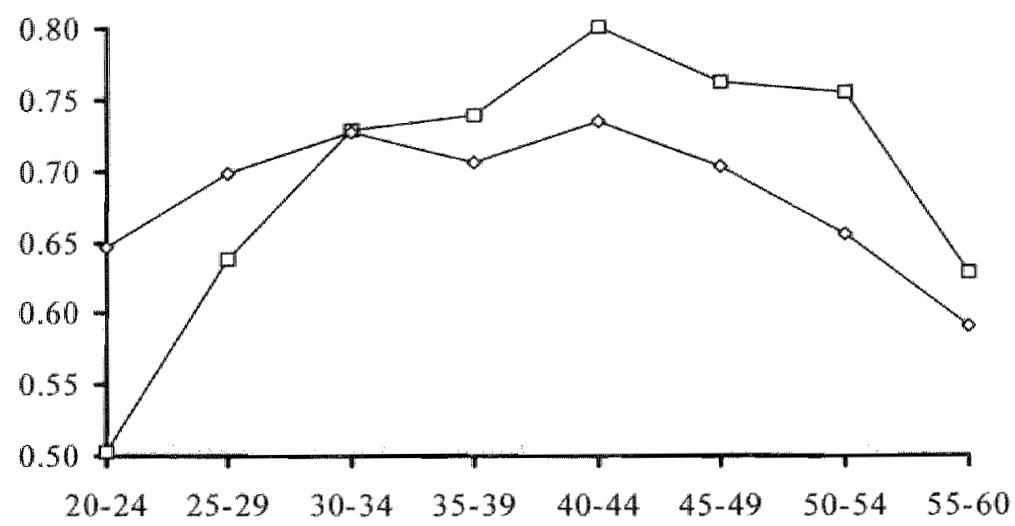

Note: The data is taken from the Skills Survey of the Employed British Workforce. The $\square$ line represents wages, which are the average log gross hourly wages (divided by 10 ). The 0 line represents the fraction of workers using a computer at work.

\section{Figure 4.2}

Percentage of Workers with Wages above Certain Thresholds and Computer Use in Britain

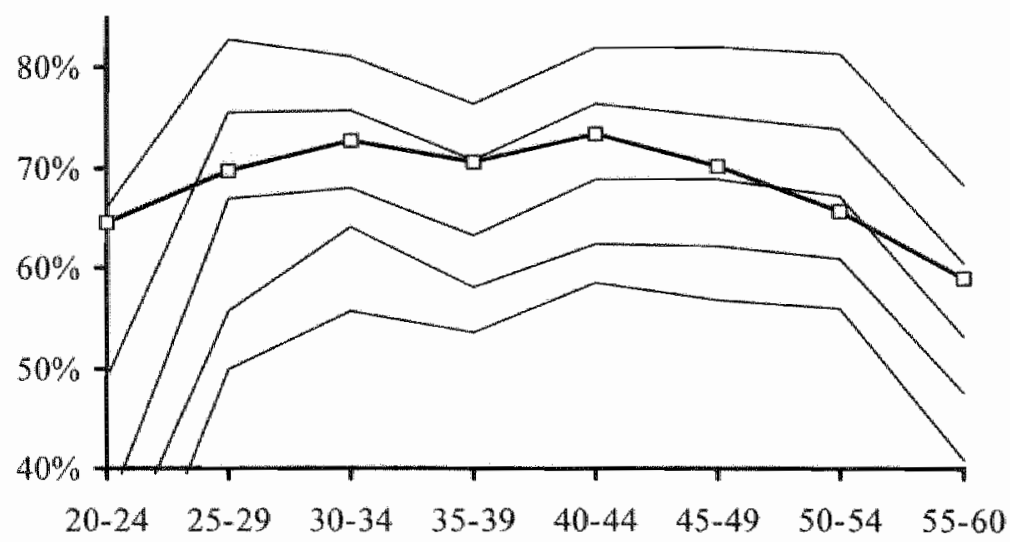

Nore: The data is taken from the Skills Survey of the Employed British Workforce. The thick $\square$ line represents the percentage of computer use at work. The thin lines represent the fraction of workers with a log gross hourly wages of at least $6.0,5.5,5.0,4.5$ and 4.0 . 
Figure 4.3

Actual Computer Use and Computer Use Predicted by Wage and Gender Only

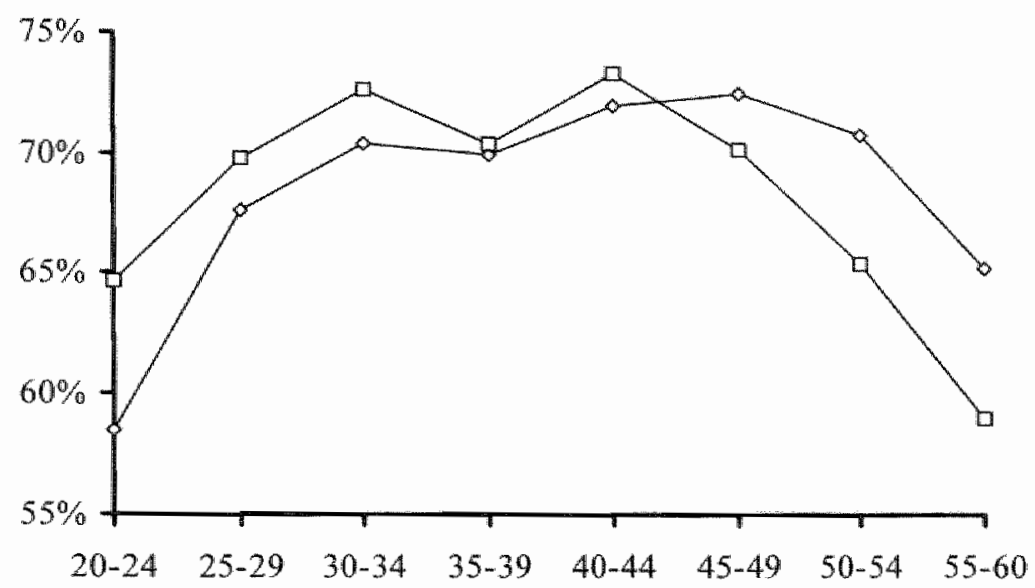

Note: The data is taken from the Skills Survey of the Employed British Workforce. The $\square$ line represents the percentage computer use at work. The $O$ line results from a calculation based on the assumption that the fraction of computer use in each gender-wage-group is equal for all ages.

\section{Figure 4.4}

Average Wages of Computer Users and Non-Users by Age

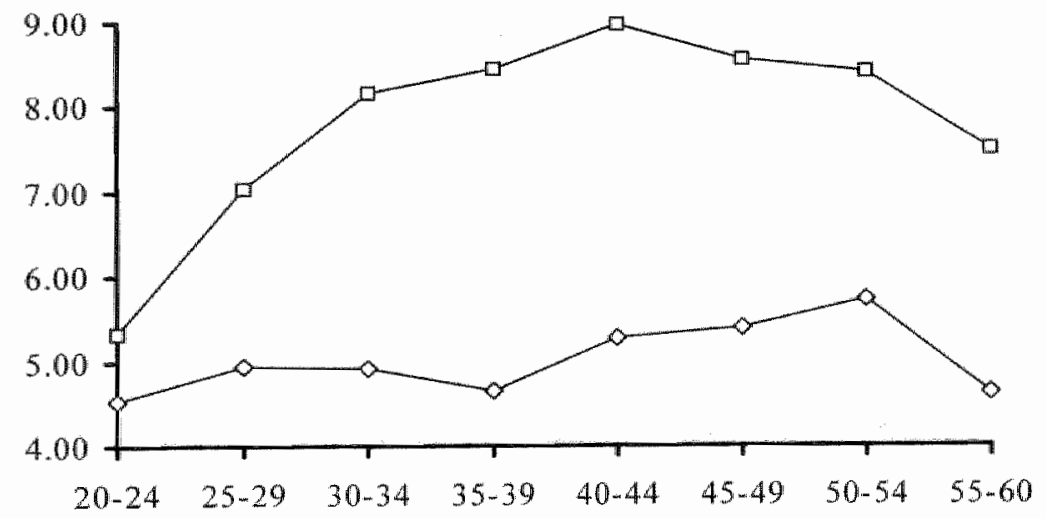

Note: The data is taken from the Skills Survey of the Employed British Workforce. The 0 line represents the average log gross hourly wage of workers not using a computer at work, while the $\square$ line represents the wages of the workers with a computer. 


\section{Figure 4.5}

Actual computer use and computer use predicted by tasks only

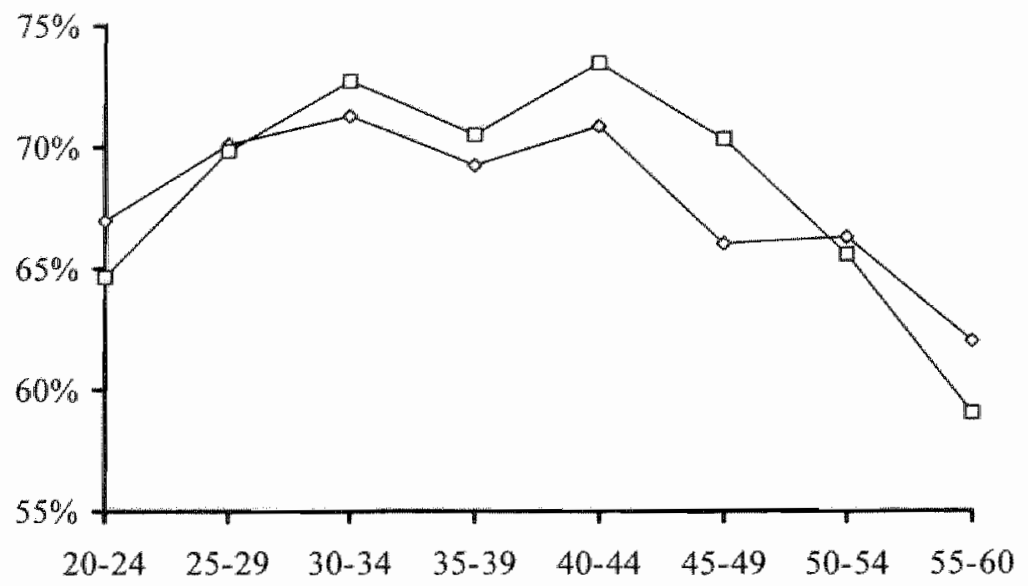

Nove: The data is taken from the Skills Survey of the Employed British Worlforce. The $\square$ line represents the percentage compute use at work. The $\theta$ line represents the predicted computer use from column [3] in Table 4.10, keeping all variables except the tasks constant.

\subsubsection{Alternative Explanations}

The literature provides a number alternative explanations for the (nonjuse of computers by older workers. First, Ahituv and Zeira (2001) put forward that the inability to cope with new technologies might force older workers to leave employment, and either become unemployed or retire early. In that case computer use divided by age group would underestimate the effects of this technology on the labour market position of older workers. Although the British data only contain information about employed workers, it is possible to test whether the data confirm this hypothesis by investigating the relationship between the fraction of older workers (50-60) in each occupational category and the degree of computerization in these occupational groups. Based on 74 2-digit occupations, an OLS-regression weighted by the number of observations in each occupational group results in a coefficient of $-.013(.034)$, which is not significant. Figure 4.6 shows the absence of the relationship graphically. A similar investigation based on 2-digit industrial codes also provides a insignificant relationship between a sector's computer use and the fraction of workers aged $50-60 .^{29}$

\footnotetext{
${ }^{29}$ In this case the estimated coefficient equals $-.025(.061)$, which is not significant either.
} 


\section{Figure 4.6}

Relationship between Average Computer Use and the Fraction of Older Worker by

Occupation (2-digit)

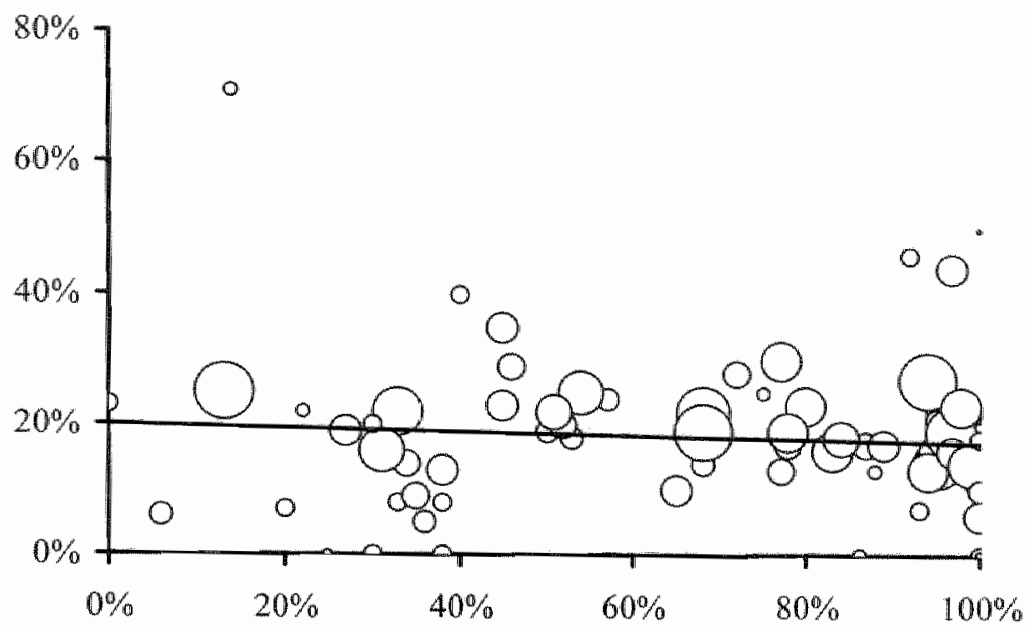

Note: The data is taken from the Skills Survey of the Employed British Workforce. For each 2-digit occupational category a dot represents the relationship between the percentage of computer use of all workers and the percentage of workers aged 50 or older. The size of the dots represents the number of observations in each occupation. The line results from weighted least squares estimation of the fraction of 50-60 year old workers as a function of computer use in the occupation.

Secondly, Friedberg (2001) argues that although the costs of acquiring computer skills might be constant in age, the benefits for older workers will be lower because they envisage retirement within a short period of time. As put forward in the model this means that the costs of introducing a computer a relatively high. This effect would imply that computer use among older workers is lower than computer use among other groups of workers only if computers have been recently introduced in the relevant sector or occupation. The change in computer use in the previous period should therefore be a good predictor of the computer use of older workers in comparison with younger workers. Table 4.12 reports the regression results of a weighted OLS regression explaining the percentage of computer use per occupation or sector by the overall computer use in this group and the change over the past five years. If Friedberg's arguments were valid, one would expect the coefficient on the change in computer use to be negative. Although the coefficients are negative in three of the four cases, they appear to be insignificant, suggesting that the prospect of retirement is not likely to be an important determinant of not using a computer. 


\section{Figure 4.7}

Relationship between Computer Use and Change in Computer Use for All Workers and Older Workers per Occupation

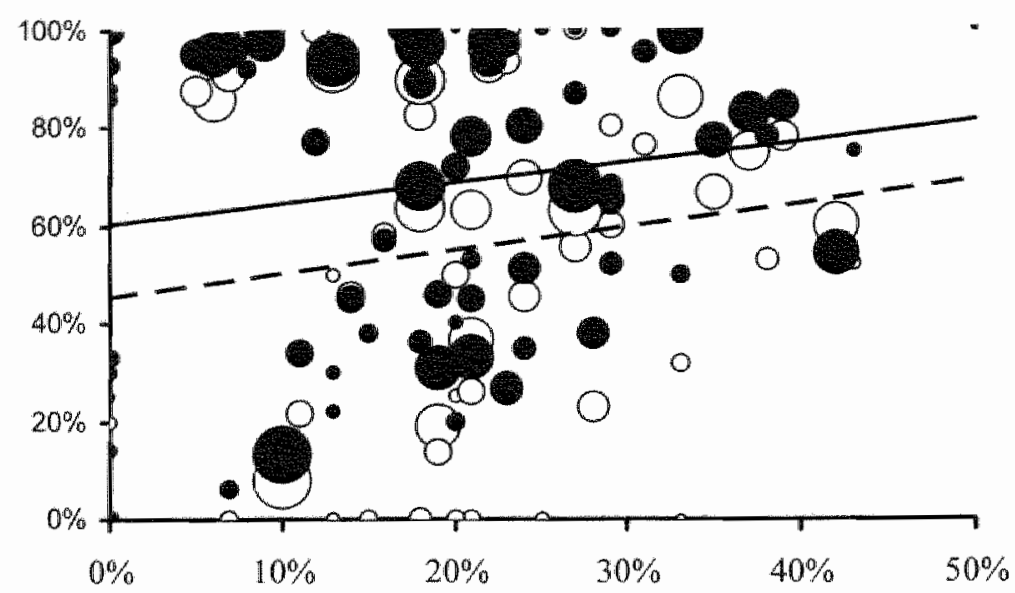

Note: The data is taken from the Skills Survey of the Employed British Workfonce. For each 2-digit occupational category a black dot represents the relationship between the percentage of computer use of all workers and the change in computer use over the period 1992-1997. Open dots represent the same relationship for the computer use among 50-60 year old workers only. The size of the dots represents the number of observations in each occupation. The solid line results from weighted least squares estimation of the percentage of computer use as a function of change in computer use in the occupation. The marked line represents a similar regression for computer use among 50 -60 year old workers.

Table 4.12

Relationship between Computer Use of Older Workers (50-60) and Computer Use of All Workers and the Recent Change in Computer Use per Occupation and Sector of Industry

\begin{tabular}{|c|c|c|c|c|}
\hline & \multicolumn{2}{|c|}{ Occupation } & \multicolumn{2}{|c|}{ Sector of industry } \\
\hline & With constant & $\begin{array}{l}\text { Without } \\
\text { constant }\end{array}$ & With constant & $\begin{array}{l}\text { Without } \\
\text { constant }\end{array}$ \\
\hline Constant & $-.073(.046)$ & & $-.160(.091)$ & \\
\hline Computer use & $1.027(.051)^{* *}$ & $.968(.035)^{*}$ & $1.092(.105)^{* * *}$ & $.944(.063)^{\mathrm{e}}$ \\
\hline$\Delta$ Computer use & $-.034(.137)$ & $-.157(.113)$ & $.152(.253)$ & $-.106(.210)$ \\
\hline Adjusted $\mathrm{R}^{2}$ & .863 & .973 & .686 & .963 \\
\hline
\end{tabular}

Note: The data is taken from the Skills Survey of the Employed British Workforce." =

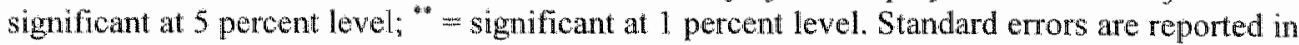
parentheses. 
Figure 4.7 shows the relationship between the change in computer use and the current computer use for both workers aged 50-60 and the labour force as a whole. Although there is a relationship between recent change and current use, the slope of this relationship is the same for older workers and all other workers. The introduction of computers therefore does not seem to affect older workers differently from younger workers.

\subsection{Computer Skills and Wages}

Although the analyses in the previous section indicate that computer use is not directly related to age, older workers might have more difficulty using a computer than younger workers. To investigate this, I will analyse whether younger workers possess more computer skills than their older colleagues. This inference seems to become apparent in the results reported in the first column of Table 4.13. Here, a worker's computer skills are taken as the dependent variable and the age classes and gender as the independent ones. The results of this regression analysis suggest a negative relationship between age and computer skills. Given that the youngest age group is the reference group, the workers in the age class $50-60$ have a probability of more than 40 percent of having computer skills one level lower than their youngest colleagues. Including educational levels does not seem to alter this picture. Interestingly, workers with higher levels of education report to have significantly higher levels of computer skills.

Since computer skills might be related to experience with using a computer and since it is clear from the analyses in the previous section that higher-educated workers (workers with higher wages) use a computer more frequently, the effect of educational level has to be separated from the experience with using a computer and type of computer use. To investigate the hypothesis that older workers have more difficulty using a computer, the following equations are estimated:

$$
S_{i}=C_{i}+\alpha A_{i}+X \beta+\gamma L_{i, 97}+\delta L_{i, 92}+\varepsilon_{i}
$$

for the relationship between computer skills and the level of sophistication of use in $1997\left(L_{i, 97}\right)$ and in $1992\left(L_{i, 92}\right)$, and

$$
S_{i}=C_{i}+\alpha A_{i}+X \beta+\gamma I_{i, 97}+\delta I_{i, 92}+\varepsilon_{i}
$$

to determine the relationship between computer skills and the importance of computer use in both years $\left(I_{i, 97}\right.$ and $\left.I_{i, 92}\right)$. The results of these two estimations and a combination of both are reported in the remaining columns of Table 4.13 .

The third column presents the estimation results of including the level of 
sophistication of computer use. These results suggest a positive correlation between the level of sophistication of computer use and computer skills. This finding is quite straightforward because more complex computer tasks probably require more advanced computer skills (see also e.g., Table 4.4). Including the level of sophistication of computer use five years prior to the survey date indicates that it is important for the level of computer skills whether a worker has used the computer for a while. Additionally, it is not very important at what level of sophistication the computer has been used, since one cannot statistically discriminate between the coefficients. This seems to indicate that to accumulate computer skills it does not really matter at what level of sophistication the computer has been used, as long as workers have experience with using computerized equipment at work. This observation is consistent with the findings in Table 4.5 that computer skills do not matter so much in terms of labour market success. In both columns [3] and [4] older workers report having significantly less advanced computer skills than younger workers, which implies that older workers have more difficulty using a computer than younger workers. What is also interesting to note is that the level of education does not have a significant impact on the level of the computer skills of a typical worker. This suggests that rather than the higher educational background itself, other variables (like experience with using computers) explain why higher-skilled workers usually have higher levels of computer skills.

In columns [5] and [6] the regression results of estimating equation (4.5) are reported. Similar to the results on the level of sophistication of computer use, the importance of computer use is positively correlated with the level of computer skills. Using a computer five years prior to the survey date has a significantly positive impact on computer skills, except in cases where the computer has not been very important for carrying out the job. What is again interesting to observe is that age and computer skills are negatively correlated. The major gap in skills is found between the age group 20-29 and the other workers (30-60 years old). Workers above the age of 50 do not seem to possess lower levels of computer skills than their 30 year old colleagues. Note also that the explanatory power of the results in columns [5] and [6] is much higher than in the previous columns. This suggests that the importance of computer use is a more important variable in understanding the level of computer skills than the level of sophistication of computer use. Including both the level of sophistication and the importance of computer use in one regression indeed shows that the importance of computer use is more important than the level of sophistication of computer use (column [7]). 


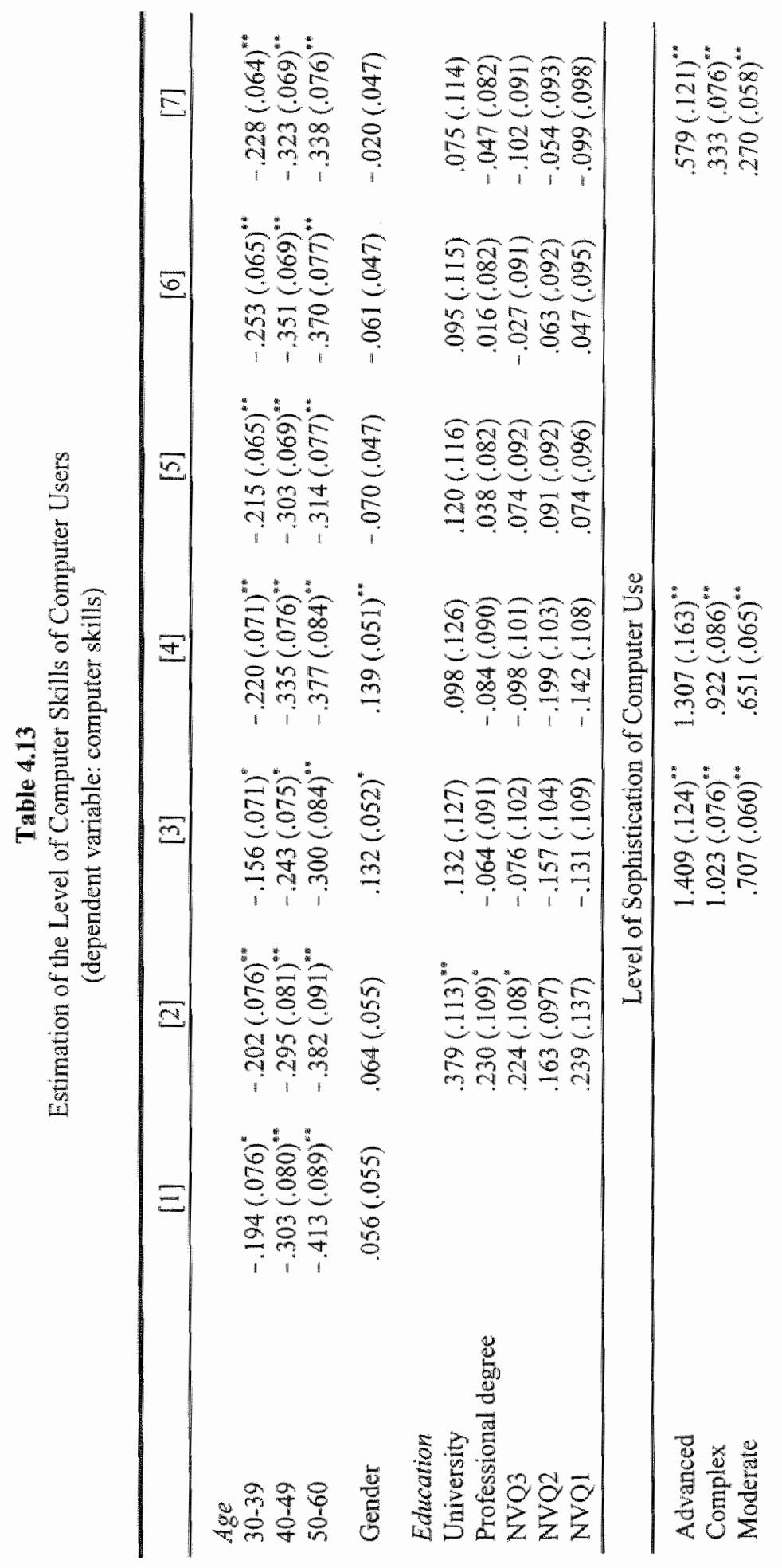




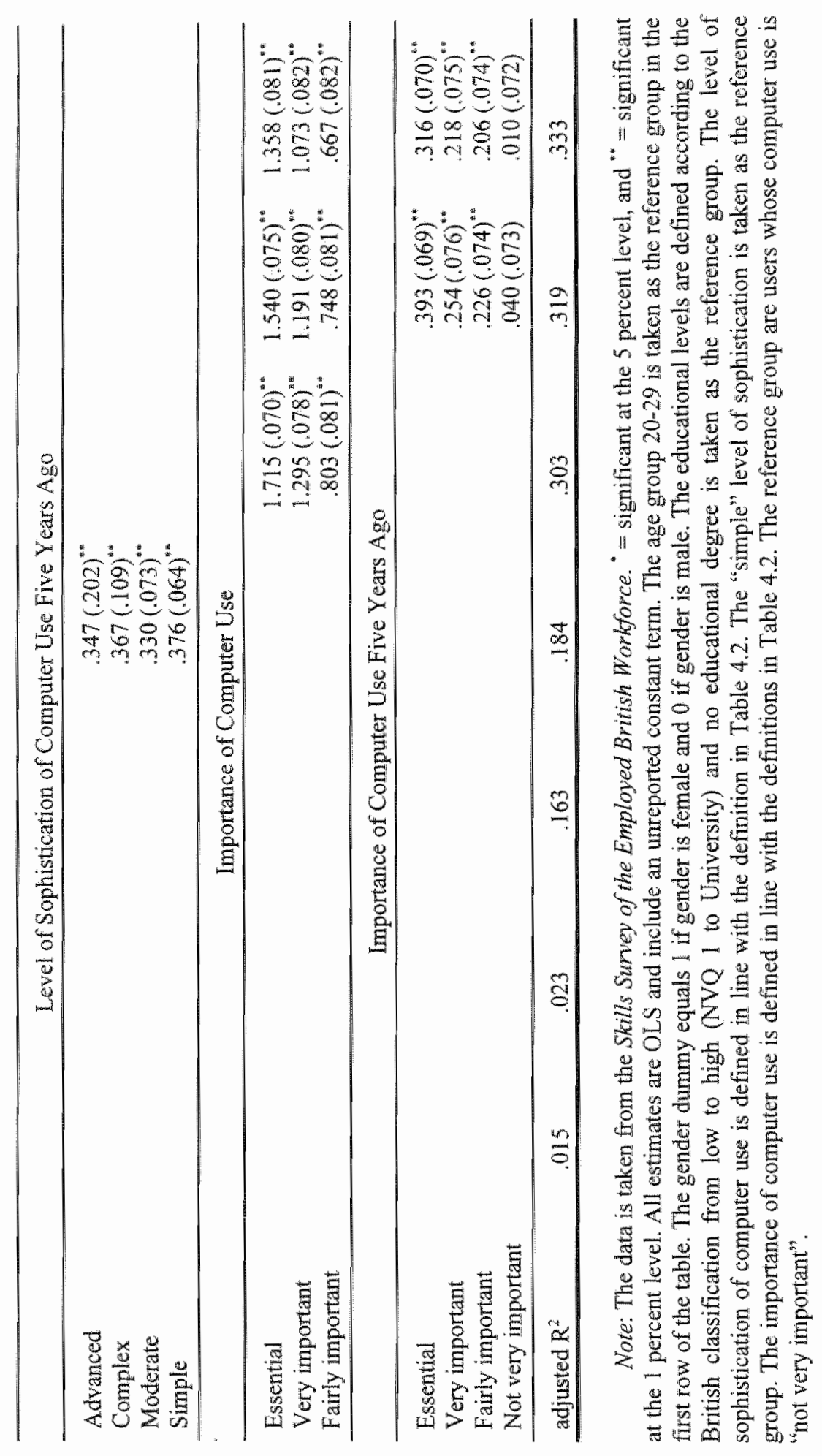




\subsection{Conclusion}

Computers have brought about a dramatic change in the labour market in the last decades. A large number of economists and commentators regard the introduction and implementation of the computer as a major determinant underlying the contemporary trend towards skill-biased technological change because the computerization of the labour market seems to go together with skill upgrading and wage inequality (e.g., Bound and Johnson, 1992 and Autor, Katz and Krueger, 1998). Until recently, computers were used mainly by skilled workers and a large number of studies report a substantial wage differential between computer users and non-users. Therefore, it has been argued that certain skills are likely to enable workers to make more effective use of the possibilities offered by a computer.

In this chapter new empirical findings have been presented showing what happens to the job when the computer is introduced. The main findings are that both computer skills and skills complementary to using a computer do not seem to be able to explain the labour market changes. Secondly, and more importantly, wages seem to be a good predictor of computer use. These results are of interest for two main reasons.

First, the estimates show that the computer wage premium is not the result of the allocation of workers possessing the highest-level skills to the most complex jobs (e.g., Krueger, 1993). Furthermore, the results indicate that the computer wage premium does not result from some spurious correlations or unobserved skills (e.g., DiNardo and Pischke, 1997). From the same perspective, both the model developed in Chapter 3 and the estimates presented here point towards an answer as to why workers in firms operating with advanced and new technologies earn higher wages on average (e.g., Doms, Dunne and Troske, 1997). Studies based on panel data which typically find that computers are first introduced among high-wage workers also seem to fit in within this line of reasoning (e.g., Entorf and Kramarz, 1997).

Secondly, the observation that it is unlikely that skills related to computer use explain the patterns of diffusion and observed wage differentials does not imply that computers are not a source of skill-biased technological change. The approach indicates that employers upgrade their workforce because computerization enables firms to use higher-skilled workers more effectively as a result of the diminishing importance of routine tasks. In this way, the introduction of the computer seems to induce a gradual upward shift in skill requirements for computerized jobs. The results of the model predict that this latter channel is an important source of skill-biased technological change. 
Appendix 4.1. Descriptive Statistics

\begin{tabular}{|c|c|c|c|c|}
\hline \multirow[t]{2}{*}{ Variable } & \multirow{2}{*}{$\begin{array}{c}\text { Percentage in } \\
\text { survey }\end{array}$} & \multicolumn{3}{|c|}{ Percentage in group } \\
\hline & & $\begin{array}{c}\text { Computer } \\
\text { use }\end{array}$ & $\begin{array}{l}\text { Union } \\
\text { coverage }\end{array}$ & $\begin{array}{l}\text { Union } \\
\text { member }\end{array}$ \\
\hline \multicolumn{5}{|l|}{ Gender } \\
\hline Malle & 52.9 & 69.2 & 46.0 & 32.4 \\
\hline Female & 47.1 & 69.1 & 51.0 & 32.5 \\
\hline \multicolumn{5}{|l|}{ Age } \\
\hline $20-29$ & 20.9 & 67.8 & 41.1 & 24.0 \\
\hline $30-39$ & 33.5 & 71.6 & 48.7 & 31.9 \\
\hline $40-49$ & 26.1 & 71.9 & 52.1 & 38.3 \\
\hline $50-60$ & 19.5 & 63.0 & 50.5 & 34.7 \\
\hline \multicolumn{5}{|l|}{ Education } \\
\hline University & 9.9 & 95.5 & 62.0 & 42.4 \\
\hline Professional degree & 12.4 & 88.9 & 60.6 & 46.9 \\
\hline NVQ3 & $\mathbb{1 5 . 2}$ & 75.1 & 53.2 & 35.8 \\
\hline NVQ2 & 34.5 & 71.6 & 45.8 & 30.0 \\
\hline NVQ1 & 8.8 & 55.1 & 38.9 & 21.8 \\
\hline No diploma & 19.3 & 40.2 & 38.5 & 24.6 \\
\hline Mariied men & 37.4 & 70.5 & 48.4 & 32.5 \\
\hline Married women & 31.9 & 67.0 & 51.0 & 33.0 \\
\hline Union coverage & 48.4 & 76.9 & 100.0 & 62.6 \\
\hline Union member & 32.5 & 76.4 & 93.3 & 100.0 \\
\hline Full-time workers & 7.4 .7 & 74.6 & 48.8 & 34.7 \\
\hline Permanent job & 82.4 & 72.2 & 53 & 36.2 \\
\hline Self-employed & 11.1 & 48.5 & 5.9 & 9.9 \\
\hline \multicolumn{5}{|l|}{ Occupations } \\
\hline Managers and Administrators & 14.6 & 83.7 & 31.9 & 19.4 \\
\hline Professionals & 10.5 & 93.8 & 72.7 & 54.2 \\
\hline Associate Professionals & 10.4 & 86.4 & 63.0 & 51.0 \\
\hline Clerical and Secretarial & 16.5 & 95.8 & 54.4 & 28.3 \\
\hline Craft and Related & 12.2 & 55.3 & 38.3 & 31.3 \\
\hline Personal and Protective Services & 10.5 & 45.2 & 46.7 & 28.2 \\
\hline Sales & 7.1 & 68.8 & 32.4 & 14.8 \\
\hline Plant and Machine Operatives & 10.7 & 42.8 & 48.1 & 38.6 \\
\hline Other & 7.5 & 17.9 & 46.7 & 26.6 \\
\hline
\end{tabular}


Sectors

Agriculture, forestry and fishing

Energy and water supply

Extraction of minerals

Metal goods, engineering and

vehicle industries

Other manufacturing industries

Construction

Distribution, hotels and catering, repairs

Transport and communications

Banking and finance, insurance,

business services and leasing

1.5

4.2

9.3

6.7

7.1

17.7

11.8

16.6

20.1

5.1
37.8

53.4

70.9

18.9

43.7

51.3

16.2

27.2

33.9

28.5

17.2

$25.5 \quad 12.4$

65.4

75.9

60.8

26.0

82.4

54.5

36.7

49.5

22.4

Note: The data are taken from the Skills Survey of the Enployed British Workforce.

\section{Appendix 4.2. Tasks}

In the estimations the importance of 35 tasks has been used. The question asked in the survey was: "In your job, how important is ...?" 35 tasks and computer usage are used to determine the importance of particular activities in terms of wage premiums. The following variables are included in the regressions: (1) paying close attention to detail, (2) dealing with people, (3) instructing, training, or teaching people, individually or in groups, (4) making speeches or presentations, (5) persuading or influencing others, (6) selling a product or service, (7) counselling, advising, or caring for customers or clients, (8) working with a team of people, (9) listening carefully to colleagues, (10) physical strength, (11) physical stamina, (12) skill or accuracy in using your hands or fingers, (13) knowledge of how to use or operate tools/equipments/machinery, (14) knowledge of particular products or services, (15) specialist knowledge or understanding, (16) knowledge of how your organization works, (17) spotting problems or faults, (18) working out the cause of problems or faults, (19) thinking of solutions to problems, (20) analysing complex problems in depth, (21) checking things to ensure that there are no errors, (22) noticing mistakes, (23) planning your own activities, (24) planning the activities of others, (25) organizing your own time, (26) thinking ahead, (27) reading written information such as forms, notices, or signs, (28) reading short documents such as reports, letters, or memos, (29) reading long documents such as long reports, manuals, articles, or books, (30) writing material such as forms, notices, or signs, (31) writing short documents, (32) writing long documents with correct spelling and grammar, (33) adding, subtracting, multiplying, or dividing numbers, (34) calculating using decimals, percentages, or fractions, and (35) calculating using more advanced mathematical or statistical procedures. 


\section{Appendix 4.3. The Returns to Computer and Writing Skills Revisited}

Krueger (1993) shows that people who use a computer at work earn 1518 percent higher wages, suggesting a substantial wage premium for computer skills. DiNardo and Pischke (1996 and 1997) observe that the use of a pen at work leads to a similar wage premium. Although knowledge of computers explains higher wages, they conclude that since almost everyone is able to use a pen, there is a more general unobserved skill that explains both the computer and the pen wage premium. This appendix replicates and re-examines the pen evidence using cross-sectional surveys from Britain and Germany. It is found that writing skills such as writing documents are highly rewarded, whereas completing forms does not yield significant returns. The main conclusion is that, although the use of both computers and pens leads to a wage premium, the character of these wage premiums is very different and reflects the market value of skills only in case of the pen. This evidence shows that the skill measure used in this chapter is most likely a valid one.

\section{A.4.1. Computer and Pen Use}

The data used to discuss the effects of computers and pens on the wage structure are taken from three cross-sections of the West German Qualification and Career Survey conducted in 1979, 1985-1986 and 1991-1992 and used by DiNardo and Pischke, and from the Skills Survey of the Employed British Workforce conducted in 1997. The main focus will be on the data on pen use and writing skills. The former can be deducted from both surveys, while the latter is only available in the British data.

Table A.4.1 summarizes the percentage of workers using computers and pens at work in Germany and Britain. Computer use has increased strongly in both countries throughout the sample years but is substantially higher in Britain than in Germany in the early 1990s. The use of pens on the job in Germany is much more stable, indicating that the diffusion of pens has reached a saturation point and that a worker who needs a pen has obtained one. In terms of the model developed in Chapter 3 one could argue that the costs of buying a pen for an employee are so low that every employee needing a pen to perform a certain task has obtained one. Since the computer is still a rather expensive piece of capital equipment, the diffusion might not have reached a saturation point yet. In the next chapter this is discussed in greater detail when the diffusion of computer through the wage distribution is addressed.

Figure A.4.1 shows the frequencies in which workers use a pen or a computer for different wage groups. The figure shows that although both pen and computer use are correlated with wages, the relationship between computer use and wages is much stronger than the relationship between pen use and wages. While 90 percent of the pen users in the higher wage groups also uses a 
computer, only 40 percent of the pen users among the low paid uses a computer.

Table A.4.1

Percentage of Workers in Germany and Britain Using Computers and Pens

\begin{tabular}{lrcccc}
\hline & \multicolumn{3}{c}{ Germany } & \multicolumn{2}{c}{ Britain } \\
\cline { 2 - 6 } & 1979 & $1985-1986$ & $1991-1992$ & 1992 & 1997 \\
\cline { 2 - 6 } Computer use & 8.5 & 18.5 & 35.3 & 47.1 & 69.2 \\
Pen use & 54.9 & 53.4 & 65.6 & - & 86.1 \\
\hline
\end{tabular}

Note: Columns [1] to [3] are replicated from Table 1 in DiNardo and Pischke (1997). The data for Britain is taken from the Skills Sumey of the Employed British Workforce. - is not available..

Analysing the pen wage premium, one would expect the pen wage premium to disappear because it is hard to imagine that the use of pens yields a wage premium. Table A.4.2 reports the coefficients of wage regressions including computer use, pen use and three interaction terms.

Figure A.4.1

Computer and Pen Use for Different Wage Groups in Germany in 1992

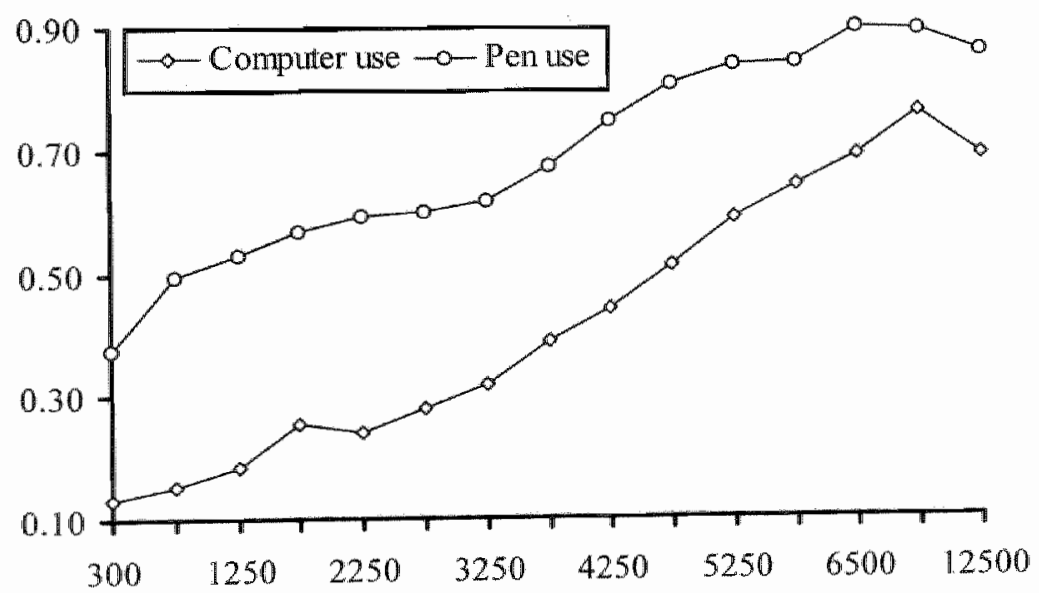

Note: The data is taken from West German Qualification and Career Survey. 
Table A.4.2

OLS Regressions for the Effect of Computer and Pen Use on Pay in Gemany and Britain (dependent variable: In (gross hourly wage))

\begin{tabular}{|c|c|c|c|c|}
\hline & \multicolumn{3}{|c|}{ Germany } & \multirow{2}{*}{ Britain } \\
\hline & 1979 & $1985-1986$ & $1991-1992$ & \\
\hline \multicolumn{5}{|c|}{$\begin{array}{l}\text { Panel A: } \\
\text { Use of Computer and Pen Entered Separately }\end{array}$} \\
\hline Computer & $.105(.010)^{4}$ & $.151(.007)^{n}$ & $.166(.006)^{*}$ & $.285(.024)^{\circ}$ \\
\hline adjusted $\mathrm{R}^{2}$ & .272 & .285 & .34 & .318 \\
\hline Pen & $.116(.006)^{4}$ & $.105(.006)^{n}$ & $.122(.006)^{*}$ & $.232(.031)^{*}$ \\
\hline adjusted $\mathbb{R}^{2}$ & .283 & .281 & .328 & .293 \\
\hline \multicolumn{5}{|c|}{$\begin{array}{l}\text { Panel B: } \\
\text { Use of Computer and Pen Entered Together }\end{array}$} \\
\hline Computer & $.087(.010)^{*}$ & $.130(.007)^{*}$ & $.144(.006)^{\circ}$ & $.252(.025)^{n}$ \\
\hline Pen & $.112(.006)^{4}$ & $.083(.006)^{*}$ & $.078(.006)^{\circ}$ & $.141(.031)^{*}$ \\
\hline adjusted $\mathrm{R}^{2}$ & .285 & .291 & .345 & .324 \\
\hline \multicolumn{5}{|c|}{$\begin{array}{c}\text { Panel C: } \\
\text { Interaction between Computer and Pen Use }\end{array}$} \\
\hline Computer $\times$ pen & $.185(.012)^{*}$ & $.205(.009)^{*}$ & $.224(.007)^{*}$ & $.385(.036)^{*}$ \\
\hline Computer $\times$ no pen & $.143(.020)^{*}$ & $.198(.015)^{*}$ & $.205(.015)^{*}$ & $.214(.060)^{*}$ \\
\hline No computer $\times$ pen & $.117(.006)^{*}$ & $.095(.006)^{*}$ & $.094(.007)^{*}$ & $.125(.038)^{4}$ \\
\hline adjusted $\mathrm{R}^{2}$ & .286 & .291 & .346 & .324 \\
\hline
\end{tabular}

Nore: " = significant at the 5 percent level. The regressions for Germany include the same control variables as Table 3 in DiNardo and Pischke (1997): intercept, schooling, experience (squared), dummies for part-time, city, female, married, married $\times$ female, and civil servants. For Britain the following control variables were included: intercept, education (university degree, professional degree, NVQ level 1-3), experience and experience squared, dummies for part-time, female, married, married $\times$ female, and civil servants (see also Table 4.5).

Panel A reports separate regressions for computer and pen use. The results suggest that the returns to computer use increase in Germany while the returns to pen use are rather stable. When entered together the pen wage premium drops between 1979 and 1992, while the computer wage premium increases from 9.0 percent in 1979 to 15.5 percent in 1992. In addition, the computer wage premium is somewhat lower in Panel B compared to Panel A but the pen wage premium has lowered more. When comparing Panel A and B 
for the United Kingdom, a similar pattern is observed. Finally, the regression results reported in Panel $\mathrm{C}$ include three interaction terms: computer $\times$ pen, no computer $\times$ pen and computer $\times$ no pen. The results indicate that the highest wage premium is obtained when using both a computer and a pen at work. Separating the impact of computers and pens on the wage structure, the latter two dummy variables are of interest: using a pen but not using a computer leads to the lowest wage premium in both countries, while using a computer but not using a pen leads to a wage premium close to the computer $\times$ pen wage premium.

\section{A.4.2. Why Do Pens Still Yield a Wage Premium?}

The surprising result from this exercise is that the pen wage premium does not disappear. This seems to suggest that the use of pens is not just a matter of unobserved heterogeneity or a white-collar effect, taken over by computer use once this is included. To find out why pens yield a wage premium, it is important to understand what workers do with a pen. From the British data one can distinguish three different applications: (i) filling in forms, notices or signs, (ii) writing short documents (for example, short reports, letters or memos), and (iii) writing long documents with correct spelling and grammar (for example, long reports, manuals, articles or books). By analysing these three "applications", three groups of workers have been selected. The first group consists of workers using a pen only for filling in forms, notices or signs. The second group uses a pen for writing short documents, but not for longer documents. Finally, the third group uses a pen for writing long documents with correct spelling and grammar.

Panel A of Table A.4.3 reports the results of the estimation of a wage equation including these three pen applications and computer use included. The results do not show a significant pen wage premium for filling in forms, notices or sign. Writing short documents ( 10.7 percent) and writing long documents (12.4 percent) yield significant wage premiums, while computer use yields the highest wage premium. This suggests that the pen wage premium is in fact a composition of wage premiums that depend on the way in which a pen is used. Panel B of Table A.4.3 relates the different applications of pens to computer use. Now, the use of a pen in combination with the use of a computer yields the highest wage premium for all three different applications. The wage premium is highest for the most "advanced" use of the pen (i.e., writing long documents with correct spelling and grammar) and lowest for the most "simple" use of the pen (i.e., filling in forms, notices or signs).

Since the pen wage premium seems to be related to the level of sophistication of its use, these results lead to the suspicion that returns to skill may be an important explanation for the pen wage premium. The British data enable us to measure the skills of the pen-using workers as well. Hence, wages 
have been regressed on writing and computer skills. The results are reported in Table A.4.4.

Table A.4.3

OLS Regressions for the Effect of Computer and Different Applications of Pen Use on Pay (dependent variable: In (gross hourly wage))

\section{Panel A:}

Specific Pen Use and Computer Use Entered Together

filling in forms, notices or signs

$.038(.045)$

Writing short documents

Writing long documents with correct spelling and grammar

Computer $.215(.026)^{*}$

Adjusted $\mathrm{R}^{2}$ .331

Panel B:

Specific Pen Use Related to Computer Use Entered Together

No jeen $\times$ computer $.218(.060)^{*}$

Filling in forms, notices or signs $\times$ computer $.137(.069)^{*}$

Writing short documents $x$ computer $.313(.048)$

Writing long documents with correct spelling and grammar $x$ $.419(.036)$ computer

Filling in forms, notices or signs $\times$ no computer

Writing short documents no computer

Writing long documents with cortect spelling and grammar $\times$ no computer

Adjusted $\mathrm{R}^{2}$

Note: " = significant at 5 percent level. The following control variables were included: an intercept, educational level (university degree, professional degree, NVQ level $[-3$ ), experience and experience squared, dummies for part-time, female, married, married $x$ female, and civil servants. The coefficients in Panel A reflect the pen wage premium for workers using a pen at a certain level, i.e., only the highest levels at which the pen is used were included. In this way unbiased estimates of the pen wage premium at different levels of use are obtained. For the coefficients in panel $\mathrm{B}$ the same argument holds.

The coefficients on computer skills are consistent with the previous findings that computer skills do not seem to have market value. Each level of computer skills leads to a high return, but since in the British survey skills are 
only measured for people using a computer, this reflects a premium for use rather than skills. If skills are relevant one would typically expect the premium to increase with the skill level. Figure A.4.2 shows the computer wage premium to be rather constant. Except for the lowest skill level of computer use. People who report that when they have to use a computer at their work while hardly ever able to do this effectively, earn significantly less. It appears, however, that these are people who have started to use a computer rather recently (see for example, Table 4.5). Since the use of a computer turns out to be related to the price of computers in relation with the wage (and since the price of computers decreases), recent (still inexperienced) users on average have lower wages. Excluding recent users from the regression leads to an almost flat relationship between computer skills and wages.

The results for the writing skills show different results. The pattern suggests that workers with the highest writing skills generally receive the highest wage premium. When entered together in a wage equation (Panel B) it is observed that being good at filling in forms, notices or signs does not give any significant reward. However, high skill levels in writing long documents lead to a wage premium. In addition, this wage premium is highest when the worker possesses the highest skill levels. Hence, the results of DiNardo and Pischke for pens from the German data seem to be picking up an effect of skills on wages. This suggests that writing skills are important when using a pen, and are consistent with DiNardo and Pischke's pen wage premium.

Since Krueger (1993) showed that computer use leads to a substantial computer wage premium, a great many authors have argued that specific skills are required in order to increase productivity by using a computer. Krueger argued that computer skills themselves are very important on the labour market, while others argued in favour of the relevance of skills complementing computers. DiNardo and Pischke (1997) have shown that not only computer use but also the use of pens lead to a wage premium. Together with their finding that the computer wage premium is a reward for skills rather than for use, they concluded that not computer skills but a more general unobserved skill should be responsible for the computer wage premium. Their conclusion was that unobserved skills explain the computer wage premium.

Here it is suggested that although the effect of pen use on wages cannot be denied, the comparison between the pen wage premium and the computer wage premium does not seem to be justified because the pen wage premium depends to a large extent on purposes for which a pen is used. Writing short or long documents leads to a premium, while filling in forms does not. Since DiNardo and Pischke did not (and could not) distinguish between these different tasks, their findings suggested that even the simplest use of pens leads to higher wages. Based on skill measures it is shown here that in contrast to computer skills, writing skills seem to be able to explain wage premiums, which provides a strong argument for the validity of the skill measure used in this chapter to investigate the impact of computer on the labour market. 
Table A.4.4

OLS Regression for the Effect of Computer Skills and Different Writing Skills on Pay in Britain (dependent variable: ln (gross hourly wage))

\begin{tabular}{|c|c|c|c|c|c|}
\hline & & & & \multicolumn{2}{|c|}{ Skill level } \\
\hline & Very high & High & Intermediate & Low & Very low \\
\hline \multicolumn{6}{|c|}{ Panel A: Skills Entered Separately } \\
\hline Computer skills & $\begin{array}{l}.285 \\
(.028)^{*}\end{array}$ & $\begin{array}{c}.306 \\
(.029)^{\circ}\end{array}$ & $\begin{array}{c}.330 \\
(.042)^{\circ}\end{array}$ & $\begin{array}{c}.315 \\
(.046)^{4}\end{array}$ & $\begin{array}{l}.113 \\
(.052)^{n}\end{array}$ \\
\hline $\begin{array}{l}\text { Filling in forms, } \\
\text { notices or signs }\end{array}$ & $\begin{array}{l}.181 \\
(.031)^{*}\end{array}$ & $\begin{array}{c}.215 \\
(.031)\end{array}$ & $\begin{array}{c}.098 \\
(.046)^{*}\end{array}$ & $\begin{array}{l}.091 \\
(.063)\end{array}$ & $\begin{array}{l}.038 \\
(.071)\end{array}$ \\
\hline $\begin{array}{l}\text { Writing short } \\
\text { documents }\end{array}$ & $\begin{array}{c}.280 \\
(.030)^{*}\end{array}$ & $\begin{array}{l}.273 \\
(.029)^{*}\end{array}$ & $\begin{array}{c}.197 \\
(.044)^{*}\end{array}$ & $\begin{array}{l}.110 \\
(.056)^{\circ}\end{array}$ & $\begin{array}{c}.088 \\
(.060)\end{array}$ \\
\hline $\begin{array}{l}\text { Writing long } \\
\text { documents with } \\
\text { correct spelling } \\
\text { and grammar }\end{array}$ & $\begin{array}{l}.272 \\
(.030)^{\circ} \\
\end{array}$ & $\begin{array}{c}.252 \\
(.028)^{4}\end{array}$ & $\begin{array}{c}182 \\
(.040)^{\prime \prime} \\
\end{array}$ & $\begin{array}{c}.147 \\
(.048)^{*}\end{array}$ & $\begin{array}{r}.127 \\
(.043)^{\circ} \\
\end{array}$ \\
\hline \multicolumn{6}{|c|}{ Panel B: Skills Entered Together } \\
\hline Computer skills & $\begin{array}{c}.206 \\
(.031)^{*}\end{array}$ & $\begin{array}{c}.222 \\
(.032)^{4}\end{array}$ & $\begin{array}{l}.260 \\
(.044)^{n}\end{array}$ & $\begin{array}{c}.253 \\
(.047)^{*}\end{array}$ & $\begin{array}{c}.066 \\
(.053)\end{array}$ \\
\hline $\begin{array}{l}\text { Filling in forms, } \\
\text { notices or signs }\end{array}$ & $\begin{array}{l}-.055 \\
(.039)\end{array}$ & $\begin{array}{c}.012 \\
(.039)\end{array}$ & $\begin{array}{l}-.042 \\
(.052)\end{array}$ & $\begin{array}{l}.033 \\
(.066)\end{array}$ & $\begin{array}{c}.008 \\
(.073)\end{array}$ \\
\hline $\begin{array}{l}\text { Writing short } \\
\text { documents }\end{array}$ & $\begin{array}{l}.141 \\
(.043)^{*}\end{array}$ & $\begin{array}{c}.123 \\
(.042)^{*}\end{array}$ & $\begin{array}{l}.076 \\
(.053)\end{array}$ & $\begin{array}{l}.001 \\
(.064)\end{array}$ & $\begin{array}{l}.035 \\
(.067)\end{array}$ \\
\hline $\begin{array}{l}\text { Writing long } \\
\text { documents with } \\
\text { correct spelling } \\
\text { and grammar }\end{array}$ & $\begin{array}{l}.137 \\
(.038)^{*} \\
\end{array}$ & $\begin{array}{r}.097 \\
(.035)^{\circ} \\
\end{array}$ & $\begin{array}{l}.044 \\
(.045) \\
\end{array}$ & $\begin{array}{r}.026 \\
(.052) \\
\end{array}$ & $\begin{array}{l}.049 \\
(.048) \\
\end{array}$ \\
\hline
\end{tabular}

Nore: " = significant at 5 percent level. The following control variables were included: an intereept, educational level (university degree, professional degree, NVQ level 1-3), experience and experience squared, dummies for part-time, female, married, married $x$ female, and civil servants. The adjusted $R^{2}$ s for Panel $A$ are $321, .291, .308$, and .309. For Panel $B$ the adjusted $R^{2}$ is 312 . Panel $B$ restricts the writing skills to one category of use, $i . e_{\text {, }}$ if a worker reports that the performs all three writing tasks, only writing long documents with correct spelling and grammar has been taken into account. This is necessary to obtain unbiased estimates of writing skills, when entered together in the wage equation. 
Figure A.4.2

The Returns to Computer and Writing Skills in Britain

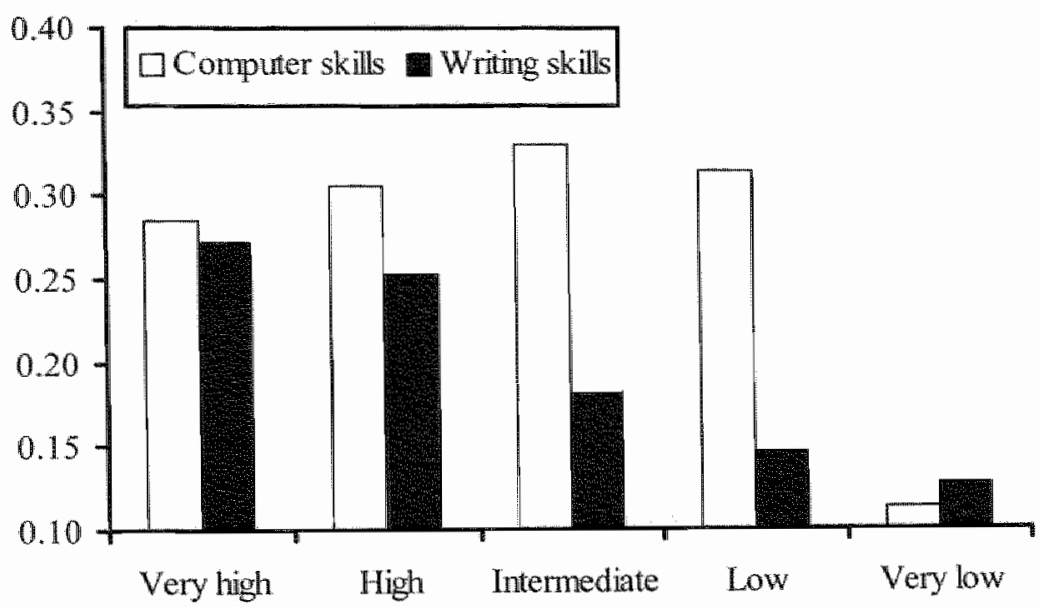

Nore: The data is taken from the Skills Survey of the Employed British Workforce. 


\section{Chapter 5}

\section{The Diffusion of Computers and the Distribution of Wages}

\subsection{Introduction}

It has been well documented that wage inequality in the United States has accelerated upon the emergence of computers in the labour market. 'Several authors have suggested that the increase in wage inequality has been caused by a complementary relationship between computers and higher skilled labour. ${ }^{2}$ In addition, computer use is more concentrated among skilled workers and computer use is associated with higher earnings. ${ }^{3}$

Although much of the econometric evidence indicates that individual computer use leads to wage increases and that particularly higher-skilled workers benefit from this, two observations need to be explained. First, computer use among unskilled workers increased substantially since the early 1980s: In 1997, 42.8 percent of the unskilled workers used a computer - an average annual growth rate of 5.4 percent between 1984 and $1997 .^{4}$ This change

It has been argued that the mid-1970s are the watershed in the acceleration of wage inequality. Greenwood's and Yorukoglu's (1997) paper entitled "1974" is indicative in this sense. It starts from the observation that the price of computer equipment fell faster after 1974 than before, which fosters adoption. See also Chapter 2 for an overview of this literature.

2 See e.g., the discussion of the econometric evidence in Chapter 2 starting from the seminal contribution of Krueger (1993) suggesting that computer users earn 10 to 15 percent higher wage because of skill advantages, which explains about half of the widening of the educational wage structure in the United States in the period 1984-1989.

${ }^{3}$ In $1984,45.2$ percent of the skilled and 21.6 percent of the unskilled workers used a computer at work and on average they eamed 17.9 and 22.0 percent higher wages than workers from the same skill group who did not use a computer. Here, skilled workers are defined as those with at least a completed college education. Unskilled workers are defined as the remaining ones. These numbers are drawn from the October Supplements of the CPS.

Computer use at work among skilled workers increased to 76.6 percent in 1997. 
in the composition of the group of computer users raises the question whether the effect of the adoption of computers on wage inequality remains unchanged if its diffusion continues and to what extent wage inequality generated by the diffusion of computers is of a permanent or temporary nature.

Secondly, the timing of the increase in wage inequality needs to be addressed in order to draw a relationship between rising wage inequality and computerization. Figure 5.1 a presents a three-year moving average of the $90^{\text {th }}-10^{\text {th }}$ percentile of the real $\log$ annual wage distribution of skilled and unskilled workers from 1963 to 2000 using data from the March Supplements of the Current Population Surveys (CPS) from 1964 to 2001. In the period 1970-2000, the average annual increase in wage inequality within the group of skilled workers equals .68 percent. Within the group of unskilled workers, the period until 1980 is characterized by a fairly stable degree of wage inequality (the average annual increase equals .36 percent). From 1980 onwards, wage inequality within the group of unskilled workers accelerates to an average annual growth rate of .52 percent. ${ }^{5}$ Considering the timing of the adoption of computers, the increase in wage inequality within the group of unskilled workers seems to be broadly consistent with the first unskilled workers adopting computers around 1980. Similarly, the relatively high average annual growth rate of within-group wage inequality for skilled workers since 1970 seems to be consistent with the first appearance of computers in the labour market.

The picture for between-group wage inequality looks quite different. Figure $5.1 \mathrm{~b}$ presents the difference between the mean $\log$ anmual wages for skilled and unskilled workers from 1963 to 2000 . The picture emerging from Figure $5.1 \mathrm{~b}$ is that between-group wage inequality contracts from 1965 until 1980 at an average annual rate of 1.27 percent. From 1980 to 2000 it has been increasing sharply at an average annual rate of 1.68 percent. ${ }^{6}$ Comparison of Figure $5.1 \mathrm{a}$ and $5.1 \mathrm{~b}$ reveals that the timing of the acceleration in betweengroup wage inequality coincides with the rise in within-group wage inequality for the unskilled and that within-group wage inequality for the skilled workers can only be connected to between-group wage inequality in the 1980 s. $^{?}$

This chapter develops a theoretical model to analyse how the diffusion of

\footnotetext{
Sver the period 1968-2000 the average annual growth rate of wage inequality equals 60 percent within the group of skilled workers and .44 percent within the group of unskilled workers.
}

"Over the period 1965-2000 as a whole, between-group wage inequality increases at an average annual growth rate of .41 percent.

\footnotetext{
"Autor, Katz and Krueger (1998) also observe that between-group and within-group wage inequality move similarly from the 1980 s onwards, but appear to have evolved differenty before.
} 
computers shapes between and within-group wage inequality. It includes three ingredients: (i) the diffusion of computers is based on cost-benefit considerations weighing the productivity benefits of computer use against the (continuously falling) costs of the computer, (ii) fully substitutable productivity differentials within the groups of skilled and unskilled workers, and (iii) an overlap in the productivity distribution of skilled and unskilled workers, which are substitutable to a limited extent. It is shown that this model is able to explain that (i) wage inequality resulting from computerization can either be a permanent or temporary phenomenon depending on differences between skilled and unskilled workers in the proportional productivity gain from using a computer, (ii) within-group wage inequality for skilled and unskilled workers starts to rise when the first (substantial group of) workers in each group adopt computers, and (iii) between-group wage inequality starts to rise when the group of skilled workers using a computer becomes sufficiently large and especially when the first (substantial group of) unskilled workers adopt computers.

Figure 5.1a

Within-Group Wage Inequality

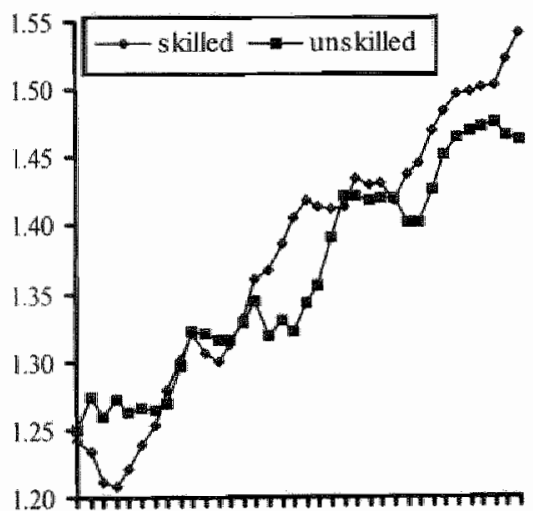

19651970197519801985199019952000
Figure $5.1 \mathrm{~b}$

Between-Group Wage Inequality

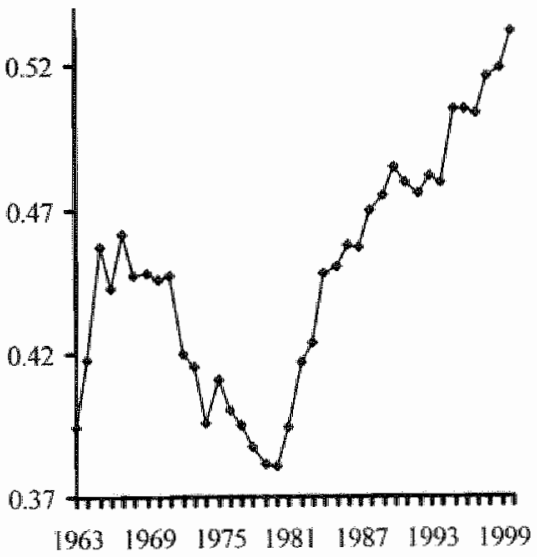

Note: All data are taken from the March CPS and include full-time full-year workers only. Skilled workers are defined as those with at least a college degree. Within-group wage inequality is measured by a three-year moving average of the $90^{\text {th }}-10^{\text {lli }}$ real $\log$ wage differential within both groups. Between-group wage inequality is defined as the difference between the real log average annual wages of both groups.

The predicted pattern of wage inequality for skilled workers $I$ and unskilled workers $J$ is the following. When it becomes beneficial for worker $i$ to 
adopt computers, initially the increased supply of efficiency units will be offset by the costs of computerization. When the costs continue to fall he gains in terms of wages, which leads to rising within-group wage inequality in group I between adopters and non-adopters. A second effect is that the supply of efficiency units of labour type $I$ increases, which dampens the relative (efficiency) wages of workers $I$ and reduces between-group wage inequality. Given the lower wages of unskilled workers, worker $j$ adopts the computer at a later point in time. When it becomes beneficial for him to adopt, within-group wage inequality in group $J$ also increases. The additional units of unskilled labour supply induce between-group wage inequality to rise. When all workers within a group have adopted computers, within-group wage inequality will fall if the costs of the computer fall further. In the hypothetical case where the costs are zero, within-group wage inequality will only continue to be larger than prior to computerization if there are differences in the productivity gain from using computers within both groups. When all unskilled workers have adopted computers, between-group wage inequality will decrease because additional efficiency units of unskilled labour are no longer supplied. If the costs of computers continue to fall and go to zero in the limit, between-group wage inequality will be permanently higher than before only if there are productivity differentials between skilled and unskilled workers in using computers. Estimating the model for the United States, using CPS data from 1963-2000, shows that the pattern is consistent. The increased productivity in terms of efficiency units turns out to be a good explanation for the evolution of relative wages. In particular, it is observed that (i) the elasticity of substitution between skilled and unskilled workers is between 2 and 3 when accounting for the additional supply of efficiency units of labour and that a considerable fraction of the time trend of relative wages is explained by the model, and (ii) the productivity gain from using computers lies between 15 and 40 percent.

The theoretical model is related to the older literature on the diffusion of new technologies, including the work of David (1969), Stoneman (1976) and Davies (1979), who argue that the costs of new technologies are important determinants of adoption and diffusion. ${ }^{8}$ In this chapter, (endogenous) wages and productivity gains determine whether computer adoption is beneficial, whereas previous diffusion models treated the determinants of the diffusion process as being exogenous. The analysis in this chapter is also related to the more recent studies on technology adoption by Chari and Hopenhayen (1991), Galor and Tsiddon (1997), Caselli (1999) and Weinberg (2001). In these papers, skilled workers have a higher probability to work with new technologies than

\footnotetext{
* The models predicting the adoption and diffusion of general purpose technologies are also consistent with the theoretical model because computer use is pervasive in a wide range of sectors in ways that change their modes of production (e.g., Bresnahan and Trajtenberg, 1995 and Helpman and Trajtenberg, 1998 ).
} 
unskilled workers because new technologies can more productively be operated by skilled workers, but they do not take into account the costs of new technologies in the adoption stage. Violante (2002) assumes noncompetitive labour markets to explain wage inequality among ex ante equal workers in relation to the adoption of new technologies. In his approach, the heterogeneity among workers is not generated by skill differentials but by technological differentials across the machines of different vintages they are matched with. The model presented in this chapter is able to distinguish between the moment of computer adoption and the productivity gain resulting from adoption in a fully competitive labour market. In addition, by distinguishing productivity differentials within the groups of skilled and unskilled workers, the theory developed in this chapter differs from the above theories and the ones developed by Greenwood and Yorukoglu (1997), Acemoglu (1998) and Kiley (1999) by explaining both between and within-group wage inequality, whereas the other studies mentioned above only analyse wage inequality either within or between groups. ${ }^{9}$ Finally, with regard to the distribution of productivity within the groups of skilled and unskilled workers, this chapter is related to the approaches of Aghion, Howitt and Violante (1998), Heckman, Lochner and Taber (1998), Galor and Moav (2000) and Gould, Moav and Weinberg (2001). They also use some (ability) distribution to examine within-group inequality. Their distributions are not overlapping, however, whereas the distribution here allows for some unskilled workers to have a higher productivity than some skilled workers, which seems to be important from an empirical point of view, because the wages of the skilled worker with the lowest levels of productivity are lower than the wages of the unskilled worker with the highest levels of productivity. In addition, their mechanism of within-group inequality is determined by differences in abilities or assignment to machines, which leads to the development and transferability of technology-specific skills driving wage inequality, whereas the mechanism of within-group inequality presented here is determined by the costs of computers relative to the wages and the productivity gains from using computers. The empirical content of the chapter for the United States is related to the explanations for wage inequality by Katz and Murphy (1992), Murphy, Riddell and Romer (1998) and Krusell, Ohanian, Ríos-Rull and Violante (2000). The theoretical and empirical observations in this chapter offer an additional explanation to rising wage inequality resulting from computerization in that it argues that the additional supply of efficiency units of labour is an important determinant in explaining the rise in between-group wage inequality since the 1980 s and accounts for a considerable fraction of the increasing demand for skilled labour.

- Caroli and Garcia-Peñalosa (2001) also present a model accounting for both between and within-group wage inequality by using differences in wage-setting behaviour and wage instability in different stages of technological development. 
The plan of the chapter is as follows. Section 5.2 presents the basic model. Section 5.3 discusses the temporary and permanent nature of wage inequality resulting from computerization. Section 5.4 investigates the timing of between and within-group wage inequality. Section 5.5 empirically addresses to what extent the theoretical model is consistent with the evolution of wages in the United States in the period 1963-2000. Section 5.6 concludes.

\subsection{The Model}

Consider a competitive economy producing a homogeneous good $Y$ that can be used for either consumption or investment. The good is produced by a labour input consisting of $S^{e}$ units of skilled and $U^{z}$ units of unskilled workers. Since there are productivity differences among skilled and unskilled workers, we define the supply in terms of efficiency units of skilled and unskilled workers as $S$ and $U$.

\subsubsection{Basic Structure of the Model}

Production: Production takes place according to a constant elasticity of substitution (CES) production function. The output produced equals

$$
Y=\left((\chi S)^{\rho}+(\psi U)^{\rho}\right)^{1 / \rho}
$$

where $\rho<1$, and the elasticity of substitution between $S$ and $U$ is $\sigma=\frac{1}{1-\rho}$. The supply of skilled and unskilled workers in efficiency units is denoted as $S$ and $U$, with $w^{e t}$ and $w_{u}^{e t t}$ being the corresponding wages in efficiency units. Competitive wages give a standard relative demand equation:

$$
w^{u t} \equiv \frac{w_{s}^{e u}}{w_{u}^{e u}}=\left(\frac{\psi U}{\chi S}\right)^{1 / \sigma} \text {. }
$$

For convenience, $w_{t i}^{e t}$ is normalized to 1 , so $w_{s}^{e t t}=(\chi S / \psi U)^{1-\rho}$.

Heterogeneity among Workers: Productivity levels are allowed to differ between and within both groups. Productivity differences might be due to unobserved heterogeneity, but might also differ from year to year due to on-thejob learning, aging, sector shifts and other influences, which need not be specified further. The productivity of skilled and unskilled workers depends on the parameters $\underline{a}_{i} \sim[\underline{\alpha}, \bar{\alpha}]$ with $\bar{\alpha}>\underline{\alpha}$ for skilled worker $i$ and $b_{j} \sim[\beta, \bar{\beta}]$ with $\bar{\beta}>\beta$ for unskilled worker $j$. The intervals of these 
parameters are allowed to overlap. ${ }^{10}$ The assumption made is that $\bar{\alpha}>\bar{\beta}>\underline{\alpha}>\beta$.

To enable an analytical solution of the model, the distribution of the productivity parameters for skilled and unskilled workers is assumed to take the following form:

and

$$
P^{s}(a)=\frac{1}{1-p} a^{\frac{2 p-1}{1-p}} p^{s}
$$

$$
P^{u}(b)=\frac{1}{1-p} b^{\frac{3 p-1}{1-p}} p^{u},
$$

where $p^{s}=(\sigma-1 / \sigma)\left(1 / \bar{\alpha}^{\sigma-1}-\underline{\alpha}^{\sigma-1}\right)$ and $p^{4}=(\sigma-1 / \sigma)\left(1 / \bar{\beta}^{\sigma-1}-\beta^{\sigma-1}\right)$ are obtained from solving the integral for the distributions of productivity parameters of both types of workers. If $\sigma=2$ the assumed distribution is such that the wage bill is uniformly distributed over the productivity parameters $a$ and $b$. For convenience, $P^{\prime \prime}(a)$ and $P^{a}(b)$ are referred to as $P^{s}$ and $P^{u}$ in the remainder of the analysis.

Productivity: Each worker has a certain productivity, which depends on his productivity parameter and whether or not this worker uses a computer. Productivity equals $q_{i}^{s}=a_{i}$ and $q_{j}{ }^{u}=b_{j}$ without using a computer and $q_{i}^{s}=a_{j} \theta^{s}$ and $q_{j}^{\prime \prime}=b_{j} \theta^{u}$ when using a computer, where $\theta^{s}, \theta^{n}>1$ is the proportional productivity gain from working with a computer. Assumptions made are that within both groups the productivity gain from using a computer is the same, while between both groups it is allowed to differ, " and for all workers there exists some computer application, which makes production more efficient.

Wages: In a competitive labour market, each efficiency unit of labour receives the same return and the wage of a worker equals the productivity parameter

10 The model does not require further specification of this heterogeneity. Because within $S$ and $U$ workers are perfectly substitutable, any productivity differential within $S$ and $U$ is reflected in the wage. Aghion, Howitt and Violante (1998) and Gould, Moav and Weinberg (2001) assume that workers differ in their adaptability to new technologies as a result of random shocks, and Violante (2002) requires that technologies differ in their productivity or quality to generate temporary within-group wage inequality. Caroli and Garcia-Penalosa (2001) use different attitudes towards risk to generate heterogeneity.

1 The alternative assumption would be a complementary relationship between the productivity parameters $a$ and $b$ and the proportional productivity gain $\theta$. Assuming such a relationship leads to earlier adoption of computers (given the costs of adoption) for workers with a proportional productivity gain $\theta^{i}>\theta^{s}$ and $\theta^{\prime}>\theta^{\prime \prime}$ and to a later adoption of computers for workers experiencing proportional productivity gains smaller than $\theta^{*}$ and $\theta^{\text {it }}$. Such an assumption would, given the costs of computers, lead to a similar pattern of diffusion, but to long-run wage inequality both between and within groups of skilled and unskilled workers. 
multiplied by the return to an efficiency unit of labour. In such a setting, employers are indifferent between employing a worker who uses a computer and one who does not because they pay the same wage for each efficiency unit of labour. This means that both the productivity gain and the costs of the computer are passed on to worker. Hence, wages equal $w_{i}^{s}=a_{i} w_{s}^{e t}$ and $w_{j}{ }^{\prime \prime}=b_{j}$ for a worker who does not use a computer and $w_{i}^{s}=a_{i} w_{s}{ }^{e d} \theta^{s}-V$ and $w_{j}{ }^{n}=b_{j} \theta^{n}-V$ for one who does, where $V$ represents the costs of the computer. These costs should be interpreted as the costs of the entire deal, i.e. hardware, software, networks, furniture and technical assistance as well as maintenance, depreciation and replacements costs. Note that $V$ is implicitly expressed in terms of $w_{u}{ }^{i v} \cdot{ }^{12}$

Wages and Computer. Adoption: The decision whether or not to adopt a computer can be written as a trade-off between the increased productivity $\theta$ and the costs of the computer $V$, given the worker"s productivity. ${ }^{13}$ The break-even productivity for computer adoption for both types of workers then equals

$$
a_{i}^{b e}=\frac{V}{\left(\theta^{s}-1\right) w_{s}^{e t}}
$$

and

$$
b_{j}^{b e}=\frac{V}{\left(\theta^{t h}-1\right)} .
$$

Equation (5.3a) and (5.3b) show that the break-even productivity at which it becomes beneficial to adopt a computer falls when (i) the costs of the computer $V$ fall, (ii) the productivity gain $0-1$ becomes larger, and (iii) the wage per efficiency unit of labour is higher. Assuming that the costs of the computer are the same for each worker and fall exogenously ${ }^{14}$ and continuously, the

\footnotetext{
${ }^{12}$ Differences in the quality of computers are not considered explicitly. Considering different vintages of computers in a perfectly competitive market, the most productive workers would be assigned to the most recent vintage (which has the highest quality). This would lead to a more pronounced level of wage inequality during the diffusion stage, but not to a differem long-ruth outcome.
}

"Note that the decision to adopt a computer might be different for each individual worker within a firm. This feature of the model is consistent with the literature on inter-and intrafirm technology diffusion. The pattem of diffusion emerging from these studies suggests that the diffusion of new technologies within firms follows a similar pattern as the diffusion of new technologies between fims (e.g., Karshenas and Stoneman, 1993 and Stoneman and Kwon, 1996).

14 The development of computers might also be endogenized by directing a certain fraction of production towards the development of computers. The allocation of labour to a research and 
productivity gain and the wage in terms of efficiency units determine the adoption of the computer. ${ }^{15}$ In other words, if the computer is rather expensive, it is only beneficial for the most productive workers to adopt one. Hence, within both groups computer costs relative to wages determine whether or not it is beneficial for a worker to adopt a computer and differences in computer use between skilled and unskilled workers also depend on differences in productivity gains. ${ }^{16}$

Supply of Efficiency Units: The supply of efficiency units of labour consists of two components. First, the sum of all productivity parameters representing total productivity before computerization. Secondly, the productivity gain $\theta-1$ for all workers using a computer. The supply of efficiency units of both types of workers then looks as follows:

$$
S=S^{e} \int_{\underline{a}}^{\bar{a}} a_{i} P^{s} d a_{i}+S^{e} \int_{a_{i}^{b e}}^{\overline{\bar{a}}}\left(\theta^{s}-1\right) a_{i} P^{s} d a_{j}
$$

and

$$
U=U^{e} \int_{\underline{B}}^{\bar{\beta}} b_{j} P^{u} d b_{i}+U^{e} \int_{b_{j}^{b e}}^{\bar{\beta}}\left(\theta^{u}-1\right) b_{j} P^{u} d b_{j}
$$

Solving these equations results in the two following expressions for the supply of efficiency units of labour:

development department of the firm or economy then leads to falling costs and higher quality of computers. However, endogenizing the development of computers does not yield additional insight into explaining wage inequality. David and Otsen (1986) develop a diffusion model in which the development of new technology is endogenous to the model. Their conditions for adoption are comparable to the ones derived here.

is The costs of the computer might be different for each worker. For example, large firms may have an advantage in maintenance and technical assistance, which leads to lower computer costs per worker. In addition, some workers need a less expensive computer (in terms of the entre deal) than others, which induces earlier adoption, all other things equal. Finally, some workers perform tasks on the basis of ready-made applications, whereas for others with higher wages and higher productivity gains no application is avallable yet. However, for simplicity the assumption made here is that the costs of the computer are given to the worker and are equal for all workers. Assuming different costs leads to earlier or later adoption (given a worker's wage and productivity gain) but do not change the results dramatically.

If, all things being equal, $\theta^{s}-1>\theta^{n}-1$, skilled workers gain more in terms of productivity from using a computer, which is equivalent to arguing that they are more efficient in using the computer. Chennells and Var Reenen (1997), Entorf and Kramarz (1997) and Entorf, Gollac and Kramarz (1999) interpret their findings for the United Kingdom and France of high-wage workers using a computer as results in favour of such an explanation. 


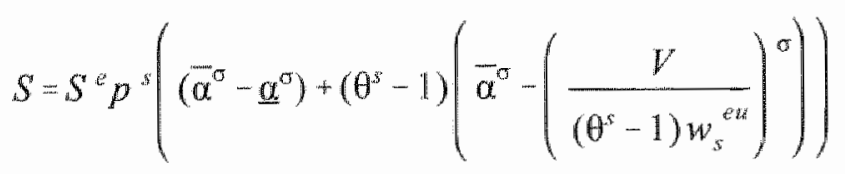

and

$$
\left.U=U^{e} p^{\mu}\left(\bar{\beta}^{\sigma}-\beta^{\sigma}\right)+\left(\theta^{\mu}-1\right)\left(\bar{\beta}^{\sigma}-\left(\frac{V}{\left(\theta^{\mu}-1\right)}\right)^{\sigma}\right)\right) \text {. }
$$

Equations (5.4a) and (5.4b) show that the supply of efficiency units of labour depends positively on the size of the distribution of the productivity parameters $\alpha$ and $\beta$, the proportional productivity gain of using a computer $\theta$ and the elasticity of substitution between skilled and unskilled workers $\sigma$ and depends negatively on the costs of the computer $V$.

\subsubsection{Equilibrium Wages}

To solve the equilibrium relative wages in efficiency units, equations (5.4a) and (5.4b) are substituted into the relative demand equation (5.2). There are five stages in the diffusion process: ${ }^{17}$ (i) no computer use, (ii) the most productive skilled workers use computers, (iii) both types of workers use computers, (iv) all skilled and a fraction of the unskilled workers use computers, and (v) all workers use computers. Table 5.1 shows the relative wages in efficiency units in each of the five stages. If there is no computer use, the relative wage in efficiency units depends on the supply of efficiency units, the distribution of productivity parameters and the elasticity of substitution between skilled and unskilled labour. In the other four stages, the relative wage in efficiency units also depends on the additional productivity from using a computer, the costs of the computer and the additional units of supply of efficiency units of labour.

Table 5.2 reports the solutions of the equilibrium wages for two skilled workers with productivity parameters $a_{1}$ and $a_{2}{ }^{18}$ The level of the wages in efficiency units and the size of the proportional productivity gain are assumed

\footnotetext{
"Note that it is possible that certain stages of diffusion will never become effective because of the overlapping productivity parameters. For example, given wages and proportional productivity gains and the distribution of productivity parameters, a worker with productivity $\bar{\beta}$ could have an only marginally larger productivity than a worker with productivity $\underline{\alpha}$, which would induce computer use among unskilled workers when all skilled workers already have one. This would rule out the third stage.

18 The equilibrim wages for other skilled workers with different productivity parameters and unskilled workers are straightforward from the results presented in Table 5.2.
} 
in such a way that the adoption of computers is assumed to take place in the following order: $\vec{\alpha}, a_{1}, \vec{\beta}, \underline{\alpha}, \beta$ and $\bar{\alpha}, \bar{\beta}, a_{2}, \underline{\alpha}, \underline{\beta}$. First, consider worker 1. with productivity $a_{1}$. When there is no computer use, his wage depends on the relative supply of efficiency units of labour, the distribution of productivity parameters and the elasticity of substitution. At the point in time when $\bar{a}=V /\left(\left(\theta^{s}-1\right) w_{s}{ }^{m}\right)$, the first computer is adopted. Once a computer is adopted, the supply of efficiency units increases as a result of the higher productivity when using a computer (e.g., equation (5.4a)). An increase in the supply of efficiency units of skilled labour has two opposing effects on the relative wage: (i) the rise in the supply depresses the relative wage in efficiency units of all skilled workers and (ii) the productivity of the worker who uses a computer has increased. The equilibrium wage for worker 1 is now lower because the additional supply of efficiency units of skilled labour has depressed the wages of the skilled workers. ${ }^{19}$

Once $a_{1}=V /\left(\theta^{s}-1\right) w_{s}^{e a}$, worker 1 adopts a computer. Now, not only does he no longer suffer from other skilled workers using a computer, but he also benefits from the proportional productivity gain $\theta^{s}$. However, he now has to pay $V$ for adopting the computer. In the third stage, the most productive unskilled worker adopts a computer and worker 1, and all other skilled workers, gain in terms of relative wages, since the extra supply of unskilled labour will increase the wage of skilled labour in terms of efficiency units. ${ }^{20}$ In the fourth stage, all skilled workers receive the productivity gain from working with a computer, but only a fraction of the unskilled workers use computers. As a consequence, the additional supply of efficiency units of skilled labour comes to a stop. This means that once the spread of computers among skilled workers is complete, they benefit from the increased supply of unskilled labour without experiencing negative wage effects from increases in their own supply. Relative wage growth therefore increases and will be positive for all skilled workers. The least productive unskilled worker also adopts a computer and the supply of efficiency units of both skilled and unskilled labour remains unchanged. With a falling costs of computers, wage differentials will fall since workers with lower wage benefit relatively more than higher wage workers. Ultimately, the relative wage equals $\left(\theta^{s} / \theta^{\prime \prime}\right)^{p}$ times the relative wage before the computerization.

\footnotetext{
19. The relative wage of the most productive skilled worker will initially also go down because at the break-even point the positive productivity effect is suppressed by $V$.
}

${ }^{20}$ A consequence of unskilled workers starting to use computers is that skilled workers who are not using computers also gain from this increased supply of unskilled labour in terms of relative wages. Due to the endogeneity of wages in the model, the rise in skilled wages increases the pace of computer adoption among skilled workers, which at the same time increases skilled labour supply in efficiency units. This effect somewhat dampens the increasing relative wages. 


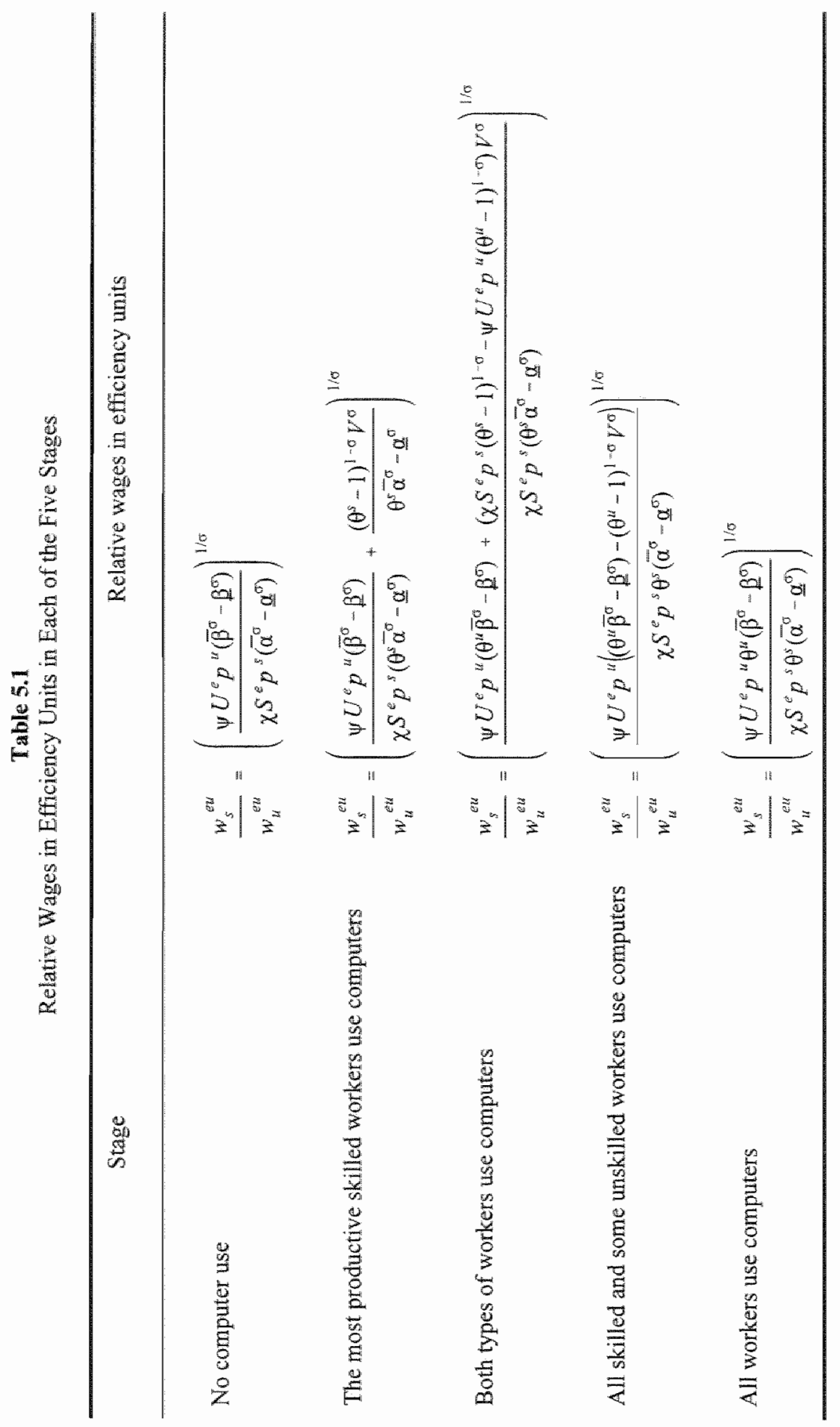



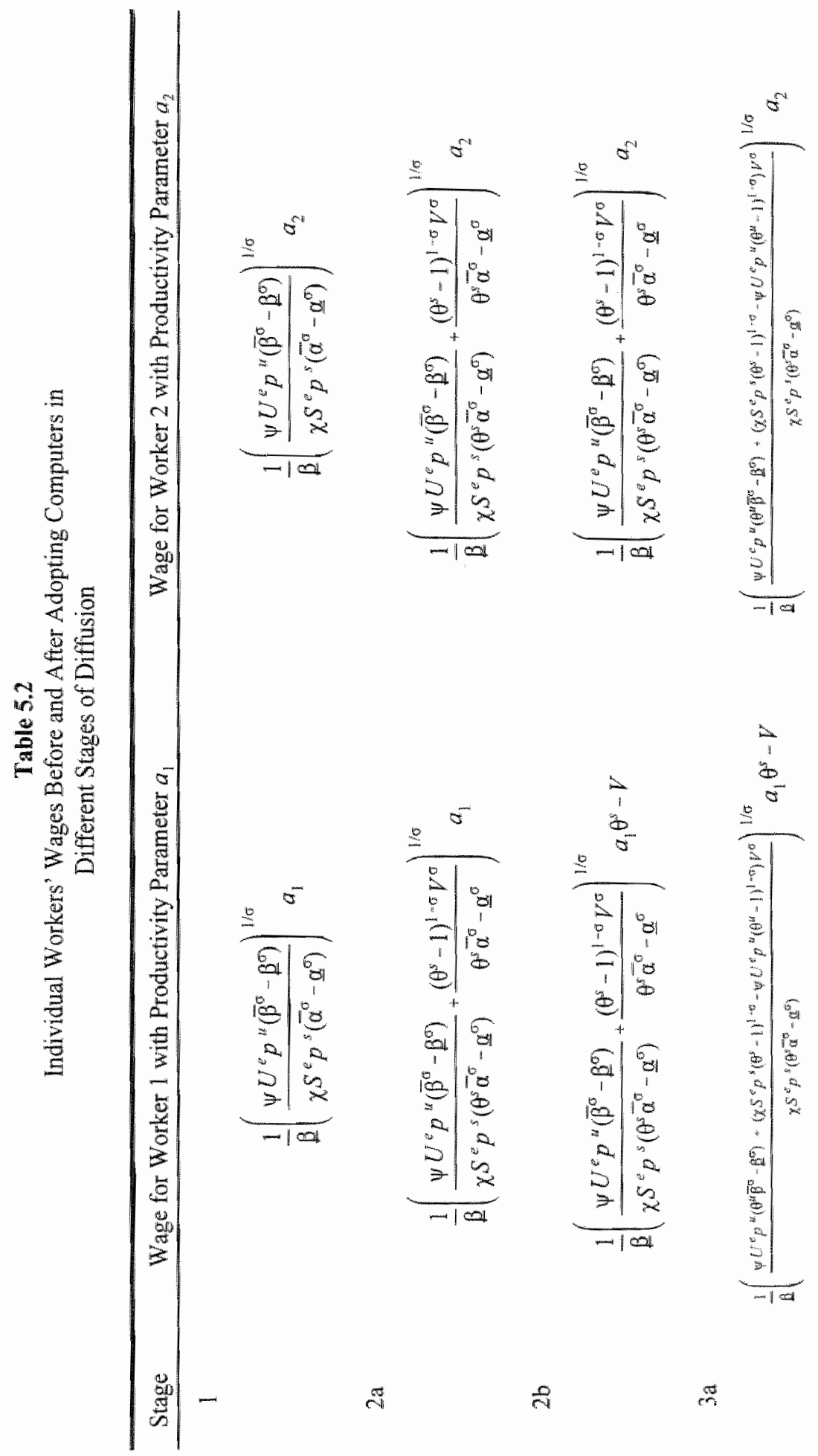

กึ

i

基 


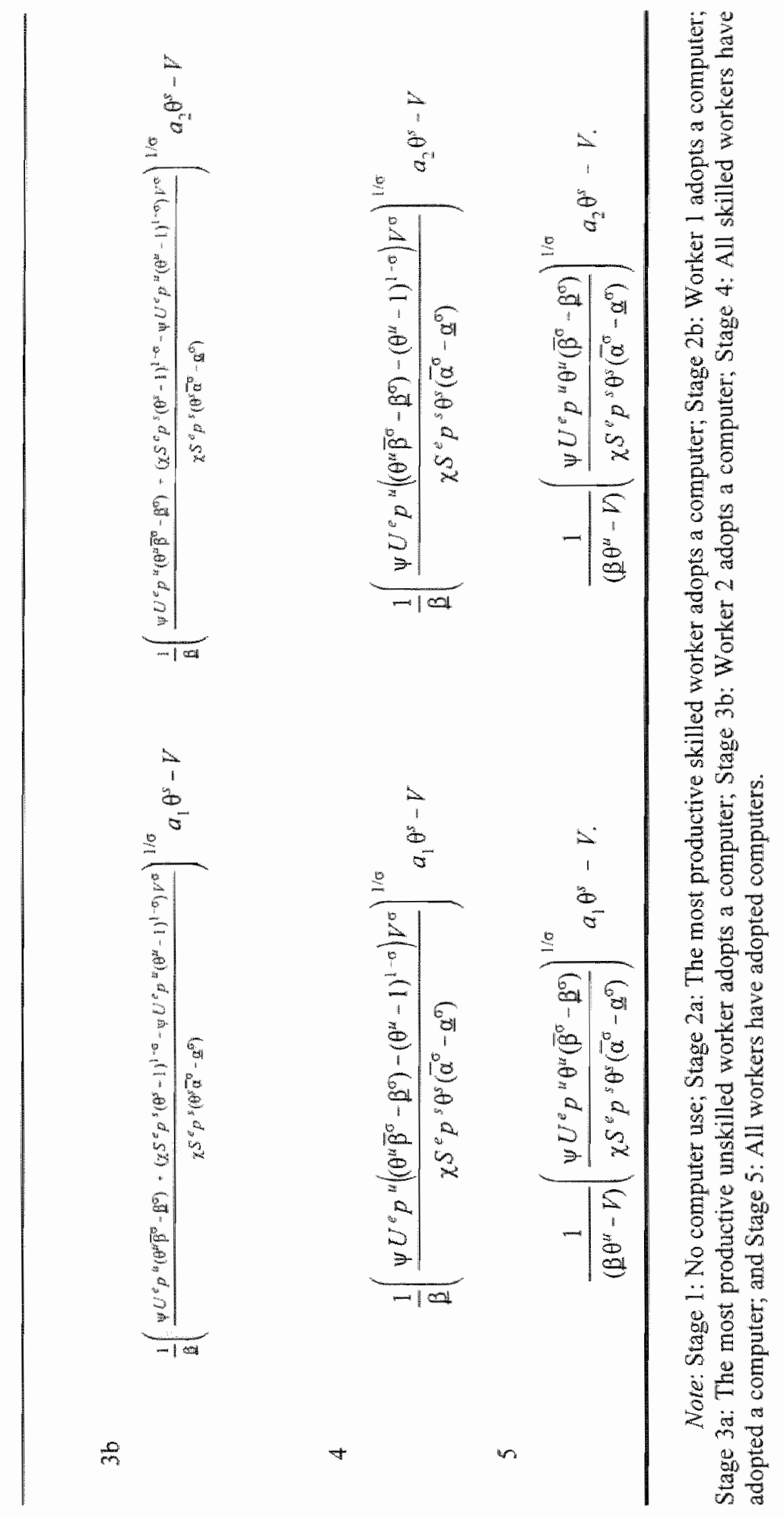


The relative wages of worker 2 are shown in the second column of Table 5.2. For worker 2 with productivity $a_{2}$ the first two stages show a similar relative wage. However, he only adopts a computer after the most productive unskilled workers have adopted one. This means that in the third stage his wages are already increasing (compared to stage 2) despite the fact that he did not adopt a computer yet. This fosters his adoption of computers because a higher wage induces computer use. When he adopts the computer at $a_{2}=V /\left(\theta^{s}-1\right) w_{s}^{c u}$, his wage increases further. Finally, the last two stages show the same pattern of relative wages as in the case of worker 1.

\subsubsection{Wage Inequality and Diffusion over Time}

Figure 5.2 presents the predictions of the model for the wages of workers with productivity levels $\bar{\alpha}, \underline{\alpha}$ and $\bar{\beta}$ relative to the least productive worker with productivity $\$$, in terms of the falling costs of adopting computers.

Figure 5.2

Relative Wages over Time

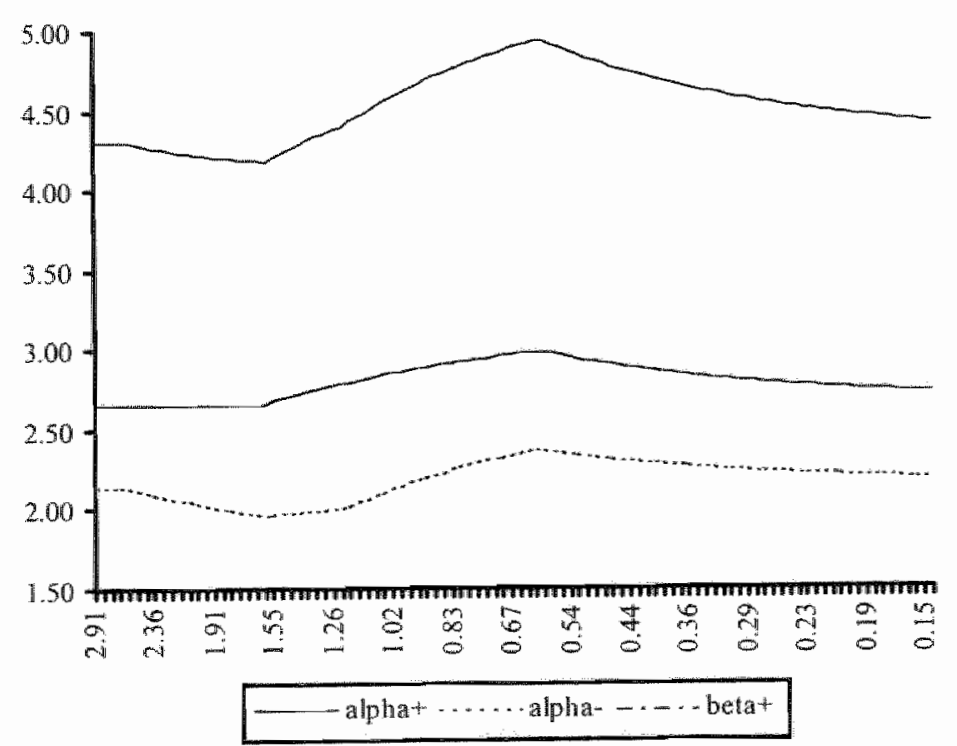

Note: The horizontal axis reports the falling costs of computers. The costs of computers are assumed to fall according to the following relationship: $V_{t}=A e^{-B t}$, where the following parameters are used: $A=3$ and $B=.03$. To generate Figure 5.2 , the following parameters are assumed: $S=100, \quad=200, \quad \rho=3, \chi=\psi=1, \vec{\alpha}=10, \alpha=5, \bar{\beta}=8, \beta=3$ and $\theta^{s}=\theta^{\prime \prime}=1.2$ 
The figure shows that if only a fraction of the skilled workers uses a computer, the relative wages for computer adopters fall relative to the least productive unskilled workers, which reflects the net effect of the productivity gain and the additional supply of efficiency units of skilled labour at the first stage of adoption. The negative effect of additional supply is captured by the line for the non-users from the skilled labour force. After the most productive unskilled workers have adopted computers, the wages of both skilled and unskilled workers rise relative to the least productive unskilled worker because the additional supply of efficiency units of unskilled labour dampens the wages of unskilled workers and because the increased productivity of unskilled adopters versus non-adopters. When all skilled workers have adopted computers, wage inequality within the group of skilled workers becomes constant, whereas the wages of skilled workers as a group are still rising relative to the wages of the unskilled workers due to the increase in the supply of efficiency units of unskilled workers adopting computers. Finally, when all workers use computers at work, wage inequality falls. If the costs of computers fall further, both between and within-group wage inequality fall, the extent depending on the different distributions and size of the productivity gains $\theta$.

\subsection{Is Wage Inequality Temporary or Permanent?}

If the costs of adopting computers are equal for skilled and unskilled workers and are falling continuously, there are two factors determining computer adoption that shape between-group wage inequality: (i) differences between the proportional productivity gains $\theta^{s}$ and $\theta^{\prime z}$ and (ii) differences in wages (e.g., equations (5.3a) and (5.3b)). Comparison of the first and final rows of Table 5.2 reveals for workers 1 and 2 that at the point of satiation their relative wages only differ from their relative wages before computerization by the factor $\left(\theta^{s} / \theta^{w}\right)^{\beta}$. This result implies that when the costs of computers fall sufficiently (i) between-group wage inequality is only a temporary phenomenon if the proportional productivity gains from using a computer are equal $\left(\theta^{x}=\theta^{t}\right)$, and (ii) differences in wages determining a different adoption point in time also lead to a temporary increase in wage inequality between those who already adopted a computer and those who did not do so yet.

The first result suggests that if $\theta^{x}>\theta^{x}$ between-group wage inequality will be permanently higher. The size of this effect depends on the elasticity of substitution and the difference between the proportional productivity gains. Similarly, if $\theta^{s}<\theta^{u}$, between-group wage inequality will be permanently lower. Figure 5.3 graphically presents these three possibilities for worker $i$ with productivity parameter $a_{i}=\bar{\alpha}$. In all three cases between-group wage inequality first falls, then sharply rises and eventually falls again. If $\theta^{x}=\theta^{*}$, between-group wage inequality resulting from computerization is a temporary 
phenomenon. If $\theta^{s}>\theta^{s}$, skilled workers adopt computers earlier (when they are more expensive) because the productivity gain is higher. This induces a faster diffusion process, which first leads to a larger drop in the skilled workers' wages but then to a stronger increase in between-group wage inequality.

\section{Figure 5.3}

Between-Group Wage Inequality over Time for Differences in Proportional Productivity Gains for Skilled and Unskilled Workers

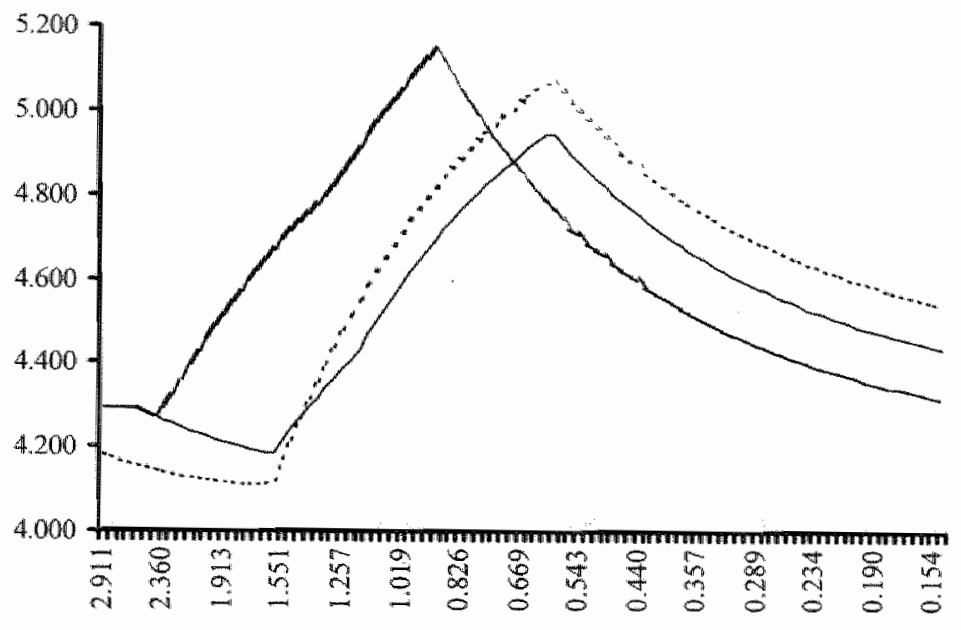

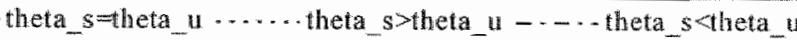

Note: The horizontal axis reports the falling costs of computers. The costs of computers are assumed to fall according to the following relationship: $V_{t}=A e^{-\beta t}$, where the following parameters are used: $A=3$ and $B=.03$. To generate the lines in Figure 5.3 , the following parameters are assumed if $\theta^{s}=\theta^{\prime \prime}: S=100, \quad U=200, \rho=3$, $x=\psi=1, \bar{a}=10, \underline{\alpha}=5, \bar{\beta}=8, \underline{\alpha}=3$ and $\theta^{s}=\theta^{x}=1.2$. if $\theta^{s}>\theta^{*}$, the same parameters are inchuded except $\theta^{5}=1.3$. If $\theta^{5}<\theta^{2}$, the same parameters are used but $\theta^{4}=1.2$ and $a^{x}=1.3$.

Eventually, between-group wage inequality falls (at the same point in time as in the situation where $\theta^{s}=\theta^{\prime}$ ) but has a permanent component depending on the size of $\rho$ and the difference between $\theta^{8 *}$ and $\theta^{\prime \prime}$. If $\theta^{* *}>\theta^{*}$, unskilled workers adopt computers earlier. This first leads to a smaller drop in skilled workers' wages because they gain at an earlier stage from the adoption of computers by unskilled workers. The effect of the additional supply of unskilled workers earlier on fosters the diffusion process among skilled workers and leads to a higher peak in between-group wage inequality. When all unskilled workers have adopted computers (at a higher 
level of computer costs), between-group wage inequality falls to a level which is lower than the initial level of between-group wage inequality, its size depending on $\rho$ and the difference between $\theta^{* *}$ and $\theta^{u}$. A similar exercise for within-group wage inequality reveals similar patterns of the extent and point in time of rising and falling wage inequality. ${ }^{21}$

The second result suggests that differences in the productivity parameters $a$ and $b$ between workers have no permanent effect on between-group wage inequality. If the proportional productivity gains are similar within both groups, differences in productivity parameters will only influence the length of the diffusion process and the extent of between-group wage inequality in the different phases of computer adoption. If all workers shared the same productivity parameter, they would adopt computers at the same point in time and there would also be no within-group wage inequality. This reveals that within-group wage inequality is also a temporary phenomenon, given that the proportional productivity gains are similar within both groups and that the costs of computers drop sufficiently.

\subsection{The Timing of Wage Inequality}

The trends presented in Figure 5.1 suggest that if one wants to draw causal relationships between the computerization of the labour market and rising wage inequality, it is important to understand and acknowledge the different timing of between-group and within-group wage inequality. Withingroup wage inequality for skilled workers has increased since the early 1970 s, within-group wage inequality for unskilled workers started to increase in the early 1980 s and between-group wage inequality fell until 1980 and increased strongly afterwards.

Within-group wage inequality for worker 1 with productivity $a_{1}$ is described by

$$
\frac{a_{1}}{\underline{\alpha}}\left(\theta^{s}-\frac{v}{w_{s}^{e u}\left(V, \theta^{s}, \theta^{u}\right) a_{1}}\right),
$$

which is decreasing in $V$ and increasing in the size of the distribution of productivity parameters and the wage in efficiency units. The extent of within-

\footnotetext{
${ }^{21}$ These results crucially depend on the assumption that there are no within-group differences in the proportional productivity gains. If this were the case and workers with a higher productivity parameter gained more from using a computer, between-group wage inequality would be permanent depending on the distribution of productivity parameters. In addition, this would induce within-group wage inequality, the size of which would also depend on the distribution of productivity parameters.
} 
group wage inequality also depends on the proportional productivity gains $\theta^{*}$ and $\theta^{2 i}$ : (i) a larger $\theta^{s}$ induces earlier adoption, and (ii) $\theta^{s}>\theta^{x i}\left(\theta^{s}<\theta^{u}\right)$ leads to a larger (smaller) difference in the timing of adoption. This means that within-group wage inequality is driven by the productivity parameters, the level of wages, the proportional productivity gains and the costs of computers. The different timing of within-group wage inequality resulting from the adoption of computers is then caused by (i) higher productivity parameters and wages for skilled workers, and (ii) higher proportional productivity gains for skilled workers, which made adoption beneficial at an earlier stage. Figure 5.4 plots the conjectures of the model for within-group wage inequality for skilled and unskilled workers as a function of the falling costs of computers. The figure shows that the increase in within-group wage inequality for skilled (unskilled) workers started when the first skilled (unskilled) workers adopted computers, which is consistent with the trends presented in Figure 5.1 a.

The behaviour of between-group wage inequality is driven by three mechanisms. First, when the first skilled worker adopts a computer, his wage equals the break-even wage but one period later his wage will be higher than the break-even wage because of the continuously falling costs of computers and the gains from using the computer. Secondly, when using a computer this worker generates more efficiency units of skilled labour, which decreases the wage in efficiency units (e.g., equation (5.4a)). Thirdly, when the first unskilled workers start to use computers, all skilled workers benefit in terms of relative wages because the additional supply of efficiency units of unskilled workers depresses their wages. The first and third mechanism induce a rise in between-group wage inequality and the second mechanism depresses between-group wage inequality.

The timing of between-group wage inequality resulting from the computerization of the labour market can then be understood as follows. When the first skilled worker gets a computer, the derivative of his wage with respect to $V$ equals

$$
\frac{\partial w_{i}^{\alpha}}{\partial V}=\frac{1}{B}\left(\frac{\theta^{s} \bar{\alpha}^{\sigma}}{\theta^{s} \bar{\alpha}^{\sigma}-\underline{\alpha}^{\sigma}}-1\right)>0 .
$$

Wage inequality between the most productive skilled worker and the least productive unskilled worker increases when this derivative is negative, since $V$ is decreasing in time. It is easy to see that the derivative is always positive, so initially the introduction of the computer among skilled workers reduces between-group wage inequality. This means that the increasing supply of efficiency units of skilled labour outweighs the proportional productivity gain at the break-even point. 
Figure 5.4

The Timing of Within-Group Wage-Inequality

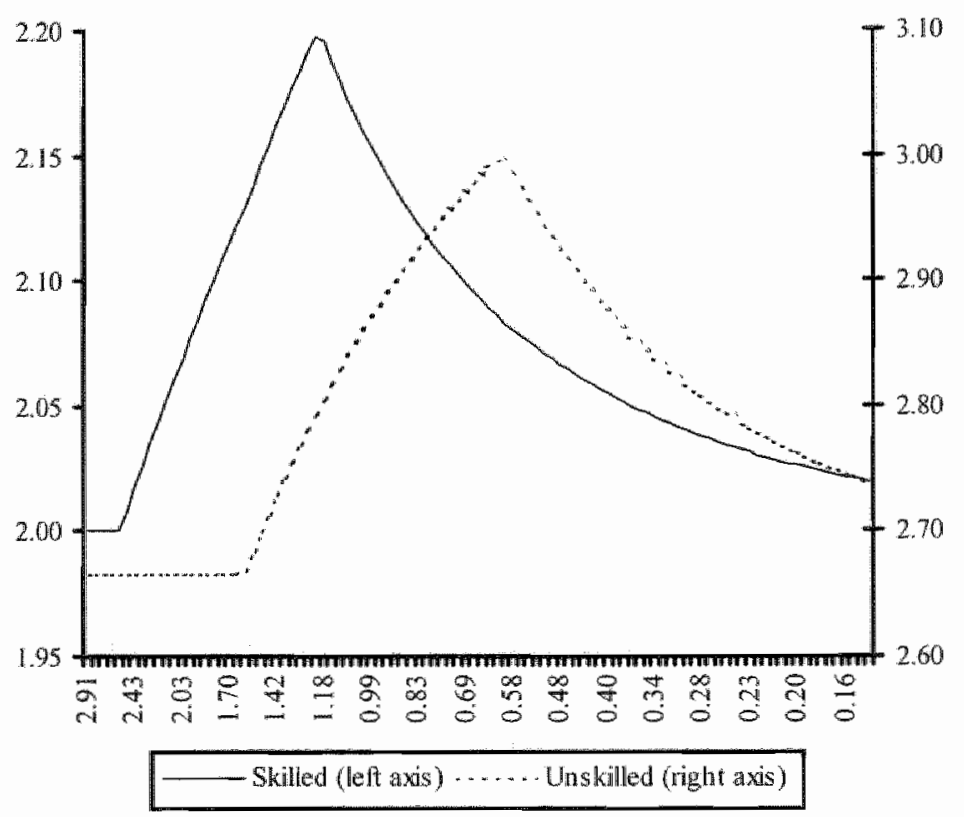

Note: The horizontal axis reports the falling costs of computers. The costs of computers are assumed to fall according to the following relationship: $V_{t}=A e^{-B t}$, where the following parameters are used: $A=3$ and $B=.03$. To generate Figure 5.4 , the following parameters are assumed: $S=100, \quad U=200, \quad=3, \chi=\psi=1, \bar{\alpha}=10, \underline{\alpha}=5, \bar{\beta}=8, \beta=3$ and $\theta^{s}=\theta^{n}=1.2$.

This situation is reversed when

$$
a_{i}=\bar{\alpha}\left(\frac{\theta^{s} \bar{\alpha}^{\sigma}-\underline{\alpha}^{\sigma}}{\theta^{\alpha} \bar{\alpha}^{\sigma}}\right)^{1 /(\sigma-1)}
$$

because at this point the derivative of the wage with respect to $V$ equals zero. ${ }^{22}$ Once it becomes beneficial for the unskilled workers to start using a computer at work, between-group wage inequality rises because $\left(\psi U^{c} P^{n}\left(\theta^{u}-1\right)^{1-\sigma}\right) /\left(\chi S^{c} P^{s}\right)>0$. This term is always positive, since $\theta^{u}>1$. The rise in between-group wage inequality is larger if the proportional productivity gain for unskilled workers is larger (see also the higher peak for

22 This result is consistent with the observations of Entorf and Kramarz (1997) for France. They observe that a worker's wage does not jump immediately when he adopts a computer but increases to a higher level rather slowly. 
$\theta^{v *}>\theta^{v_{t}}$ in Figure 5.3) and if $\left(\psi U^{e} P^{u}\right) /\left(\chi S^{e} P^{s}\right)$ is relatively large. This implies that the additional supply of efficiency units of unskilled workers depresses their wages and induces between-group wage inequality to rise. Depending on the size of the proportional productivity gain and the distribution of productivity parameters, this rise can be more or less severe. Hence, between-group wage inequality starts to increase once unskilled workers adopt computers, which is consistent with the timing of the increase in between-group wage inequality depicted in Figure $5.1 \mathrm{~b}$. Between-group wage inequality will continue to rise if $-\partial w_{a} / \partial V>-\partial w_{b} / \partial V$, which will be the case as long as $a_{i}>b_{j}\left(\theta^{a} / \theta^{s}\right)$. Given $\theta^{*}=\theta^{s}$, between-group wage inequality falls once the diffusion of computers is complete.

\subsection{Empirical Analysis}

\subsubsection{Data and Construction of Variables}

The March Demographic Supplements of the CPS from 1964 to 2001 are used in the empirical analysis for information about the standard labour-market variables and to construct labour supply. The October Supplements from 1984, 1989,1993 and 1997 are used for information about computer use.

Labour supply is computed for skilled and unskilled workers. Skilled workers are defined as workers with at least a completed college education and unskilled workers as the other ones. Workers who have been employed in the previous year are used. Full-time workers are weighted with a factor 1, and parttime workers with the number of hours worked in the preceding week divided by 40 (the average number of hours worked by the full-time workers). Since the exact number of weeks worked is not known for several years in the data, fullyear workers are weighted with a factor 1 and part-year workers with a factor one half. ${ }^{23}$

To avoid measurement problems, part-time and part-year workers are not included when constructing the wage variable. Only full-time full-year salaries are used, which provides information on the gross annual wages. Since the dispersion in productivity parameters, reflected by wage differentials within the groups of skilled and unskilled workers, is essential to the model, no correction has been made for demographic factors. To compute real wages the price deflator for personal consumption expenditures from the National Income Product Accounts (NIPA) is applied. ${ }^{24}$ In terms of the model, wage differentials

\footnotetext{
23 The use of alternative weights does not change the results in a qualitative sense.
}

3* The data are taken from the Annual Revision of the NIPA made avalable by the Bureau of Economic Analysis. $1992=100$. 
between skilled and unskilled workers are of interest but within-group wage differentials are also important. The average wages for workers with productivity $\bar{a}$ are defined as the $90^{\text {th }}$ percentile of the wage distribution of skilled workers and the average wages for workers with productivity $\underline{\alpha}$ as the $10^{\text {th }}$ percentile of this wage distribution. Similarly, the average wages for workers with productivity $\bar{\beta}$ are defined as the $90^{\text {th }}$ percentile of the unskilled workers" wage distribution and the average wages for workers with productivity $\beta$ as the $10^{\text {thi }}$ percentile of the unskilled workers" wage distribution. ${ }^{25}$ Since the composition of the U.S. labour force changed in the period 1963-2000, an alternative measure of the wage development has also been used. This alternative measure has been constructed by defining 32 cells for four age group, four educational groups and controlling for gender. ${ }^{26}$ These 32 cells have been weighted such that the year 2000 is the base year. Thus, the composition of the workforce and labour supply within the groups of skilled and unskilled workers is equal in all years. ${ }^{27}$

Information about computer use at work is available only for four years in the October Supplements. From these years, computer use has been imputed for 1963-2000. Using full-time full-year workers, computer use among skilled workers equals 45.2 (1984), 62.8 (1989), 70.4 (1993) and 76.6 (1997) percent. Among full-time full-year unskilled workers computer use equals 21.6 percent in $1984,33.1$ percent in $1989,37.6$ percent in 1993 and 42.8 percent in 1997. To calculate computers use in the other years, the wages of the marginal worker using a computer have to be identified. For 1984, the marginal skilled worker is assumed to be at the $54.8^{\text {th }}$ percentile $(100-45.2$ percent computer use) of the wage distribution. A similar exercise is performed for the other three years and the unskilled workers. Using these four data points and years, the equation $\ln w=C+\alpha Y+\varepsilon$ is estimated for skilled and unskilled workers, where $\ln w$ is the $\log$ of the real annual wage, $C$ is a constant, $Y$ are the years for which computer use is known and $\varepsilon$ is an error term with the usual properties. In this setting $\ln w$ can be treated as the break-even wage. Using the October wages the equation for skilled workers is $\ln w=8.240-.030 \mathrm{Y}$ and that for unskilled workers is $\ln w=7.633-.024 Y$. To generate computer

${ }^{25}$ In the regression analysis also included tests whether the results are sensitive to using the $80^{\text {th }}, 70^{\text {th }}, 20^{\text {th }}$ and $30^{\text {th }}$ percentiles of both wage distributions.

26. The age groups are $<29,30-39,40-49$ and $>50$, the educational groups are less than highschool, highschool degree, more than highschool but less than a college degree, and a college degree or more.

${ }^{27}$ The use of more than 32 cells does not significantly change the regression results but leads in some instances to rather low numbers of workers in each cell. The use of less than 32 cells also gives comparable results. 
use, all workers with wages in year $Y$ above the break-even wage are set to use a computer at work.

Figure 5.5

Imputed Computer Use in the United States 1963-2000

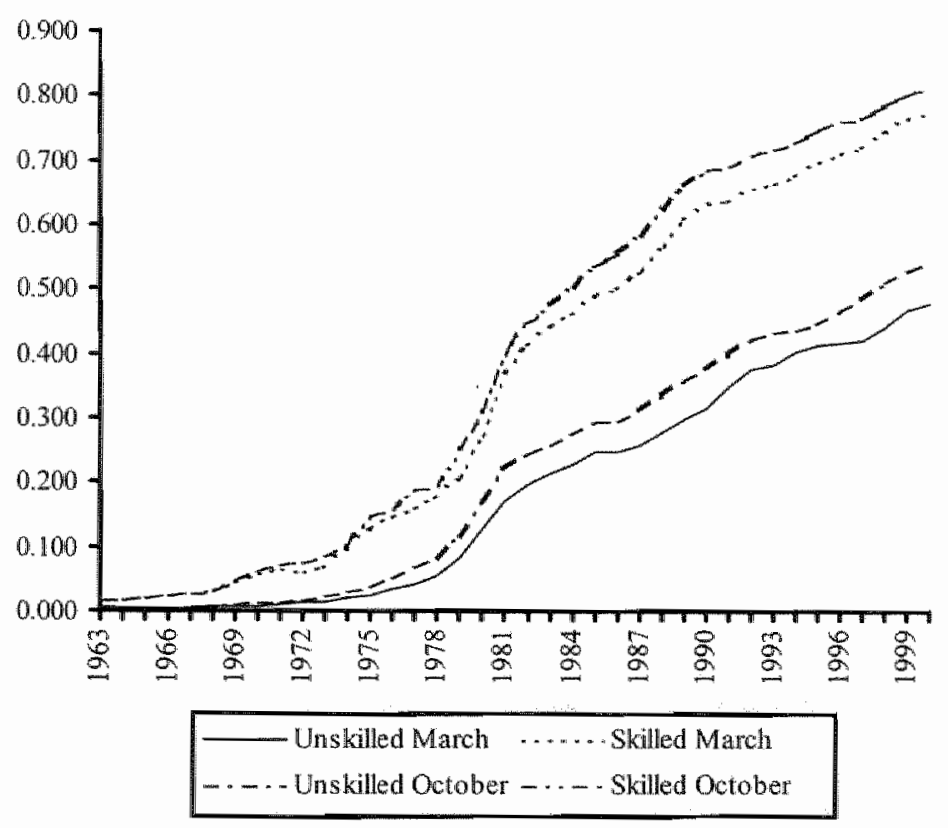

Note: All data are taken from the March CPS from 1964 to 2001. The imputed March series in Figure 5.5 are generated by estimating a wage equation using real March wages to estimate a wage equation for the years in which computer use is available. "The imputed October series use real October wages to estimate a wage equation for the years in which computer use is available.

Figure 5.5 plots this imputed computer use for the 1963-2000 period for both using the October and March wages to estimate computer use. ${ }^{28}$ The pattern of diffusion is consistent with the often found S-shaped diffusion pattern of new technologies. ${ }^{29}$ From Figure 5.5 it can be read that computer use for the skilled workers has increased rather rapidly since the early $1970 \mathrm{~s}$ and that computer use for the unskilled workers started to rise around 1980. The

\footnotetext{
${ }^{28}$ Using the March wages results into $\ln w=8.149-.028 Y$ for skilled workers and $\ln w=7.905-.026 Y$ for unskilled workers.

${ }^{29}$ See e.g., David (1969) for a clear exposition of the S-curve of technology diffusion.
} 
percentage of computer use in 1984 among skilled workers predicted by the imputation is 46.3 percent for the March wages and 50.4 percent for the October wages, whereas real computer use among skilled workers equals 45.2 percent. ${ }^{30}$ For the other years, the predicted and observed figures are also comparable. ${ }^{31}$ This implies that the estimates of computer use based solely on break-even wages mirrors the adoption of computers relatively well.

\subsubsection{Econometric Specification of the Model}

In the theoretical model, assumptions about the distribution of productivity parameters have been made to generate an analytical solution. For the estimation the actual distribution of productivity parameters is used. In accordance with the labour demand equation (5.2) and allowing for a time trend $\left(e^{\gamma}{ }^{\prime}\right)$ in the wages, the relative wage in efficiency units equals

$$
w^{e u}=\left(\frac{\psi U}{\chi S}\right)^{1 / \sigma} e^{\gamma_{1} t} .
$$

The supply of skilled labour $S$ in efficiency units can be determined from

$$
S=S^{e}+S^{e}\left(\theta_{s}-1\right) F_{s},
$$

where $F_{s}$ denotes the fraction of efficiency units of skilled workers using a computer. This fraction equals

$$
F_{s}=\frac{\int_{c u} a_{i} p^{s} \mathrm{~d} a_{i}}{\int_{c h} a_{i} p^{s} \mathrm{~d} a_{i}+\int a_{i} p^{s} \mathrm{~d} a_{i}},
$$

where $c u$ is defined as computer users and no as non-users. From this equation, $a_{i}$ is not observed directly, but can be derived from the information about wages

30 This prediction for computer use is consistent with the figures presented by Greenwood and Yorukoglu (1997) and Jorgenson (2001) on the falling prices and subsequently rising investments in and use of computers at work.

The predicted figures equal 61.5 (1989), 67.0 (1993) and 72.6 (1997) percent for the March wages and 66.5 (1989), 72.2 (1993) and 77.1 (1997) for the October wages. For unskilled workers predicted computer use equals $23.0(27.6), 30.1(36.0), 38.5(43.5)$, and $42.3(48.7)$ for the March (October) wages in the four years for which real computer use is known. These figures show that compared to actual computer use at work, the March sample under predicts computer use and the October sample over predicts computer use to some extent. 
according to

$$
a_{i}=\frac{w_{i}+V}{\theta_{s}}=\frac{w_{i}+\left(\theta_{s}-1\right) w_{h e}^{s i}}{\theta_{s}} .
$$

In principle, this expression could be substituted in equation (5.6) and estimated. However, analysis of the data shows that for reasonable values of $\theta_{s}, F_{s}$ is almost constant in $\theta_{*}$. To avoid estimation problems, $F$ is therefore approximated by

$$
F_{s}=\frac{\int w_{i} p{ }^{s} \mathrm{~d} a_{i}}{\int_{c a} w_{i} p{ }^{s} \mathrm{~d} a_{i}+\int_{n o} w_{i} p{ }^{s} \mathrm{~d} a_{i}},
$$

which can be understood as the wage-bill share of computer users as a fraction of the wage bill of all skilled workers.

For unskilled workers, $F_{u}$ is approximated in a similar way. The supply of unskilled workers in efficiency units equals $U=U^{e}+U^{e}\left(\theta_{u}-1\right) F_{u}$. Substituting this expression in equation (5.5) and (5.6) provides an econometric equation for the wage ratio of skilled and unskilled labour in efficiency units.

Another problem is that wages in terms of efficiency units are not directly observed. To evaluate the theoretical model, the following has been estimated: (i) the wage ratio of skilled versus unskilled workers, (ii) the $90^{\text {th }}-10^{\text {th }}$ percentile wage differential of skilled workers, and (iii) the $90^{\text {th }}-10^{\text {th }}$ percentile wage differential of unskilled workers. The wage of a skilled worker equals

$$
w_{i}=\gamma_{0} w_{s}^{e x t}+\gamma_{0}\left(\theta_{\mathrm{si}}-1\right) w_{s}^{e x t} C_{i}^{s}-V C_{j}^{s} \text {, }
$$

where $C_{i}^{s}=1$ if worker $i$ uses a computer and 0 otherwise. Since $V=\left(\theta_{s}-1\right) w_{b e}$, averaging over all skilled workers leads to

$$
\bar{w}_{s}=\gamma_{0} w_{s}^{c u}+\gamma_{0}\left(\theta_{s}-1\right) w_{s}{ }^{\prime \prime \prime} \bar{C}-\left(\theta_{s}-1\right) w_{b c} \bar{C}
$$

where a bar over a variable indicates an average term. Dividing by $\bar{w}_{u}$, rearranging terms and taking logs gives

$$
\ln \left(\frac{\bar{w}_{s}}{\bar{w}_{w}}\right)=\ln \left(\gamma_{0} w^{u} Z+\gamma_{0}\left(\theta_{s}-1\right) w^{e u} \bar{C}-\left(\theta_{s}-1\right) \frac{w_{b e}}{\bar{w}_{w}} \bar{C}\right),
$$

where $Z=\left(\bar{w}_{u}+\left(\theta_{u}-1\right) w_{b e}^{u} \bar{C}_{u}\right) /\left(\bar{w}_{u}\right)$. Substituting equation (5.5) for $w^{e t t}$, this equation can be estimated by non-linear least squares with 
$\theta_{s}, \theta_{u}, \gamma_{0}$ and $\gamma_{j}$ as the unknown parameters. If not all subgroups of skilled workers are equally substitutable with unskilled workers and vice versa, the estimate for between-group wage inequality will underestimate the productivity gains from computer use, because such productivity gains have not affected the other group.

In a comparable way, the $90^{\text {ih }}-10^{\text {th }}$ percentile wage differential within the group of skilled workers can be written as

$$
w_{90^{j i t}}^{s}=\gamma_{0} w_{s}^{e s i}+\gamma_{0}\left(\theta_{s}-1\right) w_{s}^{e u} C_{90^{j h}}^{s}-V C_{90^{s i s}}^{s}
$$

where $C_{90^{s_{i}}}^{*}$ indicates the years in which the $90^{\text {th }}$ percentile of the wage distribution of skilled workers adopted a computer. According to the imputed computer use data, this is after $1974 .{ }^{32}$ Dividing by equation $(5.10) w_{10^{\text {th }}}^{s}$ yields the equation for estimating within-group wage inequality:

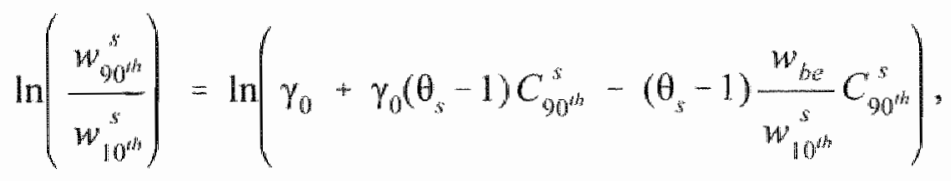

which also has to be estimated by non-linear least squares. Similarly, the regression equation for the within-group inequality of unskilled workers is

$$
\ln \left(\frac{w_{90^{t h}}^{u t}}{w_{10^{t h}}^{u t}}\right)=\ln \left(\gamma_{0}+\gamma_{0}\left(\theta_{u t}-1\right) C_{90^{u t h}}^{u t}-\left(\theta_{u}-1\right) \frac{w_{b c}}{w_{10^{t h}}^{u t}} C_{90^{u h}}^{u}\right) \text {. }
$$

If there is heterogeneity in the computer equipment, the estimate for withingroup wage inequality will overestimate the average productivity gains from computer use because it measures the productivity gains of the worker at the $90^{\mathrm{ilh}}$ percentile relative to the worker at the $10^{\mathrm{h}}$ percentile. If the allocation of computers is optimal, the most productive worker will get the best computer.

\subsubsection{Basic Estimates}

Table 5.3 reports estimates for $1963-2000$ of $\ln w^{e n}=\alpha t+\beta \ln (S / U)+\varepsilon$, which is similar to the equation used by Katz and Murphy (1992) to estimate for the period 1963-1987. The first column reports estimates not taking into

\footnotetext{
32 For the March series computer use among skilled workers equals 10.0 percent and for the October series computer use equals 10.6 percent in 1974.
} 
account any additional efficiency units of labour resulting from computerization. In the next four columns, the additional supply of efficiency units are controlled for by including $\theta^{*}$ after 1974 and by including $\theta^{*}$ after $1980 .{ }^{33}$ In the second column, $\theta^{s}=\theta^{u}=1.2,1.3$ in the third column, and 1.4 in the fourth column. The last three columns report estimates for $\theta^{\text {ti }}=1.1$ and $\theta^{5}=1.2,1.3$ and 1.4. The rows at the bottom of Table 5.3 report estimates when weighing the supply of labour and wages to keep the composition of the labour force constant.

Table 5.3

Some Basic Estimates of the Time Trend and the Elasticity of Substitution for Different Productivity Gains from Using Computers

\begin{tabular}{cccccccc}
\hline & $\theta=1$ & $\theta=1.2$ & $\theta=1.3$ & $\theta=1.4$ & $\begin{array}{c}\theta^{s}=1.2 \\
\theta^{n}=1.1\end{array}$ & $\begin{array}{c}\theta^{s}=1.3 \\
\theta^{*}=1.1\end{array}$ & $\begin{array}{c}\theta^{s}=1.4 \\
\theta^{*}=1.1\end{array}$ \\
\hline \multirow{3}{*}{$\beta$} & -.549 & -.464 & -.412 & -.366 & -.453 & -.390 & -.339 \\
& $(.105)$ & $(.066)$ & $(.056)$ & $(.048)$ & $(.074)$ & $(.067)$ & $(.061)$ \\
$\alpha$ & .024 & .021 & .019 & .018 & .022 & .020 & .019 \\
& $(.004)$ & $(.003)$ & $(.002)$ & $(.002)$ & $(.003)$ & $(.003)$ & $(.003)$ \\
\hline \multirow{2}{*}{$\beta$} & -.531 & -.536 & -.493 & -.448 & -.550 & -.513 & -.472 \\
& $(.179)$ & $(.116)$ & $(.097)$ & $(.083)$ & $(.121)$ & $(.103)$ & $(.089)$ \\
$\alpha$ & .028 & .028 & .027 & .025 & .030 & .030 & .030 \\
& $(.007)$ & $(.005)$ & $(.004)$ & $(.003)$ & $(.005)$ & $(.005)$ & $(.004)$ \\
\hline
\end{tabular}

Note: All data are taken from the 1964-2001 March CPS files. The dependent variable is the log of the ration of the average wages of skilled and unskilled workers. Skilled workers started to use computers in 1974 and unskilled workers in 1980.

The regression results reported in the first column are comparable to the estimates reported by Katz and Murphy (1992). They obtain an estimate for $\beta$ of -.71 for a comparable but different definition of skilled and unskilled workers, compared to -.55 here, suggesting an elasticity of substitution between skilled and unskilled workers of $1.82(-1 / \beta)$. The use of the weighted series does not lead to a significantly different estimate. The annual increase in the demand for skilled labour is about 2.4 percent, which is lower than the 3.3 percent obtained by Katz and Murphy (1992). Adjustment of the supply of skilled and unskilled

\footnotetext{
33 These are the years in which 10 percent of the population within both groups use computers according to the imputed computer use shown in Figure 5.5. Including years close to 1974 and 1980 does not substantially change the results. Including thresholds of 5 and 15 percent does not qualitatively change the results.
} 
workers by including the additional supply of efficiency units of labour resulting from computer use leads to significantly higher estimates for the elasticity of substitution between skilled and unskilled labour. For the nonweighted series, the elasticity of substitution increases to 2.73 if $\theta^{s}=\theta^{t t}=1.4$, with the annual increase in the demand for skilled labour remaining being fairly constant. Similarly, the results are comparable when assuming different proportional productivity gains for skilled and unskilled workers (here the elasticities of substitution lie between 2.21 and 2.95). Because the regression includes only 38 aggregate observations and there is likely to exist serial correlation in the relative wages, these estimates have to be interpreted with care. However, the estimates being larger when including the adjusted labour supply series suggest an increase in wage inequality to explain the pattern of the data. Whereas Katz and Murphy (1992) explain the trend towards lower between-group wage inequality in the $1970 \mathrm{~s}$ and rising wage inequality since 1980 by a rather low rate of substitution between skilled and unskilled workers, these estimates suggest that a significantly higher elasticity of substitution between skilled and unskilled workers is also able to explain the data when the supply is adjusted for the productivity gain experienced by computer users.

\subsubsection{Between-Group Wage Inequality}

Table 5.4 reports the results from estimating equation (5.9). The first column reports estimates in which the proportional productivity gains are not allowed to differ from one another, i.e. $\theta^{s}=\theta^{u}$. In addition, the data used are not weighted for differences in composition and the figures of imputed computer use have been taken from the October estimates. The table reports an estimate for $\theta^{s}=\theta^{n}=1.15$, an elasticity of substitution of 2.52 and a time trend of approximately 1.4 percent a year, which reflects the average annual increase in the demand for skilled labour. These estimates suggest that the proportional productivity gain from computer use is substantial ( 15 percent) and lies between approximately 5 and 25 percent. This productivity gain can also be interpreted as the costs of the computer relative to the wage of the marginal worker who just adopted a computer. Considering that these are the costs for the entire deal, this estimate seems reasonable. Finally, the relatively low estimate for the time trend compared to the estimate presented in the first column of Table 5.3 suggests that the model is able to explain about 40 percent of the increased demand for skilled labour.

The second column of Table 5.4 reports estimates allowing for differences in the productivity gain between skilled and unskilled workers. The point estimate is about 19 percentage points higher for skilled workers 
compared to unskilled workers $\left(\theta^{s}=1.27\right.$ and $\left.\theta^{*}=1.08\right)$ and also substantially higher for skilled workers than the 15 percent productivity increase reported in the first column, where $\theta^{s}=\theta^{u}$. This suggests that skilled workers gain more in terms of productivity than unskilled workers. However, the margins are rather large and it is not possible to statistically discriminate between the coefficients for skilled and unskilled workers. The elasticity of substitution turns out to be relatively high, but given the substantial margins, its precise magnitude is not so clear from this regression. The time trend is .9 percent, which is lower than in the previous estimates.

Overall, these results suggest that including the productivity gains from using computers and the subsequent additional supply of efficiency units of labour is important to explain the developments in between-group wage inequality. ${ }^{34}$

Table 5.4

Estimates for Between-Group Wage Inequality

\begin{tabular}{|c|c|c|c|c|c|c|c|c|}
\hline & \multicolumn{4}{|c|}{$\begin{array}{l}\text { Equall Proportional } \\
\text { Productivity Gains }\end{array}$} & \multicolumn{4}{|c|}{$\begin{array}{l}\text { Different Proportional } \\
\text { Productivity Gains }\end{array}$} \\
\hline & \multicolumn{6}{|c|}{$\begin{array}{l}95 \% \text { confidence } \\
\text { Interval }\end{array}$} & \multicolumn{2}{|c|}{$\begin{array}{c}95 \% \text { confidence } \\
\text { interval } \\
\end{array}$} \\
\hline & Estimate & $\begin{array}{l}\text { Standard } \\
\text { Error }\end{array}$ & Lower & Upper & Estimate & $\begin{array}{c}\text { Standard } \\
\text { Error }\end{array}$ & Lower & Upper \\
\hline$\theta$ & 1.150 & .045 & 1.058 & 1.242 & & & & \\
\hline$\theta_{s}$ & & & & & 1.272 & .071 & 1.128 & 1.416 \\
\hline$\theta_{u}$ & & & & & 1.079 & .058 & .961 & 1.197 \\
\hline$\sigma$ & 2.517 & .556 & 1.388 & 3.646 & 4.298 & 1.837 & .560 & 8.037 \\
\hline$y_{1}$ & .014 & .004 & .005 & .022 & .009 & .004 & .000 & .017 \\
\hline$y_{0}$ & .299 & .127 & .042 & .557 & .585 & .264 & .048 & 1.121 \\
\hline $\mathbb{R}^{2}$ & & & & .785 & & & & .812 \\
\hline
\end{tabular}

Note: All data are taken from the 1964-2001 March CPS files. The dependent variable is the log of the ration of the average wages of skilled and unskilled workers. Computer use is imputed using the October Supplements of the 1984, 1989, 1993 and 1997 CPS files (see the note below Figure 5.5). The regressions are performed by non-linear least squares.

${ }^{34}$ When weighing the wages and labour supply, the results turn out to be similar. 


\subsubsection{Within-Group Wage Inequality}

Table 5.5 reports the results of estimating equations (5.11) and (5.12) for within-group wage inequality. The estimation is based on an analysis of the $90^{\text {th }}-10^{\text {th }}$ percentile of both wage distributions and uses the non-weighted data and computer use imputed from the October series presented in Figure 5.5. The regression equation is set such that for computer use below the 10 percent level, within-group wage inequality is constant. The first column of Table 5.5 reports an estimate for the proportional productivity gain of $\theta^{s}=1.41$ with margins between 1.35 and 1.47. This suggests a productivity gain of around 40 percent from using a computer. The regression results reported in the second column of Table 5.5 suggest a similar proportional productivity gain for unskilled workers $\left(\theta^{\prime \prime}=1.41\right)$ although the confidence interval is somewhat wider. In terms of the costs of using a computer, these estimates are rather high (also compared to the estimates for between-group wage inequality). They suggest that the costs of the computer are approximately 40 percent of the wage of the marginal worker who adopts the computer. ${ }^{35}$ However, the size of the estimated coefficients is consistent with the regression coefficients reported by Bresnahan, Brynjolfsson and Hitt (2002, Table 8). They argue that there are large adjustment costs to the successful use of computers, which are not only due to the installation of computers itself but also to the change in organization structure and other coinventions going along with computerization. ${ }^{36}$

To investigate whether these relatively high estimates are sensitive to the measure of within-group wage inequality, two different definitions have also been tested. First, the $80^{\text {th }}-20^{\text {th }}$ percentile of the wage distribution has been used as a measure of wage inequality. Now, $\theta^{s}=1.21$ with a lower margin of 1.15 and an upper margin of 1.26 and $\theta^{\prime \prime}=1.28$ with margins of 1.18 and 1.38 . Secondly, the $70^{\text {th }}-30^{\text {th }}$ percentile of both wage distributions have been investigated. Here, $\theta^{s}=1.15(1.10,1.20)$ and $\theta^{u}=1.12(1.00,1.24)$. These estimates suggest that the proportional productivity gains are lower when within-group wage inequality is allowed to fluctuate after 20 and 30 percent of the workers within each group have adopted computers.

The interpretation of the different estimates for the proportional

${ }^{35}$ Using the figures for imputed computer use from the March series leads to comparable estimates. Weighing the data to control for compositional changes during 1963-2000 gives estimates of $\theta^{*}=1.29$ and $\theta^{*}=1.47$.

${ }^{36}$ An alternative interpretation of these estimates for the productivity gain compared to the between-group estimates is to consider different vintages of computers. This would lead to the interpretation that the productivity gain of the latest vintage of computers - compared to not using a computer - equal approximately 40 percent. 
productivity gains in Tables 5.4 and 5.5 can be viewed upon as lower and upper bound productivity gains. The relatively low estimate for the productivity gain reported in Table 5.4 suggests that the additional supply plays an important role, and the relatively high estimates for the productivity gain reported in Table 5.5 are probably caused by addressing all within-group differences to computerization. When using a more moderate definition of within-group wage inequality, the effects are much more modest, suggesting lower productivity gains more in line with the estimates of between-group wage inequality.

Table 5.5

Estimates for Within-Group Wage Inequality

\begin{tabular}{|c|c|c|c|c|c|c|c|c|}
\hline & \multicolumn{4}{|c|}{ Skilled workers } & \multicolumn{4}{|c|}{ Unskilled workers } \\
\hline & \multicolumn{6}{|c|}{$\begin{array}{l}95 \% \text { confidence } \\
\text { interval }\end{array}$} & \multicolumn{2}{|c|}{$\begin{array}{c}95 \% \text { confidence } \\
\text { interval }\end{array}$} \\
\hline & Estimate & $\begin{array}{c}\text { Standard } \\
\text { Error }\end{array}$ & Lower & Upper & Estimate & $\begin{array}{c}\text { Standard } \\
\text { Error }\end{array}$ & Lower & Upper \\
\hline$\theta_{s}$ & 1.413 & .029 & 1.354 & 1.472 & & & & \\
\hline$\theta_{u s}$ & & & & & 1.412 & .047 & 1.317 & 1.507 \\
\hline$\gamma_{0}$ & 3.524 & .030 & 3.463 & 3.584 & 3.634 & .033 & 3.568 & 3.700 \\
\hline $\mathrm{R}^{2}$ & & & & .883 & & & & .751 \\
\hline
\end{tabular}

Nore: All data are taken from the 1964-2001 March CPS files. The dependent variable is the $\log$ of the $90^{\text {th }}-10^{\text {th }}$ percentile wage differential within both groups. Computer use is imputed using the October Supplements of the 1984, 1989, 1993 and 1997 CPS filles (see the note bellow Figure 5.5). The regressions are performed by non-linear least squares.

\subsection{Conclusion}

This chapter offers a theoretical model to explain increasing betweengroup and within-group wage inequality resulting from the spread of computers since the $1970 \mathrm{~s}$. The model conjectures that through the falling costs of computers, its adoption is determined by wages and proportional productivity gains. As a consequence, the composition of the group of workers using computers has changed over time. The diffusion path and the changing composition of computer users determine the extent and timing of betweengroup and within-group wage inequality resulting from the adoption and diffusion of computers. It has been shown that within-group wage inequality 
starts to increase once the first workers in each group have adopted computers. Consistent with the numbers depicted in Figure 5.1, this happened in the early 1970 s for skilled and around 1980 for unskilled workers. Between-group wage inequality started to rise when the first unskilled workers adopted computers. The reason for between-group wage inequality to rise is that additional supply of efficiency units of unskilled labour depresses the unskilled workers" wages. An empirical analysis using CPS data suggests that the pattern of betweengroup and within-group inequality predicted by the theoretical model is consistent with the pattern of wage inequality in the United States in the period 1963-2000. The model explains an additional 40 percent of the rising betweengroup wage inequality. In addition, it is shown that the relatively low values for the elasticity of substitution between skilled and unskilled workers from the literature are likely to reflect the omission of additional supply of efficiency units. The estimates presented here lie between 2 and 3 . The estimates for the proportional productivity gain of using a computer are between 15 and 40 percent.

For the further diffusion of computers through the labour market, the theory predicts falling between-group and within-group wage inequality when the diffusion is complete and when the costs of the computer continue to fall. In the hypothetical situation where the costs of computer adoption are zero, between-group wage inequality resulting from computerization will continue to exist if the productivity gains experienced is higher for skilled workers than for unskilled workers. Although the confidence intervals are rather large, the estimates suggest a slightly higher productivity gain for skilled workers, which would generate a permanent increase in wage inequality due to computerization. Within-group wage inequality resulting from computerization will also disappear if the productivity gains are equal within the groups of skilled and unskilled workers. If these gains are different, workers gaining more in terms of productivity will receive higher wages. 


\section{Chapter 6}

\section{Job Complexity and Skill Upgrading}

\subsection{Introduction}

Why did wage inequality in the Netherlands not rise to the extent it did in the United States in the face of rapid skill-biased technological change over the past decades? One source of evidence on this question indicates that wagesetting institutions in most continental European countries prevent wage inequality from substantially increasing. The often-mentioned examples are the presence of union wage bargaining, unemployment benefits, and minimum wages, which induce wage compression and prevent wage inequality from rising. Another source of evidence suggests that the relative supply of skilled workers has increased more in continental European countries than in the United States since the 1960s. In the face of accelerating skill-biased technological change this leads to relatively less pressure on the skilled labour market and hence to relatively less increasing wages in European countries than in the United States.

Of these two sources of evidence, the first one has been the more popular explanation among both politicians and economists. After all, it seemed to offer an explanation for rising unemployment among relatively unskilled workers in the continental European countries resulting mainly from minimum wages and rising wage inequality in the United States (e.g., Krugman, 1994, OECD, 1994 and Blau and Kahn, 1996). This explanation leads to a number of complications, however, due to the fact that unemployment in continental Europe increased for both skilled and unskilled workers, not simply for the unskilled. Hence, it does not seem to be a likely candidate to explain changing wage structures over time. The second explanation of rising wage inequality in the United States relative to continental European countries is the relative shortage of skilled workers in the United States (e.g., Katz, Loveman and Blanchflower, 1995, Murphy, Riddell and Romer, 1998, Acemoglu, 2001 and Card and Lemieux, 2001). The argument here is that although the supply of skilled workers has increased in the United States since the $1960 \mathrm{~s}$, it seems to be insufficient to keep up with the increasing demand due to skill-biased technological change. Since the Netherlands is a small open economy, its 
exposure to skill-biased technological change is likely to be similar to that in the United States. Hence, the explanation that the supply of skilled labour has been sufficient to keep up with a rising skilled labour demand might be a valid reason why wages remained much more stable in the Netherlands.

This chapter examines the wage structure of the Netherlands over the 1986-1998 period and its underlying determinants by means of a simple assignment model. This assignment approach allows us to separate the effects of labour demand and supply on the wage structure and therefore to provide insight into the determinants of wages in the Netherlands. The data used are drawn from the bi-annual database of the Organisation for Strategic Labour Market Research (OSA) for the labour market characteristics of workers aged 18-65. The findings are the following. First, observable characteristics like education and experience seem to be important in explaining the Dutch wage structure. This suggests that increasing wage differentials can be explained by the upgrading of educational requirements. Secondly, job complexity seems to have been increasing as well. While no direct link with computerization can be established in the data, these findings are consistent with the predictions of the model in Chapter 3 that upgrading of skill requirements and a focus on nonroutine job activities are likely to have occurred. Thirdly, wage differentials do not seem to have increased dramatically, which is consistent with a sufficient supply of higher-skilled workers in the Netherlands to absorb the acceleration of skill-biased technological change.

At least three features of the analysis set it apart from previous work. First, an assignment approach is applied to determine job complexity and a worker's skill level, which assigns heterogeneous workers to heterogeneous jobs. This strategy provides insight into the relative allocation of workers to jobs, as well as measures for the return to skills by suggesting an indirect approach to measure the skills required for a certain job. The integration of this simultaneous supply and demand framework and the characterization workers by skill levels and jobs by complexity levels help to both assign skills to jobs and to observe, over time, whether some jobs have become more complex than others (given the required skill level). In this manner the evolution of the wage structure can be monitored not only by comparing wages between different groups of workers but also by implicitly considering the underlying matching process, something the earlier relative-supply-demand studies lack. This matching process is important because it reveals information on the changing skill composition and complexity of jobs over time." Secondly, it is not necessary to divide the labour market into two groups of workers - skilled and unskilled - as most of the previous work does to be able to generate empirical

\footnotetext{
'See Cameiro, Heckman and Vytacil (2001) for an overview of the advantages of using assignment models starting from Roy (1950) and (1951) and Tinbergen (1956).
} 
results consistent with a relative-supply-demand framework. Here a continuous mapping of workers to jobs is considered, which is a novel contribution to the existing literature on wage inequality. ${ }^{2}$ Thirdly, a market-based explanation is provided for the relative stable structure of wages in the Netherlands, whereas most previous studies have focussed on labour market institutions in explaining the wage structure of the Netherlands and other continental European countries. ${ }^{3}$

The plam of the chapter is as follows. In the next section the data are discussed. Section 6.3 develops an accounting exercise to show a picture of the wage structure in the Netherlands in the period 1986-1998. Section 6.4 presents the concept of job complexity and maps the changes in labour demand and labour supply. Section 6.5 concludes.

\subsection{Data and Preliminary Figures}

The data utilised in this chapter are drawn from seven surveys conducted by the Organisation for Strategic Labour Market Research (OSA) from 1986 to 1998. For the seven biannual years, 2,325 (1986), 2,279 (1988), 2,352 (1990), $2,399(1992), 2,531(1994), 2,654(1996)$ and 2,896 (1998) observations are available.

Other comparable studies documenting the Dutch labour market in this respect are rather scarce. Draper and Manders (1997) have shown that laboursaving technological change explains most of the changes in the wage structure in the period 1969-1993. Less recent studies which have reached similar conclusions are Broer and Jansen (1989) and Hebbink (1991). Broer and Jansen divided the labour force into three categories and focussed on employment, education and productivity. They found that higher levels of education had a significant influence on productivity growth in the 1970s and 1980s. Hebbink also considered three types of labour and found that skilled labour and capital are complements, but that employment of unskilled labour has been worsened by a reduction in the price of capital. Bruinshoofd, Hollanders and Ter Weel (2001) investigate wage inequality in the Dutch manufacturing sectors using knowledge spillovers from research and development. They confirm that

As shown in Chapters 2 and 5, Katz and Murphy (1992) compose two groups of workers by developing a weighting scheme to distinguish between skilled and unskilled workers. Most empirical studies following Katz and Murphy have used similar ways to compose two groups of workers (see also Murphy and Welch, 1992 and Gould, Moav and Weinberg, 2001).

* See also Leuven, Oosterbeek and Van Ophem (1998) for a relative demand-supply explanation of wage inequality in European countries. They question Blau and Kahn's (1996) results of an institution-based explanation. 
workers employed in knowledge-intensive manufacturing sectors receive a higher wage than workers in less knowledge-intensive sectors. Secondly, the wages paid to skilled workers relative to unskilled workers in knowledgeintensive sectors are higher than those in less knowledge-intensive sectors. ${ }^{*}$ Gottschalk and Joyce (1998), using the Luxembourg Income Study, empirically examine nine $\mathrm{OECD}$ countries, among wich the Netherlands. They observed for the 1980s that the Netherlands was in a middle group of countries (also including countries like Australia, Canada and Israel), experiencing increases in inequality, but less so than the United States and the United Kingdom. ${ }^{5}$ In particular, they argue that

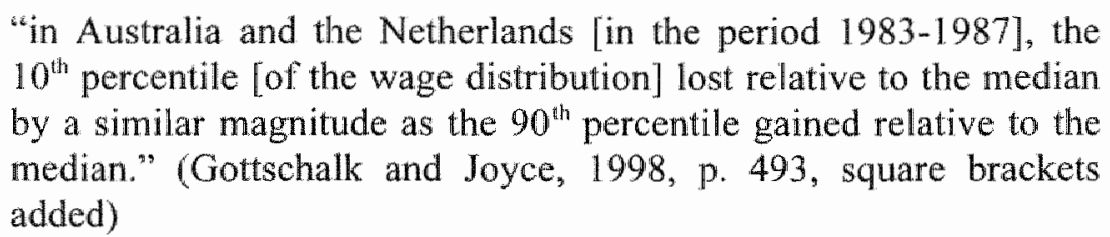

To obtain an understanding of the wage structure in the Netherlands in the period 1986-1998, Figure 6.1 graphs the median, $10^{\text {th }}$ and $90^{\text {th }}$ percentile of the log gross hourly wage distribution. For ease of comparison the figures are indexed to 100 in 1986 for all three series. The overall picture from this figure is that wages have steadily risen over this period. An acceleration of hourly earnings in the 1980s and 1990s of the above-median wage workers, like in the United Kingdom and United States, is not observed. The median wage series show an almost 12 percent increase in wages for the workers at the $50^{\text {th }}$ percentile during the period 1986-1998. The pattern of this series is quite linear and shows a steady increase in the log hourly wage. For the $90^{\text {th }}$ percentille of the wage distribution, the log gross hourly wage rose relatively fast until 1992 (more than 11 percent), while after 1992 the wage increase was far more modest. In the 1990 s the increase in the wage series of the $90^{\text {th }}$ percentile worker is comparable to the wage increase of the median worker, similar to the results documented by Hartog, Oosterbeek and Teulings (1993) and Gottschalk and Joyce (1998) for the 1980s. As is clear from the figure, the story is different for the $10^{\text {th }}$ percentile of the wage distribution. Since the partial abandoning of

\footnotetext{
"Of course many studies of the typical (wage) features of the Dutch labour market have been performed (see Teulings and Hartog, 1998, for an overview). The majority of these deal with the Dutch welfare state (e.g., Broersma, Koeman and Teulings, 2000), the duration of unemployment in the Netherlands (e.g., Gorter, Nijkamp and Rietveld, 1992), matching or assigning workers to jobs (e.g., Van Ours, 1991 and Teulings, 1995), and overeducation (see for example, Borghans and De Grip, 2000, for an overview).
}

"See also Hartog, Oosterbeek and Teulings (1993). For the period 1979-1989, they do not find a substantial increase in wage inequality in the Netherlands either. 
the legal minimum wage in the early 1990 s, wages at the bottom part of the labour market have increased far less compared to the median and top earners. The wage of the $10^{\text {th }}$ percentile worker increased by no more than some 3 percent in the period 1990-1998, whereas wages of the median and $90^{\text {th }}$ percentile worker grew by almost 8 percent. This contrasts previous findings, because traditionally the bottom part of the wage distribution moved along with the median wages due to the coupling of the minimum wage growth to the average wage growth. This led, in the Netherlands, to a relatively stable increase in wages, without a tendency towards increasing wage inequality. Hence, the reduced policy interference in the $1990 \mathrm{~s}$ might have contributed to increased dispersion between the $10^{\text {th }}$ percentile of the wage distribution and the median and top part. This trend towards increasing wage inequality is likely to be dampened by recent consensus policies between employers, employees and the government to moderate wages at the top part of the wage distribution. This is consistent with the kink in the line for the $90^{\text {th }}$ percentile of the wage distribution, which seems to follow a different trend in the $1990 \mathrm{~s}$, more in line with the median and $10^{\text {th }}$ percentile of the wage distribution.

Figure 6.1.

Indexed Log. Gross Hourly Wages by Percentile in the Netherlands, 1986-1998 (1986=100)

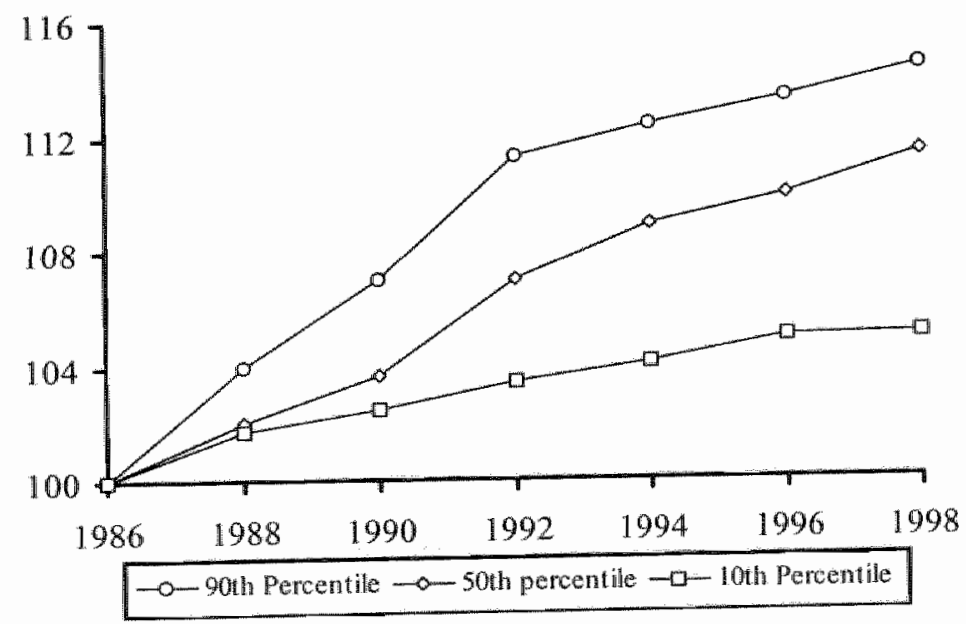

Note: The data is taken from the biannual OSA database

The evolution of the log gross hourly wage for this degree of wage inequality is shown in Figure 6.2. Wage inequality is simply measured by the log gross hourly wage differential between the highest ten percent and the lowest ten percent of the wage distribution and the deviation from the median earners: $90^{\text {th }}-10^{\text {th }}, 90^{\text {th }}-50^{\text {th }}$ and $50^{\text {th }}-10^{\text {th }}$ percentile of the wage distribution. 
The degree of wage inequality between the $90^{\text {th }}$ and $10^{\text {th }}$ percentille of the wage distribution increased until 1992. After 1992, the degree of inequality is relatively stable, which might indeed exhibit the effects of the consensus policies between labour unions, employer's organizations and the government in the 1990s. This consensus also resulted in wage moderation and improved conditions for the median and bottom earners and hence in some narrowing wage distribution since the late $1980 \mathrm{~s}$. Indeed, the difference between the $90^{\text {th }}$ and $50^{\text {th }}$ percentile is first increasing, followed by a slight decrease in the wage differential in the $1990 \mathrm{~s}$. The difference between the $50^{\text {th }}$ and the $10^{\text {th }}$ percentile also increased until 1992 and then remained fairly stable until 1996. In 1998 a rise in the wage differential seems to be on the rise again."

\section{Figure 6.2}

Indexed Log Gross Hourly Wages by Differences Between Percentiles in the Netherlands, $1986-1998(1986=100)$

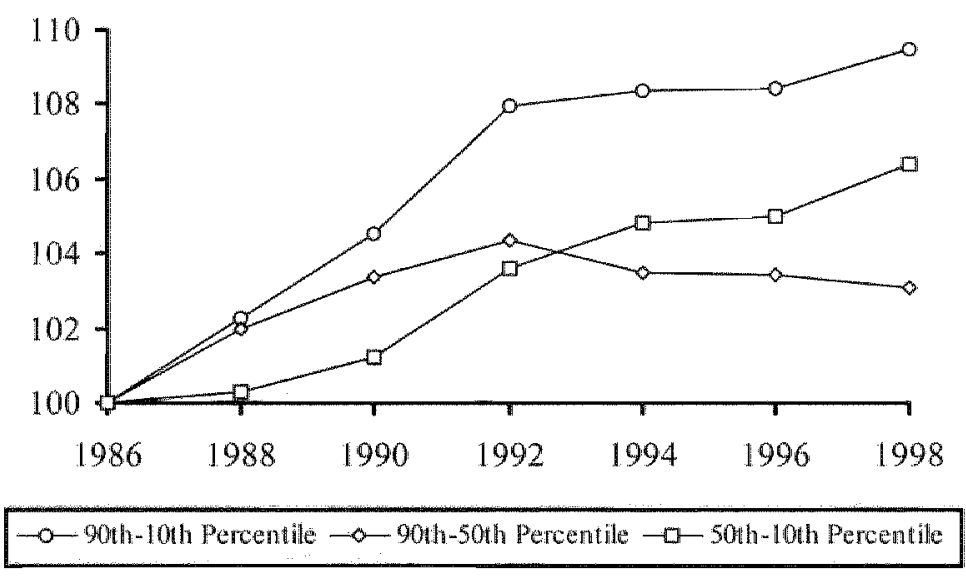

Nore: The data is taken from the biannual OSA database

Regardless of the valuable information offered in Figure 6.1 and 6.2 , the overall picture sketched might be too simple. Let us therefore explore the wage structure of the Netherlands in the most recent period in somewhat greater detail. To gain an understanding of the mechanism creating wage inequality, let us start with an exposition of the explanation most economists have favoured with regard to wage inequality in the United States. This explanation is driven

\footnotetext{
${ }^{6}$ Kahn (2000), using the International Social Suney Programme data from 1985 to 1994 for fifteen OECD countries, finds that greater union coverage and membership lead to higher relative pay and lower relative employment at the bottom part of the labour market. The reverse seems to be currently true in the Netherlands. Relative pay has been modest and employment at the bottom part of the labour market has increased significantly.
} 
by an increase in the supply of skilled workers, which changes the impact of the size of skill-complementary technologies (e.g., Katz and Murphy, 1992, Acemoglu, 1998, Autor, Katz and Krueger, 1998 and Kiley, 1999) or which makes it more profitable to create jobs designed for skilled workers (e.g., Kremer and Maskin, 1996 and Acemoglu, 1999). In this way, the composition of jobs undergoes a change in favour of skilled workers, thereby altering the structure of wages. Bound and Johnson (1992) and Juhn, Murphy and Pierce (1993) offer an attractive way of doing so. Then, by considering the assignment of heterogeneous workers to jobs (instead of considering only skilled and unskilled workers), a simple assignment approach is applied (e.g., Rosen, 1974, Sattinger, 197 and 1993, Teulings, 1995 and 2000, and Gould, 2002) to see whether job complexity and the required skill level have changed over the period 1986-1998?

\subsection{A Simple Framework}

To examine the wage structure, a useful framework for isolating both observable and unobservable dimensions is to write a simple wage equation such as

$$
\omega_{i t}=X_{i \gamma} \beta_{t}+\mu_{i r^{*}}
$$

where $\omega_{i t}$ is the $\log$ hourly wage for individual $i$ in year $t, X_{i t}$ is the vector of individual characteristics and $\mu_{i,}$ is the component of $\log$ hourly wages accounted for by some unobservable dimension of the wage. Following Bound and Johnson (1992) and Juhn, Murphy and Pierce (1993), the unobservable dimension $\mu_{i r}$ is split into an individual's wage position in the residual distribution, $\varphi_{i t}$, and the distribution function of the wage equation's residuals, $F(\cdot)$ :

$$
\mu_{i t}=F_{i}^{-1}\left(\varphi_{i t} \mid X_{i t}\right)
$$

where $F_{i}^{-1}\left(\cdot \mid X_{j i}\right)$ is the inverse cumulative residual distribution for workers with characteristics $X_{i n}$ in year $f$. In such a framework, changes in the wage distribution among workers arise from three different sources: (i) changes in the distribution of $X^{\prime \prime} \mathrm{s}$; (ii) changes in the $\beta$ 's; and (iii) changes in the distribution of the residuals.

Independent work by Gould (2000) provides a similar exercise of wage inequality in the United States but focuses on the importance of ability as a determinant of wage inequality. Similarly, Kaboski (2001) shows that standard theories that ignore occupation and comparative advantage overstate inequality effects of education and experience levels. 
The level of wage inequality can be derived by measuring deviations from the mean of $\beta$ and $F_{i}^{-1}\left(\cdot \mid X_{i l}\right)$ as follows:

$$
\omega_{i t}=X_{i j} \bar{\beta}+X_{i t}\left(\beta_{t}-\bar{\beta}\right)+\bar{F}^{-1}\left(\varphi_{i t} \mid X_{i j}\right)+\left[F_{i}^{-1}\left(\varphi_{i t} \mid X_{i t}\right)-\bar{F}^{-1}\left(\varphi_{i t} \mid X_{i j}\right)\right]
$$

where a bar over the variables indicates mean values. The first term on the right-hand side of equation (6.3) captures the effect of a changing distribution of vector $X$ given prices $\beta$. The second term captures just the opposite: changing skill prices given the distribution of $X$. The last term indicates changes in the distribution of the residuals. Exploring this equation further opens possibilities to reconstruct the wage distribution in the face of three ceteris paribus situations.

First, with a fixed $\beta$ and a fixed residual distribution, $\log$ hourly wages are determined by

$$
\omega_{i t}^{\prime}=X_{i t} \bar{\beta}+\bar{F}^{-1}\left(\varphi_{i j} \mid X_{i p}\right)
$$

The major advantage of using equation (6.4) is that it allows us to investigate how compositional changes in the Dutch labour market have affected the entire wage distribution and not merely its variance, i.e., changes in observable quantities at fixed prices. For example, this could be changes in the supply of particular workers or particular skills.

Secondly, if both $X^{\prime}$ 's and $\beta^{\prime}$ 's vary over time, $\omega_{i r}$ is determined by the following specification:

$$
\omega_{i f}^{2}=X_{i f} \beta_{r}+\vec{F}^{-1}\left(\varphi_{i f} \mid X_{i j}\right)
$$

Analysing equation (6.5) results in the prediction of $\log$ hourly wages for worker $i$ in year given his observable characteristics, the wage equation estimated for year $t$, and the assignment of a residual $i$ based on the cumulative distribution for all years, i.e., changes in the observable characteristics' prices.

Thirdly, if all three sources of change arise, equation (6.1) has to be analysed, i.e..,

$$
\omega_{i t}^{3}=X_{i t} \beta_{f}+F_{t}^{-1}\left(\varphi_{i r} \mid X_{i s}\right)=X_{i r} \beta_{t}+\mu_{i t}
$$

Now, subtracting equation (6.6) from equation (6.5) gives the change in the distribution of the unobservable dimension of the wage distribution.

Figure 6.3 shows the results of this accounting exercise for $\omega^{1}, \omega^{2}$ and $\omega^{3}{ }_{i 1}-\omega^{2}$ it presenting the $\log$ gross hourly wage differential between the $90^{\text {th }}$ and $10^{\text {ih }}$ percentille of the wage distribution from 1986 to 1998 . The figure illustrates that the estimates for $X_{\text {ir }}$ have the largest contribution to the $90^{\text {th }}-10^{\text {th }} \log$ hourly wage differential in all years. This implies that the changes in, for example, the 
level of education and the experience composition of the work force have had a direct effect on the level of wage inequality. The contribution is nearly 60 percent in 1986 and 1988 and then increases to almost 70 percent in the early 1990 s. Finally, in 1998 the contribution of observed quantities falls again to 60 percent.

The contribution of $\beta_{t}$, the observed prices, is much less than the contribution of $X_{i r}$. This reinforces the observation of many studies that in the Netherlands returns to education have been relatively low. ${ }^{8}$ Moreover, the rapid increase in educational attainment since the late 1960 s has not resulted in a large increase in the wage gap between the highest and lowest percentile of the wage distribution, as Juhn, Murphy and Pierce (1993) observe for the United States since the late 1970 s.

Figure 6.3

$90^{\text {th }}-10^{\text {th }}$ Percentile of the Log Gross Hourly Wage Differential and Components, 1986-1998

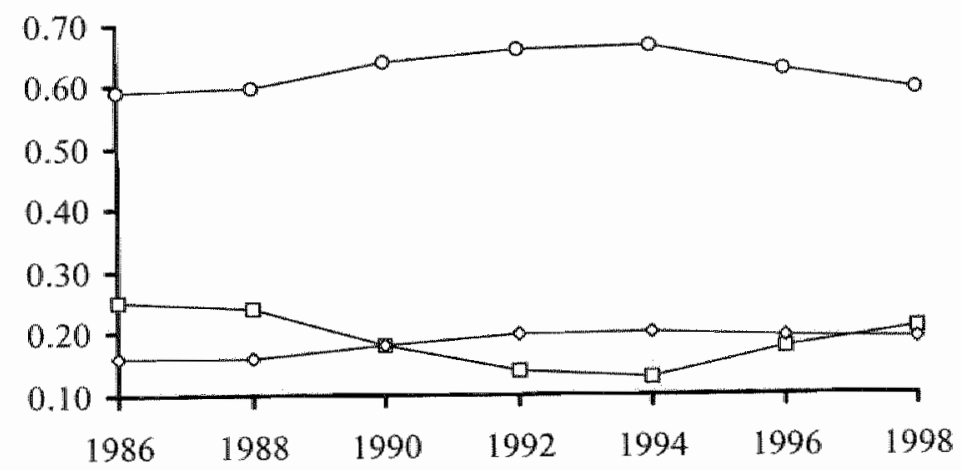

-0 - Observed Quantity $\rightarrow-$ Observed Price $-0-$ Unobserved

Note: The data is taken from the biannual OSA database

Finally, Figure 6.3 shows the component due to changes in the residual term. This component lies between 15 and 20 percent in all years. As the figure shows, the correlation between the change in this unobserved component and the change in observed quantity is high. This means that the evolution of within-group inequality (measured by the unobserved residual component) seems to go hand in hand with developments in observed quantities. On the basis of this finding it may be concluded that the dimensions of skill (which are defined here as personal characteristics, including experience and education)

In particular, Gottschalk (1997) notices that the relatively small increase in inequality in the Netherlands reflects a decline in the college wage premium, which largely offsets the substantial increase between experience groups and the increase in inequallity within groups. 
and differences within a specific class of employees are not rewarded with very different prices in the labour market. Hence, not much variation in wages between sectors is to be expected in the Netherlands. ${ }^{9}$

Table 6.1 reports the results of a further analysis of the wage structure investigating the predicted values of the wage differential between the $90^{\text {th }}$ and $10^{\text {th }}$ percentile of the wage distribution, the $90^{\text {th }}-50^{\text {th }}$ and the $50^{\text {th }}-10^{\text {th }}$ percentile for (i) personal characteristics, (ii) experience, (iii) education, and (iv) the latter two together. Column [1] of Table 6.1 shows the coefficient of the total change in the subsequent percentiles for the period as a whole. The second column reports the results of addressing the contribution of observed quantities and the percentage explained by this change in observed quantities. Columns [3] and [4] exhibit results from the same analysis for observed prices and the unobserved residual.

Panel A refers to the change in personal characteristics over the period 1986-1998. As the panel shows, changes in observed prices and unobservables do not have noticeable influence compared to the coefficient of observed quantities. Apparently, wage gaps are relatively well understood in terms of differences in observable quantities and not so much in terms of different wages within different sectors. The residual term is also relatively unimportant. Compared to the findings for the United States as put forward in Juhn, Murphy and Pierce (1993, Table 4), the residual term is rather small. For the United States, much of the wage differentials is explained by unobserved prices and quantities.

Panel B, C and D highlight two important variables included in the workers' personal characteristics: experience and education. From these panels quite similar patterns can be observed. The change in unobservable quantities and prices is larger than in Panel $A$ but still these results indicate that personal characteristics like experience and education seem to be reasonably well able to explain wage differentials.

The implications of these preliminary explorations of the data provide an initial insight into the structure of wages in the Netherlands and can be summarized as follows. First, wage changes between the top, median and bottom part of the labour market are mainly caused by such variables as education and experience. Secondly, similar workers do not experience different prices for their skills. This indicates that observed prices do not seem to contribute much to wage inequality and that within-sector wage inequality is relatively unimportant in the Netherlands. It should be noted, however, that in Panel $\mathrm{C}$ of Table 6.1 the price and residual components are larger than those in Panel A. Particularly with respect to education the coefficients are higher,

\footnotetext{
"Given the (annual) agreements between the government, employers and unions, this does not seem to be a highly surprising result.
} 
which is consistent with an indication of some sort of shortage driving up the prices of labour.

Another, more indirect insight that can be gained from the above results is the following. As shown in the previous chapters, the introduction of computers is likely to have contributed to increased wage dispersion. Following the above results, the Dutch labour market seems to have been able to cope relatively well with computerization, since wage inequality has not increased dramatically. This observation will be explained in greater detail below.

Table 6.1

Observable and Unobservable Components in Wages in the Netherlands, 1986-1998

\begin{tabular}{|c|c|c|c|c|}
\hline & $\begin{array}{c}\text { [1] } \\
\text { Total } \\
\text { Change }\end{array}$ & $\begin{array}{c}{[2]} \\
\text { Observed } \\
\text { Quantities }\end{array}$ & $\begin{array}{c}{[3]} \\
\text { Observed } \\
\text { Prices }\end{array}$ & $\begin{array}{c}\text { [4] } \\
\text { Unobserved } \\
\text { component }\end{array}$ \\
\hline \multicolumn{5}{|c|}{ Panel A: Personal Characteristics } \\
\hline $\begin{array}{l}90^{\text {th }}-10^{\text {th }} \\
90^{\text {th }}-50^{\text {th }} \\
50^{\text {th }}-10^{\text {th }}\end{array}$ & $\begin{array}{l}.313 \\
.136 \\
.177 \\
\end{array}$ & $\begin{array}{l}.194 \\
.090 \\
.104\end{array}$ & $\begin{array}{l}.065 \\
.020 \\
.045 \\
\end{array}$ & $\begin{array}{l}.054 \\
.029 \\
.025 \\
\end{array}$ \\
\hline \multicolumn{5}{|c|}{ Panell B: Experience } \\
\hline $\begin{array}{l}90^{\text {th }}-10^{\text {th }} \\
90^{\text {th }}-50^{\text {hh }} \\
50^{\text {th }}-10^{\text {th }}\end{array}$ & $\begin{array}{l}.313 \\
.136 \\
.177 \\
\end{array}$ & $\begin{array}{l}.164 \\
.087 \\
.077 \\
\end{array}$ & $\begin{array}{l}.075 \\
.030 \\
.045 \\
\end{array}$ & $\begin{array}{l}.056 \\
.026 \\
.030 \\
\end{array}$ \\
\hline \multicolumn{5}{|c|}{ Panel $\mathrm{C}$ : Education } \\
\hline $\begin{array}{l}90^{\text {th }}-10^{\text {th }} \\
90^{\text {thin }}-50^{\text {th }} \\
50^{\text {tht }}-10^{\text {th }}\end{array}$ & $\begin{array}{l}.313 \\
.136 \\
.177\end{array}$ & $\begin{array}{l}.161 \\
.081 \\
.080\end{array}$ & $\begin{array}{l}.082 \\
.033 \\
.049 \\
\end{array}$ & $\begin{array}{l}.070 \\
.020 \\
.050\end{array}$ \\
\hline \multicolumn{5}{|c|}{ Panel D: Experience and Education } \\
\hline $\begin{array}{l}90^{\text {th }}-10^{\text {th }} \\
90^{\text {th }}-50^{\text {th }} \\
50^{\text {th }}-10^{\text {th }}\end{array}$ & $\begin{array}{l}.313 \\
.136 \\
.177 \\
\end{array}$ & $\begin{array}{r}.162 \\
.084 \\
.078 \\
\end{array}$ & $\begin{array}{l}.076 \\
.032 \\
.044 \\
\end{array}$ & $\begin{array}{l}.074 \\
.035 \\
.039 \\
\end{array}$ \\
\hline
\end{tabular}

Note: The data are taken from the biannual OSA database. Initial estimates OLS with the log of the gross hourly wage as the dependent variable. Personal characteristics are age, age $2 / 100$, non-Dutch, female, married, female $\times$ married and level of education. Experience is a proxy of the age of the employee, education is measured by years of education. Panel $A$ includes experience and education measured by age, age squared and years of education. Column [1] shows the results of estimating equation (6.1), column [2] exhibits the results of estimating equation (6.4), column [3] shows the results of estimating equation (6.5). Finally, column [4] is the result of subtracting equation (6.6) from equation (6.5). 
Finally, some authors argue that improvements in access to postsecondary education and appropriate training may be necessary to allow the wage benefits of new general-purpose technologies, like computers, to be more widely shared because these lead to an increased demand for educated workers. Murphy, Riddell and Romer (1998) argue that this is particularly true for the United States. Freeman and Katz (1995) add to this that countries with at least modest increases in skill differentials by the end of the 1980 s experienced some decline in the rate of growth of the supply of skilled workers. Other countries, like the Netherlands, have already established relatively good access to postsecondary education and are likely to have faced a relatively larger increase in the supply of skilled labour than in the United States from the 1960s on. The increase in the supply of skilled labour in the United States is often argued to be the result of the Vietnam War rather than improved access to education in the 1960 s. To avoid being drafted to serve in Vietnam, being in college turned out to be an effective way of doing so. Hence, many young men went to college during the Vietnam War. Of course, this effect on skilled labour supply is likely to capture only some part of the increasing supply, but it has nevertheless been argued to be an important component of the increasing supply (e.g., Acemoglu, 1998).

In the next section, the developments in the Dutch labour market are discussed in more detail to show the underlying phenomena with regard to the wage structure, there by focussing on both the demand and supply side of the labour market.

\subsection{Assigning Workers to Jobs}

The aim of this section is to explain differences and changes in the returns to skill and the allocation of workers to jobs over time by investigating changes in labour demand and supply. To do so, I estimate changes in the assignment of workers to jobs over the period 1986-1998. A two-stage procedure will be applied based on simple OLS estimates. In the first stage, the relationship between wages and personal characteristics is estimated for all years separately. In addition, the relationship between wages and job characteristics is estimated. The former is used as a characterization of skill, the latter as a characterization of job complexity. In the second stage, the estimates for skill and job complexity are compared to investigate the assignment of skill to job complexity. In addition, I will analyse to what extent the assignment of workers to jobs has changed over time.

\subsubsection{First-Stage Estimation Results}

Table 6.2 summarizes some results for each biannual year between 1986 
and 1998. Panel A, B and C report the results of simple ordinary least squares (OLS) regressions on $\log$ gross hourly wages. In the first panel only laboursupply characteristics are taken into account, Panel B includes only labourdemand characteristics and Panel $\mathrm{C}$ includes only sector-specific characteristics. The supply side characteristics are personal characteristics such as level of education, age, race, gender and marital status, whose predicted values are used as a measure of skill. Demand-side characteristics include job characteristics such as job level, firm size and leadership, whose predicted values are used as a measure of job complexity. The variables in Panel $\mathrm{C}$ investigate whether some sectors pay higher wages than others, whose predicted values are used to indicate whether there has been upgrading within or between sectors. ${ }^{10}$

In doing so, it is assumed that job complexity is defined independently of skill. While this might be open to question when performing a general regression analysis, this approach helps to separate demand and supply effects in explaining the wage structure, which is the main purpose of the exercise. Alternatively, a measure for skill could be taken as endogenous (e.g., Teulings and Vieira, 1999). The advantage of taking skill as the dependent variable is that any compensating differentials are removed from the measure of job complexity." A major drawback, which justifies the use of wages as the endogenous variable in the analysis, is that a measure of skill is very hard to construct and probably even more subject to a biased estimate (as discussed in Chapter 2). See Teulings and Gautier (2001) for a similar approach.

Skill: The most important results concerning the supply side of the labour market, reported in Panel A of Table 6.2, are that age has its usual positive effect on $\log$ hourly wages. This is likely to be the result of the presence of seniority payment schemes and the fact that, in general, more experienced workers (measured by age) receive higher wages. However, the wage premium resulting from such schemes is subject to diminishing returns because the $\operatorname{age}^{2 / 100}$ coefficient is negative and significant. The final row of Panel $\mathrm{A}$ shows that each year of additional education yields a return between 4 and 6 percent. The level of education is measured in five categories each containing some standard years of education: 12 for the lowest level (i.e. 8 years of primary

10i The latter estimate might not be so obvious at first sight. However, as pointed out by Roy (1951) and more formally by Heckman and Sedlacek (1985) and Heckman and Honore (1990), there could be an interaction between skill, job complexity and sector characteristics. For example, it is unclear whether the entry of worker i into sector $j$ at some point in the wage distribution of sector $j$ causes sector $j$ 's wage variance (within-sector wage inequality) to grow larger than it would have been if the proportion of workers had been held constant over time.

"In order to avoid compensating differentials to affect the job complexity measure, I have also used the calculated predicted values for skill from a mincerian wage equation instead of $\log$ wages. However, this gives the same results in qualitative terms. 
education and 4 years of secondary education) and 22 for the highest level of education; the intermediate levels contain 16, 18 and 20 years of education, respectively. Discrimination with respect race does not seem to be significantly present. Discrimination with respect to gender seems to be substantial, except when controlling for the jobs women occupy (mainly low-skilled jobs). Finally, married employees obtain is a wage premium. The level of significance of the regressions is measured by the adjusted $R^{2}$ statistic. ${ }^{12}$ This statistic lies between .279 (1992) and .499 (1994) for Panel. $\mathrm{A}$, which are frequently found values for cross-sectional regressions, particularly when it is noted that Panel A only supply-side characteristics.

Job Complexity: The demand side of the labour market is taken into account by distinguishing 5 different job levels (elementary, low, medium, high and scientific), which are divided into white-collar and blue-collar jobs (with the exception of elementary jobs). These demand-side or job characteristics are aggregated from more than a 1,000 four-digit occupational titles into these 9 categories, according to the 1994 CBS SBI code scheme, which categorizes mainly on the basis of an analysis of the type of work done in a particular job. ${ }^{13}$ Panel $B$ in Table 6.2 shows that, relative to a low-level blue-collar job, the expected pattern of increasing wages along with increasing job levels is present in all years. However, when taking into account the same job level for each single year it can be observed that the wage premium of the high-level and scientific jobs, relative to a low-skilled blue-collar job, has dropped since the early 1990s. This is consistent with the pictures sketched previously, where the wage differential between the high-paid and the others did not rise. The fact that high-level and scientific blue-collar jobs are rewarded with a higher wage than comparable white-collar jobs may be the result of a relative decline in the

\footnotetext{
12. Some argued that the regression in Panel $\mathrm{A}$ of Table 6.2 could alternatively be run at once with dummies for six of the seven biannual years (one reference year). This is sometimes preferred because the intercept might change or shift over time as a result of technological progress (and inflation). If 1986 is taken as the year of reference, the coefficients (and their standard errors) do not change dramatically: Intercept $(.023(.051))$, Age $(.068(.002))$. Age $/ 100(-.001(.000))$, Non-Dutch $(.007(.003))$, Female $(-.159(.008))$ and Married $(.032$ $(.009))$. The year dummies are for $1988(.140(.017)), 1990(.286(.017)), 1992(.352(.018))$, $1994(.328(.018)), 1996(.397(.017))$ and $1998(.447(.017))$. The reason for choosing the analysis as shown in Table 6.2 is that the coefficients of each biamual year are used in the analysis that follows.

13 The 1994 CBS SBI code is used for all years. Although other CBS SBI codes are available for years prior to 1994, the data are analysed with this SBI code only. This is done mainly to obtain consistent comparisons of job levels for all years. A disadvantage may be that on the one hand some jobs disappeared in the period 1986-1994, while new jobs have been created since 1994 on the other.
} 
enrollment rate and subsequent scarcity of workers having done technological studies. Oosterbeek and Webbink (1997) find that the market share of science and engineering in university education decreased from 35 percent in 1960 to 22 percent in 1989 . This decline in relative high-level blue-collar supply may have led to a wage premium above the average high-level worker wage premium shown in Panel B.

I have also tested whether firm size has an impact on log hourly wages. This has shown that larger firms pay higher wages, ranging from 1.6 percent in 1988 to 4.2 percent in 1996 . The overall picture suggests that this effect increases over time. Finally, a proxy of the managerial skills of employees has been made by investigating the wage premium with regard to the number of workers supervised by a particular person. The data are divided into six classes: supervising none, 1 to 4 persons, 5 to 9,10 to 19,20 to 49 and over 50 . It turns out that a worker supervising other workers is rewarded with a more or less constant wage premium of about 6 to 7 percent. The explanatory power of the regressions in Panel $B$ is more limited than in Panel $A$. The adjusted $R^{2}$ is lowest in $1990(.213)$ and highest in $1996(.363)$.

Sector Upgrading: The effects of sector characteristics on log hourly wages in Panel $C$ of Table 6.2 show results that may not seem very robust at first sight. This is of course due to unobserved heterogeneity between an unknown distribution of workers within these sectors. However, relative to the transport sector, workers in some sectors obtain significantly lower or higher wages throughout the sample period. The reason for reporting these estimates is that the predicted values are used to explore the possibility of skills being valued differently across sectors. Rosen (1983) and Heckman and Scheinkman (1987) develop the conditions under which the returns to each skill are equivalent across sectors. Estimates by Heckman and Scheinkman show that the hypothesis of uniform pricing of skills across sectors has to be rejected. The most likely reason for non-uniform returns to skills is due to the fact that workers cannot unbundle their skills and sell them separately on the market at the going price. Rather, they have to sell their skills to the market as a bundle even though their individual skills are valued differently across sectors.

\subsubsection{Second-Stage Estimation Results}

The information from Table 6.2 can be used to describe the interaction of skill and job complexity. To analyse this interaction empirically, consider the predicted values of the regression in Panel A of Table 6.2 as a measure of a worker's skill. This is a plausible assumption, since the set of personal characteristics is a reflection of a worker's capabilities standard to the literature. Similarly, consider the linear combination of job characteristics in Panel B of Table 6.2 as a measure of the complexity of the job. This is consistent with the 
extent of substitution between job levels and types. The predicted values in Panel $\mathrm{C}$ of Table 6.2 can be viewed as a measure of "within" or "between" sector changes in the assignment of workers to jobs, i.e. "upgrading" (e.g., Berman, Bound and Griliches, 1994, Berman, Bound and Machin, 1998 and Haskel and Slaughter, 1998). In this regard, "within" changes are defined as changes in the wage-bill share of particular workers within a sector. "Between" changes reflect changes in the composition of the workforce between different sectors in the economy. ${ }^{14}$

Panel A of Table 6.3 first shows the correlation between the measure of skill and job complexity. The correlation coefficients are rather low initially but steadily increase over time. This suggests that over time higher skilled workers have been assigned to more complex jobs and that this is increasing over the sample period. This is an interesting observation because it suggests that over time the assignment of workers to jobs has become more efficient. This more efficient assignment of workers to jobs following the increase in skilled labour supply since the 1960s might be the result of technological change.

Panel A also contains the same information on the correlation of a worker's skill and the sector of employment, showing a relation between skill and sectoral upgrading. This measure is clearly not as strong as the first correlation because the relationship between skill and sector might be subject to many other effects. However, the correlation coefficients do point towards increasing between-sector "upgrading" (higher correlation coefficients), which induces higher wages. This suggests that although sectors do not move in a similar fashion, they do move more in line with on another in 1998 than in 1986, which is consistent with the findings of Gould (2002) for the United States and the analysis of Gould, Moav and Weinberg (2001) that technology is absorbed differently by different sectors.

Finally, Panel A analyses the correlation of the predicted values of job complexity and sectoral upgrading. This steadily rising correlation coefficient indicates which sectors reward similar jobs with higher wages relative to other sectors. The correlation coefficient is rather low, suggesting that jobs of similar complexity in different sectors are not valued in a similar way. This is consistent with the findings of Berman, Bound and Machin (1998) for several OECD countries that the bulk of the change in the prices for skills is going on within, rather than between, sectors, and with the findings of Gould (2002) for

\footnotetext{
${ }^{14}$ Machin and Van Reenen (1998) define the aggregate change in the skilled proportion over a given time period $\Delta P$ as $\Delta P=\sum_{i} \Delta S_{i} P_{i}+\sum_{i} \Delta P_{i} S_{i}$, where $P_{i}$ is the proportion of skilled workers in industry $i$ and $S_{i}$ is the share of total employment in industry $i$. Underlined variables denote a time mean. The first term on the right-hand side is the change in the aggregate proportion of skilled workers that can be attributed to shifts "between" industries with different proportions of skilled workers. The second term in the expression is the change that can be attributed to changes in the proportion of skilled workers "within" industries.
} 
the United States in the period 1970-1992 that within-sector wage inequality is more important than between-sector wage inequality. This leads to different valuations for similar job complexity levels between sectors, which is consistent with the observation that workers may be "trapped" in a particular occupational cell..$^{\text {s }}$

In Panel B, the values of all three measures for 1986-1998 are reconsidered, weighing personal, job and sector characteristics with their coefficients for 1986. In this manner, it is possible to compare the values of the skill and job complexity and sector upgrading for all seven years. From Panel B it can be observed that, comparing 1986 with 1998, the mean of the skill measure rose by 16.4 percent (from 2.244 to 2.408 ), the mean of the measure of job complexity rose, in a comparable manner, by 16.6 percent (from 2.293 to 2.459 ) and the mean of the measure of sector upgrading rose by only 10.3 percent (from 2.331 to 2.434 ). ${ }^{16}$ The first two observations are consistent with the arguments presented by Acemoglu (1998) in that the increase in the average level of job complexity as a result of the increasing demand for skilled workers has been captured by the rise in the supply of skilled workers. However, the complexity of the sectoral component is not catching up with the rise in both demand and supply. These results give an explanation as to why wages have not markedly risen in the Netherlands: If the increased demand for skilled workers as a result of technological change has been captured by a sufficient supply of skilled workers, there is no need for employers to pay higher wages. The reason for this almost perfect adjustment might reflect a more efficient assignment of workers to jobs since 1980s. This is also supported by the results from Panel A in Table 6.3, which indicate a more efficient assignment of workers to jobs over the period 1986-1998.

Finally, in Panel $\mathrm{C}$ of Table 6.3, the measures from Panel $\mathrm{B}$ of job complexity and sector upgrading are regressed on the measures of skill. Separate regressions show that the effect of an additional unit of skill on the

15 Job complexity also plays a role in the distinction between worker types (e.g ", blue-collar versus white-collar workers). Gould (2002) argues in this respect that the skills that determine a worker's ability as a doctor are very different from those used as a factory worker. As a consequence, those who are good at being doctor may not be very productive factory workers and vice versa. Substituting a professor of chemistry with a professor of economics rather will turn out to be a disaster. Hence, the extent of substitution between different types of workers is very limited. This limited substitution leads to distinct "occupational cells" "and might be an explanation for the boom in wages of some occupations, such as software programmers and other 1T-related workers.

16. Note that the standard deviation of personal characteristics is subject to persistent increases in the 1990 s, whereas the standard deviation of job complexity is fairly constant, indicating a greater diversity of skilled labour. This may mean that the supply of workers has experienced. some difficulties keeping up with demand. 
expected complexity of the job is significantly higher in 1998 than in 1986. The results with regard to sector upgrading point into the same direction but are less marked. In general, the coefficient remains constant with some peaks in 1988 and 1994. Secondly, combining both job complexity and sector upgrading it is possible to explain a large part of the effects of an additional unit of skill on the expected overall complexity. Again, the coefficient is rising over time.

In terms of the predictions of a similar approach by Teulings (1995), this means - if job complexity is a function of skill - that the distribution of the skill function in terms of complexity has narrowed, which runs counter to the empirical results obtained by Teulings. He finds that the effects of an additional unit of skill on the expected complexity of the job a worker performs is less in 1988 than in 1982. The main reason given for this was that

\begin{abstract}
"the large supply of highly skilled workers makes it less likely that they will obtain highly complex jobs in 1988 than was previously the case." (Teulings, 1995, p. 285)
\end{abstract}

This suggests that the findings by Teulings (1995) and many others for the Netherlands for the 1980s do not apply to the 1990 s and that technological change is most likely to have indeed increased job complexity throughout the 1990 s, thereby increasing the returns to education and assigning workers more efficiently, which is consistent with the observations of Gould (2002) for the United States. ${ }^{17}$

\title{
6.4.3. Computerization
}

While no direct information on computer use is available from the data, distinguishing sectors on the basis of their innovative efforts might be a fruitful exercise to investigate whether the trends differ between different sectors. In addition, it might be useful to distinguish between a blue-collar and a whitecollar labour market because upgrading between these two types of occupations might have been very different over the period 1986-1998. Since most studies reveal more upgrading in the white-collar occupations, the hypothesis would be that job complexity has increased to a larger extent in white-collar occupations. Whether this has led to higher wages is of course also a matter of skill supply. ${ }^{t 8}$

\footnotetext{
17 The results are also consistent with the model developed by Kaboski (2001). In a growththeoretical setting he shows that most models including only two types of labour overstate the growth and inequality effects of rising education and experience levels.
}

${ }^{18}$ If the labour market is segmented into a higher-skilled (college and university graduates) and a lower-skilled (secondary education at most) sample and these segments are analysed separately, the coefficients turn out to be higher in the higher-skilled labour market. Of 
Distinguishing sectors by their technological advancement is often done by looking at R\&D efforts. Using the OECD classification the two following groups can be distinguished: high-tech sectors are chemicals and other industry, and the remaining industries are low-tech. Yet, this might not be an adequate definition to investigate computerization because low-tech service sectors use computers more often than high-tech sectors. Hence, I have added other services, banks, non-profit services and the government sector to the high-tech sectors. Performing a similar analysis as reported in Table 6.2 and 6.3 reveals the following results.

First, for both high-tech and low-tech sectors, the correlation of the predicted values of skill and job complexity is rising over time, whereby the coefficients for the low-tech are rising more rapidly than those for the high-tech sectors. This suggests that particularly in the low-tech sectors the match between skill and job complexity has improved over time. However, for the high-tech sectors the correlation coefficients are higher in all years (and significantly so in 1986, 1998 and 1994), suggesting a more efficient match between skill and job complexity than in the low-tech sectors. It seems hard to link this result to computerization, but one explanation could be that computer use in the high-tech sectors was substantial to begin with, resulting in a relatively efficient assignment of workers to jobs; and that computer use is increasing in the low-tech sectors, resulting in a more efficient allocation of workers to jobs, which are growing more rapidly over the period 1986-1998. Secondly, the correlation coefficients between skill and sector of employment are also increasing for both groups, suggesting a more similar pattern between sectors at the end of the period compared to the beginning (1986). The correlation coefficients are significantly higher for the low-tech industries until 1992; after that it is not possible to statistically discriminate between them. ${ }^{19}$

conrse, while this procedure leads to lower coefficients by definition (at least half of the vertical distance between the highest and the lowest skills is removed), the heterogeneity among skilled workers is higher than among unskilled workers. This observation is consistent with the findings that higher-skilled jobs often involve more non-routine procedures and that the costs associated with allocating the "wrong" skilled worker to some skilled job are much higher than the costs of a mis-allocation in the lower-skilled segment of the labour market. It is also consistent with a higher job complexity among relatively skilled jobs. Mowever, from a theoretical point of view this does not seem to be the right way to analyse the data. Estimating wage equations to yield skill, job complexity and upgrading measures separately leads to bias in the estimates, because this does not allow a skilled worker to occupy an unskilled job. Distinguishing blue- and white-collar workers, on the other hand, is likely to yield fewer problems in that the vertical trajectory of the labour market from low- to high-skilled occupations continues to exist, while the horizontal possibilities to substitute workers and jobs are limited to either white- or blue-collar jobs.

The coefficients are also much higher than the ones reported in Table 6.3., Panel A. For the low-tech (high-tech) sectors the correlation coefficients are $.370(.321), .352(.307), .374$ 
The differences between the high-tech and low-tech sectors might be explained by the fact that upgrading is present (higher correlation coefficients over time) but that within the low-tech sectors this correlation is more equally distributed. This result is consistent with the estimates of Gould (2002), suggesting that different sectors adopt new technologies at different points in time and that high-tech industries exhibit a rather disperse pattern of adoption relative to lowtech industries (which adopt technologies at a later stage of development). Finally, the correlation coefficients of the predicted values of job complexity and sector upgrading are rather similar to the coefficients reported in Table 6.2 . For both the high-tech and low-tech sectors it is not possible to discriminate between the joint and separate estimates. In addition, the coefficients are rising over time. This suggests that different sets and combinations of skills receive a different return in different sectors and provides evidence for the withinsectoral pattern of skill upgrading reported in the literature.

Distinguishing a blue-collar and white-collar labour market yields the following results. For all three sets of correlation coefficients, the sample of white-collar workers yields higher estimates. However, the growth over time is higher in the blue-collar occupations, although not significant. These results suggest that white-collar workers are more efficiently assigned to jobs than their blue-collar colleagues and that both types of workers are more efficiently assigned to jobs over time. ${ }^{20}$ Whether or not this is the result of computerization or not is not clear, but the hypothesis that computerization has led to an increasing level of job complexity and to a focus on non-routine job activities combined with the fact that white-collar workers use computers more often than blue-collar workers, is consistent with the results put forward in the literature. Secondly, the higher correlation coefficients for white-collar workers when comparing a worker's skill and the sector of employment suggest that the whitecollar labour market is more homogeneous than the blue-collar labour market. This seems to be plausible because white-collar jobs between sectors are rather similar compared to blue-collar jobs, which often involve higher levels of firm and sector-specific skills. Finally, the corretation between job complexity and sector of employment for white-collar workers relative to blue-collar workers suggests that white-collar skills are valued more equally across sectors than blue-collar skills. Consistent with the coefficients for skill and sector of employment, this suggests that white-collar skills are more widely applicable and that the demand for white-collar skills is relatively homogeneous.

$(.320), .358(.313), .392(.365), .412(.379), .41 \Perp(.388), .412(.384)$, respectively. This reveals that the decomposition of sectors is performed in such a way that the two groups distinguished are moving in a relatively similar way and are hence subject to relatively similar trends.

20 Since elementary jobs cannot be split into white-and blue-collar jobs, they are included in both estimates. 


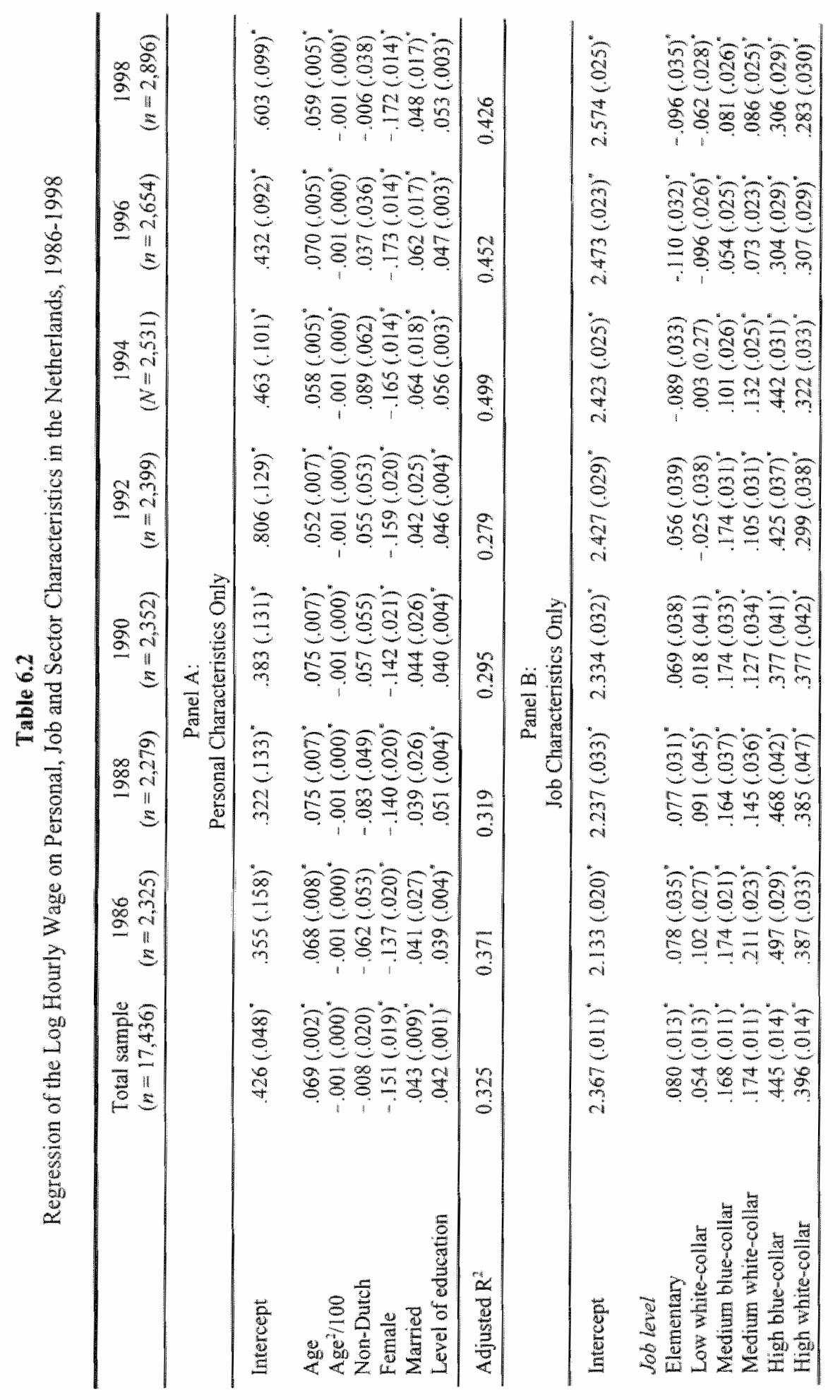




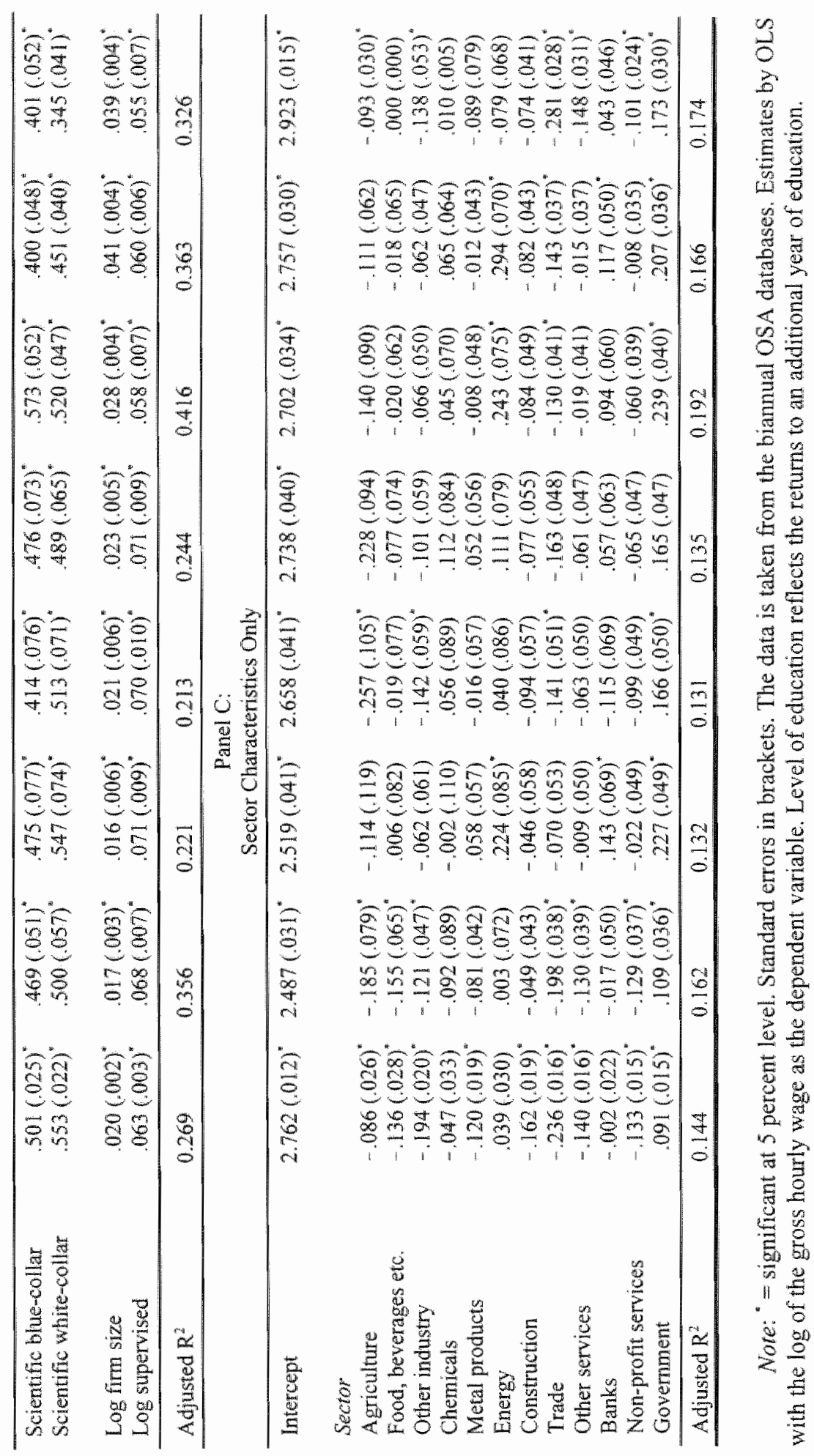




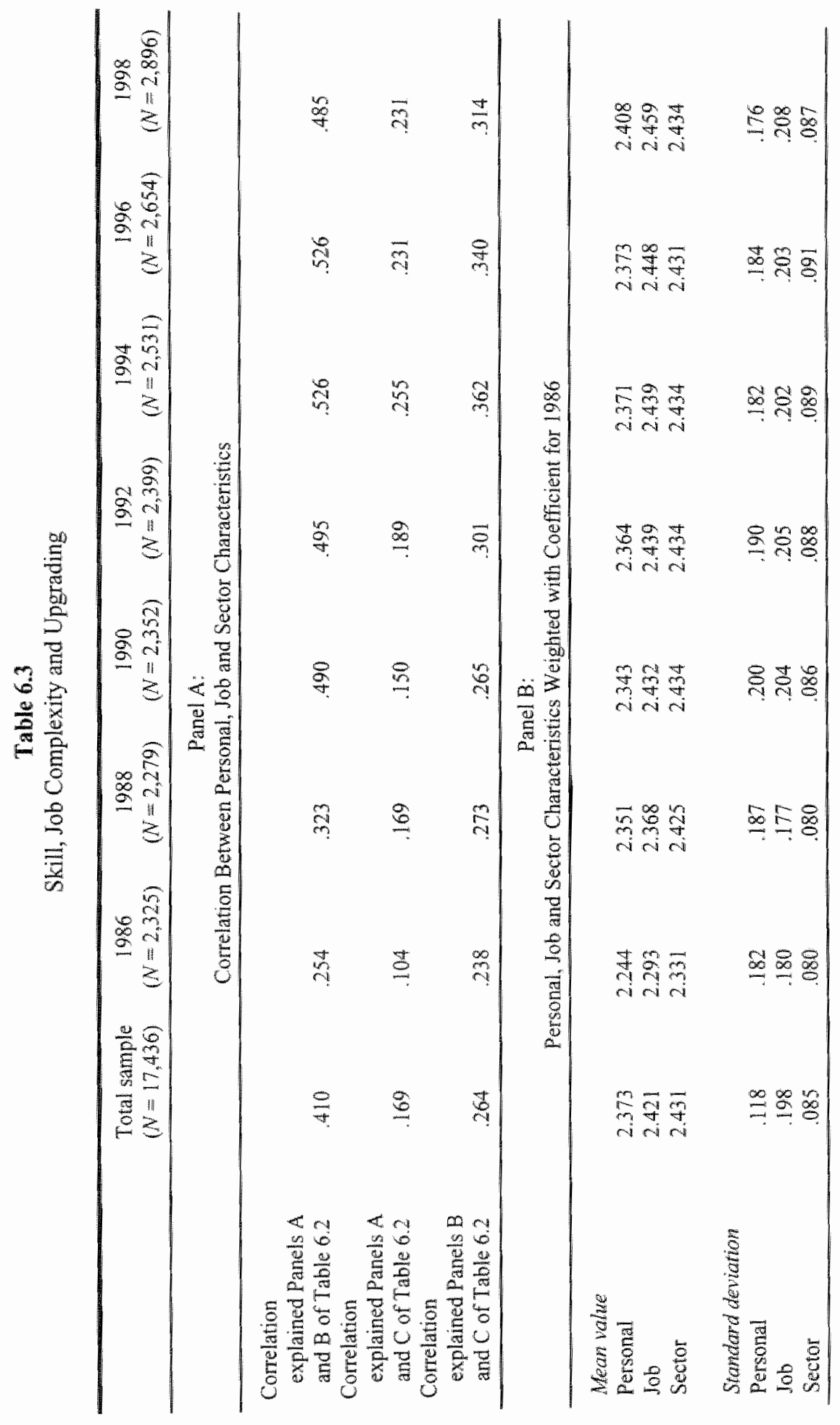




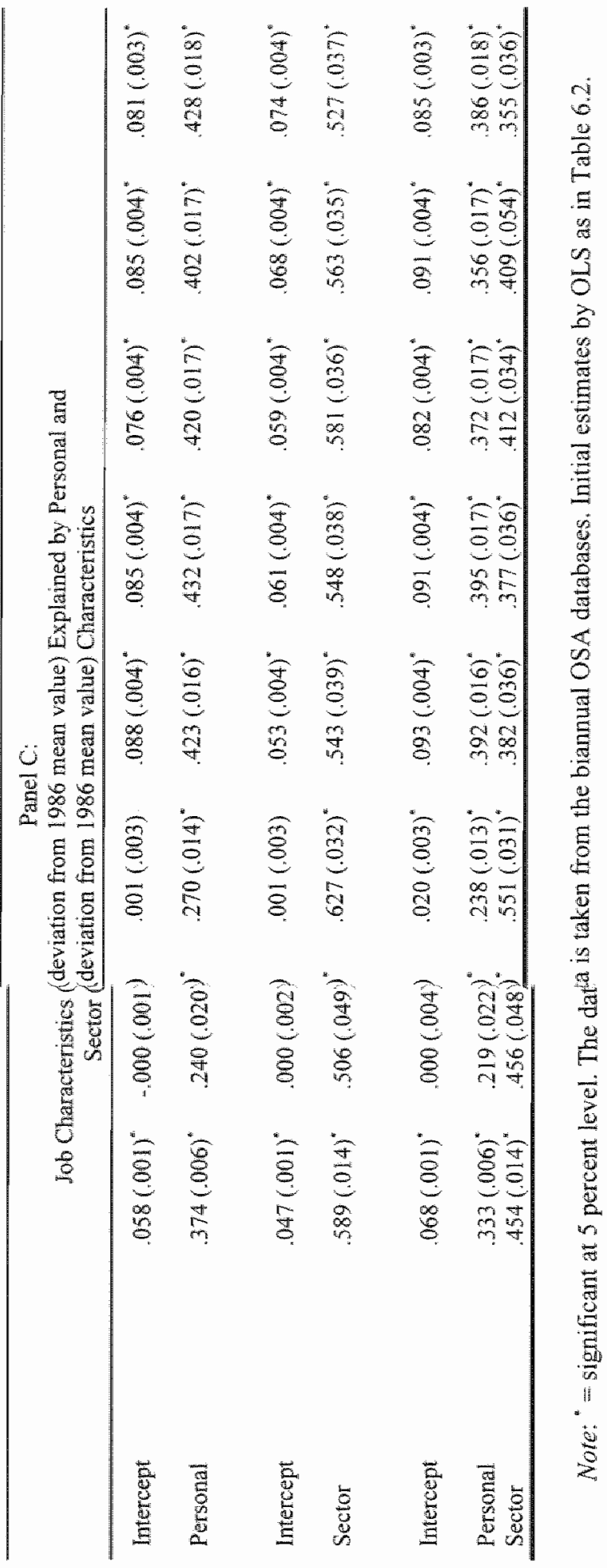




\subsection{Conclusion}

The two primary goals of this chapter have been to investigate whether a simple relative-supply-demand model is consistent with the wage structure of the Netherlands over the period 1986-1998 and to investigate whether a simple assignment approach is able to provide insights into the separate and joint impact of labour demand and supply over this period to explain upgrading. The first major finding is that there exists a link between the return to skill and the assignment of workers to jobs, which yielded predictions for the return to skill, the allocation of workers to jobs, and the distribution of wages, which is consistent with a relative-supply-demand framework. The analysis also offered an explanation for the relative stable wage structure in the Netherlands in the period 1986-1998 despite the labour market changes following from rapid technological change during this period. Although the data set is relatively small, the results are statistically strong and significant. Finally, it is found that higher skilled workers have been assigned to more complex jobs and that this trend has increased over the sample period, suggesting that the assignment of workers to jobs has become more efficient. This result is reinforced by the increase in the average level of complexity of labour demand, which goes together with the rise in the level of skills among workers. Together, these results provide an explanation as to why wages have been relatively stable in the Netherlands: The increase in the demand for skilled workers as a result of technological change has been captured by a sufficient supply of skilled workers, which has led to a more efficient assignment of workers to jobs and not to increasing wages as in the United States. 



\section{Chapter 7}

\section{Summary and Conclusions}

The diffusion and widespread use of computers has radically changed the labour market. This study has provided an understanding of the determinants of computer use, how computerization has changed the way in which people work, and how computerization impacts the wage structure and the allocation of workers to jobs. The first main insight of this study is that the wage costs in relation to the costs of computers are the most important determinant of computer adoption and that (computer) skills, level of education and experience have no significant impact on computer use. The second main insight is that the changing wage distribution both between and within groups of workers as a result of computerization is likely to be a temporary phenomenon resulting from the different timing of adoption both within and between groups of workers rather than from skill-biased technological change. The third main insight is that computerization has led to skill upgrading because the computer emphasizes the skilled part of the job, i.e., the computer takes over routinized job activities whereas the non-routinized tasks have to be carried out by the worker. This increases job complexity and the demand for skills.

\subsection{Summary}

Chapter 2 offered an overview of the empirical and theoretical contributions on the diffusion of computers through the labour market, which has been linked to and coincided with an acceleration of wage inequality in some countries (most notably the United States and the United Kingdom) and upgrading of the workforce.

First, an investigation of the U.S. wage structure from 1963 to 2000 reveals that the acceleration of wage inequality between the groups of skilled and unskilled workers did not start until the early 1980s. However, in the early 1980 s a large number of skilled workers used a computer for a while and it seems surprising that the surge in between-group wage inequality did not start until that point in time. Wage inequality within the group of skilled workers started in the early 1970 s, which coincides with the period when the first workers adopted computers. By the same token, wage inequality within the 
group of unskilled workers have accelerated since the early 1980s, when the first unskilled workers started to use a computer. Numerous studies reviewed and summarized in Chapter 2 provide arguments as to why wage inequality between skilled and unskilled workers has accelerated as a result of the adoption of new technologies, such as computers. They all conclude that skilled workers have an advantage in working with computer equipment because the costs of adoption are lower.' However, the timing of the rise in wage inequality between skilled and unskilled workers, observed since the early 1980s, is inconsistent with such arguments because skilled workers already used computers in the 1970 s and one should hence observe rising between-group wage inequality in the $1970 \mathrm{~s}$. Other studies have acknowledged this caveat to some extent and focus on wage inequality within the groups of skilled and unskilled workers. They model rising wage inequality between ex ante homogeneous workers upon the introduction of a new technology. In these settings, some workers are assigned to the new technology, become more efficient and gain higher wages, while others are left with the old technology. The mechanisms through which this occurs are often assumed to be random factors (Caroli and Garcia-Peñalosa, 2001) or labour-market frictions (Violante, 2002). While these models are consistent with the empirical observations about rising within-group wage inequality, the assignment of workers to computers seems to be a non-random process, and labour market frictions are unlikely to explain the assignment of workers to machines to such a large extent. ${ }^{2}$ In addition, these approaches have hardly anything to say about rising betweengroup wage inequality since the early $1980 \mathrm{~s}$.

Secondly, from micro-econometric studies it has become clear that computer users earn substantially higher wages than non-users. Krueger's (1993) study showed that computer users earn 10 to 15 percent higher wages. Entorf and Kramarz (1997), Chennells and Van Reenen (1997) and Entorf, Gollac and Kramarz (1999) have shown that these workers already earned

1 These costs are reflected in, for example, learning costs (e.g., Galor and Tsiddon, 1997 and Caselli, 1999), advantages in adaptation to the new technology (e.g., Greenwood and Yorukoglu, 1997, Aghion, Howitt and Violante, 1998, Gould, Moav and Weinberg, 2001 and. Violante, 2002) and experience (e.g., Chari and Hopenhayen, 1991 and Weinberg, 2001).

2 Trade liberalization and deunionization have also been proposed as explanations. However, both of these failed to explain rising within-group wage inequality. The most important reason for trade liberalization being an unlikely explanation is that its impact on wage inequality would be too large considering the size of trade with non-OECD countries. Nor is deunionization likely to be able to explain rising within-group wage inequality because its timing is inconsistent with the empirical observations, for example, in the United Kingdom within group wage inequality for skilled workers started to rise in the mid-1970s while union density continued to increase until the early 1980s. Aghion (2002) addresses similar questions and puzzles in a Schumpeterian growth theory framework. 
higher wages prior to computer adoption. In other words, it does not seem to be clear what drives the higher wages of computer users. Alternative explanations have been that some workers are more likely to work with a computer because they have higher levels of computer skills (Green, 1999), that unobserved heterogeneity, which is reflected in a worker's wages but not in his observed skill level, determines computer use (DiNardo and Pischke, 1997), and that more-educated workers adapt more easily to new technologies than lesseducated workers (Entorf and Kramarz, 1997). However, there is no consensus as to which of the proposed explanations is consistent with the observed patterns of computer use. First, a wage premium for computer skills of 10-15 percent seems to be too high when one thinks of the shop assistant using a computerized cash register compared to the other shop assistant using a manual one. Secondly, unobserved skills of computer users might play a role in the determinants of computer use, but again a 10-15 percent reward for this component of a computer user's skills set is likely to be too high. Finally, the figures on computer use at work reveal that not only the more-educated and higher-skilled workers use computers, but that also the less-educated and lowerskilled part of the workforce has adopted computers.

Finally, the first two observations are drawn from the perspective of the individual worker given the job he is allocated to. An important question which has not been addressed in many studies, is what happens to the job when the computer is adopted. The observations show that firms adopting computers have upgraded their workforces for a given job relative to firms not using computers. It has been argued that computers take over the routine job activities and that the worker has to manually perform the skilled job activities. This has led to an increase in job complexity and a rise in the demand for more-skilled workers. This has been investigated from the angle of the job (Autor, Levy and Murnane, 2001), the organization (Lindbeck and Snower, 2000 and Garicano, 2001) and the cooperation between different types of workers (Kremer and Maskin, 1997 and Acemoglu, 1999). However, the consequences for the assignment of workers to jobs in the face of computerization have not been addressed extensively.

Hence, the questions addressed in this study are why some workers use computers and others do not use one yet, how it impacts between-group and within-group wage inequality, to what extent the computerization of the labour market is able to explain the increase in between-group wage inequality since the early 1980 s and the rise in within-group wage inequality for skilled workers since the early 1970 s and unskilled workers since the early 1980s, and what the impact of the adoption of computers is on the skill requirements of the job and labour demand in general.

To understand the determinants of computer use - and to answer the question why some workers use computers and others do not - an experiment might help. In Chapter 3 such an experimental approach has been developed by 
considering what happens when agent $T$ gets a computer. In such a stylized setting it is possible to highlight one job and investigate the changes in this job upon the introduction of a computer. The job of agent $T$ has been selected and he has been assigned to a computer in his job. To perform the job, agent $T$ has to fulfil two tasks, where it has been assumed that task 1 represents aspects of the job that can be computerized and that task 2 is one that cannot be computerized. The arrival of the computer in his job has been shown to affect the time requirements needed to fulfil both tasks. The time to carry out task 1 and task 2 depends both on his skill level and the product specifications. Hence, the required skill level and the specifications of the product he produces are subject to change when the computer is adopted. The experiment implies that agent $T$ no longer has to perform task 1 manually but has to operate a computer which assists him in performing this job aspect. However, due to the complementarity between computers and skills, the performance of task 2 might also be amended and modified. In this stylized setting, the determinants of computer adoption can be reviewed. Based on a threshold model of diffusion, it has been shown that the determinants of computer use are (i) a worker's skills, (ii) the extent to which the tasks he has to carry out are likely to be subject to computerization, and (iii) his wage level.

These three possible determinants of computer use have been empirically explored in Chapter 4 using unique data from the Skills Survey of the Employed British Workforce, carried out in 1997. This survey contains detailed and unique information about the importance of tasks workers have to carry out at work. In addition, information about the extent to which workers are able to perform these tasks effectively is also available from this survey. Finally, the level of sophistication of computer use is reviewed, which reveals information about the use of computers at the job and helps to distinguish different computer tasks. The analysis in Chapter 4 puts forward the following results. First, computer skills are likely to be unimportant in explaining why computer users earn higher wages than non-users. The results show that the level of computer skills does not influence the wages these workers receive. The fact that computer users earn higher wages in a simple OLS wage equation seems to be driven by the fact that they use a computer, not by the skills they possess to do so. Even within different levels of sophistication of computer use, computer skills are not rewarded by the employer. Only at the highest level of sophistication of computer use (e.g., programming and developing software) do computer skills have a positive impact on the worker's wage. This latter result is plausible, since workers using computers as their main task are likely to be rewarded for it. The reading of the other results is - consistent with the model - that computer use is likely to be of secondary importance and that the skills to use a computer are not the main reason a worker is hired for. The second contribution of Chapter 4 is an analysis of the determinants of computer use. An estimate of the probability of computer use shows that a worker"s wage level is the most 
important determinant of computer use. ${ }^{3}$ In addition, particular tasks, such as writing, reading and calculating, also increase the probability of computer use. Interestingly, women have a higher probability of using a computer, which is consistent with the observation that computers reduce some of the physical disadvantages of female workers in some occupations (e.g., Weinberg, 2000). Another important finding is that age and experience do not seem to have an effect on the probability of computer use. This runs counter to the popular belief that older workers have a disadvantage in using new technologies, such as computers (e.g. Ahituv and Zeira, 2001), and is consistent with the observations of Friedberg (2001) that computer use is surprisingly flat over the life cycle. Finally, a worker's educational level has no direct influence on the probability of using a computer. This finding can be interpreted as evidence that a worker's skill level does not directly influence the use of computers at work. There is only a small (and in most specifications insignificant) indirect effect of education on the likelihood of computer use through the wage variable. ${ }^{4}$

These results have important implications for the previous microeconometric studies and evidence put forward on the computerization of the labour market. For example, Krueger's (1993) findings that computer users earn $10-15$ percent higher wages because they use their computer skills is unlikely to hold. Rather, the causation is reversed: computer use does not lead to higher wages, but higher wages lead to computer use. In addition, arguments pointing to advantages for skilled workers over unskilled workers in using computers because of skill reasons do not seem to hold either, because education and experience have no direct impact on the likelihood of computer use. In addition, these results have implications for the discussion surrounding skill-biased technological change. Since skilled workers use computers because of their higher wages and not because of skill advantages, the thesis that computers lead to permanent wage inequality and even to a "digital divide" does not seem to hold.

But then the next question is how these arguments translate to the macroeconomic level to explain (i) the observed pattern of computer diffusion and wage inequality (both between-group and within-group wage inequality)

Since wages are an endogenous variable, instruments for the wages are used to estimate the likelihood of computer use. These instruments are rellated to unionization of the job. The disadvantages and possible caveats of using unionization variables as instruments to determine identification of the model are discussed extensively is Sections 4.5 .1 and 4.52. The conclusion from several checks on the instruments is that they are sufficiently strong from an econometric point of view and that they do not influence the estimation results viewed from an economic perspective (identification seems to be no problem).

4 The positive impact of being female on computer use is reduced by this indirect effect through wages because women generally earn lower wages, which reduces the probability of adopting a computer. 
and (ii) skill upgrading. The first question is addressed in Chapter 5, which develops a theoretical model to explain the adoption and diffusion of computers starting from the observations that (i) over time the group of workers using computers has changed, and (ii) the timing of between-group and within-group wage inequality is different. With respect to the first observation, the data show that computers were not only used by skilled workers in the 1990 s but that almost half of the unskilled workforce also adopted computers by 1997 , the rate of which is higher than the adoption rate of skilled workers. This questions the suggested complementarity between skilled workers and computers - and perhaps the complementarity between technology and skills in general - and raises the issue whether the surge in wage inequality between skilled and unskilled workers, resulting from computer use, is a temporary or permanent phenomenon. With regard to the second observation, the data show that withingroup wage inequality for skilled workers started to increase in the early 1970 s, which is consistent with the period in which the first skilled workers adopted computers. Within-group wage inequality then increases because there is a discrepancy in the productivity between computer users and non-users, which is reflected in the wage. Within-group wage inequality for unskilled workers started to increase around 1980 , which is consistent with the first unskilled workers adopting computers. However, wage inequality between skilled and unskilled workers fell until 1980 and then rapidly increased. If the computerization of the labour market causes wage inequality within groups of rather homogeneous workers, why did not wage inequality between skilled and unskilled workers increase until around 1980, when a substantial number of skilled workers had already adopted computers and only a marginal fraction of the unskilled started to adopt computers? Most theoretical contributions discussed in Chapter 2 predict an immediate increase in between-group wage inequality when skilled workers adopt computers (or other new technologies), because they assume a complementary relationship between skilled labour and new technologies in the production function (e.g., which $Y$ is output, $S(U)$ is the input of skilled (unskilled) labour, and $A$ is technology). The model developed in Chapter 5 includes three crucial ingredients to explain how computers affect the wage structure, inspired by the approach developed in Chapter 3: (i) the adoption of computers is based on a cost-benefit decision driven by the productivity benefits weighted against the costs of adoption for al] workers, either skilled or unskilled, (ii) skilled (unskilled) workers are fully substitutable (and thus ex ante homogeneous) in producing the skilled (unskilled) part of production, (iii) productivity levels of skilled and unskilled labour are distributed such that the most productive unskilled worker has a higher productivity level than the least productive skilled worker.

Using these three ingredients, the model first conjectures that wage inequality resulting from the computerization of the labour market can be either 
temporary or permanent depending on the proportional productivity gains from using computers. Only when skilled workers (as a group) are more productive in using computers than unskilled workers will between-group wage inequality be a permanent phenomenon. If not, the model predicts that between-group wage inequality falls once the level of diffusion reaches a certain point (depending on the distribution of productivities). In the hypothetical situation where the costs of computers are zero, between-group wage inequality resulting from computerization disappears altogether and between-group wage inequality is back at its pre-computerization level. Within-group wage inequality will be permanent if there are differences in productivity gains within the groups of skilled and unskilled workers. If the most productive skilled worker gains more from using the computer than the least productive one, within-group wage inequality will be permanent. Such a situation occurs when there is a complementary relationship between a worker's productivity level and his use of the computer. As empirically shown in Chapter 4, this is unlikely to be the case. Hence, within-group wage inequality rises until all workers within a group of workers have adopted computers. From then on, within-group wage inequality falls if the costs of computers drop further. Bringing the model to the data, using the March Demographic Supplements of the U.S. Current Population Surveys, reveals no significant differences between productivity gains for skilled and unskilled workers in the period 1963-2000 in the United States, although the point estimates for skilled workers are somewhat higher.

The second prediction of the model is that it offers an explanation for the different timing of between-group and within-group wage inequality. The model shows that there are three different effects of computer adoption on the timing of wage inequality. Consider the following explanation. At $t=0$ the most productive skilled worker $i$ adopts a computer because it becomes beneficial for him to perform his job using a computer. At this point in time, he is indifferent between using a computer or not because, on the one hand, he gains in terms of productivity but, on the other hand, he has to pay for adopting and using the computer. Because he becomes more efficient, he produces more efficiency units of labour, which increases the supply of efficiency units of skilled labour and depresses the skilled labour's wages per efficiency unit of labour. The model shows that it is likely that the increased supply effect outweighs the increased productivity effect at $t=0$. This has a negative effect on the relative wages of skilled workers, which is larger than the negative effect experienced by worker $i$. The reason for this is that worker $i$ also gains from his increased productivity because he supplies more efficiency units of labour. Hence, between-group wage inequality will fall, but within-group wage inequality for skilled workers will increase because worker $i$ becomes more efficient. This effect continues (depending on the parameters of the model and the elasticity of substitution between skilled and unskilled labour) until the first unskilled worker $j$ adopts a computer at $t=1$. Now, there is a third effect on wage 
inequality (besides the increased productivity and supply of efficiency units of skilled workers) because the supply of efficiency units of unskilled workers is increasing. The model predicts that within-group wage inequality for the unskilled workers increases from $t=1$. More importantly, between-group wage inequality will also increase now because the growing supply of efficiency units of unskilled workers dampens their wages to such an extent that relative wages increase. To summarize, the timing of within-group wage inequality is consistent with the first workers in each group adopting computers and between-group wage inequality does not start to rise until the first unskilled workers adopt computers. Considering the data for the United States, the timing of between-group and within-group wage inequality predicted by the model is consistent with within-group wage inequality for skilled (unskilled) workers starting to rise in the early 1970s (around 1980) and between-group wage inequality increasing after the early $1980 \mathrm{~s}$. Bringing the model to the data reveals that the proportional productivity gain lies (consistent with estimates by others) between a lower bound of 15 percent and an upper bound of 40 percent, where additional tests reveal that gains around 20 percent are probably the most likely ones.

The second macroeconomic issue that needs to be addressed is whether computer use leads to skill upgrading. The analysis in Chapter 5 takes the job as given, whereas an analysis of skill upgrading requires an analysis of the assignment of workers to jobs in a changing environment. The approach developed in Chapter 3 predicts that employers are likely to upgrade their workforce after the computer has been adopted because more attention (and probably more production time) will be devoted to non-routine job activities. The reason for this is that the computer mostly takes over the routine part of the job and leaves the worker with the more complex field of operation. At the macroeconomic level this is likely to translate into an increase in the demand for skilled labour given a certain job. To analyse whether employers have upgraded their workforce at the macroeconomic level, an assignment approach is helpful because labour supply and demand can be analysed simultaneously. This is important because observing an increase in the skill level in job $k$ over time does not necessarily imply an increase in the complexity of this job requiring higher-skilled workers. It might also be due to an increase in the supply of a particular type of labour or a decrease in the supply of another type of labour exogenous to the employer. Chapter 6 offers an assignment approach in which a distinction is made between labour demand and supply. To do so, workers are characterized by their skill level and jobs by their level of complexity. In this way the wage structure of the Netherlands in the period $1986-1998$ is analysed.

The first step in the analysis is to investigate the wage structure by distinguishing observable and unobservable dimensions of the wage structure. This is important in that it provides insight into the determinants of changes in 
the wage distribution over time. In particular, pursuing a wage-accounting model reveals that changes in the wage distribution can be attributed to (i) changes in the distribution and supply of observable worker characteristics (labour supply), (ii) changes in the returns to observable components (labour demand), and (iii) a residual term, which is often interpreted as capturing technological change. The results of estimating this model for the Netherlands reveal that most of the changes in the wage structure can be attributed to changes in observable worker characteristics and changes in observed prices. The residual component does not affect the wage structure to a large extent. As an initial explanation of changes in the wage structure of the Netherlands, this means that skill demand and supply adjusted over the period 1986-1998, which is consistent with a changing labour market as a result of computerization.

The second step is to use this information in an assignment model. The model used in Chapter 6 first estimates different wage regressions for the supply and demand side of the labour market and then derives from these estimates whether the mapping of demand and supply has changed over time. Changes in the mapping of demand and supply can then be attributed to either skill upgrading (demand) or differences in the configuration of labour supply. ${ }^{5}$ The results from this assignment exercise are the following. During the period 1986-1998 employers upgraded their workforce considerably by assigning higher-skilled workers to jobs previously occupied by other workers. This has not led to large increases in the returns to skills because the assignment of workers to jobs has become more efficient. This increased efficiency is confirmed by findings suggesting an increase in the complexity of the average job, which went together (in most instances) with an increase in labour supply. The results suggest that although the Dutch labour market has faced increases in job complexity, wages have not increased substantially.

The final step of the analysis is to relate these findings to computerization. Although no direct information about computerization is available in the data, some sectors and occupations use computers more often than others. Analysing these sectors and occupations reveals differences in the point estimates for job complexity, but hardly any significant differences in skill upgrading. This might be due to the fact that in some occupations computers had been used previously and hence upgrading already took place before 1986 . The results suggest that particularly in the low-tech sectors the assignment of workers to jobs has become more efficient and that particularly in these sectors upgrading took place. This is likely to be consistent with low-tech sectors being in the middle of the process of adopting computers and adjusting their demand for labour. In addition, upgrading in the low-tech sectors is developing more

5 Sectoral differences are also taken into account because some sectors might use more skilled workers than others. In addition, wages paid to similar workers might also be different in different sectors. 
smoothly than in the high-tech sectors. This is consistent with patterns observed by Gould (2002) for the United States indicating that different high-tech sectors adopt computers at different points in time but that low-tech sectors adopt computers at the same point in time. Such a pattern of adoption leads to different skills receiving different prices in different sectors over time, for example, in the earlier stages of adoption other skills are needed than later on when the technology is mature and the technology is applied differently between sectors hence demanding different sets of skills.

Overall, these estimates are consistent with the prediction of upgrading of skill requirements over time as a result of technological change and particularly computerization.

\subsection{Future Research}

This study has presented a new perspective on the economics of technological change and the labour market with a particular focus on how computerization has changed the labour market. It has done so both from a microeconomic and macroeconomic point of view by presenting evidence on how computers change the tasks workers have to carry out within a given job, how job complexity and skill upgrading have increased, and how computerization has changed the distribution of wages between relatively skilled and unskilled workers. Yet, one might want to criticize the current analysis because computerization and the recent ICT revolution have much wider labour market implications than the ones described here. Let me discuss three areas of (potential) future research not discussed in this piece of work, which might certainly represent relevant contributions to the understanding of how computerization changes the labour market.

First, the computerization of the workplace has without any doubt led to substantial organizational change (e.g., Caroli and Van Reenen, 2001 and Bresnahan, Brynjolfsson and Hitt, 2002). There appears to be some evidence that computers and particularly information and communication technology have amplified reorganizations of the work process, reducing the share of lessskilled and increasing the share of more-skilled workers on the one hand and specializing in employing less-skilled workers on the other. Production processes have generally become more knowledge-intensive, workers operate increasingly in teams and quality circles, and skilled and unskilled workers join forces in teams of equal skill level leading to the production of either high-tech or low-tech products (e.g., Kremer and Maskin, 1997 and Acemoglu, 1999). In addition, reorganization processes appear to be driven by a variety of forces mostly related to computerization. First, the hierarchy of firms is argued to have become flatter because communication technology allows managers to communicate with an increasing number of workers, and information 
technology allows the workers to deal with more tasks on their own (e.g., Garicano, 2001). Secondly, the introduction of flexible machine tools and programmable equipment is capable of performing a wider spectrum of tasks, which has enabled firms to give customers more individualized treatment and has resulted in greater interaction with customers via, for example, the Internet (e.g., Brynjolfsson and Hitt, 2000). Thirdly, the upgrading of the workforce and the increasing complexity of jobs has not only led to "job deepening" in the sense that an individual worker has improved his performance in one task, but also involved substantial "job widening" or "multi-tasking" resulting from increased opportunities to acquire skills. This has led firms to reorganize and integrate tasks more smoothly (e.g., Lindbeck and Snower, 2000). The link between organizational change and organizational structure, skill upgrading and computerization is an interesting field for future study, in which some have already attempted to measure a complementary relationship between organizational change and skill upgrading related to computerization. As has been shown in this study, a potential problem with the papers on skill-biased organizational change is that finding correlations between information technology and organizational change, or between these factors and measures of economic performance of the firm, is not sufficient to prove that these practices are more than just statistical artifacts, unless a full structural approach specifies the production relationships and the driving forces of increasing skilled labour demand, reallocation of work and tasks in relation to computerization.

Another important issue is the meaning of the concept of complementarity with regard to computers and skill Case-study evidence in Levy and Murnane (1996) suggests that computers generally complement moreskilled workers and substitutes for the less-skilled workers. Autor, Levy and Murnane (2001) present evidence that computers take over the routine activities of the job, while non-routine job activities continue to be fulfilled by the workers themselves. However, the analysis in Chapter 5 has shown that the complementarity between computers and workers changes over time. At first, it looked as if only more-skilled workers were able to use computer equipment, but we now know that a significant part of the less-skilled workers also uses computers. Hence, computer technology does not seem to be complementary to more-skilled workers only. A line for future research would be to explore the relationship between computers and skills at different levels of sophistication of computer use and at different skill levels. Do some skills increase in value and, if so, are these skills the same for all workers or do some skills become more important for the more-skilled workers while other skills become more important for the less-skilled part of the workforce? Investigating the complementarity between computers and skills from such an angle would yield great insight beyond what happens to the job and workers in the face of computerization presented in Chapter 3. Borghans, Marey and Ter Weel (2002) provide an initial analysis into this issue by presenting evidence of computer- 
skill complementarity in 11 European countries for highly-educated school leavers.

A final issue not discussed here but of central importance to the debate is that computers have not only influenced work but also had a great impact on learning, both in formal education and training. Since education aims at preparing people for their labour market career, computers might affect both what should be learned and how this is learned. For analytical purposes it is therefore important to distinguish these changes in the educational production function from the educational objective function. There are at least four possible options in which computers could support education that are worth considering. The first is to use computers in the classroom to teach students how to work with a computer and focus on teaching computer skills, even though these skills are shown to be not rewarded in their labour market careers. The second reason is to provide computer-aided instruction gives pupils and students a more or less individualized programme to acquire skills at their own pace. In an ideal situation this could save an enormous amount of teaching time and the role of the teacher would become entirely different. Thirdly, the Internet can be used to look for information and to make pupils aware of the information available beyond the school's own library. Finally, training and education programmes can be delivered through the Internet. To investigate the impact of computerization on learning and the effects of computer-aided instruction on a student's success, an experimental approach could help because the main problem in analysing the effects of computerization on a student's school performance and labour market success is the selectivity issue. Obviously, computer skills will be correlated with other skills and schools using computeraided instruction tend to be schools with a better performance anyway. Angrist and Lavy (2002) have investigated the impact of computer-aided instruction on the performance of students in Israel. The main problem of an experiment like the one they describe and analyse is that only one software package is tested. This makes their approach vulnerable to the critique that the wrong packages have been chosen and that other packages would perform much better. Rather than testing the performance of one specific package one might propose to change the question into the following: "What aspects of computer-aided instruction contribute positively to the learning process?". Therefore the use of a number of alternative packages is preferred. These different packages should vary over a certain range of (observable) characteristics that can be used as explanatory variables in the analyses. 


\section{References}

Acemoglu, Daron (1998), "Why Do New Technologies Complements Skills? Directed Technical Change and Wage Inequality," Quarterly Joumal of Economics, vol. 113, no. 4, pp. 1055-1090.

Acemoglu, Daron (1999), "Changes in Unemployment and Wage Inequality: An Alternative Theory and Some Evidence," American Economic Review, vol, 89, no. 4, pp. 1259. 1278.

Acemoglu, Daron (2000), "Patterns of Skill Premia," Mimeo, MIT, September.

Acemoglu, Daron (2001), "Cross-Country Inequality Trends," Mimeo, MIT, September.

Acemoglu, Daron (2002), "Technical Change, Inequality, and the Labor Market," Journal of Economic Literature, vol. 40, no. 1, pp. 7-72.

Acemoglu, Daron and Robert Shimer (2000), "Wage and Technology Dispersion," Review of Economic Stuaies, vol. 67, no. 3, pp. 585-608.

Adams, James D. (1999), "The Structure of Firm R\&D, the Factor Intensity of Production, and Skill Bias," Review of Economics and Staristics, vol. 81, no. 3, pp. 499-510.

Aghion, Philippe (2002), "Schumpeterian Growth Theory and the Dynamics of Income Inequality," Econometrica, vol. 70, no. 3, pp. 855-882.

Aghion, Philippe, Peter Howilt and Gianltica Violante (1998), "Technology, Knowledge and Within-Group Inequality," Mimeo, University College London, November.

Ahituv, Avner and Joseph Zeira (2001), "Technical Progress and Early Retirement," Mimeo, Hebrew University, February.

Allen, Steven G. (2001), "Technology and the Wage Structure," Joumal of Labor Economics, vol. 19 , no. 2 , pp. 440-483.

Angrist, Joshua D. (1991), "Instrumental Variables Estimation of Average Treatment Effects in Econometrics and Epidemiology," NBER Technical Working Paper 115.

Angrist, Joshua D. and Victor Lavy (2002), "New Evidence on Classroom Computers and Pupil Learning," Economic Journal, vol. 112, forthcoming.

Arabsheibani, G. Reza and Alan Marin (2000), "If Not Computers Then What? Returns to Computer Use in the U.K. Revisited," Mimeo, London School of Economics, November.

Ashton, David, Bryn Davies, Alan Felstead and Francis Green (1999), "Work Skills in Britain," Working Paper, ESRC Centre on Skills Knowledge and Organisational Performance, Oxford and Warwick Universities, June.

Asplund, Rita (1997), "Are Computer Skills Rewarded in the Labour Market? Evidence for Finland," Mineo, ETLA, November.

Autor, David H., Lawrence F. Katz and Alan B. Krueger (1997), "Computing Inequality: Have Computers Changed the Labor Market?" NBER Working Paper 5956.

Autor, David H., Lawrence F. Katz and Alan B. Krueger (1998), "Computing Inequality: Have Computers Changed the Labor Market?," Quarterly Journal of Economics, vol. 113 , no. 4, pp. 1169-1213.

Autor, David H., Frank Levy and Richard J. Murnane (2001), "The Skill Content of Recent 
Technological Change: An Empirical Exploration," Mimeo, MIT, January.

Autor, David H., Frank Levy and Richard I. Mumane (2002), "Upstairs, Downstairs: Computers and Skills on Two Floors of a Large Bank," Industrial and Labor Relations Review, vol. 55, no. 3, pp. 432-447.

Baldwin ${ }_{4}$ John, Timothy Dunne and John Haltiwanger (1998), "A Comparison of Job Creation and Job Destruction in Canada and the United States" Review of Economics and Sitatistics, vol. 80, no. 3, pp. 347-356.

Bartel, Ann P. and Nachum Sicherman (1993), "Technological Change and Retirement Decisions of Older Workers," Journal of Labor Economics, vol. 11, no. 1, pp. 162183.

Bartel, Ann P. and Nachum Sicherman (1999), "Technological Change and Wages: An Interindustry Analysis," Joumal of Political Economy, vol. 107, no. 2, pp. 285-325.

Beaudry, Paul and David Green (1998), "What is Driving U.S. and Canadian Wages: Exogenous Technical Change or Endogenous Choice of Technique?" NBER Working Paper 6853.

Bell, Brian D. (1996), "Skill-Biased Technical Change and Wages: Evidence from a Longitudinal Data Set," Mimeo, Nuffield College, October.

Berman, Eli, John Bound and Zvi Griliches (1994), "Changes in the Demand for Skilled Labor within U.S. Manufacturing Industries," Quarterly Journal of Economics, vol. 1.09 , no. 1, pp. 367-398.

Berman, Eli, John Bound and Stephen Machin (1998), "Implications of Skill-Biased Technological Change: International Evidence," Quarterly Joumal of Economics, vol. 113, no. 4, pp. 1245-1279.

Berman, Eli, Kevin Lang and Erez Siniver (2002), "Language Skill Complementarity: Returns to Immigrant Language Acquisition," Labour Economics, forthcoming.

Berman, Eli and Stephen Machin (2000), "Skill-Biased Technology Transfers: Evidence of Factor-Biased Technological Change in Developing Countries," Mimeo, Boston University, February.

Berndt, Ernst R. and Catherine Morrison (1995), "High-Tech Capital Formation and Economic Performance in U.S. Manufacturing Industries: An Explorative Analysis," Joumal of Economericics, vol. 65, no. 1, pp. 9-43.

Bertrand, Marianne and Sendhil Mullainathan (2001), "Do People Mean What They Say? Implications for Subjective Survey Data," American Economic Review, vol. 91, no. 2, Papess and Proceedings, pp.67-72.

Betts, Julian (1997), "The Skill Bias of Technological Change in Canadian Manufachuring Industries," Review of Economics and Statistics, vol 79 , no. 1, pp. $146-150$.

Blau, Francine D. and Lawrence M. Kahn (1996), "International Differences in Male Wage Inequality: Institutions versus Market Forces," Joumal of Political Economy, wol. 104, no. 4 , pp. $791-836$.

Blechinger, Doris and Friedhelm Pfeiffer (2000), "Technological Change and Skill Obsolescence," in Edwcation, Training and Employment in the Knowledge-Based Economy, Hans Heijke and Joan Muysken, eds. (MacMillan, London).

Boeri, Tito and Lutz Bellmann (1995), "Internal and External Adjustment to New Technologies," Economics of Inmovation and New Technology, vol. 5, no. 2, pp. 325343.

Borghans, Lex and Andries de Grip (2000), "Skills and Low Pay: Upgrading or Overeducation?", in Labour Market Inequalities: Problems and Policies in International Perspectwe, Mary Gregory, Wiemer Salwerda and Stephen Bazen, eds. (Edward Elgar, Cheltenham), pp. 198-223.

Borghans, Lex, Philip Marey and Bas ter Weel (2002), "Computers and Skill Upgrading in 
Europe," Mimeo, Maastricht University, January.

Borghans, Lex and Bas ter Weel (2002), "Do Older Workers Have More Trouble Using a Computer than Younger Workers?" Research in Labor Economics, vol. 21, pp. 139173.

Bound, John and George E. Johnson (1992), "Changes in the Structure of Wages in the 1980s: An Evaluation of Alternatiwe Explanations," Americon Economic Review, wol. 82, no.

2. pp. $371-392$.

Braverman, Harry (1974), Labor and Monopoly Capital: The Degradation of Work in the Twentieth Century (New York: Monthly Review Press).

Bresnahan, Timothy F. (1999), "Computerisation and Wage Dispersion: An Analytical Reinterpretation," Economic Joumal, vol. 109, Fearures, pp. F390-F415.

Bresnahan, Timothy F., Erik Brynjolfsson and Lorin Hitt (2002), "Information Technology, Workplace Organization, and the Demand for Skilled Labor: Firm-Level Evidence," Quarterly Jownal of Economics, vol. 117, no. 1, pp. $339-376$.

Bresnahan, Timothy F. and Manuel Trajtenberg (1995), "General Purpose Technologies: Engines of Growth?" Joumal of Econometrics, vol. 65, no. 1, pp. 83-108.

Broer, D. Peter and W.J. Jansen (1989), "Employment, Schooling and Productivity Growth," De Economist, vol. 137 , no. 3 , pp. $425-453$.

Broersma, Lourens, Jan Koeman and Coen N. Teulings (2000), "Labour Supply, the Natural Rate, and the Welfare State in the Netherlands: The Wrong Institutions af the Wrong Point in Time," Oxford Economic Papers, vol. 52, no. 1, pp. 96-118.

Bruinshoofd. Allard, Hugo Hollanders and Bas ter Weel (2001), "Knowledge Spillovers and Wage Inequality: An Empirical Analysis of Dutch Manufacturing," LABOUR Review of Labour Economics and Industrial Relations, vol. 15, no. 4, pp. 641-662.

Brynjolfsson, Erik and Lorin Hitt (2000), "Beyond Computation: Information Technology, Organizational Transformation and Business Performance," Journal of Economic Perspectives, vol. 14 , no. 4, pp. 23-48.

Card, David (1996), "The Effect of Unions on the Structure of Wages: A Longitudinal Analysis," Econometrica, vol. 64, no. 4, pp. 957-979.

Card, David (2001), "The Effects of Unions on Wage Inequality in the U.S. Labor Market," Industrial and Labor Relations Review, vol. 54, no. 2, pp. 296-315.

Card, David and John E. DiNardo (2002), "Skill-Biased Technological Change and Rising Wage Inequality: Some Problems and Puzzles," NBER Working Paper 8769.

Card, David, Francis Kramarz and Thomas Lemieux (1999), "Changes in the Relative Structure of Wages and Employment: A Comparison of the United States, Canada and France," Canadian Joumal of Economics, vol. 32 , no. 4, pp. 843-877.

Card, David and Thomas Lemieux (2001), "Can Falling Supply Explain the Rising Return to College for Younger Men? A Cohort-Based Analysis," Quarterly Lowmal of Economics, vol. 116, no. 2, pp. 705-746.

Cameiro, Pedro, James J. Heckman and Edward Vytlacil (2001), "Estimating the Returns to Education When It Varies Among Individuals," Mimeo, University of Chicago, April.

Caroli, Eve (2001), "Organizational Change, New Technologies and the Skill Bias: What Do We Know?," in Technology and the Future of European Employmen, Pascal Petit and Luc Soete, eds. (Cheltenham: Edward Elgar).

Caroli, Eve and Cecilia Garcia-Peñalosa (2001), "Risk Aversion and Rising Wage Inequality," Mineo, CEPREMAP, March.

Caroli, Eve and John Van Reenen (2001), "Skill Biased Organizational Change? Evidence from a Panel of British and French Establishments," Ouarterly Joumal of Economics, vol. 116, no. 4, pp. 1449-1492.

Caselli, Francesco (1999), "Technological Revolutions," American Economic Review, vol. 89, 
no. 1, pp. $78-102$.

Caselli, Franesce and John W. Coleman II (2001), "Cross-Country Technology Diffusion: The Case of Computers," American Economic Review, wol. 91, no. 2, Papers and Proceedings, pp. 328-335.

Chari, V.V. and Hugo Hopenhayen (1991)" "Vintage Human Capital, Growth, and the Diffusion of New Technology," Joumal of Political Economy, vol. 99, no. 6, pp. $1142-1165$.

Chennells, Lucy and John Van Reenen (1997). "Technical Change and Earnings in British Establishments" Economica, vol. 64, no. 3, pp. 587-604.

Chennells, Lucy and John Van Reenen (1998), "Establishment Level Earnings, Technology and the Growth of Inequality: Evidence from Britain," Economics of Innovation and New Technology, vol. 5, no. 2, pp. 139-164.

Chennells, Lucy and John Van Reenen (1999), "Has Technology Hurt Less Skilled Workers? An Econometric Survey of the Effects of Technical Change and the Structure of Pay and Jobs," Mimeo, Institute for Fiscal Studies, March.

Chiswick, Brian and Paul Miller (1995), "The Endogeneity between Language and Earnings: International Analyses," Jourmal of Labor Economics, vol. 13, no. 2, pp. 246-288.

Committee for Economic Development (1999), "New Opportunities for Older Workers," Statement by the Research and Policy Committee of the Committee for Economic Development.

Connoly, Robert A., Barry T. Hirsch and Mark Hirschey (1986), "Union Rent Seeking, Intangible Capital and the Market Value of the Firm," Review of Economics and Staristics, vol. 68, no. 4, pp. 567-577.

David "Paul A. (1969), "A Contribution to the Theory of Diffusion," Memorandum No. 71, Research Center in Economic Growth, Stanford University, June.

David, Paul A. (1975), The Mechanization of Reaping in the Ante-Bellum Midwest, in Technical Change, Innovation and Economic Growth, Paul A. David, ed. (Cambridge: Cambridge University Press).

David, Paul A. and Trond E. Olsen (1986), "Equilibrium Dynamics of Diffusion when Incremental Technological Innovations Are Foreseen," Richerche Economiche, vol. 40, no. 3, pp. 738-770.

Davies, Stephen (1979), The Diffusion of Process Innovarions (Cambridge: Cambridge Uniwersity Pressis.

Davis, Stewen J. and John Haltiwanger (1991), "Wage Dispersion between and within U.S. Manufacturing Plants, 1963-86," Brookings Papers on Economic Activiry, pp. 1. $15-1.80$.

Denny, Kevin and Stephen J. Nickell (1992), "Unions and Investment in British Industry," Economic Journal, vol. 102, no. 3, pp. 874-887.

Desjonqueres, Thibaut, Stephen Machin and John Van Reenen (1999), "Another Nail in the Coffin? Or Can the Trade Based Explanation of Changing Skill Structures Be resurrected?" Scandinavian Journal of Economics, vol. 101, no. 2, pp. 533-554.

DiNardo John and Jörn-Steffen Pischke (1996), "The Return to Computer Use Revisited: Have Pencils Changed the Wage Structure too?," NBER Working Paper 5606.

DiNardo John and Jorn-Steffen Pischke (1997), "The Return to Computer Use Revisited: Have Pencils Changed the Wage Structure too?," Quarterly Joumal of Economics, vol. 112, no. 1. pp. 291-303.

Doms, Mark, Timothy Dunne and Kenneth R. Troske (1997), "Workers, Wages and Technology," Quarterly Journal of Economics, vol. 112, no. 1, pp. 253-290.

Donald, Stephen G. and Whitney K. Newey (2001), "Choosing the Number of Instruments," Economerrica, vol. 69 , no. 5 , pp. $1161-1191$. 
Draper, Nick and Arie Manders (1997), "Structural Change in the Demand for Labour" De Economist, vol. 145, no. 3, pp. 521-546.

Dunne, Timothy, Lucia Foster, John Haltiwanger and Kenneth R. Troske (2000), "Wage and Productivity Dispersion in U.S. Manufacturing: The Role of Computer Investment;" NBER Working Paper 7465.

Dustmann, Christian and Arthur van Soest (2001), "Language Flwency and Eamings: Estimation with Misclassified Language Indicators," Review of Economics and Statistics, vol. 83, no. 4, pp. 663-674.

EITO (2000), European Information Technology Observatory, (Frankfurt am Main: European Economic Interest Grouping).

Entorf, Horst, Michel Gollac and Francis Kramarz (1999), "New Technologies, Wages, and Worker Selection," Joumal of Labor Economics, vol. 17, no. 3, pp. 464-491.

Entorf, Horst and Francis Kramarz (1997), "Does Unmeasured Ability Explain the Higher Wages of New Technology Workers?" European Economic Review, vol. 41, no. 6, pp. $1489-1509$.

Fallick, Bruce C. and Kevin A. Hassett (1999), "Investment and Union Centification," Joumal of Labor Economics, vol. 17, no. 3, pp. 570-582.

Felstead, Alan, David Ashton and Francis Green (2000), "Are Britain's Workplace Skills Becoming more Unequal?," Cambridge Joumal of Economics, vol. 24, no. 3, pp. 709724.

Ferguson, Ronald (1993), "New Evidence on the Growing Value of Skill and Consequences for Racial Disparity and Returns to Schooling," Mimeo, John F. Kennedy School of Government, September.

Fernandez, Roberto M. (2001), "Skill-Biased Techological Change and Wage Inequality: Evidence from a Plant Retooling," American Joumal of Saciology, vol. 107, no. 2, pp. $273-320$.

Freeman, Christopher and Luc Soete (1994), Work for All or Mass Unemployment? Computerized Technical Change into the $21^{s t}$ Century (London: Pinter).

Freeman, Christopher and Luc Soete (1997), The Economics of Industrial Innovation (MIT Press: Cambridge MA).

Freeman, Richard B. and Lawrence F. Katz (1995), Differences and Chonges in Wage Structures (The University of Chicago Press: Chicago).

Friedberg, Leora (2001), "The Impact of Technological Change on Older Workers: Evidence from Data on Computers," NBER Working Paper 8297.

Galor, Oded and Omer Moav (2000), "Ability-Biased Technological Transition, Wage Inequality, and Economic Growth," Quarterly Journal of Economics, vol, 115, no. 2, pp. 469-497.

Galor, Oded amd Daniel Tsiddon (1997), "Technological Progress, Mobility, and Economic Growth," American Economic Review, vol. 87, no. 3, pp. 363-382.

Garicano, Luis (2000), "Hierarchies and the Organization of Knowledge in Production," Joumal of Political Economy, vol. 108 , no. 5, pp. 874-904.

Garicano, Luis (2001), "Decentralization and Inequality: The Impact of Information Technology on Organizational Structure and Income Distribution," Mimeo, University of Chicago, August.

Geroski, Paul A. (2000), "Models of Technology Diffusion," Research Policy, vol. 29, no. 3 , pp. 603-625.

Goldin, Claudia and Lawrence F. Katz (1998), "The Origins of Technology-Skill Complementarity," Qwarterly Journal of Economics, vol. 113, no. 3, pp. 693-732.

Gorter, Cees, Peter Nijkamp and Piet Rietveld (1992), "The Duration of Unemployment on the Dutch Labour Market: A Proportional Hazard Model," Regional Science and 
Urban Economics, vol. 22 , no. 2, pp. 151-174.

Gottschalk, Peter (1997), "Inequality, Income Growth and Mobility: The Basic Facts," Journal of Economic Perspectives, vol 11, no. 1, pp. 21-40.

Gotschalk, Peter and Mary Joyce (1998), "Cross-National Differences in the Rise in Earnings Inequality: Market and Institutional Factors," Review of Economics and Statistics, wol. 80, no. 2, pp. $489-502$.

Gould, Eric D. (2000), "Inequality and Ability," Mimeo, Hebrew University, November.

Gould, Eric D. (2002), "Rising Wage Inequality, Comparative Adwantage, and the Growing Importance of General Skills in the United States: 1966-92," Jowrmal of Labor Economics, woll. 20, no. 1, pp. 105-147.

Gould, Eric D., Omer Moav and Bruce A. Weinberg (2001), "Precautionary Demand for Education, Inequality, and Technological Progress," Journal of Economic Growth, vol. 6 , no. 4, pp. $285-315$.

Green, Francis (1999), "The Value of Skills," Mimeo, University of Kent, June.

Greenan, Nathalie, Jacques Mairesse and Agnès Topiol-Bensaid (2001), "Information Technology and Research and Development Impacts on Productivity and Skills: Looking for Correlations on French Firm-Level Data," in Information Technology. Productivity, and Economic Growth. Matti Pohjola, ed. (Oxford: Oxford University Press), pp. $119-148$

Greenwood, Jeremy, Zvi Hercowitz and Per Krusell (1997), "Long-Run Implications of Investment-Specilic Technological Change," American Economic Review, vol. 87, no. 3 , pp. 342-362

Greenwood, Jeremy and Mehmet Yorukoglu (1997), "1974," Camegie-Rochester Conference Series on Public Policy, vol. 46, no. 1, pp. 49-95.

Griliches, Zvi (1957), "Hybrid Corn: An Exploration in the Economics of Technological Change," Econometrica, vol. 25 , no. 4, pp. 501-522.

Griliches, Zvi (1969), "Capital-Skill Complementarity," Review of Economics and Staristics, vol. 51, Conference Proceedings, pp. 465-468.

Groot, Loek F.M. and Andries de Grip (1991), "Technological Change and Skill Formation in the Bank Sector," Economics of Education Review, vol. 10, no. 1, pp. 57-71.

Habakkuk, H.J. (1967), American and British Technology in the Nineteenth Century: The Search for Labour-Saving Imewtions (Cambridge: Cambridge University Press).

Haisken-DeNew, John P. and Christoph M. Schmidt (1999), "Money for Nothing and Yotr Chips for Free? The Anatomy of the PC Wage Differential," Mimeo, German Institute for Economic Research, February.

Hamilton, Barton M. (1997), "Retums to Computer Skills and Black-White Wage Differentials," Mimeo, John M. Olin School of Business, March.

Handel, Michael (1999), "Computers and the Wage Structure," Mimeo, Jerome Levy Economics Institute, October.

Hannan, Michael T. and Joln Freeman (1989), Organizational Ecology (Cambridge MA: Harvard University Press).

Harrigan, James and Rita Balaban (1999), "U.S. Wages in General Equilibrium: The Effects of Prices, Teclmology and Factor Supplies, 1963-1991," Mimeo, Federal Reserve Bank of New York, September.

Hartog, Joop, Hessel Oosterbeek and Coen N. Teulings (1.993), "Age, Wages and Education in the Netherlands," in Labour Morke Implications of European Ageing, Paul Johnson and Klaus F. Limmermann, eds. (Cambridge University Press: Cambridge), pp. 182211.

Haskel, Jonathan and Ylva Heden (1999), "Computers and the Demand for Skilled Labour: Industry- and Establishment-Level Panel Evidence for the UK," Economic Joumal, 
vol. 109, Conference Proceedings, pp. C68-C79.

Haskel, Jonathan and Mathew J. Slaugther (1998), "Does the Sector Bias of Skill-Biased Technical Change Explain Changing Wage Inequality?," NBER Working Paper 6565.

Hebbink, Gerard (1991), "Employment by Level of Education and Production Factor Substitutability," De Economist, vol. 139, no. 3, pp. 379-399.

Heckman, James J. and Bo E. Honore (1990), "The Empirical Content of the Roy Model," Econometrica, vol. 58, no. 5, pp. 1121-1149.

Heckman, James J., Lance Lochner and Christopher Taber (1999), "Explaining Rising Wage Inequality: Explorations with a Dynamic General Equilibrium Model of Labor Earnings with Heterogeneous Agents," Review of Economic Dynamics, vol. 1 , no. 1, pp. $1-58$.

Heckman, James J. and Jose Scheinkman (1987), "The Importance of Bundling in a GromanLancaster Model of Earnings," Review of Economic Studies, vol. 54, no. 2, pp. 243255.

Heckman, James I. and Guilherme L. Sedlacek (1985), "Heterogeneity, Aggregation and Market Wage Functions: An Empirical Model of Self-Selection in the Labor Market," Journal of Political Economy, vol. 93, no. 6, pp. 1077-1125.

Heckman, James J, and Edward Vytlacil (2000), "Identifying the Role of Cognitive Ability in Explaining the Level of and Change in the Return to Schooling," N.BER Working. Paper 7820 .

Helpman, Elhanan and Manuel Trajtenberg (1998), "Diffusion of General Purpose Technologies," in General Purpose Technologies and Economic Growth, Elhanan Helpman, ed. (Cambridge MA: MTT Press), pp. 85-120.

Hildreth, Andrew K.G. (2001), "A New Voice or a Waste of Time? Wage Premiums from Using Computers for Communication in the UK Workplace," British Jownd of Industrial Relations, vol. 39, no. 2, pp. 257-284.

Hirsch, Barry T. and Albert N. Link (1987), "Labor Union Effects on Innovative Activity," Jownal of Labor Economics, vol. 8, no. 2, pp. 323-332.

Hollanders, Hugo and Bas ter Weel (2002), "Technology, Knowledge Spillovers, and Changes in Employment Structure: Evidence from Six OECD Countries" Labour Economics, vol. 9 , forthcoming.

Hubbard, Thomas N. (2001), "Information, Decisions, and Productivity: On-Board Computers and Capacity Utilization in Trucking," NBER Working Paper 8525.

Jensen, Robert (1983), "Innovation, Adoption and Diffusion when there Are Competing Innovations," Journal of Economic Theory, vol. 29, no. 1, pp. 161-171.

Jerome, Harry (1934), Mechanization in History (New York, NBER).

Jorgenson, Dale W. (2001), "Information Technology and the U.S. Economy," American Economic Review, vol. 91, no. 1, pp. 1-32.

Jovanovic, Boyan (1998), "Vintage Capital and Inequality," Review of Ecomomic Dywamics, vol. 1, no. 2, pp. 497-530.

Juhn, Chinui, Kevin M. Murphy and Brooks Pierce (1993), "Wage Inequality and the Rise in Returns to Skill," Journal of Political Econowy, wol. 101, no. 2, pp. 410l-442.

Kaboski, Joseph P. (2001), "Growth, Technology, and Inequality with Rising Schooling Attainment," Mimeo, Ohio State University, December.

Kahn, James and Jong-Soon Lim (1998), "Skilled Labor-Augmenting Technical Progress in U.S. Manufacturing," Quarterly Journal of Economics, vol. 113, no. 4, pp. 1281-1308.

Kahn, Lawrence M. (2000), "Wage Inequality, Collective Bargaining and Relative Employment 1985-94: Evidence from 15 OECD Countries," Review of Economics and Statistics, vol. 82 , no. 4, pp. 564-579.

Kamien, Morton I. and Nancy L. Schwartz (1972), "Timing of Innovations under Rivalry." 
Econometrica, vol. 40, no. 1, pp. 43-60.

Karshenas, Massoud and Paul L. Stoneman (1993), "Rank, Stock, Order, and Epidemic Effects in the Diffusion of New Process Technologies: An Empirical Model, Rand Journal of Economics, vol. 24, no. 4, pp. 503-528.

Katz, Lawrence F. (2000), "Technological Change, Computerization, and the Wage Structure," in Understanding the Digital Economy, Data. Tools, and Research, Erik Brynjolfsson and Brian Kahin, eds. (MIT Press, Cambridge MA), pp. $217-244$.

Katz, Lawrence F, and David H. Autor (1999), "Changes in the Wage Structure and Eamings Inequality," in Handbook of Labor Economics, wol. 3, Orley Ashenfelter and David H. Card, eds. (North-Holland: Amsterdam), pp. 1463-1555.

Katz, Lawrence F. and Kevin M. Murphy (1992), "Changes in Relative Wages, 1963-1987: Supply and Demand Factors," Quarterly Joumal of Economics, vol. 107, no. 1, pp. $35-78$.

Kiley, Michael T. (1999), "The Supply of Skilled Labour and Skill-Biased Technological Progress," Economic Journal, vol. 109, no, 5, pp. 708-724.

Kramarz, Francis (2001), "Computers and Labour Markets: Intemational Evidence," in Information Technology, Productivity, and Economic Growh, Matti Pohjola, ed. (Oxford: Oxford Lniversity Press), pp. 99-118.

Krashinksy, Harry (2000), "Do Marital Status and Computer Usage Really Affect the Wage Structure?," Mimeo, Princeton, May.

Kremer, Michael and Eric D. Maskin (1997), "Wage Inequality and Segregation by Skill," Mimeo, MIT, June.

Krueger, Alan B. (1993), "How Computers Have Changed the Wage Structure: Evidence from Microdata, 1984-1989," Quarterly Joumal of Economics, vol. 108, no. 1, pp. 3360.

Krugman, Paul (1994), "Part and Prospective Causes of High Unemployment," in Reducing Unemployment: Current Issues and Policy Options, Federal Reserve Bank of Kansas City.

Krusell, Per, Lee Ohanian, Victor Rios-Rull and Giovanni L. Violante (2000), "Capital-Skill Complementarity and Inequality: A Macroeconomic Analysis," Econometrica, vol. 68, no. $5, \mathrm{pp}, 1029-1053$.

Lang, Kevin (2001), "Of Pencils and Computer Use," Mimeo, MIT, January.

Lantz, Ans (1997), "Heavy Users of Electronic Mail," Inernational Joumal of Human Computer Interaction, vol. 10, no, 2, pp. 361-379.

Leigh, Duane E. and Kirk D. Gifford (1999), "Workplace Transformation and Worker Upskilling: The Perspective of Individual Workers," Indusrial Relations, vol. 38, no. 2, pp. $174-191$.

Lemieux, Thomas (1998), "Estimating the Efrects of Unions on Wage Inequality in a Panel Data Model with Conparative Advantage and Nonrandom Selection," Jownal of Labor Economics, vol. 16, no. 2, pp. 261-291.

Leuven, Edwin, Hessel Oosterbeek and Hans van Ophem (1998), "Explaining Intemational Differences in Male Wage Inequality by Differences in Demand and Supply of Skill," Mimeo, University of Amsterdam, March.

Levy, Frank, Ann Beamish, Richard J. Murnane and David H. Autor (1999), "Computerization and Skills: Examples from a Car Dealership," Mimeo, MTT, November.

Levy, Frank and Richard J. Murnane (1996), "With What Skills Are Computers Complements?" American Economic Review, vol. 86, no. 2, Papers and Proceedings, pp. 258-262.

Lindbeck, Assar and Demis J. Snower (2000), "Multitask Leaming and the Reorganization of 
Work: From Tayloristic to Holistic Organization," Jowrnal of Labor Economics, vol. 18, no. 2, pp. 353-376.

Lintnet, V.G., M.J. Pokorny, M.M. Woods and M.R. Blinkhom (1987)" "Trade Unions and Technological Change in the U.K. Mechanical Engineering Industry," British Joumal of Industrial Relations, vol. 25, no. 1, pp. 19-29.

Lloyd-Ellis, Huw (1999), "Endogenous Technological Change and Wage Inequality," American Economic Review, vol. 89, no. 1, pp. 47-77.

Machin, Stephen (1996), "Changes in the Relative Demand for Skills," in Acquiring Skills, Alison Booth and Dennis J. Snower, eds. (Cambridge University Press, Cambridge), pp. $129-146$.

Machin, Stephen and John Van Reenen (1998), "Technology and Changes in Skill Structure: Exidence from Seven OECD Countries," Quarterly Joumal of Economics, vol. 113, no. 4 , pp. 1216-1244.

Machin, Stephen J. and Sushil Wadhwani (1991), "The Effects of Unions on Investment and Innovation: Evidence from WIRS," Economic Joumal, vol. 101, no. 2, pp. 324-330.

Mansfield, Edwin (1963), "The Speed of Response of Firms to New Technologies," Quarterly Joumal of Economics, vol. 77, no. 1, pp. 290-311.

Mansfield, Edwin (1968), The Economics of Technological Change (New York: Norton).

Martinez-Ross, Ester (2001), "Wages and Innovations in Spanish Manufacturing Firms," Applied Economics, vol. 33, no. 1, pp. 81-89.

McPhail, Fiona (2000), "What Caused Earnings Inequality to Increase in Canada during the 1980 s?," Cambridge Joumal of Economics, vol. 24, no. 2, pp. 153-175.

Metcalfe, Stan (1970), "Diffusion of Innovation in the Lancashire Textile Industry," Manchester School, vol. 38, no. 1, pp. 145-162.

Miller, Paul and Charles Mulvey (1997), "Computer Skills and Wages," Austratian Ecomomic Papers, vol. 36, no. 2, pp. 106-113.

Mokyr, Joel (1990), The Levers of Riches: Technological Creativity and Econtomic Progress (New York: Oxford University Press).

Murnane, Richard J., John B. Willett and Frank Levy (1995), "The Growing Importance of Cognitive Skills in Wage Determination," Review of Economics and Statistics, voll 77, no. 1 , pp. $251-266$.

Murphy, Kevin M., W. Craig Riddell and Paul M. Romer (1998), "Wages, Skills, and Technology in the United States and Canada," in General Purpose Technologies and Econowic Growth, Elhanan Helpman, ed. (The MT Press: Cambridge MA), pp. $283-$ 309.

Murphy, Kevin M. and Finis Welch (1992), "The Structure of Wages," Ouarterly Jownal of Economics, vol. 107, no. 1, pp. 285-326.

Murphy, Kevin M. and Finis Welch (2000), "Wage Differentials in the 1990s: Is the Glass Half-Full or Half-Empty," Mimeo, University of Chicago, February.

Nickell, Stephen J. and Brian D. Bell (1996), "Changes in the Distribution of Wages and Unemployment in OECD Countries," American Economic Review, vol. 86, no. 2, Papers and Proceedings, pp. 302-308.

OECD (1994), Jobs Sindy (Paris: OECD).

OECD (2000), "Aduit Literacy and Life Skills: Computer Literacy," Mimeo, OECD, Paris.

Oosterbeek, Hessel (1997), "Returns from Computer Use: A Simple Test on the Productivity Interpretation," Economics Letters, vol. 55, no. 1, pp. $273-277$.

O'Shaughnessy, K.C., David 1. Levine and Peter Cappelli (2001), "Changes in Managerial Pay Structures 1986-1992 and Rising Returns to Skills," Oxford Economic Papers, vol. 53, no. 3 , pp. $482-506$.

Osterman, Paul (1994), "How Common Is Workplace Transformation and Who Adopts It?," 
Industrial and Labor Relations Review, vol. 34 , no. 2, pp. 125-146.

Peracchi, Franco and Finis Welch (1994), "Trends in Labor Force Transitions of Older Men and Women," Joumal of Labor Econmics, vol. 12, no. 1, pp. 210-242.

Reilly, Kevin (1995), "Human Capital and Information: The Employer Size-Wage Effect," Journal of Human Resources, vol. 30, no. 1, pp. 1-18.

Rosen, Sherwin (1974), "Hedonic Prices and Implicit Markets: Product Differentiation in Pure Competition," Journal of Political Economy, vol. 82, no. 1, pp. 34-55.

Rosen, Sherwin (1983), "A Note on Aggregation of Skills and Labor Quality," Journal of Human Resoupces, vol. 18, no. 2, pp. $425-431$.

Roy, Andrew D. (1950), "The Distribution of Earnings and of Individual Output," Economic Jowrnal, wol. 60, no. 3 , pp. 489-505.

Roy, Andrew D. (1951), "Some Thoughts on the Distribution of Earnings," Oxford Economic Papers, vol. 3, no. I, pp. 135-146.

Sakellariou, Chris and Harry Patrinos (2000), "Labour Market Performance of Tertiary Education Graduates in Vietnam," Asian Economic Journal, vol. 14, no. 2, pp. 147165.

Salter, W.E.G. (1966), Productivity and Technical Change (Cambridge: Cambridge University Press).

Sattinger, Michael (1975), "Comparative Advantage and the Distribution of Earnings and Abilities," Econometrica, vol. 43, no. 3, pp. 455-468.

Sattinger, Michael (1993), "Assignment Models of the Distribution of Eamings," Jotumal of Economic Literature, vol. 31 , no. 3, pp. $831-880$.

Schmookler, Jacob (1966), Imention and Economic Growh (Cambridge MA: Harvard University Press).

Schultz, Theodore (1975), "The Value of the Ability to Deal with Disequilibria," Jouma" of Economic Literature, vol. 13, no. 3, pp. 827-846.

Smith, Adam (1776), An Inquiry into the Nature and Causes of the Wealth of Nations.

Spenner, Kenneth I. (1985), "The Upgrading and Downgrading of Occupations," Review of Educational Research, vol. 55, no. 1, pp. 125-154.

Spenner, Kenneth I. (1990), "Skill: Meaning, Methods and Measures," Work and Dccupations, vol. 17, no. 2, pp. 399-421.

Staiger, Douglas and James H. Stock (1997), "Instrumental Variables Regression with Weak Instruments," Econometrica, vol. 65, no. 3, pp. 557-586.

Stoneman, Paul L. (1976), Technological Diffusiom and the Computer Revolwtion (Oxford: Oxford University Press).

Stoneman, Paul L. and Myung-Joong Kwon (1996), "Technology Adoption and Firm Profitability," Economic Journal, vol. 106, no. 5, pp. 952-962.

Taymaz, Erol (1991), "The Impact of Trade Unions on the Diffusion of Technology: The Case of NC Machine Tools," British Joumal of Industrial Relations, wol. 29, no. 2, pp. 303311.

Teulings, Coen N. (1995), "The Wage Distribution in a Model of the Assignment of Skills to Jobs," Jounal of Political Economy, vol. 103, no. 1, pp. 280-315.

Teulings, Coen N. (2000), "Aggregation Bias in Elasticities of Substitution and the Minimum Wage Paradox," Imternational Economic Review, vol. 41, no. 2, pp. 359-98.

Teullings, Coen N and Pieter A. Gautier (2001), "Search and the City," Mimeo, Tinbergen Institute, July.

Teulings, Coen N. and Joop Hartog (1998), Corporatism or Competition? Labour Contracts, Institutions and Wage Structures in Intermational Comparison (Cambridge University Press: Cambridge).

Teulings, Coen N. and José A.C. Vieira (1999), "Urban versus Rural Return to Human 
Capital in Portugal, A Cook-Book Recipe for Applying Assignment Models," Mimeo, Timbergen Institute, May.

Tinbergen, Jan (1956), "On the Theory of Income Distribution," Weltwirschaftiches Archiv, vol. 77, no. 1, pp. 156-175.

Tinbergen, Jan (1975), Income Differences: Recent Research (Amsterdam: North-Holland).

Vainiomaki, Jari and Seppo Laaksonen (1995), "Inter-Industry Wage Differentials in Finland: Evidence from Longitudinal Census Data for 1975-85," Labour Economics, woll. 2, no. 2, pp. $161-173$.

Van Ours, Jan C. (1991), "The Efficiency of the Dutch Labour Market in Matching Unemployment and Vacancies," De Economist, vol. 139, no. 3, pp. $358-378$.

Violante, Giovanni L. (2002), "Technological Acceleration, Skill Transferability, and the Rise in Residual Inequality," Quarterly Jowmat of Economics, vol. 117, no. 1, pp. 297-338.

Weinberg, Bruce A. (2000), "Computer Use and the Demand for Female Workers," Industrial and Labor Relations Review, voll. 53 , no. 2, pp. 290-308.

Weinberg, Bruce A. (2001), "Experience and Technology Adoption," Mimeo, Ohio State University, April.

Welch, Finis (1970), "Education in Production," Joumal of Political Economy, vol. 78, no. 2, pp. 312-327.

Williams, Bruce (1986), "Technical Change and Fluctuations in Employment," in Techwology and the Human Prospect: Essays in Honour of Christopher Freeman, Roy MacLeod, ed. (London: Pinter), pp. 173-193.

Zubotf, Shoshana (1988), In the Age of the Smart Machine: The Furure of Work and Power (New York: Basics Books). 



\section{Summary in Dutch}

De snelle diffusie en het op dit moment bijna universele gebruik van computers heeft de arbeidsmarkt en de wijze waarop wordt gewerkt ingrijpend gewijzigd. De analyse in deze studie geeft inzicht in wie, wanneer en waarom een computer is gaan gebruiken ter ondersteuning van de werkzaamheden, hoe computerisering de manier waarop wordt gewerkt heeft veranderd en hoe de introductie en proliferatie van computers op het werk de loonverdeling en de allocatie van werknemers en banen heeft gewijzigd. Deze studie heeft drie nieuwe inzichten gegenereerd.

Ten eerste blijkt dat de loonkosten ten opzichte van de kosten van een computer (waarbij zowel de regelmatige vervanging wan de hardware, de software, het meubilair en het netwerk als de technische assistentie in beschouwing dienen te worden genomen) de belangrijkste determinant van computergebruik is. Het is belangrijk op te merken dat (computer)vaardigheden, het niveau van het genoten onderwijs, werkervaring en leeftijd geen significant positief effect hebben op de kans op computergebruik op het werk. Het veelvuldige gebruik van computers door relatief hoger opgeleiden ten opzichte van lager opgeleiden kan worden verklaard uit het feit dat hoger opgeleiden over het algemeen meer verdienen en dientengevolge eerder het punt bereiken waarop de aanschaf en het gebruik van een computer rendabel is en niet een computer gebruiken vanwege een complementaire relatie tussen opleidingsniveau, ervaring en het vermogen de computer te kunnen bedienen.

Ten tweede komt naar voren dat de toenemende loonongelijkheid zowel binnen (homogene) groepen van werknemers als tussen relatief geschoolde en ongeschoolde werknemers - die is toe te schrijven aan de diffusie van computers op het werk, een tijdelijk fenomeen is dat wordt veroorzaakt door de verschillende momenten waarop werknemers een computer (zijn) gaan gebruiken. De analyse toont aan dat er geen verschillen zijn in de productiviteitswinst die wordt geboekt als gevolg van computergebruik tussen relatief geschoolde en ongeschoolde werknemers. De toename in de loonongelijkheid als gevolg van de computerisering in vele landen is dus slechts tijdelijk en niet het gevolg van een beter adaptief of leervermogen van hoger opgeleiden of van een technologische ontwikkeling in het voordeel van hoger opgelleiden (skill-biased technological change), maar veeleer een gevolg van de initiële (i.e., voordat er computers waren) verschillen in lonen en productiviteit tussen en binnen groepen van werknemers. 
Ten derde blijkt uit deze studie dat de computerisering van de arbeidsmarkt heeft geleid tot een toename in de vraag naar vaardigheden en heeft geleid tot een toename in de vraag naar geschoolde werknemers. De reden voor de toegenomen vraag naar hoger opgeleide werknemers kan worden verklaard doordat computers weelal de routinematige werkzaamheden overnemen. De toename kan dus worden verklaard door een focus op de nietroutinematige taken die niet door de computer worden uitgevoerd. Het zijn echter niet de vaardigheden die gebruikt moeten worden om de computer te bedienen die in belang zijn toegenomen, maar juist de vaardigheden die de kern van het beroep betreffen: de creativiteit en het schrijverstalent van de romanschrijver worden nog essentiëler, terwijl het foutloos typen en het perfect beheersen van de Nederlandse taal van secundair belang zijn wanneer een PC met spellingcontrole wordt gebruikt.

Hoofdstuk 2 geeft een overzicht van zowel het empirische als theoretische onderzoek met betrekking tot de invloed van nieuwe technologie, en met name van computers, op de arbeidsmarkt en de manier waarop werknemers de configuratie van en verdeling wan tijd tussen hun taken zien veranderen. Het beschikbare onderzoek richt zich in het bijzonder op een directe relatie tussen de introductie van computers en de toename in de loonongelijkheid in het Verenigd Koninkrijk en de Verenigde Staten. Deze toename van de loonongelijkheid wordt toegeschreven aan technologische veranderingen die in het voordeel zijn van relatief hoger opgeleide werknemers. Wanneer de loonstructuur van de Verenigde Staten van 1963 tot en met 2000 wordt bekeken, komt naar voren dat de toename in loonongelijkheid tussen relatief geschoolde en ongeschoolde werknemers pas in het begin van de jaren 80 zichtbaar wordt. Rond het begin van de jaren 80 gebruikten echter reeds veel relatief geschoolde werknemers een computer en het patroon van loonongelijkheid lijkt dus inconsistent met theorieën die veronderstellen dat de stijging van de loonongelijkheid het directe gevolg is van het gebruik van computers door relatief hoger opgeleiden. Loonongelijkheid binnen de betrekkelijk homogene groep van relatief hoger opgeleiden nam reeds toe vanaf het begin van de jaren 70, wat overeen komt met het moment waarop de eerste geschoolde werknemers computers gingen gebruiken. Analoog: loonongelijkheid binnen de groep van lager opgeleide werknemers nam pas toe vanaf het begin van de jaren 80 , het moment waarop de eerste ongeschoolde werknemers computer gingen gebruiken. Tussen deze groepen is pas sinds de jaren 80 een verhoging van de loonongelijkheid waarneembaar.

De studies die in Hoofdstuk 2 worden beschouwd en samengevat, geven argumenten waarom de loonongelijkheid tussen geschoolde en ongeschoolde werknemers is toegenomen als gevolg van de adoptie en het gebruik van nieuwe technologie, zoals computers. De meeste studies concluderen dat geschoolde werknemers een voordeel genieten in het werken met computers, omdat de kosten van het gebruik en het overstappen van oude naar nieuwe technologie 
lager zijn voor geschoolde werknemers. Bij deze kosten moet gedacht worden aan leerkosten, adaptief vermogen en werkervaring. Echter, de timing van de toename van loonongelijkheid tussen relatief geschoolde en ongeschoolde werknemers komt niet overeen met deze argumenten, ondat geschoolde werknemers reeds sinds het begin van de jaren 70 met computers zijn gaan werken en dus loonongelijkheid tussen geschoolde en ongeschoolde werknemers vanaf begin jaren 70 zichtbaar moet zijn.

Verschillende andere studies hebben dit gebrek tot op zekere hoogte onderkend en concentreren zich op loonongelijkheid binnen de groepen van geschoolde en ongeschoolde werknemers. Zij modelleren de toename in loonongelijkheid tussen ( $\mathrm{ex}$ ante) homogene werknemers op het moment dat een nieuwe technologie operationeel en geïmplementeerd wordt. In zo'n omgeving worden sommige werknemers gekoppeld aan de nieuwe technologie, met als gevolg dat ze productiever worden en een hoger loon ontvangen, terwijl andere werknemers (met dezelfde vaardigheden en andere kenmerken) blijven werken met de oude technologie en een relatief lager loon ontvangen. Het mechanisme dat deze vorm van loonongelijkheid verklaart, wordt vaak gemodelleerd als een willekeurig proces of door middel van arbeidsmarktfricties waardoor informatie-belemmeringen leiden tot een verschillende allocatie van dezelfde vaardigheden. Hoewel deze modellen consistent zijn met de empirische observaties met betrekking tot loonongelijkheid binnen groepen werknemers, is het niet aannemelijk dat het gebruik van computers geheel is gebaseerd op of is toe te schrijven aan random variabelen of arbeidsmarktfricties. Daarnaast hebben deze modellen bijna niets te zeggen over de toename van loonongelijkheid tussen groepen werknemers.

Uit econometrische studies blijkt tevens dat computergebruikers een substantieel hoger loon ontvangen dan niet-gebruikers. Het is echter niet duidelijk waarom dit zo is. Sommige studies vinden in een cross-sectie analyse dat computergebruikers een loonpremie van 10-15 procent ontvangen, terwijl studies die gebruik maken van longitudinale en panel data vinden dat computergebruikers voordat zij een computer gingen gebruiken ook al een hoger loon ontvingen. Er worden een aantal verklaringen voor het hogere loon van computergebruikers gegeven: (i) sommige werknemers zouden een hogere kans op computergebruik hebben, omdat zij over meer (computer)vaardigheden beschikken, (ii) niet te verklaren heterogeniteit tussen werknemers zou ervoor zorgen dat sommige werknemers een hoger loon ontvangen, terwijl dit niet in hun meetbare/observeerbare vaardigheden en werkervaring naar voren komt, en (iii) hoger opgeleide werknemers passen zich gemakkelijker aan de computer aan dan lager opgeleide werknemers, omdat hun adaptief vermogen hoger is. Er is echter geen consensus over welke verklaring overeenkomt met de geobserveerde patronen. Ten eerste lijkt een loonpremie van $10-15$ procent voor computervaardigheden erg hoog wanneer (gecontroleerd voor een uitgebreide set van persoons- en baankenmerken) een caissière die gebruik maakt van een 
computergestuurde kassa wordt vergeleken met een caissière die slechts een elektronische kassa gebruikt. Ten tweede is er altijd enige niet te verklaren heterogeniteit aanwezig, maar een loonverschil van $10-15$ procent lijkt te veel om geheel toe te dichten aan deze vorm van heterogeniteit tussen werknemers die gebruik maken van een computer en degenen die dat niet doen. Tenslotte blijkt uit de cijfers dat niet slechts hoger opgeleide werknemers gebruik maken van computers, maar dat ook een niet geringe fractie van de lager opgeleide werknemers een computer op het werk gebruikt.

Een derde punt van aandacht is dat zowel de theoretische als empirische studies zich voornamelijk hebben gericht op de werknemer gegeven de allocatie van zijn vaardigheden in een bepaalde baan. Een belangrijke vraag die niet vaak aan de orde is geweest, is wat er gebeurt met de baan wanneer de computer wordt geimplementeerd. Cijfers tonen aan dat bedrijven die computers gebruiken in thet productieproces, hogere eisen stellen aan hun arbeidskrachten - voor een gegeven baan - dan bedrijven die (nog) geen computers gebruiken. Er is gesteld dat computers routinematige taken overnemen en dat de werknemer de niet-routinematige taken voor zijn rekening neemt. Dit heeft geleid tot een hoger niveau van baancomplexiteit en een verhoging van de eisen die aan werknemers worden gesteld. Dit is geanallyseerd vanuit het perspectief van de baan, de organisatie en de coöperatie tussen verschillende werknemers, maar de allocatie van werknemers en banen in het licht van de computerisering van het productieproces is een onderbelicht onderwerp.

Vandaar dat de vragen die in deze studie worden geanalyseerd de volgende zijn. Waarom gebruiken sommige werknemers een computer en andere (nog) niet? Wat is de invloed van de computer op loonongelijkheid zowel binnen als tussen groepen van relatief geschoolde en ongeschoolde werknemers? Hoe verandert de baan en de werknemer als gevolg van de computer en wat heeft dit voor gevolgen voor de vraag naar vaardigheden?

Een experimentele opzet kan inzicht genereren in de beslissing met betrekking tot computergebruik - en tevens de vraag beantwoorden waarom sommige werknemers wel en andere niet een computer gebruiken. In Hoofdstuk 3 wordt zo'n gedachten-experiment ontwikkeld door te kijken naar wat er gebeurt met agent $T$ wanneer hij een computer krijgt. In een gestileerde omgeving is het mogelijk de veranderingen in slechts én baan - die van agent $T$ - te belichten wanneer een computer wordt geïntroduceerd. Om zijn baan uit te oefenen, moet agent $T$ twee taken verrichten. Er wordt verondersteld dat taak 1 aspecten van de baan bevat die kunnen worden gecomputeriseerd en dat taak 2 de niet-computeriseerbare componenten van de baan behelst. Wanneer agent $T$ een computer krijgt, heeft dit invloed op de tijd die nodig is beide taken uit te voeren. De tijd die nodig is de baan als zodanig uit te voeren, hangt af van de vaardigheden van de werknemer en de specificaties van het product dat wordt gemaakt. De benodigde vaardigheden en het product zullen veranderen wanneer de computer zijn intrede doet. Het experiment zorgt ervoor dat agent $T$ taak 1 
niet meer "handmatig" hoeft uit te voeren, maar nu de computer moet bedienen die hem assisteert bij het uitvoeren van taak 1 . Als voorbeeld kan gedacht worden aan de hoofdredacteur van een krant, die relevante informatie moet verzamelen om de krant te vullen (taak 1) en zijn team moet motiveren en monitoren (taak 2). Voordat hij een computer had, moest hij informatie verzamelen door gebruik te maken van verschillende kanalen (telefoon, tijdschriften, kranten etc.) en die doorspelen aan zijn redacteurs. Het gebruik van de computer - en met name het gebruik van email en het Internet - kan dit proces veel efficiënter laten verlopen. De uitvoering van taak 2 zou ook kunnen wijzigen, omdat er wellicht een complementaire relatie bestaat tussen het gebruik van de computer en de vaardigheden van agent $T$, dat wil zeggen, de computer zou de vaardigheden die niet kunnen worden gecomputeriseerd, kunnen benadrukken; dit zijn wellicht vaardigheden waarover met name hoger opgeleide werknemers beschikken. In het geval van de hoofdredacteur wordt het managen en monitoren van het team veel belangrijker dan het verzamelen en scheiden van informatie. In deze gestileerde omgeving blijken de volgende drie aspecten van de baan en de werknemer van belang te zijn voor het gebruik van een computer: (i) de vaardigheden waarover de werknemer beschikt - meer vaardigheden zouden tot een meer efficiënt gebruik van de computer kunnen leiden, (ii) de computeriseerbaarheid van de taken die de werknemer moet uitvoeren - sommige taken zijn slechts tegen zeer hoge kosten te computeriseren (schoonmaken van het toilet), terwijl andere taken tegen relatief geringe kosten te computeriseren zijn (typen), en (iii) de hoogte van het loon een hoger loon leidt tot hogere potentiële besparingen op arbeidskosten en makkt het werken met een computer eerder rendabel.

Welke van de drie aspecten uit deze experimentele opzet computergebruik het best verklaren is een empirische vraag die in Hoofdstuk 4 wordt beantwoord. De empirische analyse maakt gebruik van data uit de Skills Survey of the Employed British Workforce, een survey gehouden in 1997 in Groot Brittannië. Deze survey bevat gedetailleerde informatie met betrekking tot het belang van een hele reeks taken die werknemers op het werk moeten uitvoeren. Daarnaast is informatie beschikbaar over de effectiviteit waarmee deze taken worden uitgevoerd. Tenslotte is voor computergebruik ook een vraag gesteld omtrent het niveau van computergebruik op het werk. Deze informatie over de computerisering van het werk is gebruikt om de verschillende computertaken te onderscheiden.

De analyse in Hoofdstuk 4 heeft de volgende resultaten opgeleverd. Ten eerste zijn computervaardigheden onbelangrijk in de verklaring waarom werknemers die een computer gebruiken meer verdienen dan degene die geen computer gebruiken op het werk. De regressieresultaten geven aan dat het niveau van computervaardigheid geen invloed heeft op de hoogte van het loon. Het feit dat werknemers die een computer gebruiken een hoger loon ontvangen, in een eenvoudige loonvergelijking, is louter toe te wijzen aan computergebruik 
en niet aan de vaardigheid waarmee de computer wordt bediend. Zelfs binnen verschillende niveau's van computergebruik - waarbij niveau's worden onderscheiden van geavanceerd (programmeren) tot eenvoudig (het printen van een kassabon) computergebruik - blijken werkgevers computervaardigheden niet te belonen. Slechts op het geavanceerde niveau van computergebruik (bijvoorbeeld om software te ontwikkelen en te programmeren) zijn computervaardigheden van belang voor het arbeidsmarktsucces. Dit laatste resultaat is uiteraard vanzelfsprekend, omdat deze werknemers de computer gebruiken voor de kerntaken van hun werk en daarvoor dus worden beloond. De conclusie die uit deze eerste resultaten naar voren komt, is consistent met het experimentele model dat veronderstelt dat computers vaak worden gebruikt voor routinematige aspecten van de baan en dat de vaardigheden die daarvoor nodig zijn niet van primair belang zijn om de baan goed te vervullen.

Het tweede inzicht dat uit de empirische analyses in Hoofdstuk 4 naar voren komt, is dat de hoogte van het loon de belangrijkste verklarende variabele voor computergebruik is. "Daarnaast verhogen bepaalde taken, zoals schrijven, lezen en rekenen de kans op computergebruik significant, terwijl taken die zijn gerelateerd aan de fysieke inspanning van het werk de kans op computergebruik significant verlagen. Een interessante bevinding is verder dat vrouwen een significant hogere kans op computergebruik hebben dan mannen. Dit komt overeen met de bevinding dat de computer in sommige beroepen de fysieke nadelen die vrouwen ondervinden gedeeltelijk wegnemen. Een andere belangrijke bevinding is dat leeftijd en werkervaring de kans op computergebruik op het werk niet beïnvloeden: het computergebruik over de levensloop blijkt vrijwel constant te zijn. Dit staat lijnrecht tegenover de populaire notie dat oudere werknemers nadelen ondervinden van de introductie van computers op de werkplek. Tenslotte heeft het niveau van onderwijs geen directe invloed op de kans op computergebruik. Deze bevinding kan worden geïnterpreteerd als bewijs dat vaardigheden niet direct van invloed zijn op het gebruik van een computer. Met andere woorden, verschillen in ervaring en opleidingsniveau tussen werknemers zijn niet van invloed op computergebruik, wat indruist tegen de gangbare notie dat hoger opgeleide werknemers meer voordeel van computergebruik hebben dan lager opgeleide werknemers. Er is slechts een klein (en in de meeste specificaties insignificant) indirect effect van

\footnotetext{
Ondat het loon een endogene variabele is, worden instrumentele variabelen gebruikt on het werkelijke effect van lonen op computergebruik te bepalen. Deze instrumenten zijn gerelateerd aan de mate van vakbondsimvloed in een bepalde baan. De mogelijke beperkingen van het gebruik van dit instrument worden uitgebreid behandeld in. Hoofdstuk 4 (Secties 4.5.1 en 4.5.2). De conclusies na het uitvoeren van verschillende testen wijzen wit dat de instrumenten vanuit econometrisch oogpunt voldoende krachtig zijn en dat, bekeken vanuit de identificatieproblematick van het model, de regressieresultaten niet worden beinvioed of vertekend door het gebruik van vakbondsinvloed als instrument voor het loon.
} 
het niveau van onderwijs op de kans op computergebruik dat loopt via het looneffect. ${ }^{2}$

De resultaten die worden gepresenteerd in Hoofdstuk 4 hebben belangrijke en verstrekkende gevolgen voor de interpretatie van de vele studies die handelen over de arbeidsmarktconsequenties van computers. Bijvoorbeeld, de claim dat computergebruikers 10 tot 15 procent meer verdienen dan niet gebruikers omdat zij worden beloond voor hun computervaardigheden is niet erg waarschijnlijk. De causaliteit is zelfs omgekeerd: computergebruik leidt niet tot een hoger loon, maar een hoger loon maakt het gebruik van een computer rendabel. Daamaast zijn argumenten die wijzen op een voordeel voor relatief geschoolde werknemers ten opzichte van ongeschoolde werknemers in het gebruik van computers ook onwaarschijnlijk, omdat de regressieresultaten laten zien dat het onderwijsniveau en werkervaring geen directe invloed hebben op de kans op computergebruik. Ook zijn hoger opgeleide werknemers niet beter in het bedienen van een computer dan hun lager opgeleide collega"s. De resultaten van Hoofdstuk 4 zeggen dan ook dat hoger opgeleide werknemers een computer gebruiken omdat ze meer verdienen en niet omdat ze een voordeel hebben dat is terug te voeren op hun hogere opleiding. Vandaar dat de stelling dat computers leiden, of hebben geleid, tot een digitale tweedeling tussen aan de ene kant geschoolde en aan de andere kant ongeschoolde werknemers niet erg plausibel is en geenszins blijkt uit een grondige analyse van de data.

De volgende vraag is nu echter hoe deze bevindingen zich vertalen naar het macro-economische niveau. Op macro-economisch niveau dient de theorie namelijk te verklaren (i) hoe loonongelijkheid (binnen en tussen groepen werknemers) en computerisering samen lijken te gaan, en (ii) waarom upgrading van de eisen die aan werknemers worden gesteld, wordt geobserveerd. De eerste vraag wordt beantwoord in Hoofdstuk 5 en de tweede vraag in Hoofdstuk 6. In Hoofdstuk 5 wordt een model ontwikkeld dat de adoptie en de diffusie van computers verklaart vanuit de volgende tweede observaties: (i) de groep werknemers die computers gebruiken is drastisch gewijzigd over de tijd, en (ii) de timing van loonongelijkheid tussen en binnen groepen is verschillend. Met betrekking tot de eerste observatie laten de cijfers zien dat computers in de jaren 90 niet slechts worden gebruikt door relatief geschoolde werknemers, maar dat bijna de helft van de ongeschoolde werknemers ook een computer gebruikt. Tevens ligt de adoptiesnelheid van de ongeschoolde werknemers hoger dan de adoptiesnelheid van de geschoolde werknemers. Deze cijfers roepen twijfels op over de complementariteit tussen relatief geschoolde werknemers en computers - en wellicht over de

- De hogere kans die wrouwen op computergebruik hebben, wordt via het indirecte effect via de loonvariabele deels teniet gedaan. De reden hiervoor is dat vrouwen gemiddeld een lager loon ontvangen dan mannen en dus een kleinere kans op computergebruik hebben. Het netto effect is echter nog steeds positief. 
complementaire relatie tussen technologie en scholing in zijn algemeenheid en leidt tot de vraag of de stijging van de loonongelijkheid in sommige landen, die kan worden toegeschreven aan het gebruik van computers, een tijdelijk of permanent fenomeen is. Met betrekking tot de tweede observatie laten de data zien dat de loonongelijkheid binnen de groep van relatief geschoolde werknemers sinds het begin van de jaren 70 aan het stijgen is. Dit komt overeen met het tijdstip van initiële adoptie onder geschoolde werknemers. Het argument om de loonongelijkheid te verklaren is dan dat werknemers die een computer gebruiken productiever worden, wat zich vertaalt in een hoger loon. Loonongelijkheid binnen de groep van relatief ongeschoolde werknemers neemt toe vanaf het begin van de jaren 80 . Dit komt overeen met het tijdstip waarop de eerste ongeschoolde werknemers een computer gingen gebruiken. Loonongelijkheid tussen geschoolde en ongeschoolde werknemers daalt echter tot het begin van de jaren 80 en neemt daarna pas toe, een tijdstip waarop al vele geschoolde werknemers een computer gebruiken en slechts een marginaal deel van de ongeschoolde werknemers een computer gebruiken. Wanneer de computerisering van de arbeidsmarkt leidt tot loonongelijkheid binnen groepen van relatief homogene werknemers, waarom gaat de loonongelijkheid tussen de groepen dan pas sinds begin jaren 80 omhoog?

De meeste modellen die in Hoofdstuk 2 worden behandeld, voorspellen een toename van de loonongelijkheid tussen geschoolde en ongeschoolde werknemers wanneer de eerste geschoolde werknemer een computer krijgt. Dit is het gevolg van een veronderstelde complementaire relatie tussen geschoolde arbeid en technologie in de productiefunctie: $Y=\left(A S^{\rho}+U^{p}\right)^{1 / \rho}$ waarbij $Y$ de productie is, $S(U)$ is de input van geschoolde (ongeschoolde) arbeid en $A$ is de technologie, in dit geval computers. Het model dat in Hoofdstuk 5 wordt ontwikkeld, is gebaseerd op het experiment in Hoofdstuk 3 en bevat drie cruciale ingrediênten die verklaren hoe computers de loonverdeling veranderen: (i) het besluit een werknemer een computer te geven ter ondersteuning van de werkzaamheden wordt gedreven door de kosten van de computer (aanschaf, onderhoud, technische assistentie etc.) af te wegen tegen de opbrengsten (productiviteitswinst), (ii) geschoolde (ongeschoolde) werknemers zijn volledig te substitueren (en dus ex ante homogeen) in het produceren van het geschoolde (ongeschoolde) deel van de productie, en (iii) de productiviteit van geschoolde en ongeschoolde werknemers kent $z o$ 'n verdeling dat het voor de eerste ongeschoolde werknemer eerder rendabel is een computer aan te schaffen dan voor de laatste geschoolde werknemer. Dat wil zeggen dat de productiviteit (en het loon) van de meest productieve ongeschoolde werknemer hoger ligt dan de productiviteit van de minst productieve geschoolde werknemer (wat in werkelijkheid ook zo is).

Gebruik makend van deze drie ingrediënten leidt dit tot het inzicht dat loonongelijkheid als gevolg van computergebruik zowel een tijdelijk als permanent karakter kan hebben, dat afhankelijk is van de proportionele 
productiviteitswinst die geboekt wordt door verschillende werknemers als gevolg van computergebruik. Slechts wanneer relatief geschoolde werknemers (als groep) productiever zijn in het gebruik van computers dan hun ongeschoolde collega's, zal de diffusie van computers leiden tot een permanente vorm van loonongelijkheid tussen geschoolde en ongeschoolde werknemers. Wanneer de proportionele productiviteitswinst gelijk is voor iedere werknemer zal de loonongelijkheid tijdelijk zijn en het gevolg zijn van de verschillende tijdstippen waarop de computer rendabel wordt voor verschillende werknemers. Dit hangt af van de hoogte van hun loon, zoals verklaard in Hoofdstuk 3 en 4 . Loonongelijkheid tussen de groepen van geschoolde en ongeschoolde werknemers zal dalen op het moment dat de diffusie een bepaald punt bereikt heeft. Dit moment hangt af van de verdeling van productiviteit binnen en tussen de groepen werknemers. In het hypothetische geval dat de kosten van de computer zo laag zijn dat alle werknemers een computer gebruiken, zal de loonongelijkheid tussen geschoolde en ongeschoolde werknemers zijn verdwenen en weer terug zijn op het niveau van voor de intrede van de computer. Loonongelijkheid binnen homogene groepen van werknemers zal van permanente aard zijn indien er verschillen zijn in de proportionele productiviteitswinst binnen deze groepen. Wanneer de meest productieve geschoolde werknemer een hogere productiviteitswinst boekt dan de minst productieve geschoolde werknemer, zal er een permanent niveau van loonongelijkheid tussen hen ontstaan dat hoger ligt dan vóór computerisering. Zo'n situatie doet zich bijvoorbeeld voor wanneer een complementaire relatie tussen technologie en scholing bestaat. Zoals empirisch blijkt uit Hoofdstuk 4 is dit niet erg waarschijnlijk wanneer het om computergebruik gaat. Vandaar dat loonongelijkheid binnen de groepen van geschoolde en ongeschoolde werknemers zal stijgen, totdat alle werknemers binnen een groep de computer zijn gaan gebruiken. Vanaf dat moment zal de loonongelijkheid terugkeren naar het oorspronkelijke niveau van het precomputertijdperk. Wanneer de voorspellingen van het model worden geconfronteerd met de data, waarbij gebruik wordt gemaakt van de March Demographic Supplements of the Current Population Surveys (CPS) blijken er geen significante verschillen te bestaan in de productiviteitswinsten voor geschoolde en ongeschoolde werknemers in de periode 1963-2000 in de Verenigde Staten. Dit komt dus overeen met een slechts tijdelijke stijging van de loonongelijkheid, die weer zal verdwijnen als de meeste werknemers een computer zijn gaan gebruiken.

Een tweede voorspelling van het model is dat het een verklaring geeft voor de verschillende timing van loonongelijkheid tussen en binnen groepen. Het model laat zien dat drie verschillende effecten van computeradoptie op de timing van loonongelijkheid kunnen worden onderscheiden. Het model voorspelt het volgende patroon. Op het tijdstip $t=0$ besluit de meest productieve geschoolde werknemer een computer te gaan gebruiken, omdat dit winstgevend 
is. Op dit tijdstip is hij indifferent tussen het werken met of zonder een computer, omdat hij een productiviteitswinst boekt door het gebruik van de computer, maar tegelijkertijd moet betalen voor het gebruik van de computer. Omdat de werknemer een productiviteitswinst boekt, produceert hij meer wat leidt tot een verhoging van het aantal efficiency eenheden geschoolde arbeid. Deze toename van het aanbod verlaagt het loon per efficiency eenheid van geschoolde arbeid. Het model laat zien dat dit verhoogde aanbod initieel leidt tot een lager loon, omdat het aanbodeffect groter is dan het productiviteitseffect. Dit heeft een negatief effect op het relatieve loon van alle geschoolde werknemers dat groter is dan het effect dat wordt ervaren door de werknemer die reeds met een computer werkt (hij profiteert van de toegenomen productiviteit, terwijl de anderen slechts last hebben van het toegenomen aanbod). Dit effect houdt aan totdat de eerste ongeschoolde werknemer een computer aanschaft op $t=1$. Vanaf dit moment is er een derde effect van computergebruik op de loonverdeling (naast het productiviteits- en aanbodeffect), omdat het aanbod van efficiency eenheden ongeschoolde arbeid toeneemt. Het model voorspelt dat - op eenzelfde wijze als het geval was voor geschoolde werknemers - vanaf $t=1$ loonongelijkheid ontstaat binnen de groep van ongeschoolde werknemers. Wat echter interessanter is, is dat de loonongelijkheid tussen geschoolde en ongeschoolde werknemers gaat toenemen als gevolg van het extra aanbod van efficiency eenheden van ongeschoolde arbeid. Het model laat zien dat dit leidt tot een verhoging van het relatieve loon en dus tot loonongelijkheid. Samenvattend voorspelt het model dat de timing van loonongelijkheid binnen groepen zal toenemen op het moment dat werknemers binnen zo'n groep een computer gaan gebruiken. Loonongelijkheid tussen geschoolde en ongeschoolde werknemers, als gevolg van computerisering, neemt echter pas toe op het moment dat ongeschoolde werknemers een computer gaan gebruiken. Wanneer cijfers voor de Verenigde Staten worden bekeken, blijkt dat de timing van loonongelijkheid die wordt voorspeld door het model consistent is met een verhoging van de loonongelijkheid binnen de groep geschoolde (ongeschoolde) werknemers vanaf het begin van de jaren 70 (jaren 80 ) en dat loonongelijkheid tussen groepen toeneemt vanaf het begin van de jaren 80 . Wanneer het model wordt geschat, met behulp van de CPS data, blijkt dat de proportionele productiviteitswinst als gevolg van computergebruik tussen 15 en 40 procent ligt. Nadere analyse wijst uit dat een productiviteitswinst rond de 20 procent de meest waarschijnlijke schatting is. Dit komt overeen met de schattingen die in andere studies worden gerapporteerd.

De tweede macro-economische vraag die moet worden beantwoord is waarom werkgevers de vraag naar vaardigheden en geschoolde arbeid hebben verhoogd als gevolg van computerisering. De analyse in Hoofdstuk 5 neemt de baan als gegeven, terwijl een analyse van upgrading vereist dat de allocatie van werknemers en banen wordt beschouwd in een dynamische omgeving. Het 
experimentele model in Hoofdstuk 3 voorspelt dat werkgevers geneigd zijn de eisen die ze aan werknemers stellen te verhogen wanneer de computer zijn intrede doet, omdat meer aandacht moet worden besteed aan het nietroutinematige deel van de productie. De reden voor deze verschuiving binnen de baan wordt toegeschreven aan het feit dat een computer veelal het routinematige deel van het werk overneemt en dat de werknemer meer tijd moet besteden aan de niet-routinematige taken. Op macro-economisch niveau zou deze tendens moeten wijzen op een verhoging van de vraag naar geschoolde arbeid, gegeven een bepaalde compositie van banen. Om te analyseren of werkgevers hun eisen hebben verhoogd, biedt een "assignment" model een goede mogelijkheid omdat in zo'n model zowel de vraag naar als het aanbod van arbeid simultaan kunnen worden meegenomen. Dit is belangrijk, omdat de observatie dat de opleidingseisen voor een bepaalde baan zijn toegenomen niet per definitie een gevolg hoeft te zijn van upgrading. Het zou namelijk ook zo kunnen zijn dat het aanbod van mensen met een bepaalde opleiding sterk is toegenomen, gegeven de vraag, wat leidt tot allocatieproblemen. In Hoofdstuk 6 wordt een "assignment" model voor Nederland geschat, waarbij banen worden gekarakteriseerd door hun niveau van complexiteit en werknemers door hun vaardighedenniveau (een compositie van werkervaring, scholing etc.). De data die hiervoor worden gebruikt zijn afkomstig van het tweejaarlijkse arbeidsaanbodpanel van de Organisatie voor Strategisch Arbeidsmarkonderzoek (OSA) voor de periode 1986-1998.

De eerste stap van de analyse is de loonstructuur te onderzoeken door een onderscheid te maken tussen verklaarbare en niet-verklaarbare componenten van de loonstructuur. Dit is van belang, omdat het inzicht geeft in de determinanten van verandering van vraag en aanbod over de tijd. De resultaten van deze analyse, waarbij gebruik wordt gemaakt van een eenvoudige accounting raamwerk, zijn dat veranderingen in de Nederlandse loonstructuur in de periode 1986-1998 zijn toe te wijzen aan (i) veranderingen in de verdeling van het aanbod van diverse vaardigheden (arbeidsaanbod component), (ii) veranderingen in de beloning van verschillende vaardigheden (arbeidsvraag component), en (iii) een residu dat kan worden geïnterpreteerd als technologische verandering. Wat opvalt aan deze regressieresultaten is dat de meeste van de veranderingen op de Nederlandse arbeidsmarkt zijn toe te wijzen aan veranderingen in de arbeidsvraag en het arbeidsaanbod. De residuele component is slechts van secundair belang in de verklaring van de loonstructuur. Wat ook opvalt, in vergelijking met studies die gebruik maken van gegevens uit bijvoorbeeld de Verenigde Staten en het Verenigd Koninkrijk, is dat de loonongelijkheid in Nederland nawwelijks is toegenomen. Als een initiële verklaring voor de veranderingen in de Nederlandse loonstructuur kan derhalve gesteld worden dat vraag en aanbod zich hebben aangepast in de meest recente periode, zonder dat dit heeft geleid tot een toename van de loonongelijkheid. Vertaling naar computerisering suggereert dat hoewel de 
vraag naar geschoolde arbeid lijkt te zijn toegenomen, het aanbod voldoende was om de lonen niet spectaculair te laten stijgen.

De tweede stap is om deze informatie te gebruken in een "assignment" model. Het model in Hoofdstuk 6 schat eerst verschillende loonvergelijkingen voor arbeidsvraag en -aanbod en gebruikt deze informatie om te kijken of vraag en aanbod zijin gewijzigd over de tijd. Een verandering van de mapping van vraag en aanbod kan dan worden toegewezen aan upgrading (vraag) of veranderingen in de configuratie van het arbeidsaanbod in de periode 1986 1998. De resultaten van deze analyse stellen dat werkgevers hun opleidingseisen behoorlijk hebben verhoogd door hoger opgeleide werknemers te rekruteren voor banen die voorheen door lager opgeleide werknemers werden uitgevoerd. Dit heeft niet geleid tot een stijging van de beloning, omdat de allocatie van werknemers naar banen efficiënter is geworden: de verhoogde complexiteit van de gemiddelde baan ging gepaard met een aanpassing van het arbeidsaanbod. Deze resultaten suggereren dat hoewel de Nederlandse arbeidsmarkt te maken heeft gehad (en te maken heeft) met een verhoging wan de baancomplexiteit, het niet heeft geleid tot een substantiële stijging van de Ionen.

De laatste stap van de "assignment" analyse is deze bevindingen te relateren aan het toenemende computergebruik. Hoewel er geen directe informatie omtrent computergebruik in de data aanwezig is, zijn sommige beroepen en sectoren meer geneigd computers te gebruiken dan andere. Een analyse van verschillende sectoren en beroepen leidt tot verschillende puntschattingen voor baancomplexiteit, maar slechts zelden tot verschillende puntschattingen voor upgrading. Dit zou het gevolg kunnen zijn van het feit dat in sommige beroepen de computer reeds relatief lang geleden zijn intrede heeft gedaan en dat de upgrading reeds heef plaatsgevonden. De resultaten wijzen dan ook richting upgrading in de low-tech sectoren, waar de computer op dit moment het productieproces en de vraag naar arbeid aan het veranderen is. Daarnaast lijkt het patroon van upgrading veel geleidelijker te verlopen in lowtech sectoren dan in high-tech sectoren. Dit komt overeen met bevindingen voor de Verenigde Staten, waarin wordt gevonden dat high-tech sectoren computers op verschillende tijdstippen zijn gaan gebruiken wat heeft geleid tot schokken in de vraag naar arbeid, terwijl low-tech sectoren op ongeveer hetzelfde tijdstip de computer zijn gaan gebruiken. Dit heeft geleid, en leidt nog steeds, tot een veel geleidelijker patroon van upgrading. Ook leidt zo'n adoptiepatroon tot een andere vraag naar vaardigheden over de tijd: in de initiële fase van computergebruik zijn andere vaardigheden van belang dan wanneer de technologie volwassen en meer gebruikersvriendelijk is. Dit zal ook leiden tot een andere viaag naar vaardigheden. Overall komen deze resultaten overeen met de voorspelling dat de computer heeft geleid tot upgrading van de vraag naar vaardigheden. 


\section{Curriculum Vitae}

Bastiaan Johan ter Weel (15 February 1975) went to secondary school in Nijverdal (College Noetsele, 1987-1993) and studied Economics in Maastricht (Maastricht University, 1993-1998). From July 1998 on he has been a researcher at the Maastricht Economic Research Institute on Innovation and Technology (MERIT). As of July 1999 he obtained a grant from the Dutch Organisation for Scientific Research (NWO) to write a Ph.D. thesis, which resulted in the present study.

"Additional information, a full list of publications, and working papers can be obtained from hitp://meritbbs,unimaas.nl/terweel. 